Purification and Properties of Some Fresh Water and Marlne Cyanobacteria Belonging to the Orders Chamaesiphonales and Pleurocapsales

By

John Battin Waterbury

A.B. (Iniversity of Vermont) 1965

M.A. (University of Callfornia) 1971

DISSERTATION

Submitted in partial satisfaction of the requirements for the degree of DOCTOR OF PHILOSOPHY

in

Bacterlology

in the

GRADUATE DIVISION

of the

UNIVIRSITY OF CALIFORNIA, BERKEILEY

Approved:

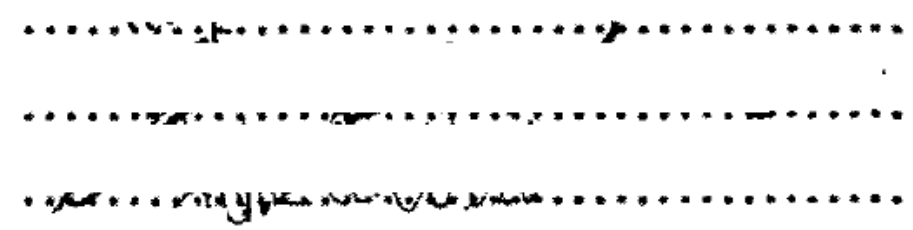

Committee in Charge 
Purification and Properties of Some Fresh Water and Marine Cyanobacteria Belonging to the Orders. Chamaesiphonales and Pleurocapsales

by

John Battin Waterbury

\section{Abstract}

A total of 34 strains of cyanobacteria (blue-green algae) representative of the orders Chamaesiphonales and Pieurocapsales were isolated in axenic culture from marine and fresh water sources. Two strains isolated from fresh water, both assignable to the genus Chamaesiphon, are unicellular cyanobacteria which reproduce by budding; the buds being formed in succession at one pole of the oval cell. These buds are the structures currently termed "exospores" by algologists. The other 32 strains, some marine and some fresh water, reproduce by the formation of small spherical spores produced through the multiple fission of a vegetative cell. In these strains the peptidoglycan and lipopolysaccharide-containing cell wall layers common to all cyanobacteria are enclosed by a third, fibrous layer which increases in thickness during vegetative cell enlargement: spores are liberated by rupture of this wall layer of the parental cell. In some strains, the fibrous wall layer is synthesized during multiple fission, and the spores, each enclosed by this layer, are immotile after release. In others, the synthesis of the fibrous wall layer is arrested during multiple fission, and the spores, inftially lacking this layer, show transient gliding motility after release. 
Among the spore-forming strains, six major strain clusters could be distinguished in terms of their developmental patterns and each strain cluster could be identified with an existing genus. These included strictly unicellular forms (Dermocarpa, Xenococcus), forms which undergo only one or two vegetative divisions (Dermocarpelia), and forms where extensive vegetative growth normally precedes spore formation (Myxosarcina, Chroococcidiopsis, Pleurocapsa). Revised definitions of the orders Chamaesiphonales and Pleurocapsales and of some of their constituent genera are proposed in the light of these findings.

The potential taxonomic utility of certain physiological and chemical properties was also examined. These included: ionic requirements including sodium, chloride, calcium and magnesium; vitamin requirements; nitrogen sources; temperature relationships; heterotrophy; pigment composttion; and mean DNA base composition. There were no clear-cut correlations between genera defined in terms of developmental patterns and groups defined in terms of any of the physiological and chemical properties examined. However, many of the latter properties will be useful in distinguishing species within each genus. Strains of marine origin can be distinguished from fresh water strains in culture by their elevated requirements for sodium, halide, calcium and magnesium.

This work has revealed the intrinsically unsatisfactory nature of the existing classification of cyanobacteria based almost exclusiveIy on the description of field materials. Many of the characters previously used to differentiate species (and even genera) are not valid. 
$-3-$

It is therefore proposed that all future taxonomic descriptions should be based on the detailed characterisation of axenic cultures, and that cultures should replace herbarium specimens as reference materials.

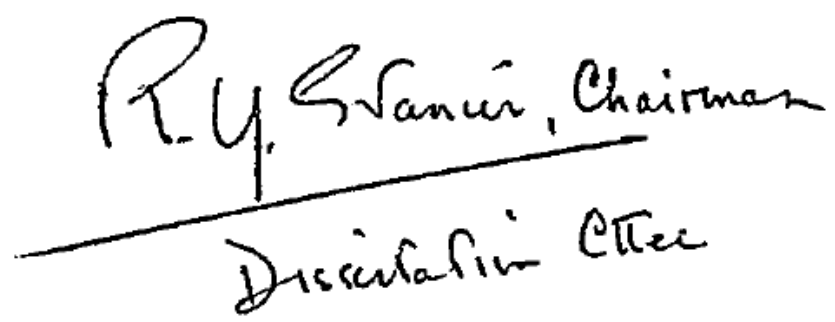


This dissertation is dedicated to Dr. Stanley W. Watson who introduced me to microbiology and encouraged me to enter graduate school.

\section{ACKNOWLEDGEMENTS}

I am indebted to many people for their assistance during the course of my graduate career which has spanned six years and three Institutions, the University of California, Berkeley, the Pasteur Institute . and the Woods Hole Oceanographic Institution. I wish to thank both Drs. Roger and Germaine Stanfer for inviting the to join their laboratory and for making my stay there one of the most memorable periods of my life. I especially thank Dr. Roger Stanier for his guidance, criticism and interest in my research profect and in the preparation of this manuscript. - I am very much indebted to Rose Marie Rippka, Josette Deruelles, Nicole Tandeau de Marsac, Dr. Christine Kenyon, Riyo Kunisawa and Dr. Michael Herdman for their valuable assistance with varlous aspects of this study.

I thank Dr. Pierre Bourrelly and Dr. Stjepko Golubic for valuable discussions on blue-green algal taxonomy, and Dr. John West and Dr. Jeremy Thorner for criticálly reading this manuscript. I also thank Jane Peterson and Frederica Valois for typing and proofreading. 
TABLE OF CONTENTS

Page

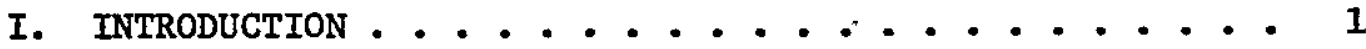

II. MATERIALS AND METHODS ............. 3

A. Blological Material ........... 3

B. Media and Conditions of Cultivation ....... 10

1. Principal Media and Growth Conditions ..... 10

2. Test Media and Determination of Growth

Requirements .......... 13

a. Ionic Requirements . . . . . . 13

b. Vitamin Requirements ......... 16

c. Nitrogen Sources . . . . . . . 17

d. Heterotrophy ............ 18

e. Maximum Temperature Permitting Growth . . 18

f. Effects of Chromatic Illumination on Pigment Synthesis .......... 18

3. Other Culture Methods .......... 20

a. Slide Culture Techniques ....... 20

b. Cultures for Electron Microscopy . . . . 22

c. Growth on Oyster Shells ........ 22

d. Spore Motillty ........... 23

e. Spore Counts ............ 23

c. Isolation and Purification of Strains ... . . . 23

1. Cyanobacteria . . . . . . . . . 23

2. Acid-Producing Chemoheterotrophic Bacteria . . 26

D. Microscopic Techniques ........... 26 
TABLE OF CONTENTS (Continued)

Page

E. Chemical Methods ............... 27

1. Isolation of DNA ............ 27

2. Other Procedures ............ 27

a. Fatty Acid Composition ........ 27

b. Pigment Analysis ........... 28

c. Protein Determination . . . . . . 28

III. RESULTS . . . . . . . . . . . . . . 28

A. Circumscription of the Orders Chamaesiphonales and Pleurocapsales . . . . . . . . . . 28

B. Structure and Development in the Pleurocapsales. - 29

1. General Features . . . . . . . . 29

a. Growth and Reproduction .... . . . 29

b. Wall Structure and Its Role in Growth and Development . . . . . . . . . . 31

1. Cell Division .......... 31

ii. Gliding Motility ........ . 35

1i1. Spore Release ......... 36

iv. Attachment to Solid Substrates . . . 37

c. U1trastructure . . . . . . . . 37

2. Specific Developmental Patterns . . . . 39

a. Dermocarpa ........ . . . . 44

b. Xenococcus ............. 73

c. Dermocarpelza ............ . 99

d. Myxosarcina . . . . . . . . 114

e. Chroococcidiopsis . . . . . . . 122

f. Pleurocapsa . . . . . . . . . . 142 
TABLE OF CONTENTS (Continued)

Page

i. Developmental Patterns ....... 142

ii. The Endolithic Habitat . . . . . 147

C. The Structure and Development of Chomaesiphon . . 193

D. Nutritional Properties of the Pleurocapsales and Chamaesiphonales . . . . . . . . . 206

1. Ionic Requirements . . . . . . . . . 206

2. Vitamin Requirements ....... . . 209

3. Nitrogen Sources ............ 209

4. Heterotrophy ........... . . 211

5. Temperature Relationships . . . . . . 213

E. Chemical Characterization of the Pleurocapsales and Chamaesiphonales..... . . . . 213

1. Pigment Composition ... . . . . . 213

2. Cellular Fatty Acid Composition ... . . 223

3. Mean DNA Base Composition ......... 225

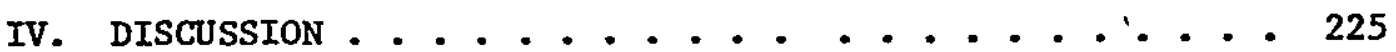

A. Physiological and Chemical Properties of

the Pleurocapsales . . . . . . . . . 225

1. Specific Ionic Requirements in Relation to Habitat . . . . . . . . . 227

2. Anaerobic Nitrogenase Synthesis . . . . 230

3. Adaptation to Chromatic Illumination . . . 232

4. Fatty Acid Composition . . . . . . . 234

5. Mean DNA Composition .......... 236

B. The Taxonomy of the Pleurocapsales and

Chamaesiphonales ............ 238 
TABLE OF CONTENTS (Continued)

Page

1. Circumscription and Redefinition of the Orders Pleurocapsales and Chaemaesiphonales and of Their Major Constituent Genera

a. Properties of Genera Assigned by Geitler to the Order Dermocarpales . . . 241

b. Properties of Genera Assigned by Geitler to the Order Pleurocapsales . . . 243

c. Redefinition of the Order Chamaesiphonales . . . . . . . . . 246

d. Redefinition of the Order Pleurocapsales ............ . . 247

i. Dermocarpa ........... 248

1i. Xenococcus ............ 248

iii. Dermocarpella ........ . 249

iv. Myxosarcina ... . . . . . . 249

v. Chroococcidiopsis ....... .. 249

vi. Pleurocapsa........... 249

2. Distinctions Between the Order Chroococcales and the Orders Chamaesiphonales and Pleurocapsales . 251

3. Sources of Confusion in Earlier Taxonomic Treatments of Certain Genera in the Pleurocapsales . 253

4. The Problem of Speciation .......... 261 


\section{INTRODUCTION}

With respect to cell structure and development, the cyanobacteria (blue-green algae) are more diverse than any other major prokaryotic group. The primary taxonomic sub-divisions among the cyanobacteria which have been proposed by phycologists are based on the structural and developmental differences within the groups. One sub-group, comprising the order Chroococeales, consists of unicellular organisms that reproduce exclusively by binary fission. A second major sub-group consists of filamentous organisms, which reproduce by, fragmentation of the filament or trichome. These filamentous cyanobacterla are assigned by most algal taxonomists to at least two orders, the Stigonematales and Nostocales, distinguished by the structure of the trichome, branched or unbranched, respectively.

The third tnajor sub-group of cyanobacteria is characterized by the ability to reproduce through the formation of spores, exther endogenous ("endospores") or exogenous ("exospores"). A11 these organisms are sessile and grow attached to solid substrates. The exospore-formers (Chamaesiphon) and some of the endospore-formers (e.g., Dermocarpa) are unicellular, and have been placed on the basis of their unicellularity In a single order, the Chamaesiphonales (or Dermocarpales). However, many endospore-formers can undergo extensive vegetative growth prior to endospore formation, thus producing cellular aggregates consisting of irregular masses or chains of cells. These organisms are commonly assigned to a separate order, the Pleurocapsales. 
Spore-forming cyanobacteria are at present a poorly characterized group. The existing descriptions are based almost exclusively on field observations which have rarely permitted an elucidation of the details of their relatively complex cellular life cycles. Very few of these organisms have so far been cultivated, even in the unialgal state. At the time this study was initiated, only five strains (one Dermocarpa, one Xenococcus, two Chroococcidiopsis and one Chomaesiphon) (see Tables I, II and IV) had been isolated in pure culture.

Nearly a11 the groups of endospore-formers are we11 represented in the microflora of the marine littoral zone, where they occur as epiphytes on other algae and as epiliths or endoliths on calcareous rocks and shells. The initial goal of this study was to isolate and purify representatives of this marine endospore-forming cyanobacterial population, in order to gain a better insight into the properties of the group. Subsequently a number of fresh water strains, including both endospore and exospore formers, were purified and added to the collection. This has enabled us to make a comparative study of the life cycles and physiological properties of a serles of cyanobacteria reasonably representative of the two orders Chamaesiphonales and Pleurocapsales. Since the taxonomic conclusions which have emerged from this study are radically different from those of all previous workers, a critical analysis of the past literature, primarily taxonomic in content, is best deferred until it can be presented in the context of the present findings.

In conclusion, we shall note previous reports on the cultivation of members of these two orders. Several authors have used unialgal cultures for observations on the structure and development of 
Chroococcidiopsis spp. (24, 39, 40, 41), Pleurocapsa fuliginosa (4) and Hyella spp. $(47,56)$. Castenholz (1I) has defined the conditions for the laboratory culture of a thermophilic endospore-former, which he Identified as Pleurocapsa minor. Two strains, identified in the present study as a Chomaesiphon sp. and a Chroococcidiopsis sp., had been previously studied in pure culture by Stanier et al. (70) who identified them as a Synechococcus sp. and a ChLorogloea sp. respectively. In all the above cases, taxonomic identifications were probably made according to the system of Geitler $(27,29)$, although this fact is sometimes not explicitly stated. Where relevant, the data provided in these reports will be discussed in the context of the present findings.

\section{METHODS AND MATERIAIS}

\section{A. Biological Material}

The sources and histories of the 40 axenic strains used in this study are summarized in Tables $I$, II, III.and IV. In these tables the strains are listed, in order of accession, within four groups: I. strains of marine origin capable of reproducing by multiple fission; II. strains of non-marine origin capable of reproducing by multiple fission; III. unicellular strains of marine origin reproducing only by binary fission and IV. unicellular strains of non-marine origin reproducing solely by budding. The symbols A (axenic) and U (unialgal) Indicate the state of strains at their time of accession from other investigators and from culture collections. Strains which were unialgal upon recelpt were subsequently purified by the author. 
T A B L E I

STRAINS OF MARINE ORIGIN, CAPABLE OF REPRODUCING BY MULTIPLE FISSION

\begin{tabular}{|c|c|c|c|c|}
\hline $\begin{array}{l}\text { Strain } \\
\text { Numbex }\end{array}$ & $\begin{array}{c}\text { Name (If any) } \\
\text { Prevlously applied }\end{array}$ & Source and Date collected & $\begin{array}{c}\text { Previous History } \\
\text { (1f any) }\end{array}$ & Ref. \\
\hline 7301 & $\begin{array}{r}\text { Dexmocarpa } \\
\text { violacea }\end{array}$ & $\begin{array}{c}\text { marine aquarium, Scripps Institute of } \\
\text { Oceanography, La Jolla, Callfornta } \\
\text { Dec. } 1964\end{array}$ & 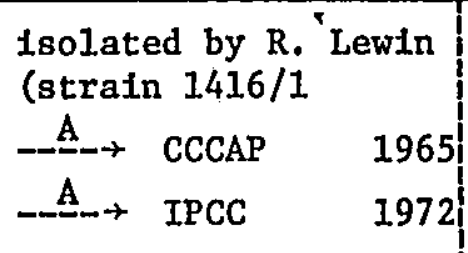 & \\
\hline 7302 & ? & $\begin{array}{c}\text { sea water tank, Artzona Marine Station, } \\
\text { Puerto Penasco, Mexico } \\
\text { Mar. } 1971\end{array}$ & & \\
\hline 7303 & & $\begin{array}{l}\text { sea water tank, Arizona Marine Station, } \\
\text { Puerto Penasco, Mexico } \\
\text { Mar. } 1971\end{array}$ & & \\
\hline 7304 & & $\begin{array}{l}\text { epiphyte on Rhodochorton sp. high inter } \\
\text { tidal zone, Bodega Marine Labaratory, } \\
\text { California } \\
\text { Jan. } 1970\end{array}$ & & \\
\hline 7305 & Dermocarpa sp. (1) & $\begin{array}{l}\text { marine aquarium, Scripps Institute of } \\
\text { Oceanography, La Jolla, California }\end{array}$ & $\begin{array}{l}\text { Isolated by R. Lewin } \\
\text { A } \rightarrow \text { IPCC } 1971\end{array}$ & \\
\hline 7306 & $\cdot$ & $\begin{array}{l}\text { rock chip, high Intertidal zone, } \\
\text { Plilar Point, California } \\
\text { Feb. } 1970 \\
\text { rock chip, high intertidal zone, } \\
\text { Horseshoe Cove, Bodega Marine Labora- } \\
\text { tory, California Jan. } 1970\end{array}$ & & \\
\hline 7310 & & $\begin{array}{l}\text { snail shel1, intertidal zone, Arizona } \\
\text { Marine Station, Puerto Penasco, Mexico } \\
\text { " Mar. } 1970\end{array}$ & & \\
\hline
\end{tabular}


T A B L E I (Continued)

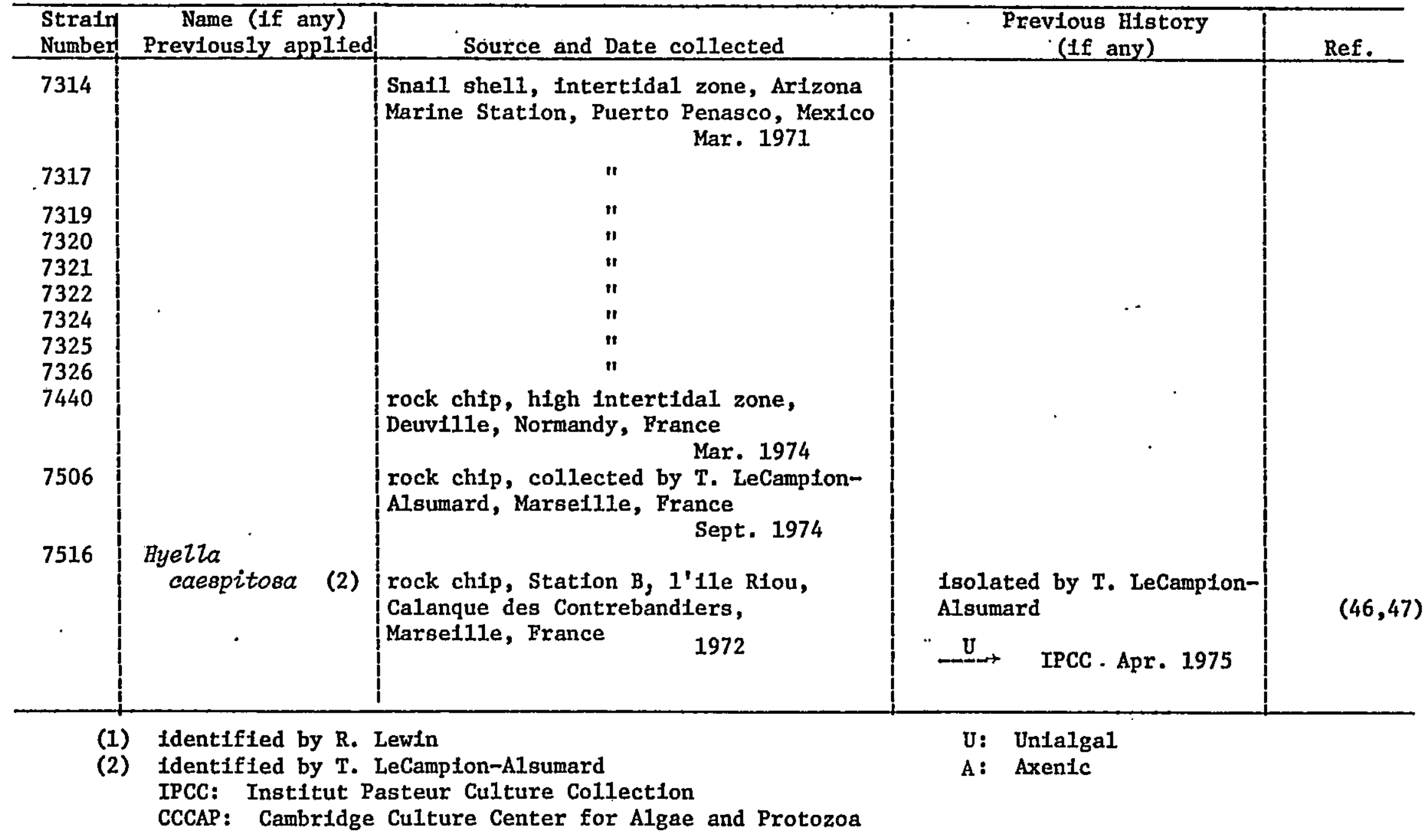


T A B L E II

STRAINS OF MARINE ORIGIN, CAPABLE OF REPRODUCING BY MULTIPLE FISSION .... . .

\begin{tabular}{|c|c|c|c|c|}
\hline $\begin{array}{l}\text { Strain } \\
\text { Numbex }\end{array}$ & $\begin{array}{c}\text { Name (1f any) } \\
\text { Previously applied }\end{array}$ & Source and Date collected & $\begin{array}{l}\text { Previous History } \\
\text { (if any) }\end{array}$ & Ref. \\
\hline 6712 & Chlorogloea $s p$. & $\begin{array}{l}\text { water sample, reservoir, Marln County, } \\
\text { California } 1967\end{array}$ & Isolated by R. Kunisawa & 70 \\
\hline 7203 & $\begin{array}{l}\text { Myxosareina (1) } \\
\text { chroococcoides } \\
\text { Chroococcidiopsis } \\
\text { thermalis }\end{array}$ & $\begin{array}{l}\text { soll sample, near Grelfswald } \\
\text { East Germany } 1962\end{array}$ & $\begin{array}{cc}\text { EMAU (Strain Al49) } & 1962 \\
\mathrm{U}_{\rightarrow} \text { CCCAP (Strain } & 1451 / 1) \\
& 1965 \\
\mathrm{~A} \rightarrow \text { IPCC } & 1972\end{array}$ & 39,41 \\
\hline 7327 & $\begin{array}{l}\text { Pleurocapsa } \\
\text { minor }\end{array}$ & Hunter's Spring, Oregon 1969 & $\begin{array}{l}\text { Isolated by R. Castenholz } \\
\text { (Strain OH-69-PM) } \\
\text { U IPCC }\end{array}$ & 11 \\
\hline 7431 & $\begin{array}{l}\text { Chroococcidiopsis } \\
\text { thermalis }\end{array}$ & $\begin{array}{l}\text { mineral spring, near San DIego, } \\
\text { Cuba } 1964\end{array}$ & $\begin{array}{l}\text { 1solated by Komarek } \\
\text { (Strain 1964/48 } \\
\text { U-+ IPCC } \\
-\because 474\end{array}$ & 39,41 \\
\hline 7432 & c. thermatis & $\begin{array}{l}\text { mineral spring, neax Santa Fe, } \\
\text { Cuba } 1965\end{array}$ & $\begin{array}{l}\text { isolated by Hindak } \\
\text { (Strain 1965/21) } \\
\text { U IPCC }\end{array}$ & 39,41 \\
\hline 7433 & c. thermalis & $\begin{array}{l}\text { soll, dried pool, Pinar del Rło, } \\
\text { Cuba } 1966\end{array}$ & $\begin{array}{l}\text { Isolated by Hindak } \\
\text { (Strain 1966/27) } \\
-\underset{U}{-} \text { IPCC }\end{array}$ & 39,41 \\
\hline
\end{tabular}


T A B L E II (Continued)

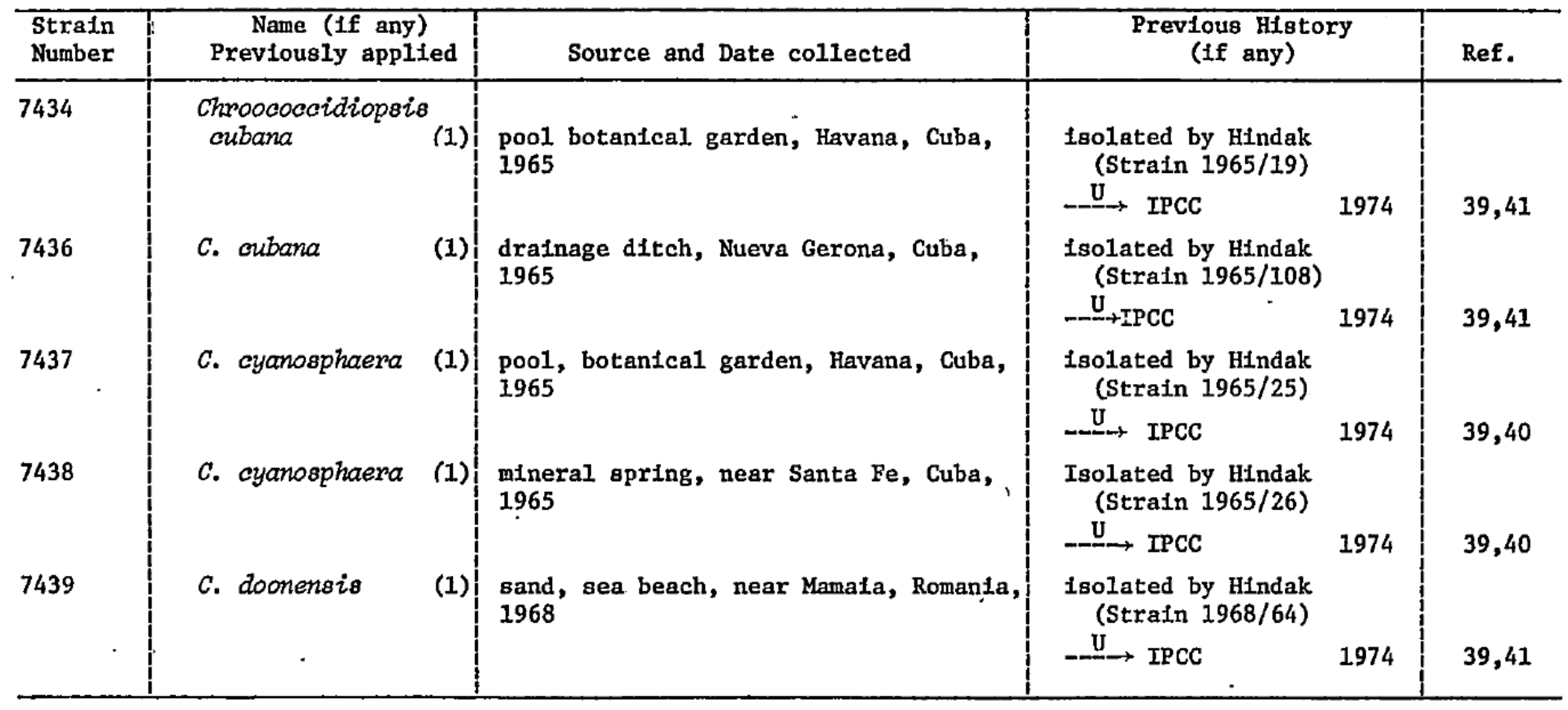

EMAU: Ennst - Moritz - Arndt - University

(1) Identifled by $\mathrm{Dr}$. Komarek

(2) subsequent identification by Dr. Komarek 
T A B L E I I I

UNICELLULAR STRAINS OF MARTNE ORIGIN, WHICH REPRODUCE EXCLUSIVELY BY BINARY FISSION

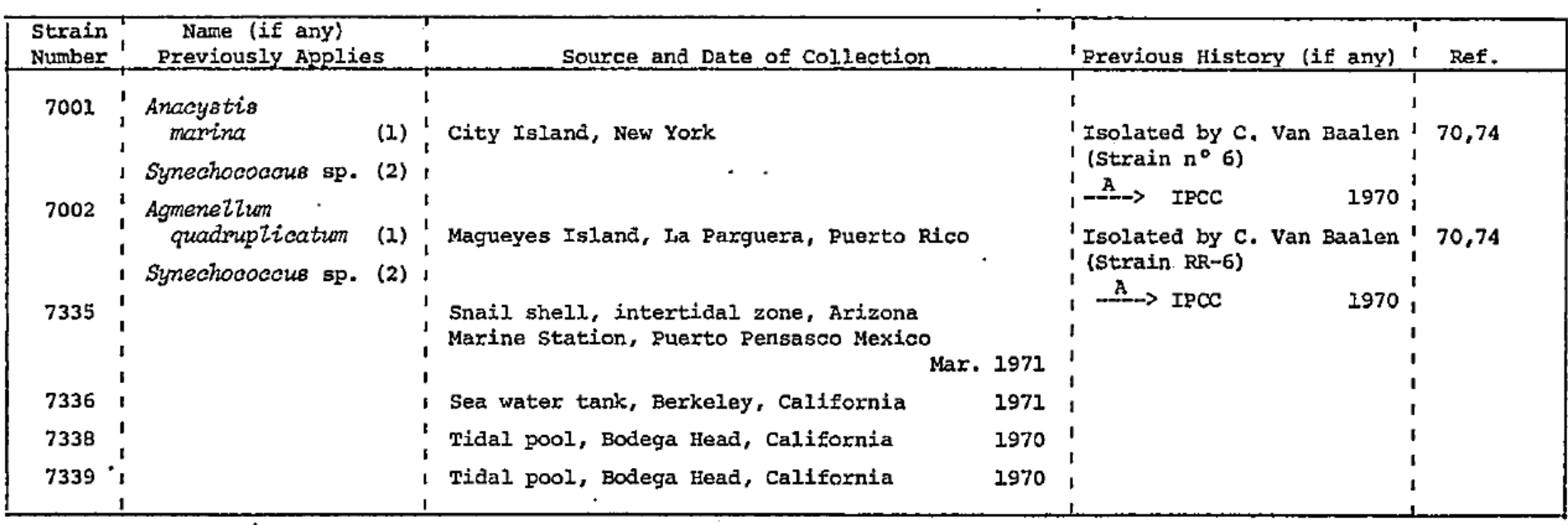

(1) Identified by Dr. Francis Drouet

-(2) Identified by Stanier et al. (70) 
TA B I E I V

UNICELLULAR STRAINS OF NON-MARINE ORIGIN, WHICH RERRODUCE EXCLUSIVELY BY BUDDING

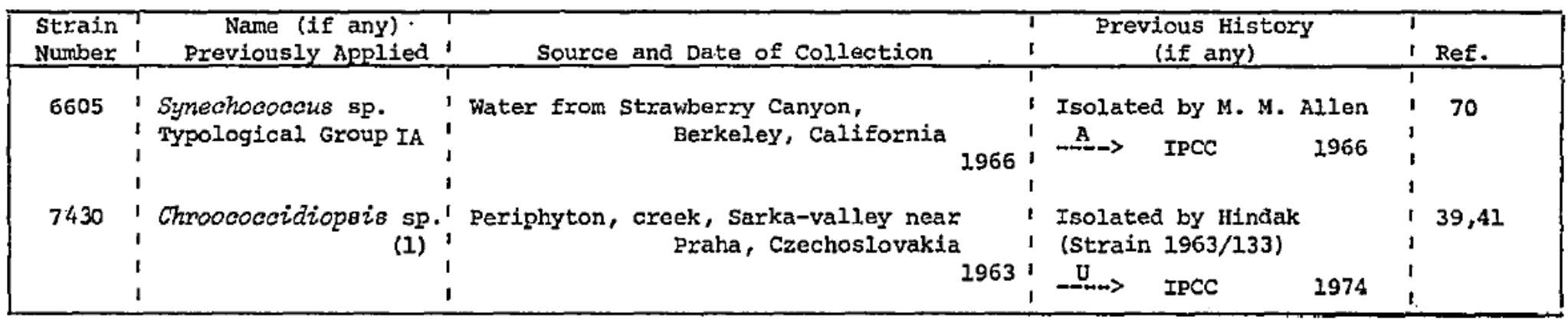

(1) Subsequently identified as Chomaesiphon sp. by Dr. Komarek (personal communication). 


\section{B. Media and Conditions of Cultivation}

\section{Principal Media and Growth Conditions}

Three basic media, the compositions of which are shown in Table $V$ were used routinely during the course of this study. Medium BG-II (70) was used as the standard medium for strains of non-marine origin. When it was used without a source of combined nitrogen or with nitrogen sources other than sodium nitrate, the sodium concentration of medium BG-11 was maintained by the addition of sodium chloride at a final concentration of $1.0 \mathrm{gm} / \mathrm{I}(\mathrm{w} / \mathrm{v})$. Medium $\mathrm{MN}$, used as the standard medium for marine strains, has a sea water base and is fortified with the minerals of medium BG-11. Medium ASN-III is a strictly synthetic medium suitable for the growth of marine strains. It is superior to medium MN for the cultivation of strains 7302, 7303, 7304, 7305, 7306 and 7310, and was used for their maintenance. Merck analytical grade chemicals and deionized water, passed through a Millipore Super-Q Water Purifier, were used for the preparation of all medla. Solid media contained Difco Bacto agar at a final concentration of $1.2 \%(w / v)$. The mineral base and the agar solutions were separately autoclaved (2) at the required concentration and mixed just perior to pouring the plates.

Three strains $(7301,7317,7002)$ have an obligate requirement for vitamin $B_{12}$. For the culture of these strains, vitamin $B_{12}$ was added to media after autoclaving at a final concentration of $4 \mu \mathrm{g} / 1$.

The media described above are poorly buffered. For some experiments, buffering capacity was increased by addition of Tris [tris(hydroxymethyl)amino methane]-HCl buffer ( $\mathrm{pH}$ 7.5), at a final concentration of $0.1 \%(w / v)$, to media after autoclaving. However, at this concentration several strains, notably 7301, 7302, 7303, 7304, 7305 and 7306 were 
Table V

COMPOSITION OF STANDARD MINERAL MEDIA

\begin{tabular}{|c|c|c|c|c|c|}
\hline \multirow{3}{*}{$\frac{\text { Ingredient }}{\text { Deionized water }}$} & \multicolumn{5}{|c|}{ Amount per 11ter } \\
\hline & $B G-11$ & \multicolumn{2}{|l|}{$\overrightarrow{\mathrm{MN}}$} & \multicolumn{2}{|c|}{ ASH - III } \\
\hline & $1000 \mathrm{~m} 1$ & 250 & $\mathrm{ml}$ & 1000 & $\mathrm{~m} 1$ \\
\hline Sea water & - & 750 & $\mathrm{~m} 1$ & - & \\
\hline $\mathrm{NaCl}$ & $-\cdots$ & - & & 25.0 & gm \\
\hline $\mathrm{MgSO}_{4}-7 \mathrm{H}_{2} \mathrm{O}$. & $0.075 \mathrm{gm}$ & 0.04 & gm & 3.5 & gm \\
\hline $\mathrm{MgCL}_{2}-6 \mathrm{H}_{2} \mathrm{O}$ & - & - & & 2.0 & gाR \\
\hline $\mathrm{KC1}$ & - & - & & 0.5 & $g m$ \\
\hline $\mathrm{CaCl}_{2}-2 \mathrm{H}_{2} \mathrm{O}$ & $0.036 \mathrm{gm}$ & 0.02 & $\mathrm{gm}$ & 0.5 & $g m$ \\
\hline $\mathrm{NaNO}_{3}$ & $1.5 \mathrm{gm}$ & 0.7 .5 & gm & 0.75 & $g m$ \\
\hline $\mathrm{K}_{2} \mathrm{HPO}_{4}-3 \mathrm{H}_{2} \mathrm{O}$ & $0.04 \mathrm{gm}$ & 0.02 & gm & 0.02 & gm \\
\hline Citric acid & $0.006 \mathrm{gm}$ & 0.003 & gm & 0.003 & gm \\
\hline Ferric ammonium citrate & $0.006 \mathrm{gm}$ & 0.003 & gm & 0.003 & gm \\
\hline EDTA (disodium potassium salt) & $0.001 \mathrm{gm}$ & 0.0005 & gm & 0.0005 & gm \\
\hline $\mathrm{Na}_{2} \mathrm{CO}_{3}$ & $0.02 \mathrm{gm}$ & 0.02 & gm & 0.02 & $\mathrm{gm}$ \\
\hline Trace metals A-5 & $1.0 \mathrm{ml}$ & 1.0 & $\mathrm{mI}$ & 1.0 & $\mathrm{ml}$ \\
\hline $\mathrm{pH}$ after autoclaving & 7.1 & 8.5 & & 7.3 & \\
\hline Osmolarity (in milliosmoles) ${ }^{(1)}$ & & 690 & & 825 & \\
\hline
\end{tabular}

A-5 Trace Metal Mix

Compound

$$
\mathrm{H}_{3} \mathrm{BO}_{3}
$$$$
\mathrm{MnCl}_{2}-4 \mathrm{H}_{2} \mathrm{O}
$$$$
\mathrm{ZnSO}_{4}-7 \mathrm{H}_{2} \mathrm{O}
$$$$
\mathrm{Na}_{2} \mathrm{MOO}_{4}-2 \mathrm{H}_{2} \mathrm{O}
$$$$
\mathrm{CuSO}_{4}-5 \mathrm{H}_{2} \mathrm{O}
$$$$
\mathrm{Co}\left(\mathrm{NO}_{3}\right)_{2}-6 \mathrm{H}_{2} \mathrm{O}
$$

Amount $(\mathrm{gm} / 1)$

2.86

1.81

0.222

0.039

0.079

0.0494

(I) Determined by freezing point depression 
inhibited by Tris buffer.

IIIumination of cultures was continuous, and was provided by fluorescent light sources. Osram Interna fluorescent lamps were used to Illuminate Iiquid cultures of small volume and plate cultures. Osram white universal circular fluorescent lamps, suspended above the culture vessels, were used to provide a reasonably even illumination of liquid cultures grown in Fernbach flasks of $1500 \mathrm{ml}$ capacity. Most of the organisms studied do not tolerate high light intensities. Stock cultures and plate cultures were generally exposed to light intensities between 200 and 400 Lux measured at' the surface of the cultures. Fernbach flasks were exposed to inftial intensities of $200 \mathrm{Lux}$, subsequently increased to $500 \mathrm{Lux}$ as the cultures developed.

No attempt was made to determine temperature optima for the strains examined. With one exception all strains grew well at 25 to $28^{\circ} \mathrm{C}$, which was routinely used for their cultivation. One strain of thermophilic origin (7327) failed to grow at this temperature and was routineIy cultivated at $37^{\circ} \mathrm{C}$.

Stock cultures were malntained in $100 \mathrm{ml}$ Erlenmeyer flasks containIng $50 \mathrm{ml}$ of liquid media,-and incubated without agitation or aeration. Cultures of larger volume $(\geq 1500 \mathrm{ml})$ were gassed continuously with air containing approximately $1 \% \mathrm{CO}_{2}(\mathrm{v} / \mathrm{v})$, and the sodium carbonate concentration was increased to $0.2 \mathrm{gm} / 1$ in order to maintain the $\mathrm{pH}$ in a favorable range. These cultures were slowly agltated by magnetic stirrers, the gassing mixture being introduced above the level of the IIquid through a Pasteur pipette at a rate of approximately $10 \mathrm{cc} / \mathrm{min}$. 


\section{Test Media and Determination of Growth Requirements}

The members of the Pleurocapsales all develop in liquid media in the form of clumps of cells, which often adhere to the glass walls of the culture vessel. As a result, it is not possible to measure quantitatively either growth rates or growth yields. Consequently, all experiments to determine the influence of nutrients or temperature on growth were qualitative, only the presence or absence of growth under a given set of conditions was recorded.

\section{a. Ionic requirements}

Heavy cell suspensions from young liquid stock cultures were pipetted onto well dried agar plates containing all nutrients except the Ion to be tested. After the liquid of the inoculating suspension had been absorbed by the agar, cells were transferred from these plates with a platinum spade to tubes of liquid medium $(7.0 \mathrm{ml})$ containing a graded series of concentrations of a given ion. A transfer to fresh medium of the same composition was made from tubes where growth had occurred at an Ionic concentration close to the limiting value. Only if growth took place on subculture was the result recorded as positive.

The minimum sodium concentration which would support growth was determined with the basal medium shown in Table VI. The chloride concentration in this medium was maintained at a minimum value of $0.2 \mathrm{M}$. The maximum level of contamination by sodium in the medium, with no added sodium chloride, was calculated to be less than $1.5 \times 10^{-5} \mathrm{M}$.

The minimum chloride concentration which would support growth was determined using the basal medium shown in Table VII. The sodium concentration was held constant at $0.1 \mathrm{M}$ for the non-marine strains and at $0.5 \mathrm{M}$ for the marine strains by the addition of sodium sulfate. The 
Table VI

BASAL MEDIUM FOR EXAMINATION OF SODIUM REQUIREMENTS

Compound

$\mathrm{NaCl}$

$\mathrm{MgCl}_{2}-6 \mathrm{H}_{2} \mathrm{O}$

$\mathrm{KC1}$

$\mathrm{CaCl}_{2}-2 \mathrm{H}_{2} \mathrm{O}$

$\mathrm{MgSO}_{4}-7 \mathrm{H}_{2} \mathrm{O}$

$\mathrm{KNO}_{3}$

$\mathrm{K}_{2} \mathrm{H} \mathrm{PO}_{4}-3 \mathrm{H}_{2} \mathrm{O}$

Citric acid

Ferric ammonium citrate

EDTA (disodium potassium salt)

$\mathrm{K}_{2} \mathrm{CO}_{3}$

Trace metals A-5
Amount per liter

Variable

$17.0 \mathrm{gm}$

$1.0 \mathrm{gm}$

1.5 gm

$0.08 \mathrm{gm}$

$0.89 \mathrm{gm}$

$0.02 \mathrm{gm}$

$0.003 \mathrm{gm}$

$0.003 \mathrm{gm}$

$0.0005 \mathrm{gm}$

$0.026 \mathrm{gm}$

$1.0 \mathrm{ml}$

$\mathrm{pH}$ after autoclaving $\simeq 7.5$ 
Table VII

BASAL MEDIUM FOR EXAHINATION OF CHLORIDE REQUIREMENTS

Compound

$\mathrm{NaC1}$

$\mathrm{Na}_{2} \mathrm{SO}_{4}$

$\mathrm{NgSO}_{4}-7 \mathrm{H}_{2} \mathrm{O}$

$\cdot \mathrm{K}_{2} \mathrm{SO}_{4}$

$\mathrm{Ca}\left(\mathrm{NO}_{3}\right)_{2}-4 \mathrm{H}_{2} \mathrm{O}$

$\mathrm{Na} \mathrm{NO}_{3}$

$\mathrm{K}_{2} \mathrm{H} \mathrm{PO}_{4}-3 \mathrm{H}_{2} \mathrm{O}$

Citric acid

Ferric ammonium citrate

EDTA (disodium potassium salt)

$\mathrm{Na}_{2} \mathrm{CO}_{3}$

Trace metals A-5 (modified)

(1)
Amount per liter

variable

variable

$.7 .0 \quad \mathrm{gm}$

0.58 gm

$0.8 g \mathrm{~m}$

0.75 g표

$0.02 \mathrm{gm}$

$0.003 \mathrm{gm}$

0.0005 gin

$0.02 \mathrm{gm}$

$1.0 \mathrm{ml}$

$\mathrm{pH}$ after autoclaving $\simeq 7.5$

(1) $\mathrm{MnSO}_{4}-\mathrm{H}_{2} \mathrm{O}$ was substitued for $\mathrm{MnCL}_{2}-4 \mathrm{H}_{2} \mathrm{O}$ in equimolar amounts. 
maximum level of contamination by chloride in the medium with no added sodium chloride was calculated to be less than $3.4 \times 10^{-6} \mathrm{M}$.

Experiments on the effects of magnesium and calcium concentrations on the growth of marlne strains were conducted using mediun ASN-III, in which the levels of magnesium sulfate and calcium chloride were varied.

Experiments attempting to substitute potassium for sodium were conducted using medium ASN-III in which sodium chloride was replaced by equimolar concentrations of potassium chloride. The effect of potassium on minimum sodium concentrations supporting growth was determined using medium ASN-III in which the concentration of sodium chloride was varled while the chloride level was maintained at $0.4 \mathrm{M}$ by the addition of potassium chloride. The halotolerance of marlne strains was examined by the use of medium ASN-III containing increased concentrations of sodium chloride.

\section{b. Vitamin requirements}

Strains were screened for vitamin requirements in ASN-III (marine strains) or BG-I1 (non-marine strains). The media were prepared with water from a Millipore Super-Q Water Purifier and all glassware was carefully washed with concentrated nitric acid. Initial experiments were conducted with a filter-sterilized vitamin mixture containing vitamins $B_{12}$, biotin and thiamine at final concentrations of $4 \mu \mathrm{g} / 1$, $2 \mu \mathrm{g} / I$ and $10 \mu \mathrm{g} / \mathrm{I}$, respectively. Subsequent experiments were conducted solely with vitamin $B_{12}$ at a final concentration of $4 \mu \mathrm{g} / 1$. Liquid cultures containing $50 \mathrm{ml}$ of medium, with and without vitamins, were inoculated from plate cultures to minimize carry-over from the previous growth media. At least four successive transfers in vitaminfree medium were made in order to demonstrate the lack of an obligate 
vitamin requirement. Strain 7002 , which has an obligate vitamin requirement for vitamin $B_{12}$ (74) was used as a control. It invariably failed to grow after one transfer in a medium not containing vitamin $B_{12}$. c. Nitrogen sources

Al1 strains were screened for their ability to use ammonia, nitrate and urea as sources of combined nitrogen. All three compounds were used at a final concentration of 0.125 gram atoms of nitrogen per liter in liquid media. All strains were also tested for their ability to grow aerobically in tubes of liquid medla lacking a source of combined nitrogen.

The screening of strains for the ability to synthesize nitrogenase anaerobically was performed by a method recently developed by Rose Marie Rippka in Dr. R. Y. Stanier's laboratory at the Pasteur Institute, Paris. Samples (approximately $10 \mathrm{ml}$ ) of young stock cultures were twice washed aseptically by centrifugation to eliminate nitrate. The cells were resuspended in $10 \mathrm{ml}$ of an appropriate nitrogen-free medium, buffered with Tris-HCI ( $\mathrm{pH} 7.5)$ and placed in sterile $75 \mathrm{ml}$ flasks, sealed with serum stoppers. $\mathrm{CO}_{2}(1 \% \mathrm{v} / \mathrm{v})$ was added to each flask with a sterile syringe. The flasks were incubated at room temperature on a rotary shaker, and illuminated from above with a circular fluorescent lamp at an intensity of 1500 Lux. After 36 hours, the nitrogen starved cells had synthesized large amounts of glycogen. At this time DCMU [3-(3,4-dichloropheny1-) 1,1-dimethylurea] was added to each flask at a final concentration of $2 \times 10^{-5} \mathrm{M}$, sufficient to inhibit completely photosynthetic oxygen production (6). After the addition of DCMU, each flask was gassed with argon for 15 minutes to remove any oxygen present, and acetylene $(10 \% \mathrm{v} / \mathrm{v})$ was added with a sterlle syringe. 
The gas phase of the flask was periodically sampled, and the presence of ethylene was determined by gas chromatography $(17,65)$.

\section{d. Heterotrophy}

A11 strains were tested. for their capacity to grow both photoheterotrophically and chemoheterotrophically with glucose, fructose and sucrose at a final concentration of $0.3 \%(\mathrm{w} / \mathrm{v})$. The tests for photoheterotrophy were conducted in tubes containing $7.0 \mathrm{ml}$ of mineral mediur supplemented with $10^{-5} \mathrm{M}$ DCMU and the sugar to be tested (63). The ability to grow chemoheterotrophically was tested in $100 \mathrm{ml}$ flasks containing $50 \mathrm{ml}$ of mineral medium supplemented with the appropriate sugar, and with Tris-HCl buffer' (when tolerated by the strain in question). These flasks were incubated in the dark at either 25,30 , or $35^{\circ} \mathrm{C}$, depending on the temperature characteristics of growth of the particular strains examined.

\section{e. Maximum temperature permitting growth}

Temperature maxima for growth were determined for all strains in tube cultures. These cultures were incubated in $7.0 \mathrm{ml}$ mineral medium at a series of different temperatures in water baths and illuminated from above with white universal circular fluorescent lamps at an intensity of approximately 300 Lux.

\section{f. Effects of chromatic illumination on pigment synthesis}

The effects of chromatic illumination were examined on liquid cultures grown in $100 \mathrm{ml}$ flasks containing $50 \mathrm{ml}$ of mineral mediun. The flasks were incubated in opaque plastic boxes equipped with loosely fitting clear plastic lids, through which the flasks were illuminated with elther red or green, light, produced by Roscolene No. 821 (red) and Roscolene No. 871 (green) gelatin filters (Rosco Laboratories, Inc., 
Figure 1

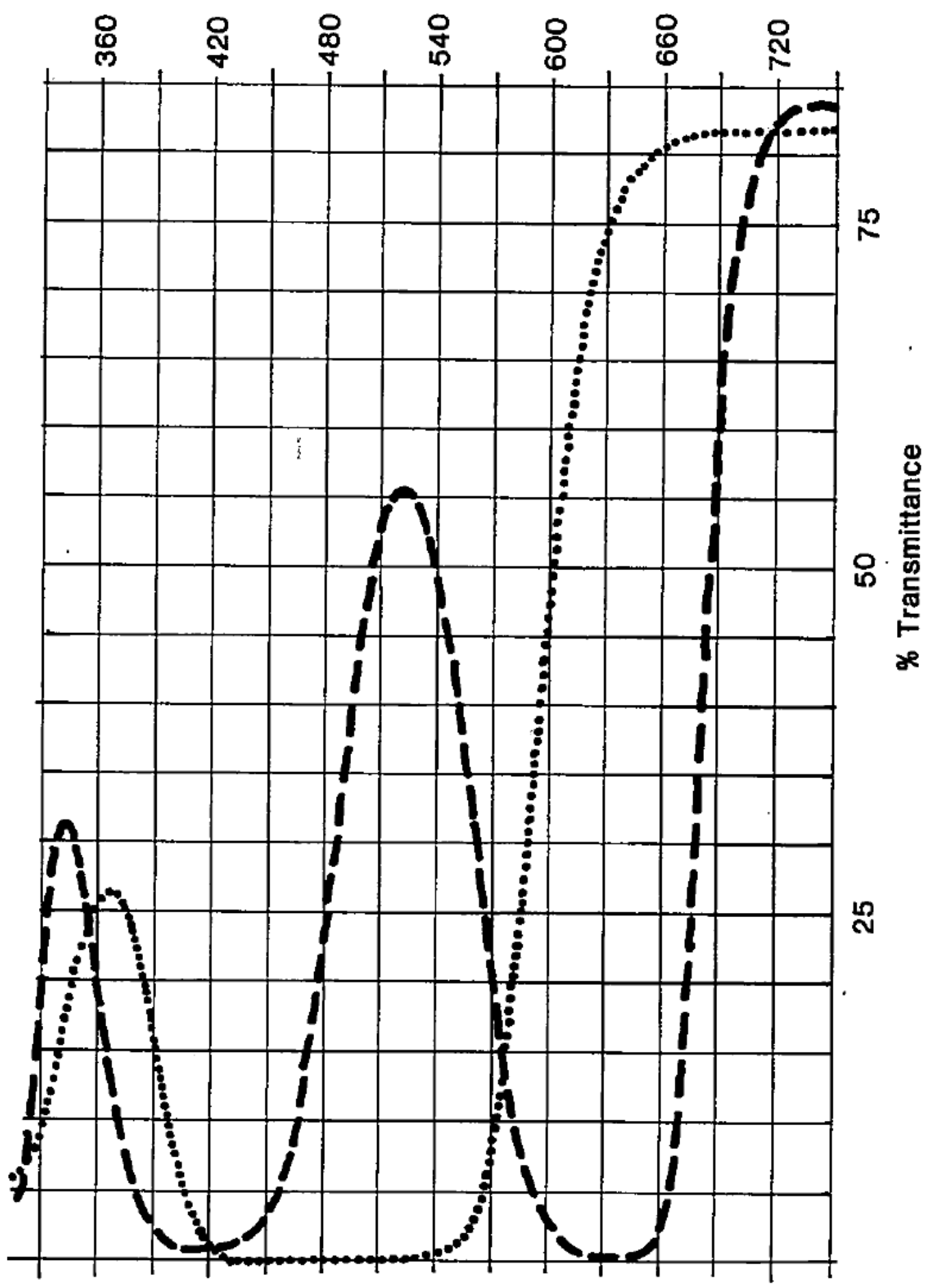

Absorption spectra and percent transmittance of .

Roscolene No. 821 (....) and Roscolene No. 871

(---) gelatin filters. 
Port Chester, New York). The absorption spectra of these filters are shown in Figure 1. White universal fluorescent lamps were used as Hight sources. The photosynthetic effectiveness of the light transmitted by the two filters is markedly different. In order to obtain roughiy equal growth rates in red and green light, white light intensities at the level of the filters were adjusted to 1800 Iux and 4000 Iux for the cultures grown in red and in green light, respectively.

3. Other Culture Methods

a. Slide culture techniques

Many of the cyanobacteria included in this study reproduce very slowly: weeks may be required for completion of their growth cycles. Thus, it was necessary to find a method of slide culture that would sustain growth and permit semi-continuous observations of development over long perlods of time. It was found that Falcon No. 3009 Cooper culture dishes, which were originally designed for the examination of liquid tissue cultures with an inverted microscope, could be used as growth chambers for this purpose. Prior to inoculation $8.0 \mathrm{ml}$ of agar medium was added to the culture dish which just filled the space between the upper and lower halves. After the medium had hardened, the cover was rotated and detached from the underlying agar, the surface of which was inoculated with a suitable dilution of freshly released spores. The cover was then replaced, and the dish was incubated at $25^{\circ} \mathrm{C}$ in a small clear plastic box which contained tissue paper moistened with a copper sulfate solution to retard evaporation and prevent fungal growth. These cultures were illuminated from above with light at intensitles between 200 and 300 Lux. At intervals, the Cooper dishes were placed on a microscope stage and examined. Photographs were made 
with a Zelss Universal microscope equipped with a long focal length condenser and a $16 \mathrm{X}$ neofluar objective, using bright field illumination. The above system has optical limitations imposed both by the thickness of the agar layer and the relatively low power of the objective. However, it permits good growth over long periods (up to four weeks) without risk of contamination and has proved extremeiy useful for determining the developmental cycles of the cyanobacteria examined.

Two of the strains'studied $(6605,7430)$ had such small cells that their developmental cycles could not be satisfactorily determined by the Cooper dish culture method described above. Instead, traditional slide culture techniques were employed. Glass slides and coverslips were carefully washed, rinsed and sterilized in glass petri dishes. A hot solution $(4.0 \mathrm{ml})$ of medium $B G-11+1 \%$ agar, prepared and sterilized as previously described, was pipetted into a sterile glass petri dish, . so that a uniformly thin layer of medium was formed at the bottom of the dish. Squares, about one-third the size of the cover slips used, were cut out of this layer and transferred aseptically to the surface of a sterile microscope slide. The upper surface of the agar was inoculated with a suitable dilution of cells and then covered with a sterile cover slip, subsequently sealed into place with paraffin (two parts paraffin to one part mineral oll w/w). These preparations were incubated, illuminated and photographed as described above, except that a 40X neofluar objective was used for their examination.

It should be noted that no attempt was made to incubate Cooper dish and slide cultures under conditions which permitted the growth of each strain at maximal rates. For example, light intensities were 
always kept very low because experience showed that freshly liberated spores are often very sensitive to 1ight. For this reason, the relative growth rates revealed by time lapse photographs of developmental sequences are not strictly comparable with one another, and in many cases are far below the growth rates obtainable at optimal Iight intensities and temperatures.

b. Cultures for electron microscopy

Several methods were used to grow cells for fixation and subsequent electron microscopic observation. Most fixations were done on cells grown in liquid cultures or on the surface of agar plates, using the standard mineral media, In some cases supplemented with combinations of vitamin $\mathrm{B}_{12}$, 'Tris-HCl buffer and sucrose $(0.3 \% \mathrm{w} / \mathrm{v})$. In order to make preparations of undisturbed colonies the organisms were grown in $0.5 \%$ agar overlays on plates of solid media. In order to observe ce11 attachment cultures were grown on the surface of small squares of dialysis membrane which, were placed on the surface of agar plates.

c. Growth on oyster shells

Oyster shells were;carefully washed, broken into small chips and sterilized by autoclaving.. Initial experiments were conducted in small glass petri dishes (approx. $50 \mathrm{~mm}$ in diameter) containting several oyster shell chips and partially filled (10 m1) with medium MN. These dishes were inoculated with axenic cultures of cyanobacteria. Subsequent experiments were conducted in $50 \mathrm{ml}$ cotton-stoppered flasks, containing oyster shell chips and $15 \mathrm{ml}$ of medium MN. These flasks were inoculated either with an axenic culture of a cyanobacterium or with both the cyanobacterium and an acid producing chemoheterotrophic bacterlum. All cultures were incubated at $25^{\circ} \mathrm{C}$ (the Petri dishes in a large sterile 
glass container), and illuminated from above with fluorescent lamps (Interna) at an intensity of approximately 200 Lux. The medium was changed at intervals of 3 to 4 weeks throughout the experiments.

d. Spore motility

Spore motility was observed on standard agar media, in Petri dishes or in Cooper dishes. Plates were inoculated with cells from stationary phase liquid cultures and incubated at $25^{\circ} \mathrm{C}$ in clear plastic boxes illuminated laterally with unidirectional light at intensitles varying from 50 to 200 Lux. In some strains, spore motility proved difficult to demonstrate. Our experience has shown that it may be necessary to use several different light intensities and conditions of culture in order to determine unambiguousiy the presence or absence of this property. e. Spore counts

In order to count the number of spores released by single parental. cells of Dermocarpa and Dermocarpella, Cooper dish cultures were inoculated with well dispersed cells from stationary phase liquid cultures and incubated at $25^{\circ} \mathrm{C}$ in clear plastic boxes. These were illuminated laterally with unidirectional light at intensities varying from 50 to 200 Iux. Following multiple fission and spore release, motile spores move away from the remains of the parental cell wall. When the released spores were sufficiently dispersed, photographs were taken, and spore counts determined on prints.

\section{Isolation and Purification of Strains}

\section{Cyanobacteria}

The nutritional requirements of the members of the Pleurocapsales do not appear to differ from those of other cyanobacteria that occur In the same natural habitats and their rates of growth are, in general, 
lower than those of other cyanobacteria. Consequently, the establishment of cultures is best achleved by direct isolation from favorable source materials collected in the field. Rock chips, mollusk shells and macroalgae (e.g., Rhodochorton) from the intertidal zone are good natural sources of the marine representatives, and all isolates discussed in this thesis were obtained from these sources. Samples were kept moist during transport to the laboratory by placing them in closed bottles or tubes which contained a piece of damp filter paper. Samples should not be covered with water, since this often leads to rapid overgrowth by non-photosynthetic bacteria.

As soon as possible after collection, the samples were examined microscopically in order to determine the most appropriate isolation procedure. Material was scraped off the natural substrate and suspended In sterlle liquid medium, tough aggregates were dispersed in a tissue homogenizer or by emulsification between two flame-sterilized microscope slides. When microscopic examination revealed the presence of a large number of contaminating organisms, the suspension was washed several times in sterile medium by repeated low-speed centrifugations. This treatment reduced substantially the population of contaminants. After such preliminary treatment, the sample was streaked on several plates, and also inoculated into a tube of liquid medium. Since well-isolated colonies are relatively rare on primary plates, the probability of a successful isolation is increased if several plates are prepared from each sample. Members of the Pleurocapsales develop on plates as small, compact colonies, which are often tough and adhere to the agar surface. Early detection and transfer of such colonies is essentlal, in order to minimize the possibility of overgrowth by other 
organisms. Consequentiy, plate cultures were examined dally with a dissecting microscope, and microcolonies were transferred as soon as they could be recognized. If such colonies could be easily dispersed, they were suspended in sterile medium and restreaked. However, in many cases it was preferable to pick the entire colony off the plate with a platinum spade under the dissecting microscope. Such colonies were transferred into tubes of liquid medium, from which additional plate cultures were prepared after sufficient growth had occurred. When primary plates did not yield any well-isolated colonies, a second set of plates was prepared from the primary liquid culture. Plating was continued until pure cultures were obtained.

With the precautions described above, the primary isolation and subsequent purification of members of the Pleurocapsales, as well as other cyanobacterla that form discrete colonies, can be readily achieved by standard bacteriological procedures. All strains isolated directly from natural samples were of marine origin. However, the same procedures were used successfully to obtain axenic cultures of fresh water strains which were received from other investigators in the unialgal state, many of which were heavily contaminated with non-photosynthetic bacterla and fungi at the tine of their receipt.

Cultures were presumed to be axenic when plates showed only one " type of colony. This was confirmed by microscopic examination of . liquid cultures and by the absence of growth after transfer to mineral medium supplemented with glucose $(0.3 \% \mathrm{w} / \mathrm{v})$ and yeast extract $(0.05 \%$ $w / v)$ and incubated in the dark. 
2. Acid Producing Chemoheterotrophic Bacteria

Acid producing chemoheterotrophic bacteria present in a unialgal culture of strain 7506 were isolated and purifled on plates of medium MN, supplemented with $0.5 \%$ glucose, $0.05 \%$ Difco nutrient broth, $0.1 \%$ ammonium chloride, $0.01 \%$ phenol red and $1.2 \%$ Difco Bacto agar. Cultures were incubated at room temperature in the dark. Acid producing colonies were purified by successive streaking on the same medium.

\section{Microscopic Techniques}

All light micrographs, except where expressly noted, were taken with bright field illumination using a Zeiss Universal"microscope equipped with Neofluar objectives.

The actual fixation, dehydration and embedding procedures for electxon microscopy have been previously described by Rippka et al. (1974) (64). In general, cells were prefixed (0.5\%) and fixed (3.5\%) in glutaraldehyde, with subsequent post-fixation in osmiun (1.0\%): During fixation, marlne strains were buffered in $0.143 \mathrm{M}$ veronal acetate buffer at $\mathrm{pH} 7.2$ supplemented with $\mathrm{CaCl}_{2}-2 \mathrm{H}_{2} \mathrm{O}(1.0 \mathrm{gm} / 1)$, sucrose $(34.0 \mathrm{gm} / 1)$ and $\mathrm{NaCl}^{\circ}(10.0 \mathrm{gm} / 1)$. Non-marine strains were buffered in $0.143 \mathrm{M}$ veronal acetate buffer at $\mathrm{pH} 7.2$ supplemented with $\mathrm{CaCl}_{2}-2 \mathrm{H}_{2} \mathrm{O}(1.0 \mathrm{gm} / \mathrm{I})$.

The initial steps of the fixation procedures varied with the growth conditions used. Cells grown in liquid media were centrifuged at low speed prior to preflxation, while cells grown on solld media could be scraped off the agar surface and suspended in prefixative directly. In both cases the cells were enrobed in agar following fixation in glutaraldehyde., Entire undisturbed colonies, grown in agar 
overlays, were removed by cutting small blocks out of the overlay and dropplng them directly into prefixative which made it unnecessary to enrobe them subsequently in agar. Small squares of dialysis membrane with cells attached to their upper surface were removed from the surface of agar plates and dropped directly into prefixative. The cells remained attached to the membrane throughout the entire fixation, de3 hydration and embedding procedure. With the exception of the squares of dialysis membrane, which required flat. embedding, all preparations were embedded in Beem capsules.

\section{E. Chemical Methods}

1. Isolation of DNA

Cells were suspended in Iysis mixture (9) and broken in a French pressure cell at 20,000 PSI. Following deproteinization in chloroformIsoamyl alcohol, 24/1 v/v), the (deoxyribonucleic acid) DNA was isolated by selective adsorption onto DNA-grade hydroxyapatite.(8) in the presence of $8 \mathrm{M}$ urea in $0.24 \mathrm{M}$ sodium phosphate buffer $\mathrm{pH} 6.9$ (MUP). The hydroxyapatite was washed repeatedly, first with MUP to remove protein and RNA (ribonucleic acid) and subsequently with $0.014 \mathrm{M}$ sodium phosphate buffer ( $\mathrm{pH}$ 6.9) to remove.the urea. The purified DNA was eluted with $0.4 \mathrm{M}$ sodium phosphate buffer $(\mathrm{pH}$ 6.9) and dialyzed against $0.1 \mathrm{X}$ standard saline citrate (54). Melting curves were determined in $0.1 \mathrm{X}$ standard saline citrate $\left(0.0195 \mathrm{M}\right.$ with respect to $\mathrm{Na}^{+}$) using a Gilford recording spectrophotometer. DNA base compositions were calculated as described by Mandel and Marmur (1968) (54).

\section{Other Procedures}

a. Fatty acid composition

Fatty acid analyses were performed by methods previously described 
by Kenyon (1972) (38).

\section{b. Pigment analysis}

Plgment analyses were performed by methods previously described by Rippka et al. (1974) (64).

\section{c. Protein determination}

Protein was determined by the method of Lowry et al. (1951) (49).

\section{RESULTS}

A. Circumscription of the Orders Chamaesiphonales and Pleurocapsales In most recent treatments of the taxonomy of cyanobacteria $(7,16$, $25,27)$, all members which reproduce regularly by the formation of spores are placed in two orders: the Chamaesiphonales (or Dermocarpales) and the Pleurocapsales. The distinguishing property of the former order is the unicellular nature of its representatives, which reproduce either by exospore or by endospore formation. The Pleurocapsales, on the other hand, is composed of colonial or filamentous cyanobacteria which reproduce only by the formation of endospores.

Observations made during the course of this study on the structure and development of representatives of these two orders have revealed that the processes of cell division underlying exospore and endospore formation are fundamentally different. Chamaesiphon, the classical representative of an exospore former, is in fact a unicelilular cyanobacterium which reproduces by budding, $1 . e .$, by a binary fission which yields daughter cells of unequal size. This distinctive mode of cell division also occurs in other groups of prokaryotes, for example certain purple bacteria (Rhodopseudomonas sp.) (59, p. 29) and certain nitrifying 
bacterla (Nitrobacter sp.) (77, p. 451). The structures described in the phycological 1iterature as "exospores" of Chamaesiphon are in reality the smaller daughter cells produced by this special varlant of binary fission.

The formation of endospores, both in the Pleurocapsales and in the Chamaesiphonales, occurs through the multiple fission of a parental cell. This leads to the production of at least four and often many more smaller daughter cells, which are then liberated by rupture of the wall of the parental cell. This mode of reproduction has not been reported in any other group of prokaryotes. Another character shared by all endospore-formers, but absent from Chamaesiphon, is the presence of an outer cell wall layer with a distinctive structure and mode of growth.

For these reasons, we propose to make an ordinal separation between the endospore-forming and budding cyanobacteria. The order Chamaesiphonales will be redefined as comprising those cyanobacteria which reproduce by budding; thus excluding the unicellular endospore-formers. The latter organisms will be reassigned to the order Pleurocapsales, now defined as Including all cyanobacteria which reproduce by multiple fission.

\section{B. Structure and Development in the Pleurocapsales}

1. General Features

a. Growth and reproduction

The members of the Pleurocapsales are distinguished from all other cyanobacteria by their mode of reproduction, which occurs through the formation and liberation of small spherical cells known in the algological Iiterature as endospores. Endospores are produced by multiple fission: 1.e., by a series of rapld, successive cleavages of a vegetative cell : 
into at least four (and usually many more) daughter cells, all enclosed by the outer wall layer of the parental cell. No increase in cell mass occurs during the cleavage process and consequently the volume of each daughter cell. is considerably less than half that of the parent cell. The spores are subsequently released through rupture of the outer wall layer of the parental cell.

In some members of the Pleurocapsales (Dermocarpa and Xenococous), multiple fisston is the sole mode of cell division: the spore increases greatly in cell mass to produce a large spherical vegetative cell which undergoes multiple fission followed by spore release. In other members of the group, however, spore enlargement is followed by one or more binary fissions, to produce a cell aggregate. It is composed of cells that are much larger than endospores and are held together by the common outer wall layer. The gross form of such aggregates is determined by the planes of successive binary fissions. Regular binary flssion in three planes at right angles to one another produces cubical packets of cells, characteristic of Myxosaraina and Chroococcidiopsis. In the Pleurocapsa-Hyella group, the planes of successive binary fissions are less regular and the aggregate consists of a mass of cells, sometimes bearing extensions in the form of cell chains, either branched or un'branched. Some or all of the cells that compose such aggregates eventually undergo multiple fission and release endospares.

Most of the existing reports on multiple fission in the Pleurocapsales indicate that it takes place by successive binary fissions (16, p. 41; 25, p. $811 ; 30$, p. 52); however, Setchell and Gardner (66, p. 20 and 26) claimed the occurrence of simultaneous cleavage in Dermocarpa sp. This specific claim of Setchell and Gardner could not 
be verified in the present investigation. As will be described in the following pages, multiple fission in the Pleurocapsales always takes place by rapid, successive binary flssions. However, in some members of the group (including Dermocarpa) this fact cannot be ascertained by Iight microscopy, and can be established only through the examination by electron microscopy of thin sections of dividing cells (Figures 7, 8, 27 and 28).

The designation of the reproductive cells produced by members of the Pleurocapsales as endospores is undesirable, since this term has long been applied by bacteriologists to a celi of an entirely different type. The bacterial endospore is a highly specialized resting cell that arises through an unequal binary fission, becomes engulfed by its larger sister cell, and thereafter undergoes an elaborate differentiation prior to its eventual release through lysis of the enclosing sister cell. The endospore of the Pleurocapsales is always formed through multiple fission and is not a resting cell, since it initiates vegetative growth immediately after its release. We propose to abandon the designation of endospore: for the reproductive cell characteristic of the Pleurocapsales, and shall refer to it hereafter as a spore.

b. Wall structure and its role in growth and development 1. Cell division

As first clearly shown by Frank et al. (22, 23), the cell wall of cyanobacteria is homologous in structure and chemical composition with the wall of other Gram negative prokaryotes. It is composed of at least two distinct layers: an inner layer, which appears homogeneous and electron-dense in thin sections, and an outer layer, with the structure, of a unit membrane when viewed in thin sectlons. The inner layer is 
destroyed by treatment with the enzyme lysozyme, and its synthesis by growing cells is inhibited by penicilin $(14,18,23,26,33,34,55)$. Both these treatments result in lysis of the enclosed cells. The sensitivity of this wall layer to lysozyme and to penicillin indicates that it is composed largely or entirely of peptidoglycan. The chemical analyses of the purified cell walls of several cyanobacteria (18, 22, $23,34)$ have shown the presence of the characteristic molecular constituents of peptidogiycans: muramic acid, glucosamine, meso-diaminopimelic acid, D-alaine and D-glutamic acid. We shall term this layer the PG layer (Figure 9). Recent analyses of cell wall preparations from cyanobacteria (78), have also shown the presence of 1ipopolysaccharides, which are known to be characteristic components of the outer wall layer in most Gram negative prokaryotes (57). It is therefore probable that the outer wall Iayer in cyanobacteria is homologous both in structure and in chemical. composition with the corresponding wall layer in other Gram negative groups. We shall term this the LP layer (Figure 9).

The PG and LP wall layers of cyanobacteria are often enclosed by an additional layer, readily distinguishable in electron micrographs of thin sections by its location, thickness and fine structure. In members of the group where such, a layer is sufficientiy distinct to be detectable by Iight microscopy, it has been designated by algologists as a sheath or enclosing membrane. Electron microscopic observations (21, p. 74-77; 44) have shown that the structure of this so-called sheath layer may vary widely among the cyanobacterla. In filamentous forms such as Lyngbya, this layer consists of a tubular sheath which surrounds the multicellular trichome, each constituent cell of which is completely enclosed only by the PG and IP wall layers (43). 
Our electron microscroplc observations have shown that in all members of the PIeurocapsales the PG and LP layers of the wall are completely enclosed by a fibrous outer layer (Figure 9) which is closely appressed to the surface of the LP layer. This layer, which will be termed the $F$ layer, cannot as a rule be resolved by light microscopy.

In the Pleurocapsales, as in other Gram negative prokaryotes, the PG and LP layers of the wall maintain a constant and characteristic thickness during the growth of the cell, except at the sites of transverse wall synthesis where the PG layer often shows a localized and transient thickening, coincident with the change in the polarity of its extension. In the.Pleurocapsales, the PG layer is approximately $6.0 \mathrm{~nm}$ wide, and the LP layer approximately $7.5 \mathrm{~mm}$ wide. These dimensions are very similar to those reported in other groups of Gram negative prokaryotes and in other cyanobacteria. Consequently, during the enlargement of the enclosed cell, the PG and LP layers increase in area, but not in thickness. However, the $\mathrm{F}$ layer increases in thickness as we11 as in area during the growth of the enclosed cell, sometimes attaining a thickness of $1000 \mathrm{~nm}$ (Figure 9).

Transverse wall formation accompanying binary fission in the P1eurocapsales is initiated by centripetal ingrowth of the PG and LP layers (Figure 39). Shortly after a transverse wa11, composed of these two layers, has been completed, each daughter cell starts to synthesize the material of the F layer evenly over its entire surface. Daughter cells, each completely surrounded by the PG and LP layers, are thus pushed apart by the synthesis of a new F layer, which thickens progressively until the onset of the following division. However, they remain enclosed by the $F$ layers formed during previous generations (Figure 58). 
Particularly if binary fission is extensive, electron micrographs of sections passing through transverse wall layers reveal clearly the existence of a series of $F$ layers, lald down in the course of successive cell divisions (Figure 58). The outermost, older portions of the $F$ layer tend to become less dense and ireegular in structure, probably because they are stretched to accommodate the increasing volume of the common mass of cells which they enclose. The F layer thus serves as a semi-elastic integument, which holds together small groups of cells formed by a few successive binary fissions (Figure 58). Eventually, enlargement of the cell mass will lead to the rupture of the outermost enclosing F layers. Nevertheless, very large cell aggregates in such genera as Myxosarcina, Chroococcidiopsis, and Pleurocapsa remain coherent, probably as a result of continued adhesion between the F layers of adjacent cells even after the destruction of the common outer F layer (Figure 39).

The synthesis of the wall layers during the course of multiple fission does not occur in the same manner in all representatives of the Pleurocapsales. In Xenococcus and Chroococcidiopsis, multiple fission Is accompanied by the synthesis of a new F layer, enclosing each cleavage product. The resulting spores are consequently each enclosed by a PG layer, an LP layer and a thin F layer at the time of their release. The much thicker $F$ layer of the parental cell remalns as a common enclosing structure unt11 the spores are liberated (Figures 20 and $38 \mathrm{~b}$ ). In all other members of the Pleurocapsales, synthesis of the F layer is arrested during the course of multiple fission, and as a consequence the spores are individually enclosed only by PG and LP wall layers at the time of their release from the common $F$ layer of the parent cell. Once 
the vegetative development of the spores is initiated, each spore starts to synthesize a new $F$ layer (Figures $7,8,27$, and 28).

\section{i1. Gilding motility}

GIIding movement, which is the sole mode of cellular locomotion in the cyanobacteria, occurs in many filamentous groups and in several unicellular forms (7, p. 296; 25, p. 800-804). With the exception of two reports that the spores of Pleurocapsa fuliginosa (4) and Endonema sp. (58) are capable of jerking movements, motility has not been described In any members of the Pleurocapsales. During vegetative growth, these organisms are invariably immotile. However, in members of the group which produce spores initially devoid of an F layer, the spores are transiently motile following their release, becoming immotile between 6 and 48 hours later, concomitant with the initiation of the synthesis of a new $\mathrm{F}$ layer.

Spore motility is most evident if the newly released spores are placed in a light gradient, where they show a pronounced phototactic response. Phototaxis may be either positive or negative, depending upon the light intensity. Migration of spores from a single parental cell of strain 7302 in a light gradient is shown in Figure 4. Comparison of successive flelds shows that immediately after liberation all (or nearIy all) of the spores are motile; thereafter, the capacity for movement is lost progressively by the members of the population. Some spores become Immotile after six hours or less, while others remain motile as long as 48 hours. The rate of movement by the spores of this strain in a IIght gradient is approximately $120 \mu \mathrm{m}$ per hour at $22^{\circ} \mathrm{C}$.

In strains where the spores are surrounded by an $F$ layer at the time of their release, spore motilfty has never been observed. Even in a 
light gradient, the spores remain closely clustered around the parental cell (Figure 15).

From the foregoing discussion, it follows that in most cyanobacteria which are capable of undergoing multiple fission, the cells produced by this division process are readily distinguishable from the cells produced by binary fission not only by their small size, but also by a difference in wall structure correlated with a capacity for gliding movement. These differences in wall structure and motility between spores and vegetative cells do not exist in the genera Xenococcus and Chroococcidiopsis, where the distinction rests solely on a difference in cell size. In Xenococcus, which divides exclusively by multiple fission, the parental cell is usualiy so much larger than the spore that size. alone is an adequate character for the recognition of a spore. In Chroococcidiopsis, which divides both by binary and by multiple fission, the similarity in size of the spores and the vegetative cells makes discrimination between them, and hence discrimination between binary and multiple fission, extremely difficult.

\section{ii1. Spore release}

In the algological literature, spore release in the Pleurocapsales has been attributed to the rupture or gelatinization of the enclosing "membrane" of the parent cell following multiple fission (7, p. 295; 16, p. $171 ; 25$, p. $812 ; 30$, p: 56). Light micrographs of the $F$ layer of parental cells following spore release in strains of Dermocarpa suggest that this layer is torn open at the time of spore release (Figure 10). Probably the spores begin to enlarge following multiple fission and their Increase in cell volume causes the rupture of the common parental $F$ layer In a manner analogous to its rupture following repeated binary 
fissions, as described in the previous section.

\section{Iv. Attachment to solid substrates}

- In nature, members of the Pleurocapsales are typically found attached to solid substrates. In the laboratory, when grown in unagitated liquid media, they adhere to the glass surface of the culture vessel. Several observations suggest that only freshly released spores l are capable of becoming attached to glass, although subsequent growth of the F layer may increase the strength of attachment. When a stationary phase culture is inoculated into a fresh 11quid medium, almost all the cells undergo multiple fission and release spores shortly after transfer. The spores attach firmly to the surface of the glass culture vessel. If the cells are subsequently detached by vigorous shaking, they do not reattach, remaining as suspended clumps in the Iiquid medium until the next round of multiple fission takes place. Moreover, when cultures are grown on solid media, the spores stick to the agar surface and to each other shortly after their release, making it difficult to remove them from the surface of the plate.

Spores do not appear' to possess specialized organelies for attachment, analogous to the holdfasts of Caulobacter (60). However, thin sections of strain 7326, growing on the surface of a dialysis membrane which had been placed onithe surface of an agar plate, show that the F layer flares out around the base of the cell, increasing the surface area in contact with the substrate, and thus probably increasing the effectiveness of attachment (Figures $26 \mathrm{c}$ and 29).

\section{c. UItrastructure}

The cellular fine structure of the Pleurocapsales is, in general, similar to that of other cyanobacteria (44); no features which could be 
considered distinctive of this group have been observed. The structure and arrangement of the various layers of the cell wall have been discussed in a previous section. The cytoplasmic membrane appears in thin sections as a unit membrane, approximately $7.0 \mathrm{~nm}$ in width (Figure 9). The photosynthetic thylakoids are structurally similar to those described for other groups of cyanobacteria $(13,45)$. The Individual thylakoids are $17.5 \mathrm{~nm}$ in width, and composed of two closely appressed unit membranes (Figure 9). In the Pleurocapsales, the thylakoids are dispersed throughout the cytoplasm in somewhat irregular parallel arrays. In each array, the individual thyakoids are normally separated by a distance of 35 to $45 \mathrm{~nm}$; the intervening space is in part occupied by a regular array of spherical phycobilisomes attached to the outer surfaces of each thylakoid. Individual phycobilisomes range in diameter from 25 to 30 nm (Figure 23a).

In certain strains of this group (e.g., 7304, 7307, 7310, 7312, 7314) a second membrane configuration is evident in many cells. It consists of stacks of closely appressed unit membranes which do not appear to bear phycobilisomes on their surfaces (Figures $7 a$ and 19a).

The structure of the nucleoplasm is similar to that of other prokaryotic organisms, appearing in thin sections as relatively electrontransparent areas filled with strands of DNA (Figures 7a, 23a, 39 and 40c). In strains of Dermocarpa (7301, 7304) and Xenococcus (7306), where large numbers of spores are produced, the DNA appears to segregate Into many well-defined nucleoids just prior to the onset of multiple fission (Figure 7a).

Most of the cytoplasmic inclusions described in other groups of cyanobacterla are evillent in the cells of the Pleurocapsales. These 
Include carboxysomes $(67,68,69)$ (FIgures 39 and 40c), often associated with the nucleoplasm; polyphosphate granules (Figure 23a); and glycogen (Figure 9).

Freshly released spores are very similar, if not identical, in fine structure to mature vegetative cells; the only obvious difference concerns the presence or absence and (if present) the thickness of the $F$ layer of the cell wall.

Thin sections of strain 7305 reveal that a very small minority of the cells contain electron-dense cylindrical inclusions with conically shaped ends measuring $50 \mathrm{~nm}$ in diameter and $110 \mathrm{~nm}$ in length, that are located in the nucleoplasm (Figure 23a). Negatively-stained preparations of the supernatants of stationary phase cultures of this strain reveal the presence of virus-like particles, whose head dimensions correspond to those of the inclusions seen in thin sections and whose tails are $6 \mathrm{~nm}$ in diameter and $400 \mathrm{~nm}$ in length (Figure 23b). It is thus likely that the inclusions present in the thin sections are cyanophage heads.

\section{Specific Developmental Patterns}

Three primary properties influence the life cycles of the members of the Pleurocapsales. These are the relative importance of binary and multiple fissions; the planes of successive binary fissions; and the presence or absence of spore motility. In terms of these criteria, the strains examined can be divided into six groups, each of which corresponds to a previously described genus, as shown in Table VIII. The assignment of strains to these genera is shown in Table IX.

For each of the six'groups, the developmental cycle has been established on the basis of three modes of examination: the gross appearance 
of mass cultures*; semI-continuous observations with the 1ight microscope on the growth of colonies from single spores in Cooper dishes ${ }^{+}$;

and electron microscopic examination of thin sections prepared from material at various stages of growth. In the ensuing accounts, the evidence obtained from these modes of examination will be presented, followed by a schematic reconstruction of the life cycle characterIstic for each of the six genera.

*Examination of mass cultures is best done on material which has been grown on a solid substrate (i.e., agar). In groups which produce large aggregates of vegetative cells with a distinctive arrangement (Myxosarcina, Chroococcidiopsis, and Pleurocapsa) the characteristic cell arrangement is often much less evident or absent in liquid cultures.

In the numerous plates which illustrate development, in Cooper dish and slide cultures (Figures $5,6,16,17,18,25,32,36,37,43,44$, $45,47,48,50,51,52,55,56,57,62,65,66$ ) the times (in hours) following the first observation are indicated by the number on each individual photomicrograph. 
Table VIII

KEY TO SUBGROUPS OF THE PLEUROCAPSALES

I - Celz division solely by multiple fission.

A Spores motile............ Dermocarpa

B Spores immotile.......... Xenococcus

II - Cell division by a combination of binary and multiple fission.

A Spore development leads to formation of a vegetative cell which undergoes one or two binary fissions, to produce a single apical cell which divides by multiple fission and releases spores; the basal cell(s) subsequently enlarges and repeats the cycle....... ................ Dermocarpezza

B Spore development followed by repeated binary fissions In three planes at right angles to one another, producing a cubical aggregate of cells, all of which normally undergo multiple fission.

1. Spores motile....... Myxosarcina

2. Spores imnotile . . . . Chroococcidiopsis

C Spore development followed by repeated binary fissions in many different planes, to produce irregular, sometimes filamentous aggregates of cells. Some or all of the cells in the aggregate undergo multiple fission. ............. Pleurocapsa 


\section{Table IX \\ GENERIC ASSIGNMENT OF STRAINS}

I. Dermocarpa

A Strains of marine origin

7301.

7302

7303

7304

B Strains of non-marine origin

7437

7438

II. Xenococcus

Strains of marine origin

7305

7306

7307

III. Dermocarpelza

One strain of marine origin

7326

IV. Myxosarcina

Strains of marine origin

7312

7325

v. Chroococcidiopsis

Strains of non-marine origin

6712

7203

7431

7432

7433

7434

7436

7439 
Table IX (Continued)

vI. Pleurocapsa

A Strains of marlne origin

7310

7314

7317

7319

7320

7321

7322

7324

7440

7506

7516

B One strain of non-marine origin

7327 


\section{a. Dermocarpa}

The genus Dermocarpa, which is represented in our collection by six strains $(7301,7302,7303,7304,7437,7438)$, includes unicellular forms which divide exclusively by multiple fission and produce motile spores. The examination of mass cultures reveals populations of spherical cells which vary.greatly in size. The contents of most of these cells appear homogeneous. However, some of the larger cells have clearly undergone cleavage, and are filled with many small spores (Figures 2 and 3 ). Spore size is uniform in each strain: some strains have spores 1.5 to $2.0 \mu \mathrm{m}$ in diameter, others have spores 3 to $4 \mu \mathrm{m}$ in diameter (see Table $X$ ). At the time of their release, the spores display gliding movement, as revealed by their phototactic response to unidirectional illumination (Figure 4). Following the cessation of movement, the spores begin to enlarge symmetrically and increase in volume until multiple fission occurs. The development of the six strains as observed In Cooper dish cultures is very similar, and is illustrated by sequences for strains 7302 (Figure 5) and 7437 (Figure 6). Until cleavage has been completed, the contents of the developing cells appear homogeneous. In each strain, the size of the parental cell at the time of multiple fission varies widely: maximum observed diameters for the cells of each strain are listed in Table $\mathrm{X}$.

The developmental process has also been studied by elecgron microscopic examination ofthin sections (Figures 7 and 8 ). Figure 7a shows the typical appearance of a cell just prior to multiple fission. It contains numerous discrete nuclear bodies (arrows), and the three wall layers are sti11 in close contact with one another. The $F$ layer, as a 
T A B E - $\mathbf{X}$

STRUCTURAL PROPERTIES OF DETMOCATPA STRAINS

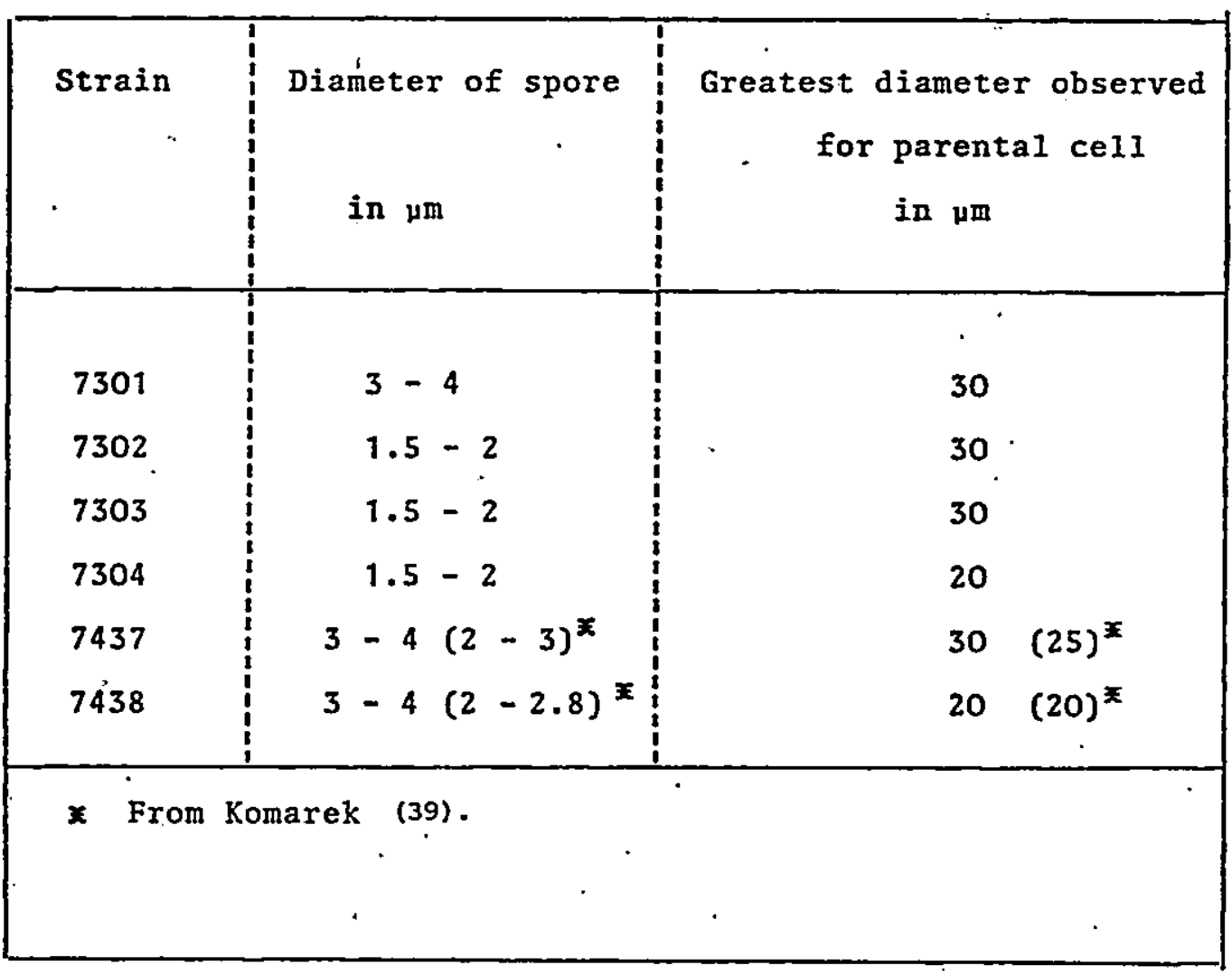


result of continuous thickening during vegetative growth, has attained a width ranging from 500 to $1000 \mathrm{~nm}$; detalls of wall structure in a cell just prior to the onset of division are shown in Figure 9. Figure $7 \mathrm{~b}$ shows a cell in the course of multiple fission; arrows point to three dividing cells. At this stage of development, the cleavage products, each enclosed by the PG and IP wall layers, have retracted from the surrounding F layer of the parental cell, and are also separated from one another. A cell which has completed multiple fission is shown in Figure 8a. Division stages are no longer present, and the final cleavage products, of roughly equal size, are surrounded only by the PG and IP wall layers. A rarely observed developmental abnormality is shown in Figure $8 \mathrm{~b}$. In this cell, a large portion of the cytoplasm has failed to undergo cleavage.

01d cultures contain many empty F layers of parental cells. Their appearance in phase contrast photomicrographs (Figures 11a and 11b) suggests that spore release has occurred by rupture of the F layer at a single point.

is

The developmental cycle of Dermocarpa is shown schematically in Figure 11.

As shown in Table $X$, spore slze is a constant strain character. The number of spores produced by single parental cells is therefore a function of the size of the parental cell at the onset of multiple flssion, which is in turn affected by environmental factors. When a culture of Dermocarpa in the stationary phase of growth is transferred to fresh medium, nearly all the cells undergo multiple cleavage and release spores within 12 to 24 hours. Hence, the number of spores 


\section{... $\quad$ TABLE XI}

The Number of Spores Released by Single Parental Cells of Dexmocarpa Strains

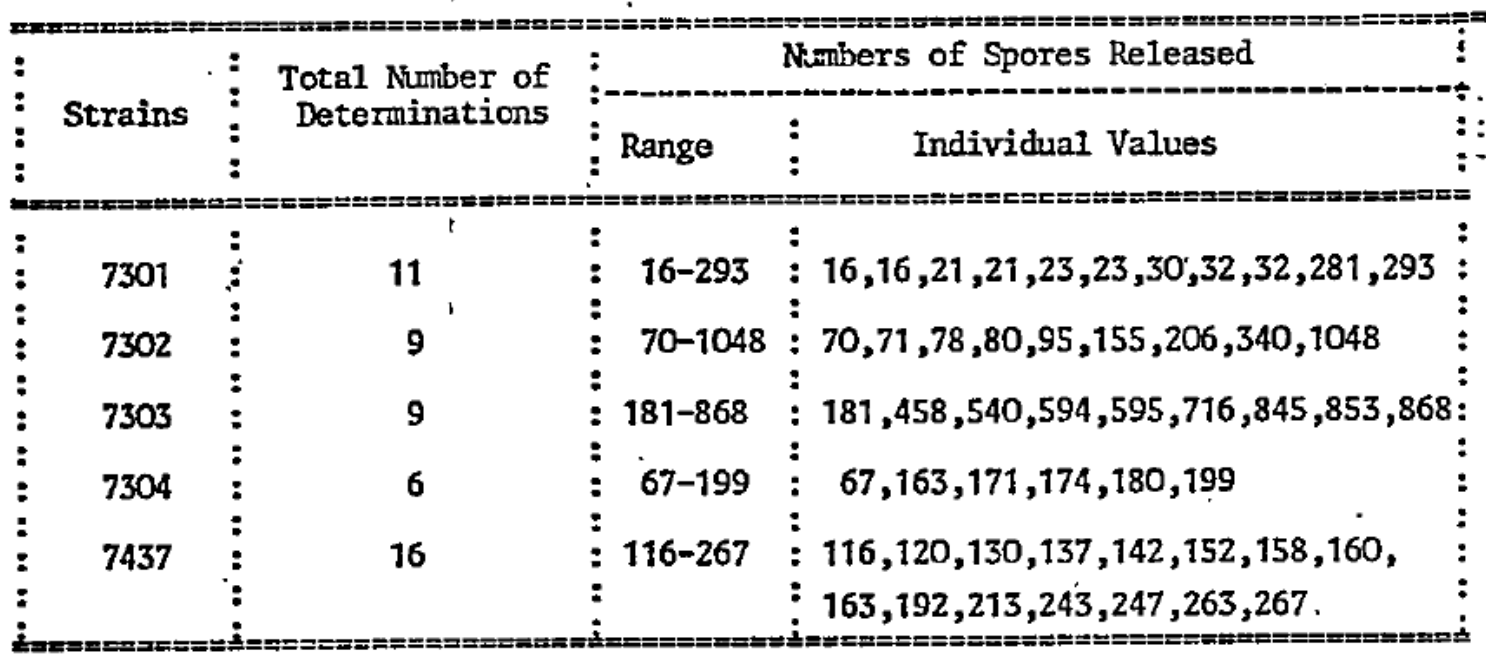


produced from single parental cells of each strain varies widely as shown In Table XI.

Since multiple fission occurs through a rapid series of successive binary fissions, the number of spores formed from a single parental cell should, in principle, conform to the series $2^{2}, 2^{3}, 2^{4}$. . . $2^{n}$. In fact, nearly all spore counts on the progeny of single parental cells deviate from this series; indeed, some of the determined values (e:g., $21,23,95,181,206,340)$ are roughly intermediate between two successive numbers of the series. This suggests that the numerous successive nuclear divisions which, accompany vegetative growth, do not always occur In synchrony. Relatively minor deviations from the successive numbers of the series such as $30\left(2^{5}=32\right)$ or $70\left(2^{6}=64\right)$ might also be explained by irregular cell divisions, resulting either in the formation of anucleate spores (number of spores greater than expected) or in the formation of multinucleate undivided segments (number of spores less than expected). In one instance of spore release from a parental cell of strain 7301, microscopic observations on the liberated spores were continued until vegetative enlargement was well underway. Of the 281 spores released, only $256\left(2^{8}\right)$ actually developed, showing that about 10 percent of the spore, progeny were non-viable. These non-viable spores may have falled to receive nuclei. Some of the electron micrographs of thin sections of strain 7304 (Figure $8 \mathrm{~b}$ ) reveal sporangia that contain, together with numerous single spores of equal size a large segment of cytoplasm which has failed to cleave completely. Such undivided segments have also been seen with the light microscope. They have never been observed to develop following release. 
When examined in the 1ight microscope, a very small fraction of the vegetative cells of strain 7437 contain a well-defined equatorial band or plate, suggestive of the occurrence of a binary fission (Figure 12a). However, electron micrographs of thin sections do not confirm this interpretation. Instead, rare cells show a localized thickening and invagination of the fibrous outer layer, which never penetrates deeply Into the cytoplasm (Figure 12b). This localized thickening of the outér wall layer appears to correspond to the equatorial band seen by light microscopy: The phenomenon is confined to strain 7437 .

Although all strains of Dermocarpa produce spherical cells when growing dispersed in 1iquid cultures, the cell form is modified when the spores develop in dense masses attached to a solid substrate (e.g., the glass surface of a culture flask). Under these clrcumstances, the cel1s become pyriform (Figure 13), as a result of mutual compression during their enlargement. The apparent polarity of such cells is imposed by the growth conditions and thus is not a genetically determined property, as is the polarity of the cell in Dermocampelza as described In a later section. 
Figure 2

Photontcrographs of mass cultures of Dermocarpa grown on agar plates of medium MN. The spherical cells.of varying size appear either homogeneous or filled with spores. a. and b. Strain 7301, X 1000; c. Strain 7302, X 1000; d. and e. Strain 7303, x 1000 . 


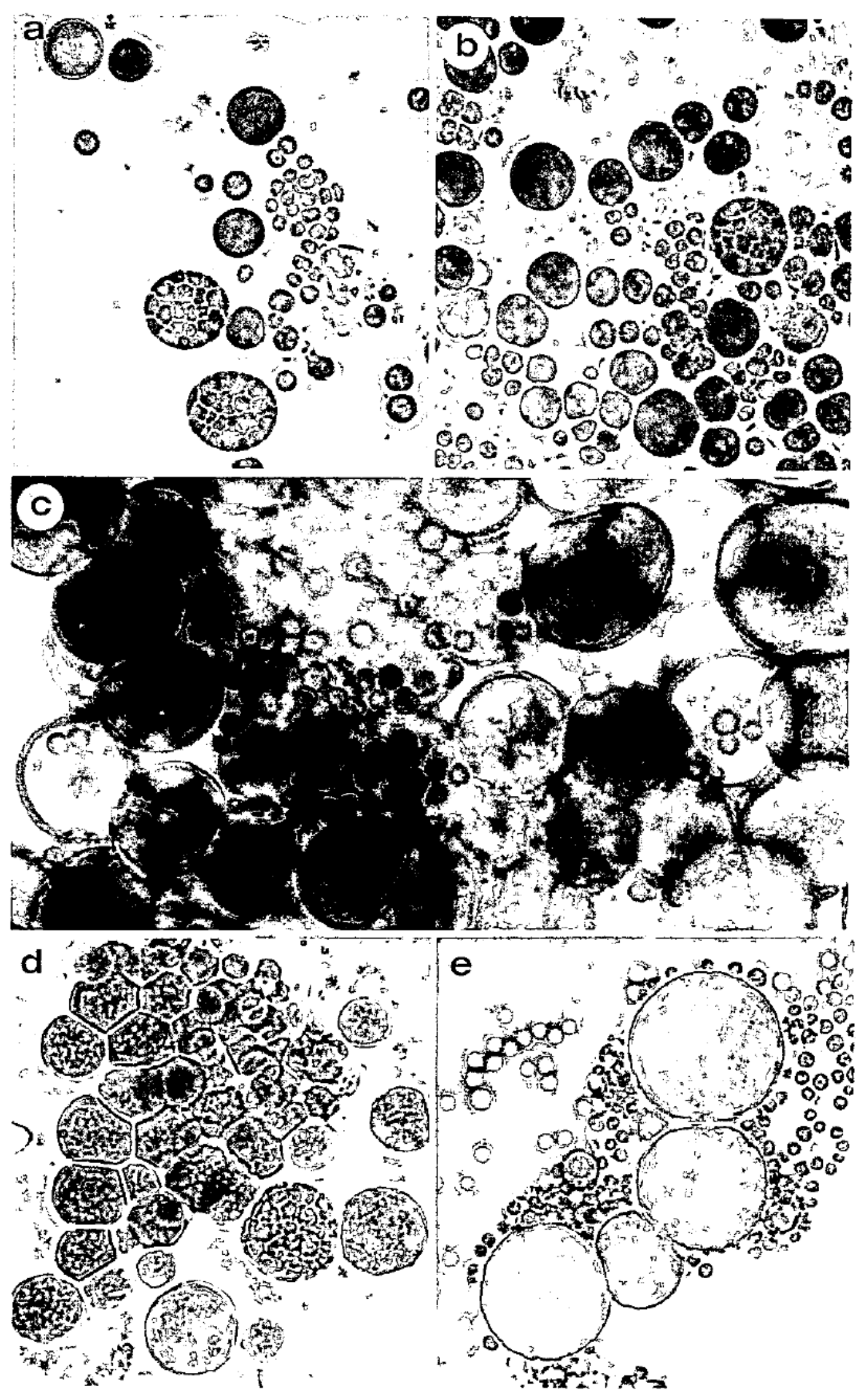




\section{Figure 3}

Photomicrographs of mass cultures of Dermocarpa grown on agar plates. a. Strain 7304 grown on medium MN, X 1000; b. Strain 7437 grown on medium BG-11, X 1000; c. and d. Strain 7438 grown on medium BG-11, X 1000 . In Figure 3c, the field includes many parental $F$ layers left behind following multiple fission and spore release. 

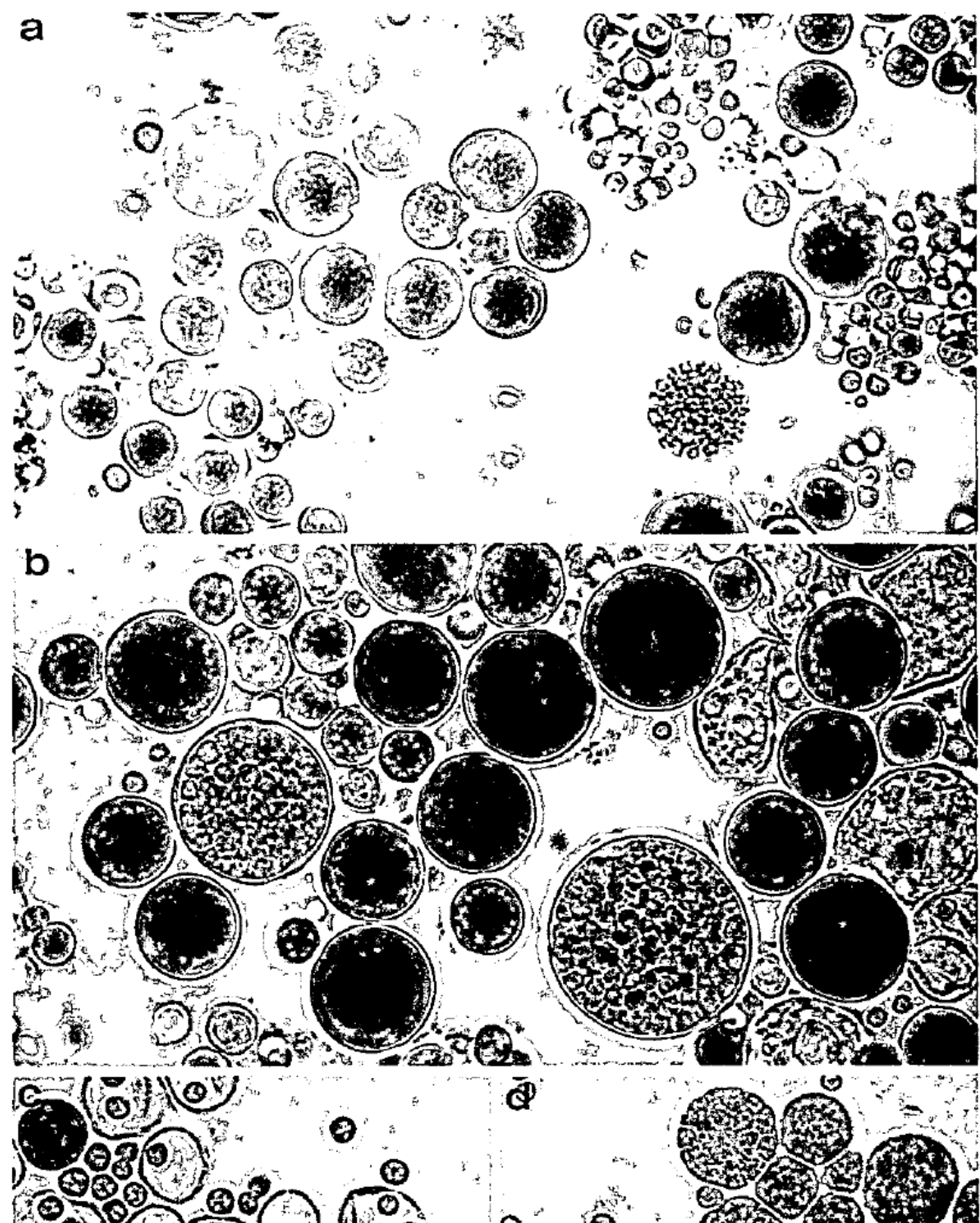

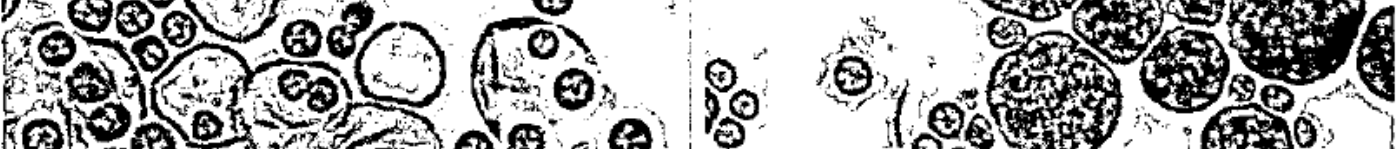

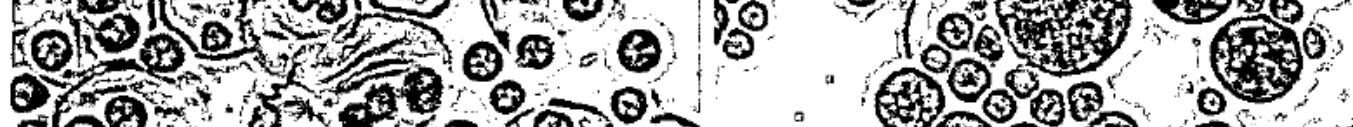
(3)

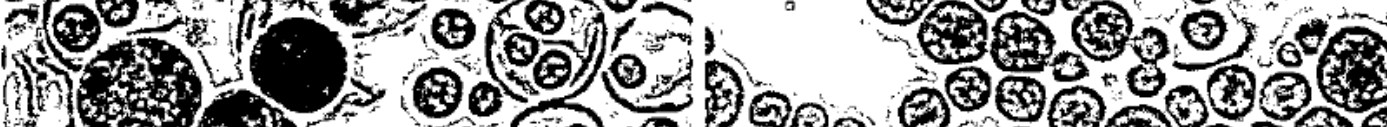

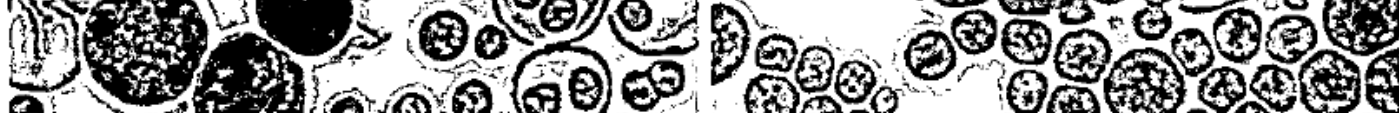

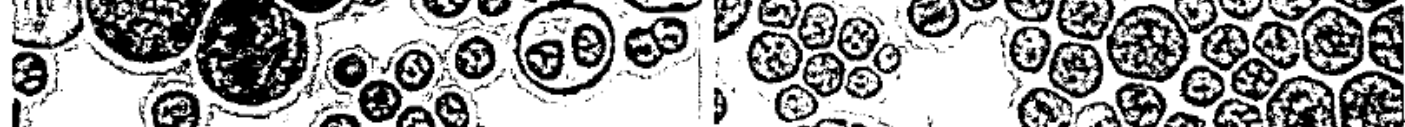

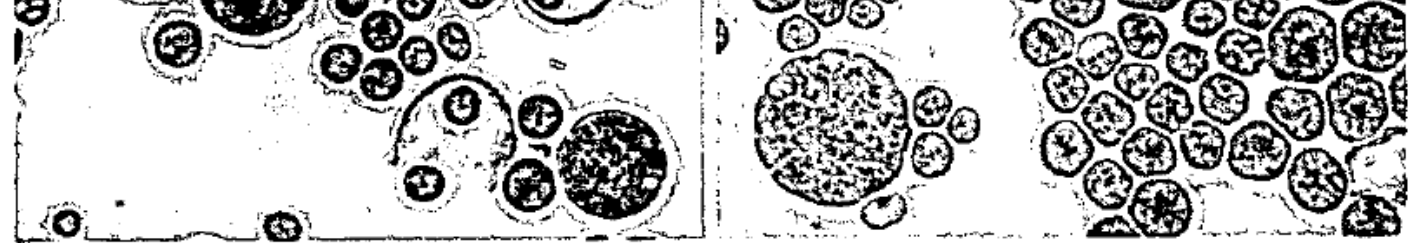


Figure 4

Photomicrographs of Dermocarpa strain 7302 grown in a Cooper dish culture on medium MN and illuminated laterally with unidirectional light. The three pictures show the phototactic response of freshly released motile spores when placed in a light gradient. The numbers in the upper left hand corners of the pictures indicate the time (in hours) after the preparation was made. The arrows indicate the direction of illumination. Note the remnants of the parental $F$

$\because \quad$ layer in the upper right hand corner of each picture X 200 . 

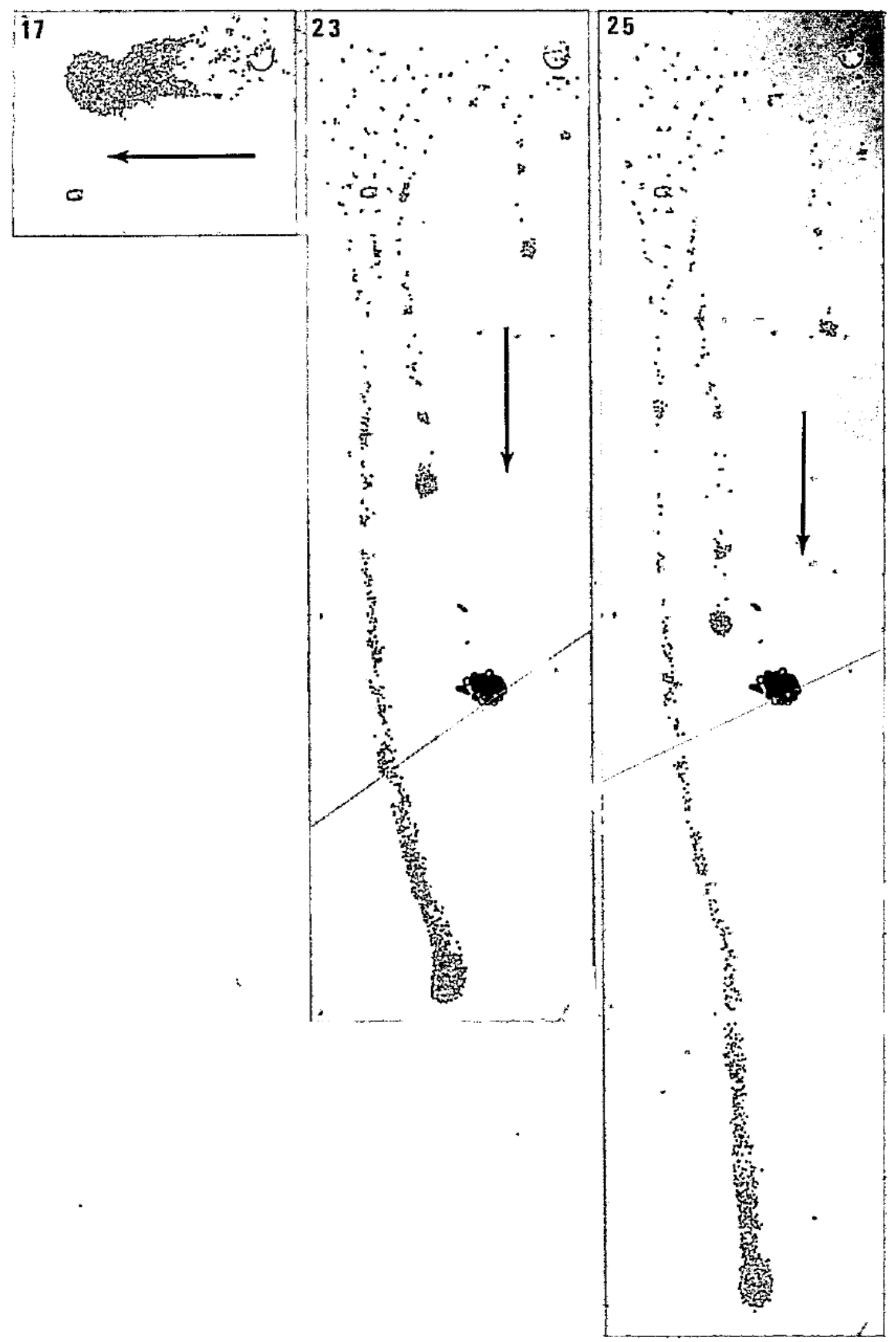
56

Figure 5

Development of Dermocarpa strain '7302 on medium MN in

a Cooper dish culture. Successive photomicrographs

of a single field, showing spore development over a period of 288 hours. X 500 . 


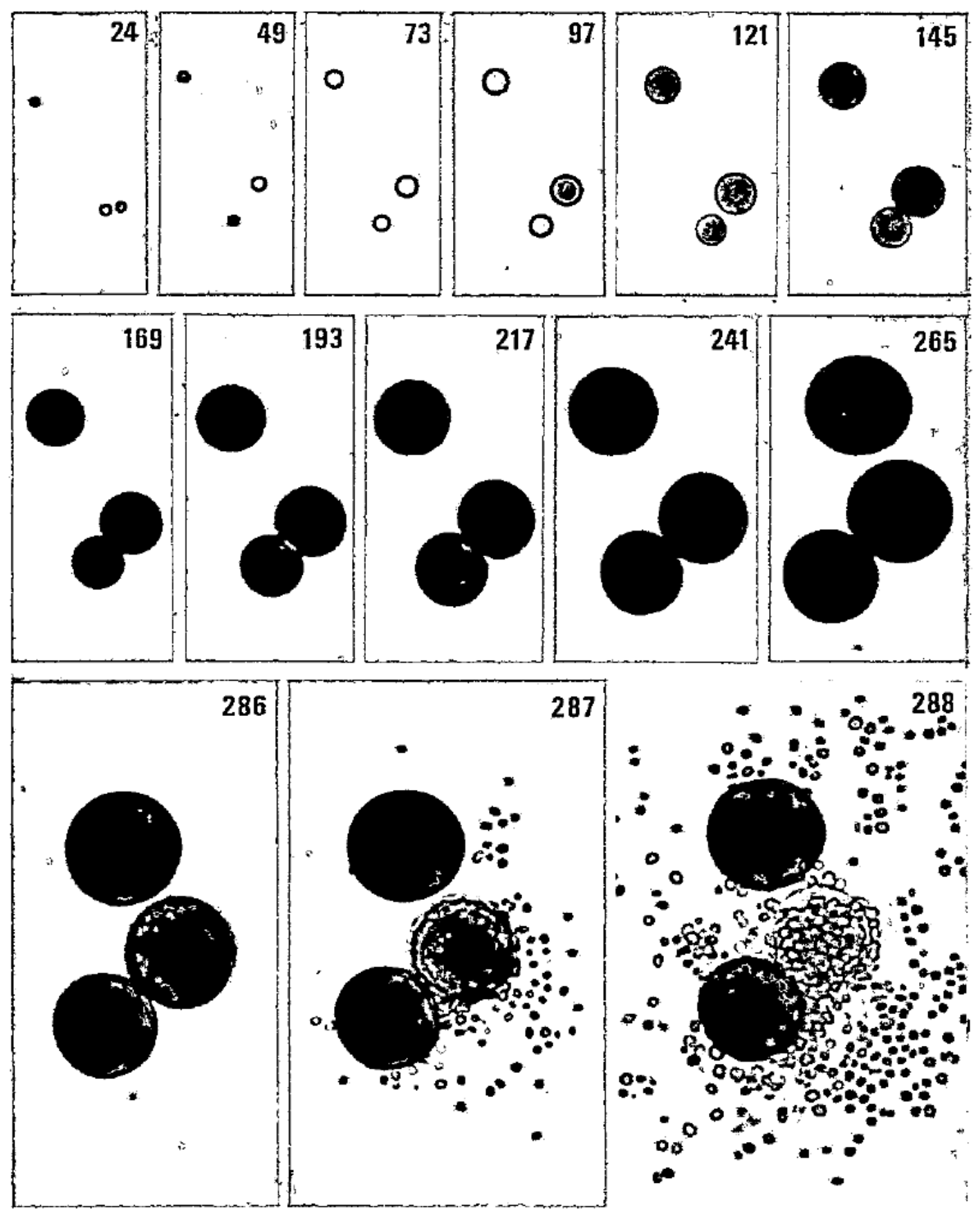




\section{Figure 6}

Development of a Cooper dish culture of Dermocarpa strain 7437 on medium BG-11, over a period of 238 hours. Arrows on the photograph taken at 238 hours point to remnants of the parental $F$ layer after spore release. $\times 500$. 


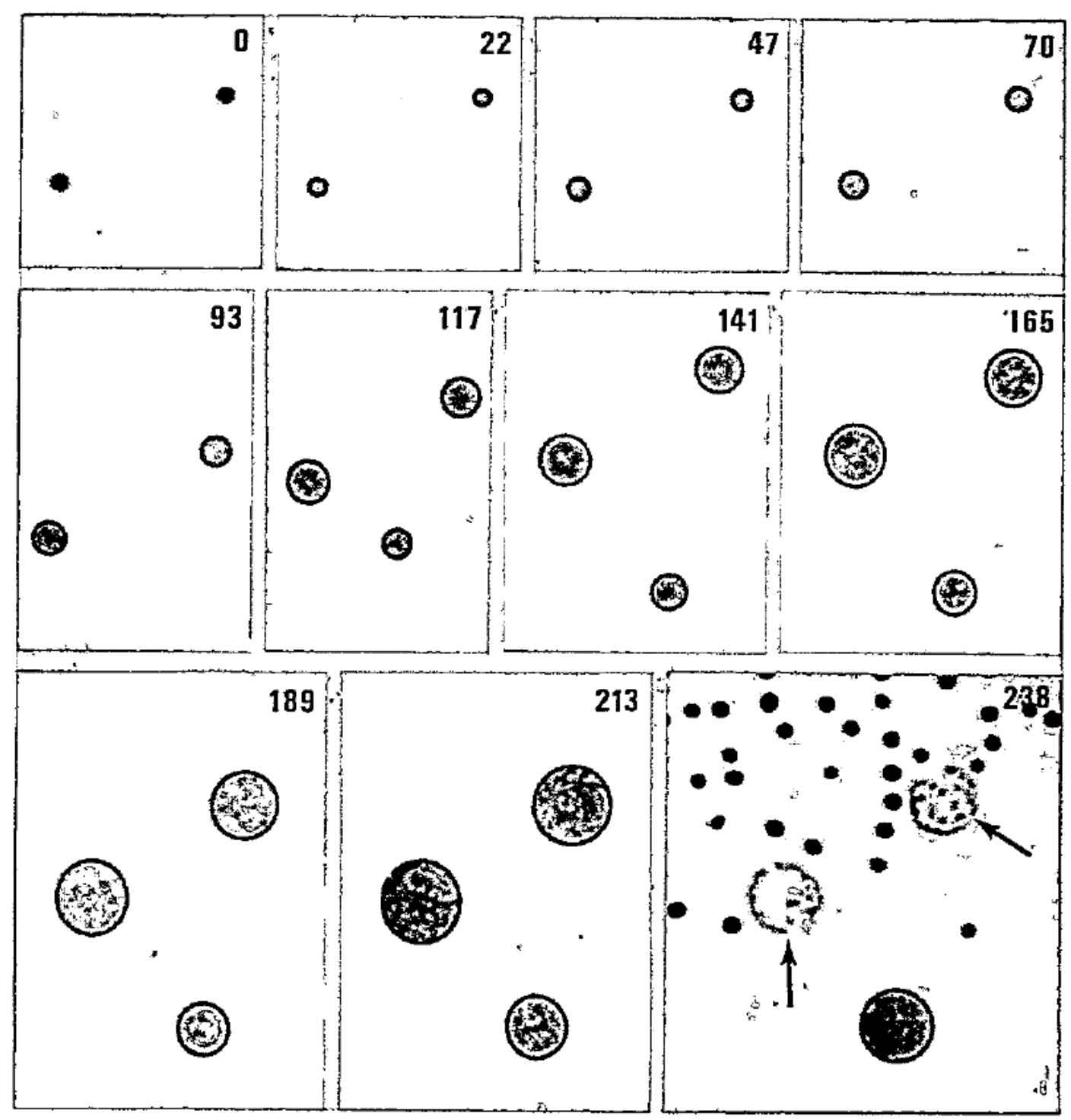




\section{Figure 7}

Electron micrographs of thin sections of Dermocarpa strain 7304 grown in Iiquid medium MN. a. A cell

just prior to the onset of multiple fission. It contains many separate nucleolds $(N)$, frequently associated with carboxysomes (C). In one area (arrow). the thylakoids occur in a closely appressed stack. XI4,000 . b. A cell in the course of muItiple fission. The cleavage products have retracted from the parental $F$ layer. Dividing cells are indicated by arrows. X 9250 . 

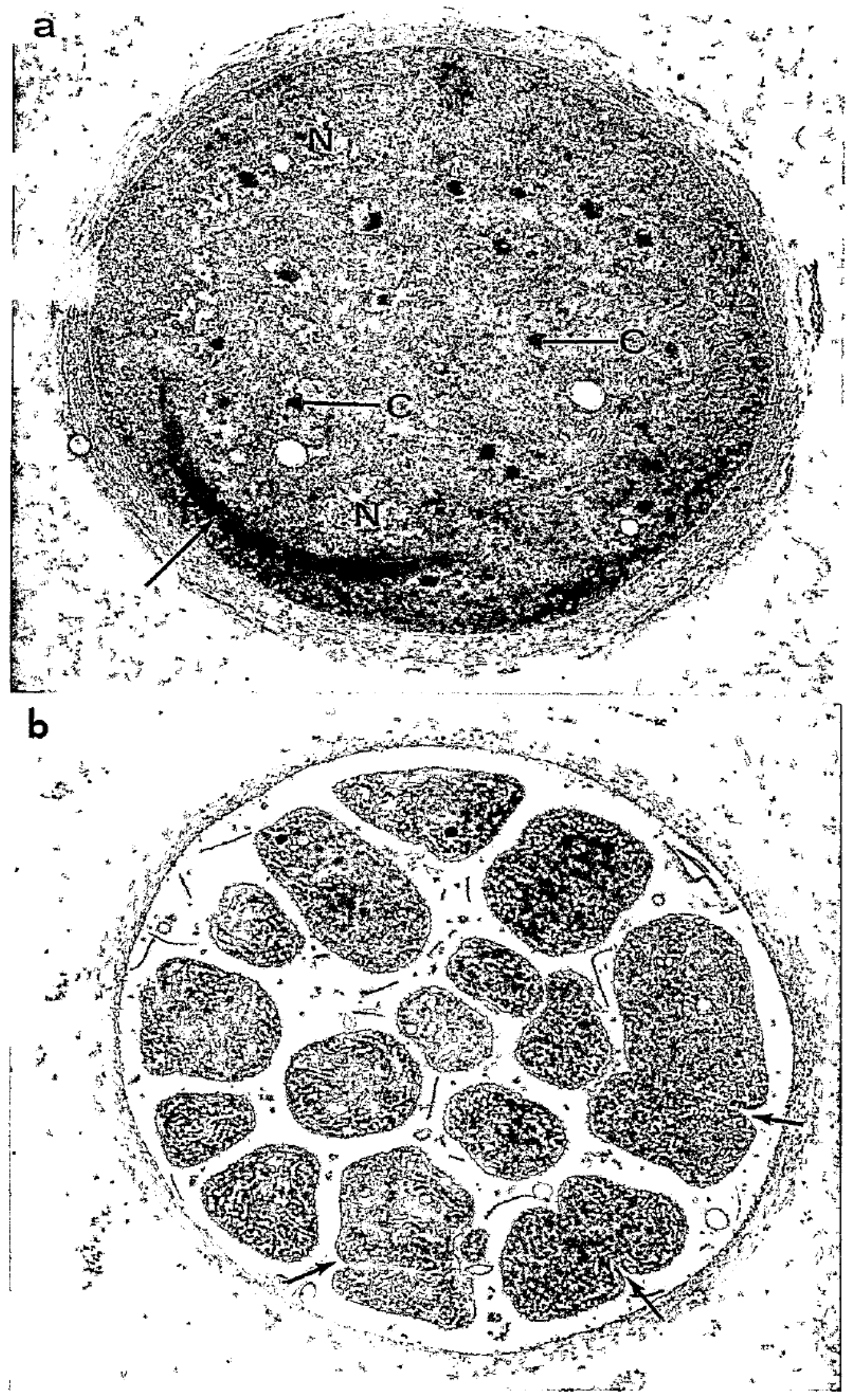
Figure 8

Electron micrographs of thin sections of.Dermocarpa strain 7304 grown in 1iquid medium MN. a. A cell which has completed multiple fission and is filled with spores surrounded only by the PG and LP wall layers. X11,500. b. A cell undergoing multiple fission which contains a large, uncleaved segment of cytoplasm. X 12,250. 

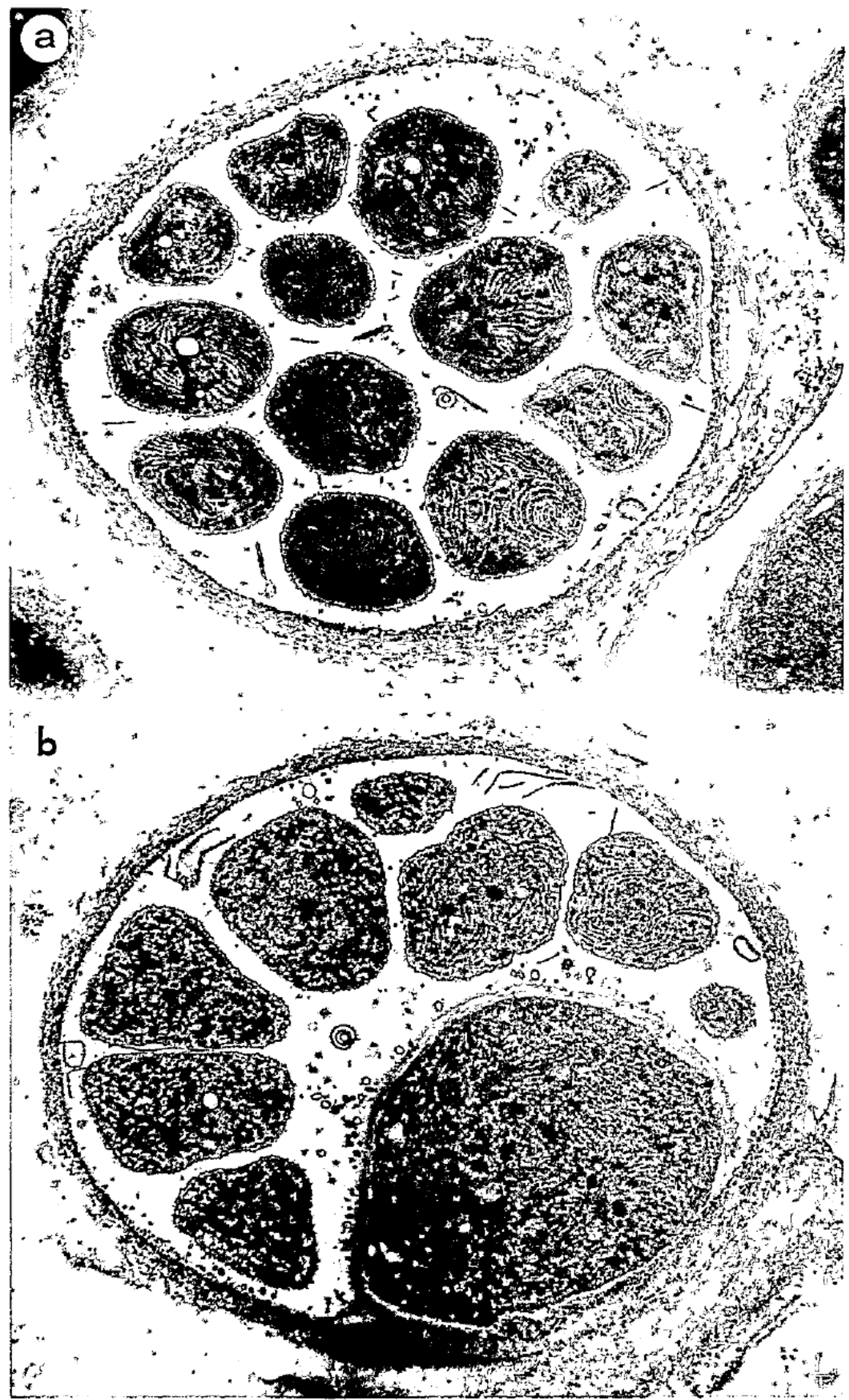


\section{Figure 9}

Electron micrograph of a thin section of Dermocarpa strain 7302 grown on an agar plate of medium MN. Note the fibrous outer cell wall (F) which is $750 \mathrm{~nm}$ thick and of variable density, the lipopolysaccharide layer of the Gram-negative cell wall (LP), the peptidoglycan layer of the Gram-negative cell wall (PG), the cytoplasmic membrane (CM), the photosynthetic thylakoids (T) composed of two closely appressed unit membranes, and glycogen granules (arrows). X 83,000. 


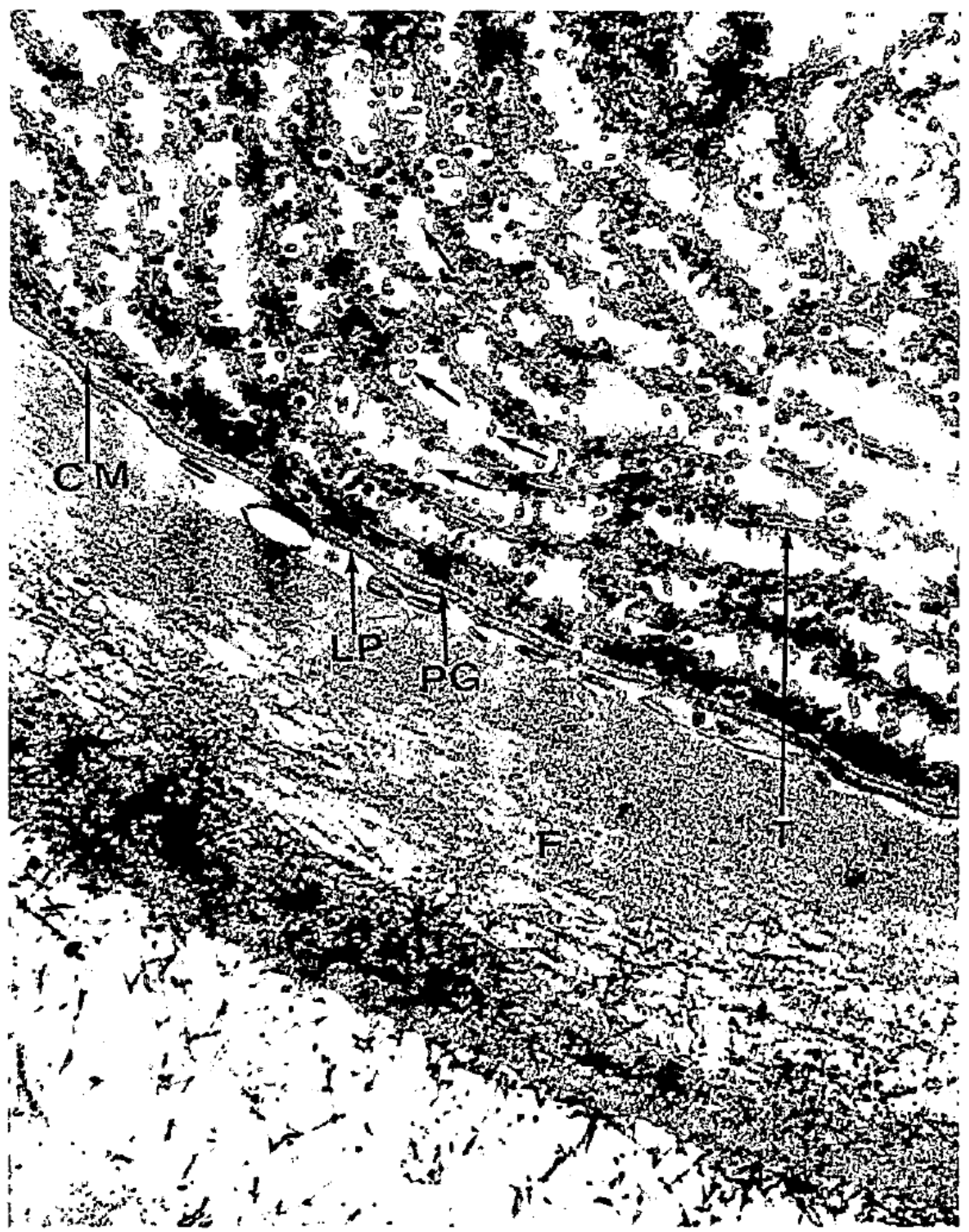


Figure 10

. The F layers of parental cells, emptied of their spore contents, in old cultures of Dermocarpa strain 7304 (Figure 10a) and strain 7437 (Figure 10b). Phase contrast, $\mathrm{x} 1000$. 


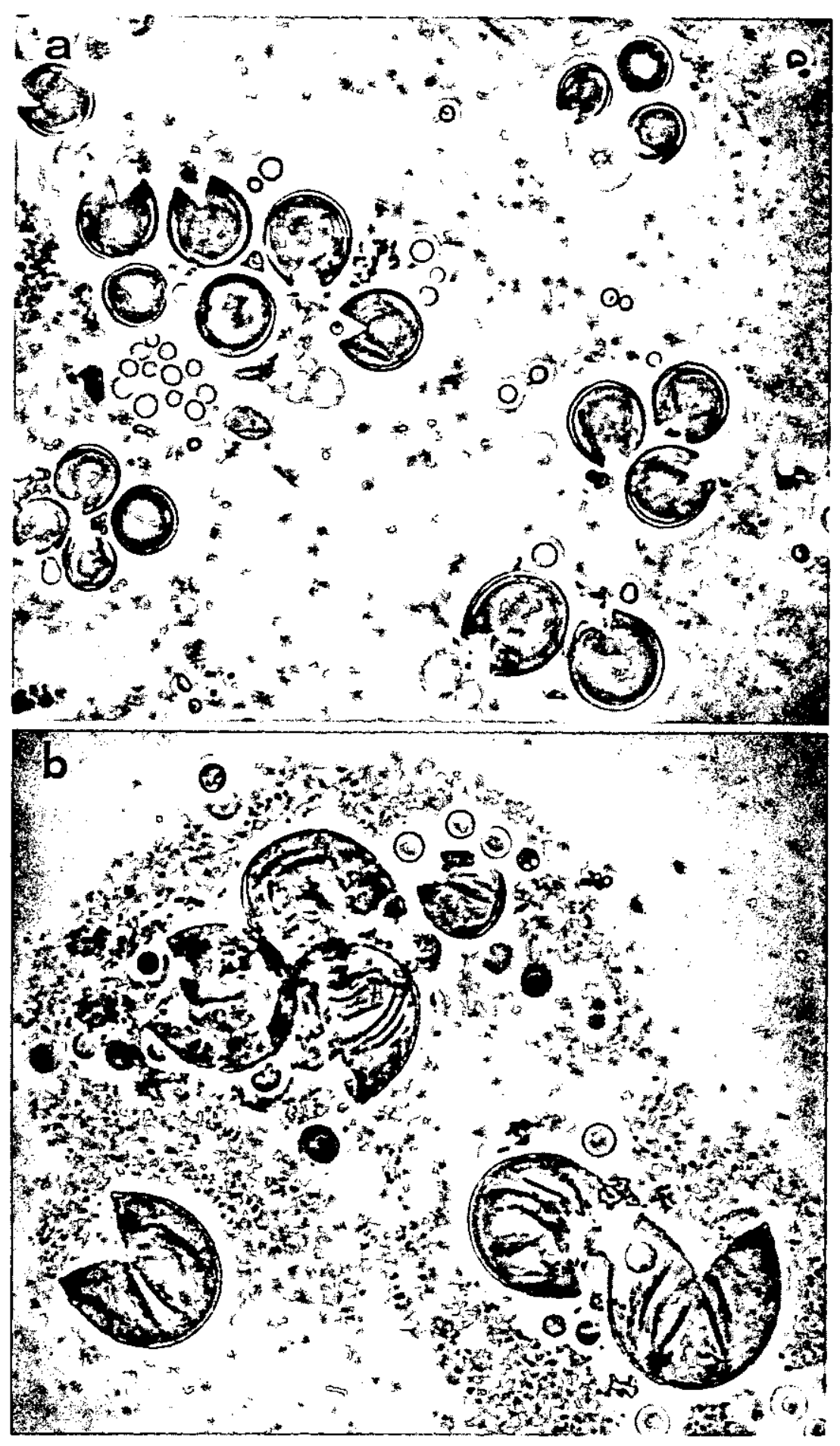


Figure 11

Schematic Developmental Cycle of Dermocarpa

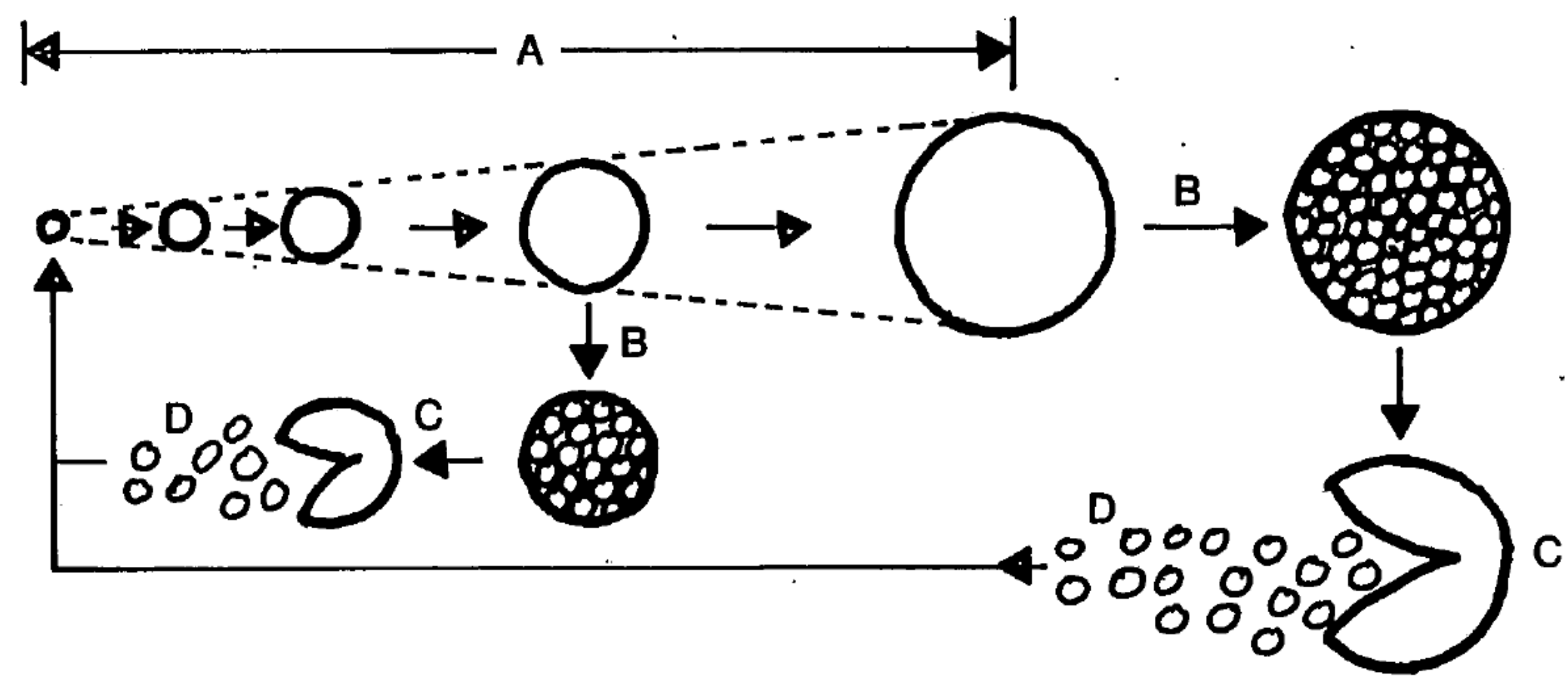

A Symmetric spore enlargement

B Multiple cleavage leading to spore formation

C Spore release

D Period of spore motility 
Figure 12

a. Photomicrograh of Dermocarpa strain 7437 grown on medium BG-11. One cell (arrow) has a well-defined equatorial band or plate, suggestive of the occurrence of binary fission. X1000. b. Electron micrograph of a thin section of Dermocarpa strain 7437 showing a localized thickening of the F layer (arrows) that appears to correspond to the equatorial band observable by light microscopy (compare with Figure 12a). X7000. 


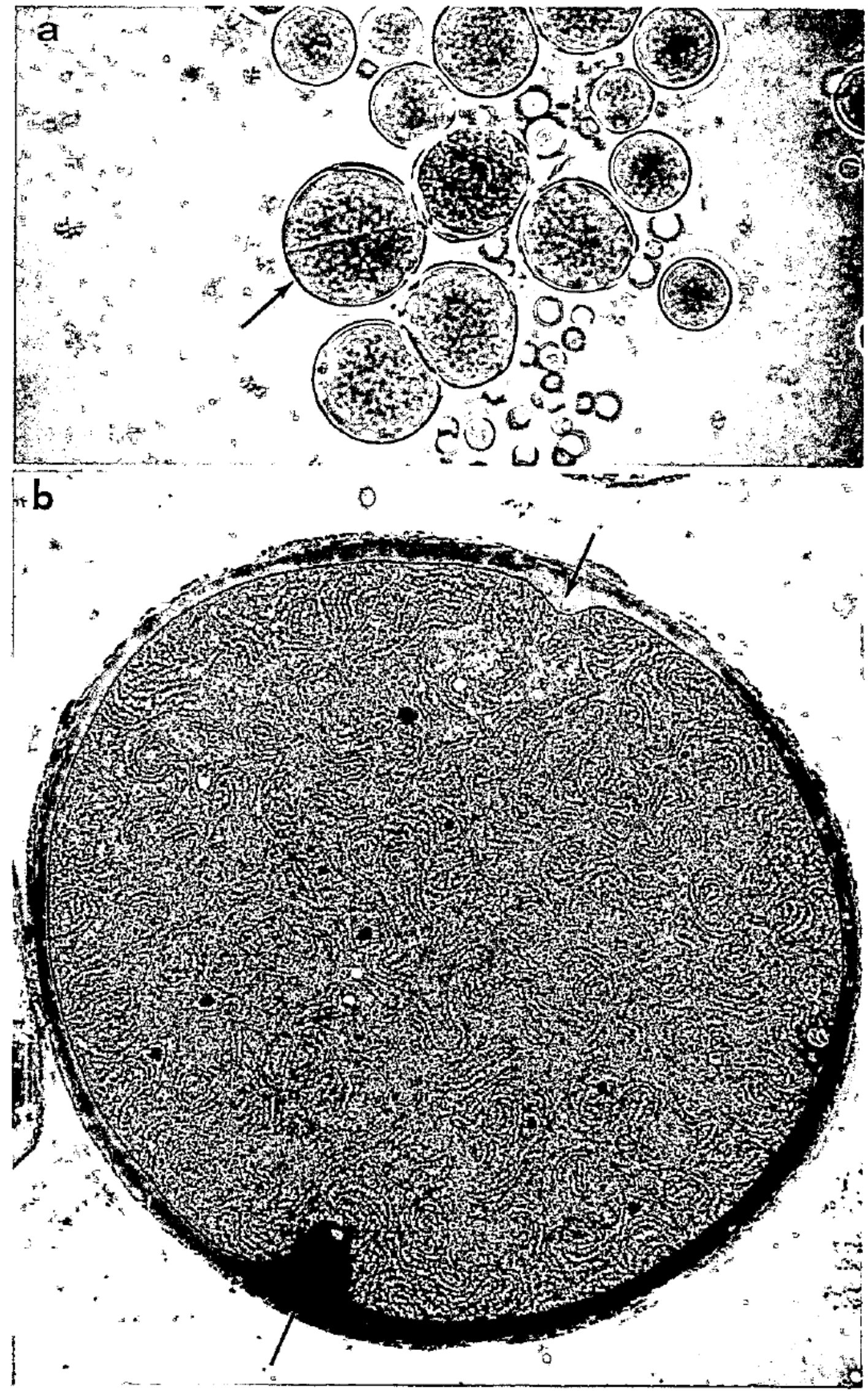




\section{Figure 13}

Photomicrographs of Dermocarpa strains 7302 (a. and b.) and 7304 (c. and d.) grown in unagitated flasks of medium MN. In such cultures many cells develop in dense masses attached to the wall of the flask. Arrows point to pyriform cells produced through mutual compression of adjacent cells which have developed under crowded conditions attached to a substrate. X 1000 . 


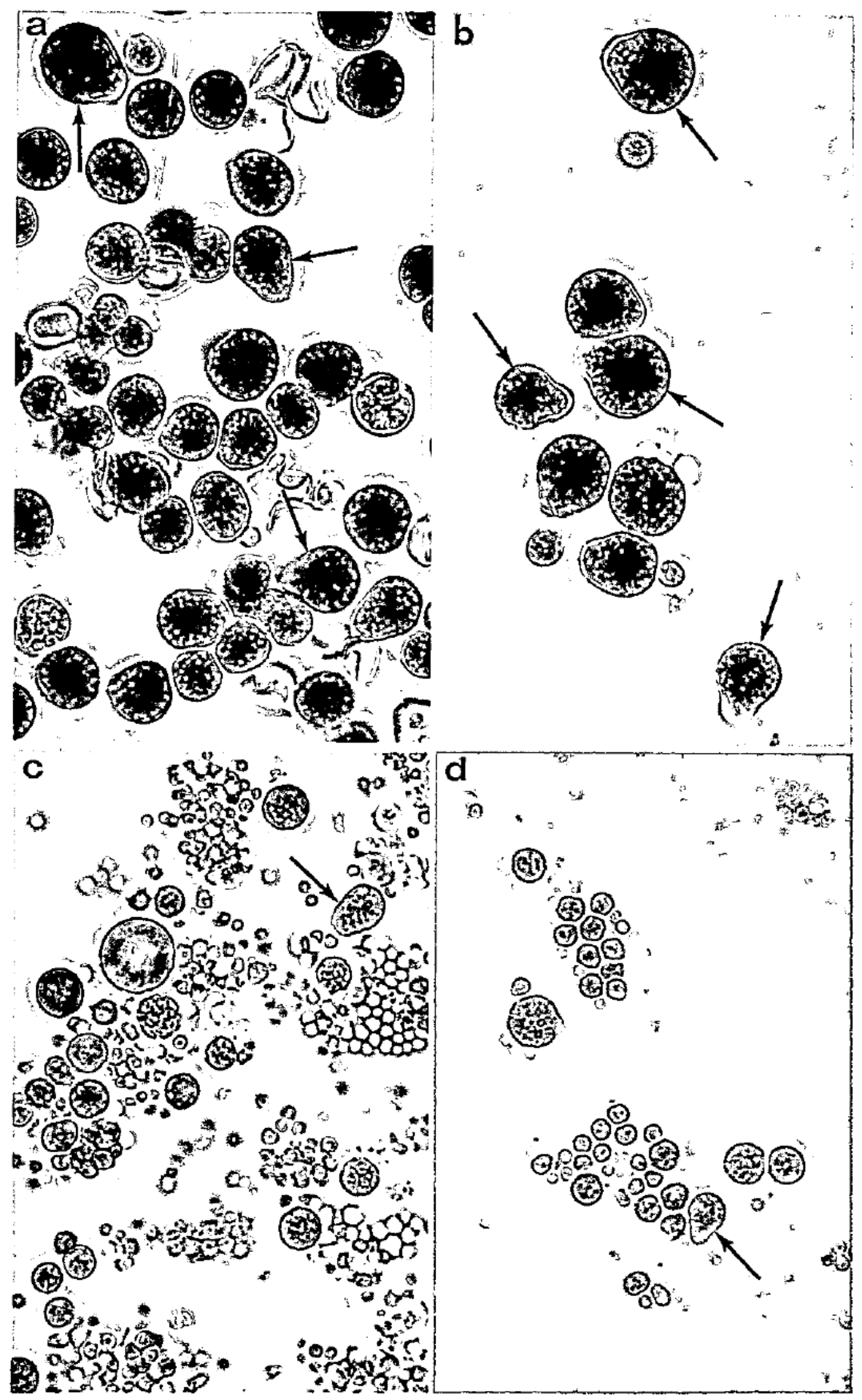




\section{b. Xenococous}

The developmental cycle of Xenococcus, represented in our collection by strains 7305, 7306 and 7307, closely parallels that of Dermocarpa; division occurs solely by multiple fission. The only difference between the two groups is that in Xerococcus synthesis of the $F$ layer accompanies multiple fission. Hence, the spores are completely enclosed by a thin $F$ layer at the time of release, and are permanently immotile.

The examination of mass cultures of Xenococcus by light microscopy (Figure 14) reveals uncleaved spherical cells of widely varying size, laxger cells that have cleaved into spores and many dividing cells which could be construed as being in the course of binary fission. This picture can be adequately interpreted only by following the development of Cooper dish cultures and by the electron microscopic examination of thin sections. The dividing cells are in fact engaged in multiple fission, the division planes being visible (unlike the corresponding stages of Dermocarpa) because the transverse walls are relatively thick and refractile as a result of the presence of the $F$ layer.

Freshly released spores are $2-3 \mu \mathrm{m}$ in diameter in all strains (Table XII). In contrast to Dermocarpa spores, they are never motile following their release and hence remain clustered around the $F$ wall layer of the parental cell, even when exposed to unidirectional illumination (Figure 15a and 15b). As in Dermocarpa, the size of the parental cell at the onset of multiple fission may vary considerably. The greatest diameters observed for parental cells were approximately $15 \mu \mathrm{m}$ in strains 7305 and 7307, and $25 \mu \mathrm{m}$ in strain 7306 (Table XII). 
T A B I E X I I

STRUCTURAI PROPERTIES OF XENOCOCCUS STRAINS

\begin{tabular}{|c|c|c|c|c|}
\hline Strain & $\begin{array}{l}1 \\
1 \\
1 \\
1 \\
1\end{array}$ & $\begin{array}{c}: \\
\text { Diameter of spore } \\
\text { in } \mathrm{\mu m}\end{array}$ & $\begin{array}{l}1 \\
1 \\
1 \\
1 \\
1\end{array}$ & $\begin{array}{c}\text { Greatest diameter } \\
\text { observed for } \\
\text { parental cell } \\
\text { in } \mu \mathrm{m}\end{array}$ \\
\hline \multirow{3}{*}{7305} & I & & 1 & \\
\hline & 1 & $2-3$ & 1 & 15 \\
\hline & 1 & & 1 & \\
\hline \multirow[t]{2}{*}{7306} & 1 & $2-3$ & 1 & 25 \\
\hline & 1 & & 1 & \\
\hline \multirow[t]{3}{*}{7307} & I & $2-3$ & 1 & 15 \\
\hline & $\mathbf{I}$ & & 1 & \\
\hline & 1 & & 1 & \\
\hline
\end{tabular}


The developmental cycles of the three strains as observed in Cooper dish cultures are shown in Figures 16-18. The resolution is not sufficient to permit detection of the successive cleavages, readily evident in light micrographs taken under more favorable optical conditions (Figure 14): hence only cell enlargement and subsequent spore release are observable in the Cooper dish cultures. The development of strains 7305 (Figure 16) and 7306 (Figure 17) is readily interpretable; both clearly reproduce by multiple fission, their growth cycles being comparable to that of Dermocarpa (Figures 5 and 6). However, the development of strain 7307 in Cooper dish cultures (Figure 18) is somewhat more difficult to interpret. At the time of spore release, some larger cells also emerge from the $F$ layer of the parental wall. The most probable explanation for this fact, supported by electron microscopic observations to be described below, is that spores are not released immedlately following their formation, but proceed to develop within the F layer of the parental cell wall, and eventually again undergo multiple fission. Spore release then occurs; but since maturation of the enclosed cells is not synchronous, some have not yet formed spores at the time of release. These constitute" the larger cells, indicated by arrows in the later photomicrographs of Figure 18.

Electron micrographs of thin sections of cells of strain 7307 at various stages of division are shown in Figures 19-21. Figure 19a shows a cell just prior to the onset of multiple fission. It is enclosed by a wall of which the three layers are closely appressed, the $F$ layer being approximately $500 \mathrm{~nm}$ thick. Several widely separated areas containing DNA fibrils are present, although the segregation of nucleoids is not as evident as in the comparable stage of Dermocarpa (see Figure 7a). Figures 
$19 b, 20 a$, and $20 b$ show successive cleavage stages. At the two-celled - stage (Figure 19b), the retraction of the PG and LP layers from the surrounding parental F layer, characteristic of multiple fission as already described for Dermocaxpa, has occurred. 'At the two- and fourcelled stages (Figures $19 \mathrm{~b}$ and $20 \mathrm{a}$ ), the cleavage products are surrounded by a loose network of Eibers, which probably represent newly synthesized $\mathrm{F}$ layer material. At later stages of multiple fisston (exemplifled by Figure 20b), each cleavage product is surrounded by a well-defined $F$ layer of uniform thickness, that is much thinner than the parental F layer. These figures can, accordingly, be interpreted without ambiguity as stages of a primary multiple fission; except for the process of a newly formed F layer enclosing the cleavage products, they correspond very closely to comparable stages in Dermocarpa (Figures $7 a, 7 b$, and $8 a)$. Figure 21 shows a section of a group of cells, all enclosed by a common F layer; several of the enclosed cells have started to undergo cleavage. This probably represents an aggregate in which spores that were not released following their formation have undergone growth and subsequent multiple fission within the $F$ layer of the origina1 parental cell.

During multiple fission, in strains 7305 and 7307 , the successive cleavages occur in alternating planes, although not necessarily in three regular planes at right angles to one another. However, during the early stages of multiple fission in strain 7306 some cells undergo two or even three successive divisions in the same plane (Figure 22).

Multiple fission and spore release can be induced in Xenococcus, as in Dermocarpa, by the transfer of cultures to fresh media. Under these conditions, the number of spores released depends on the size of the 
cells at the time of transfer, and can vary from as few as four spores (Figure 14c) to 100 or more.

A diagramitic representation of the developmental cycle of Xenococcus is shown in Figure 24. 
Figure 14

Photomlcrographs of mass cultures of Xenococcus grown on. agar plates of medium MN. a., b. and c. Strain 7305, : X 1000; d. and e. Strain 7306, X 1000; f. and g. Strain 7307, X 1000. Arrows point to dividing cells. 
a

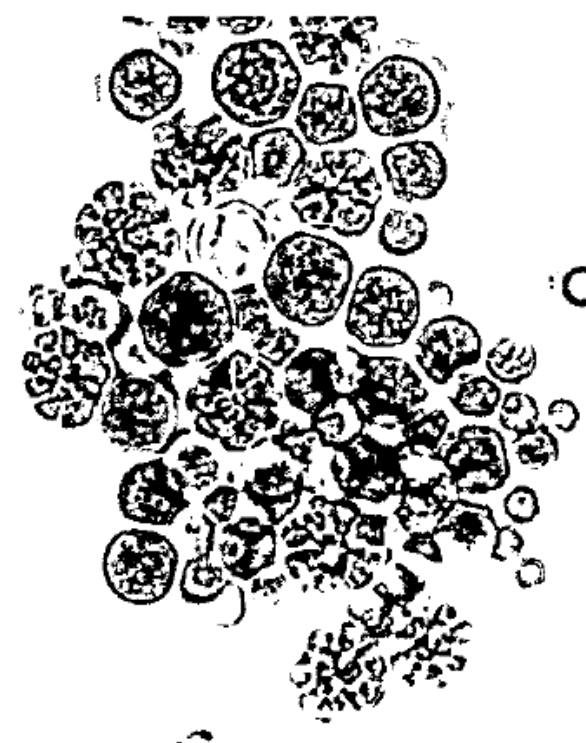

2

d

2

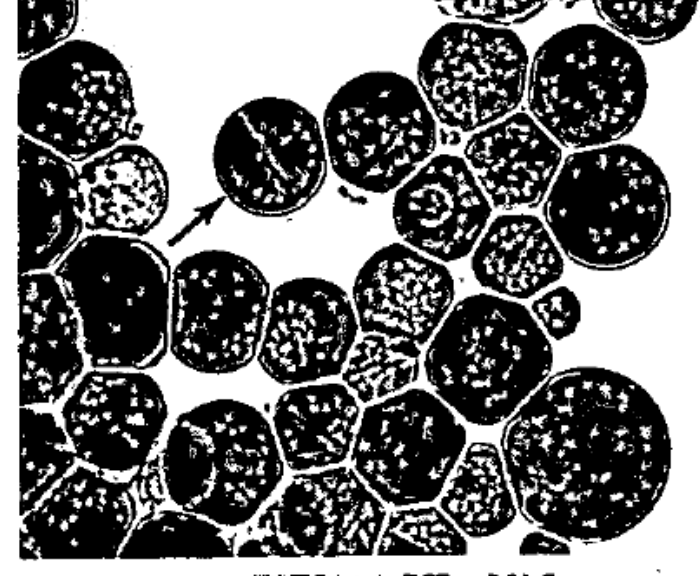

$\mathrm{f}$ b

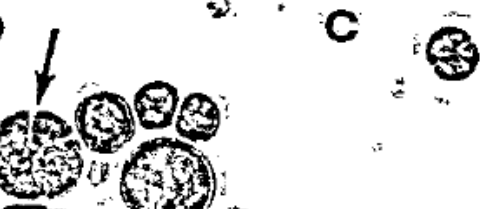

0.

i 6rian

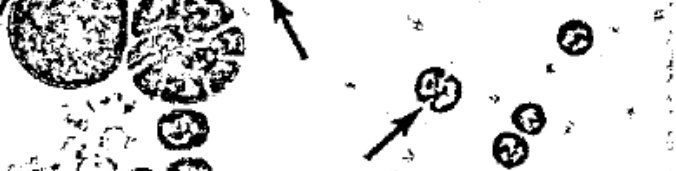

100

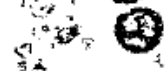

(2)

e

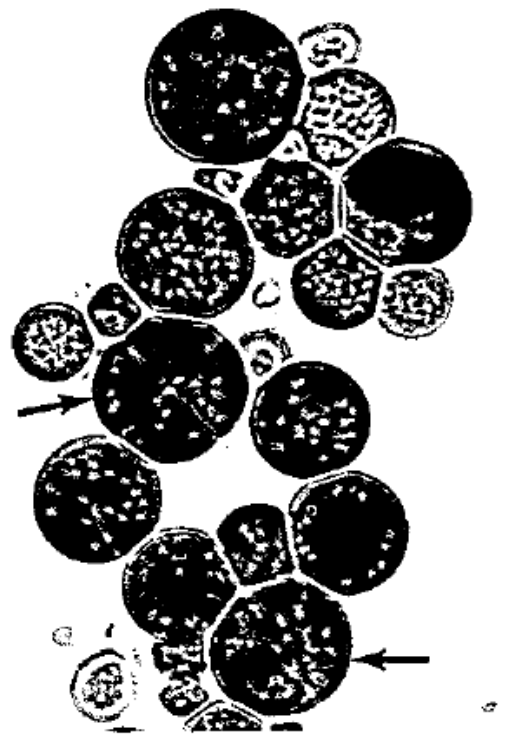

Ig

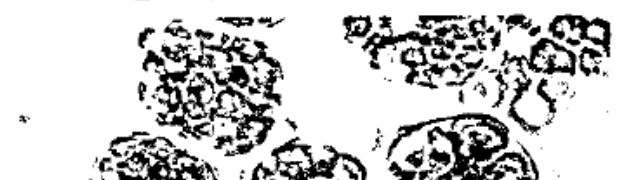

4

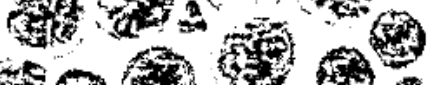

601 0

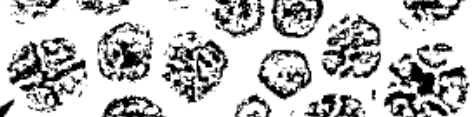

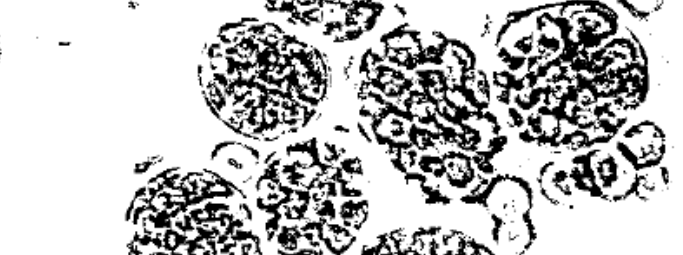

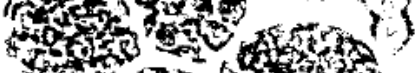

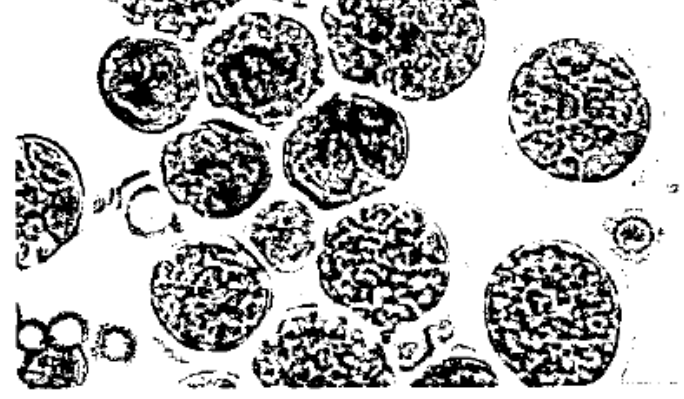




\section{Figure 15}

An illustration of the absence of a phototactic response by spores of Xenococcus strain 7305 (Figure 15a and 15b) and Chroococcidiopsis strain 6712 (Figure 15c). Each photomicrograph shows a group of freshly released spores in Cooper dish cultures subjected to unidirectional illumination. The spores remain closely and evenly clustered around the remains of the parental cells. a. and b., X 500; c. X300. Compare with the behavior of the motile spores of Dermocarpa (Figure 4). 


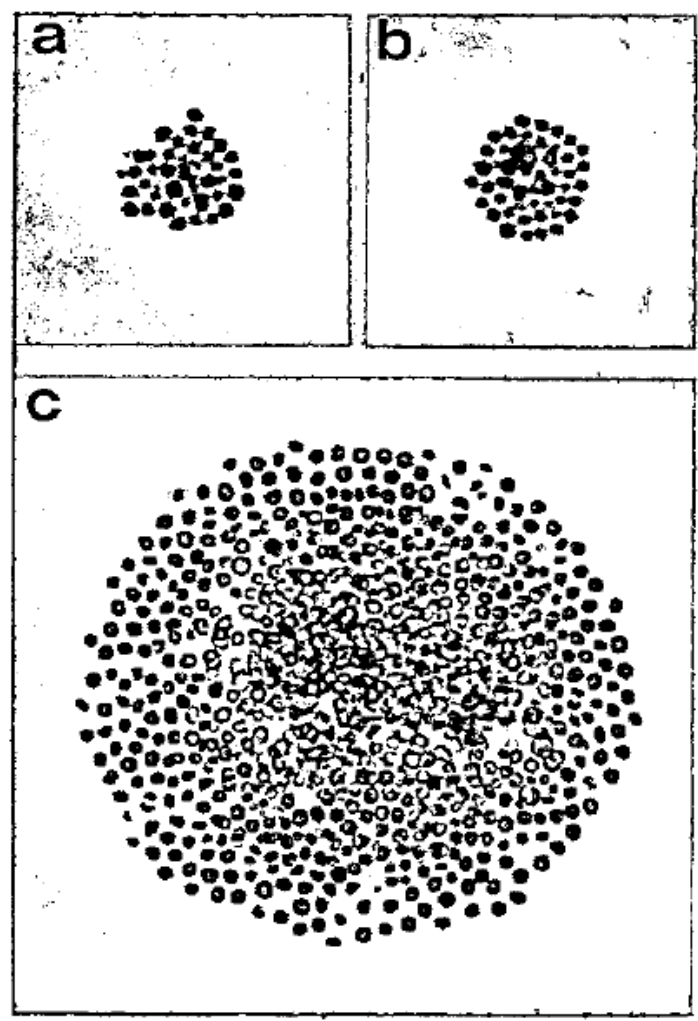


Figure 16

The development of Xenococcus strain 7305 on medium MN in a Cooper dish culture over a total period of 347 hours. The cell had completed spore release after 131 hours. After 347 hours, spore release from cells of the second generation had begun. The successive divisions which lead to spore formation (see Figure 14) are not visible, as a result of the relatively poor resolution under these conditions of examination. X 500 . 


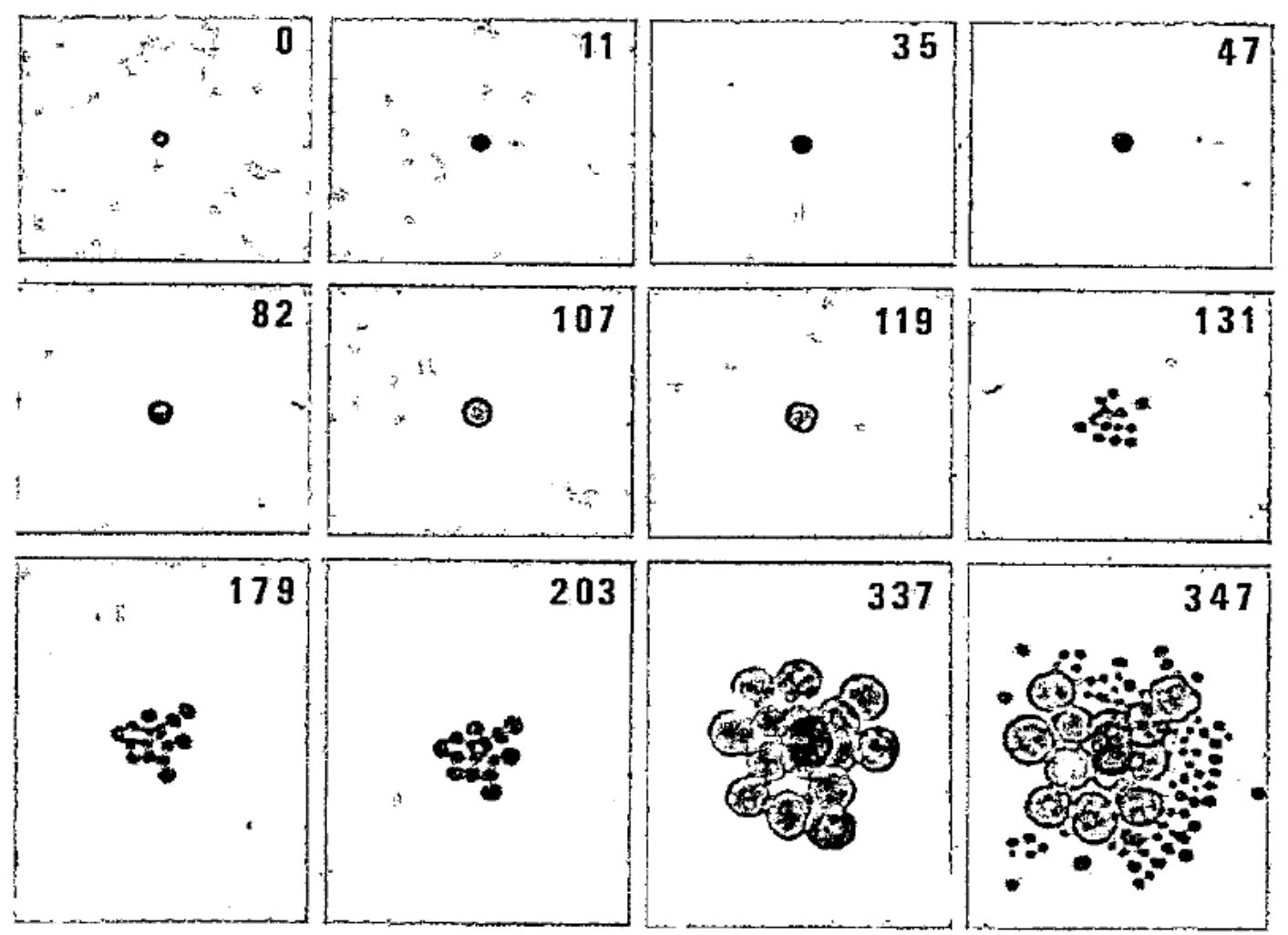


Figure 17

The development of one spore of Xenococcus strain 7306 on medium MN in a Cooper dish culture over a total period of 123 hours. X 500. The developmental pattern is very similar to that of strain 7305 (see Figure 16). 


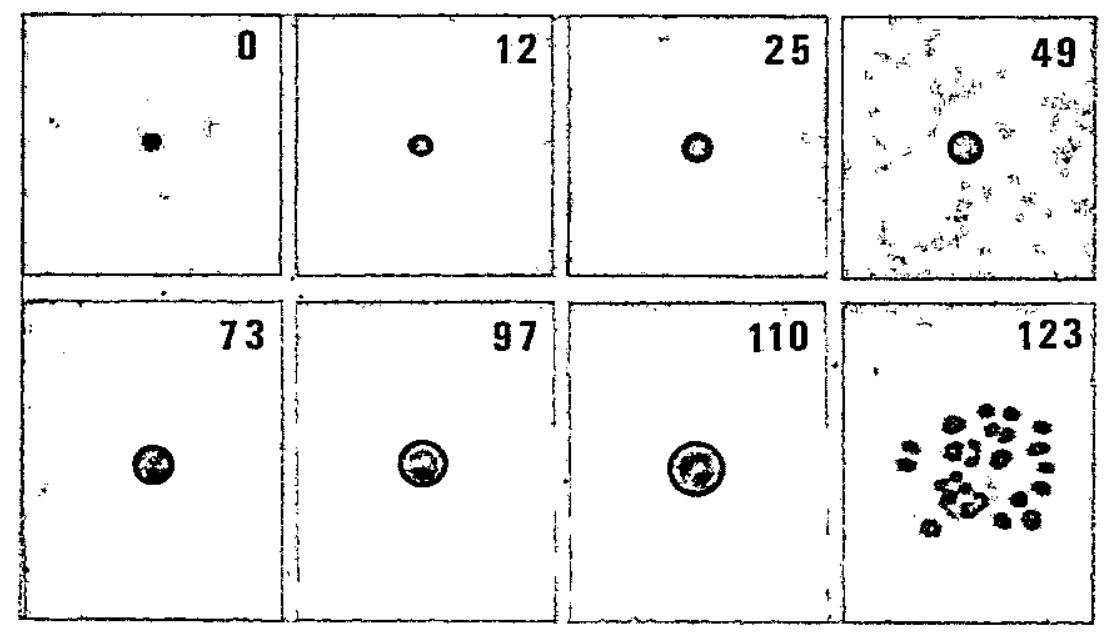




\section{Figure 18}

The development of two spores of Xenococcus strain 7307 on medium $M N$ in a Cooper dish culture over a total period of 334 hours. In this strain, multiple fission is often followed by either delayed or incomplete spore release. Spore enlargement may therefore occur within the F layer of the parental cell. The arrows in the photographs taken at 264 and 286 hours point to large cells which have developed in this manner. X 500 . 


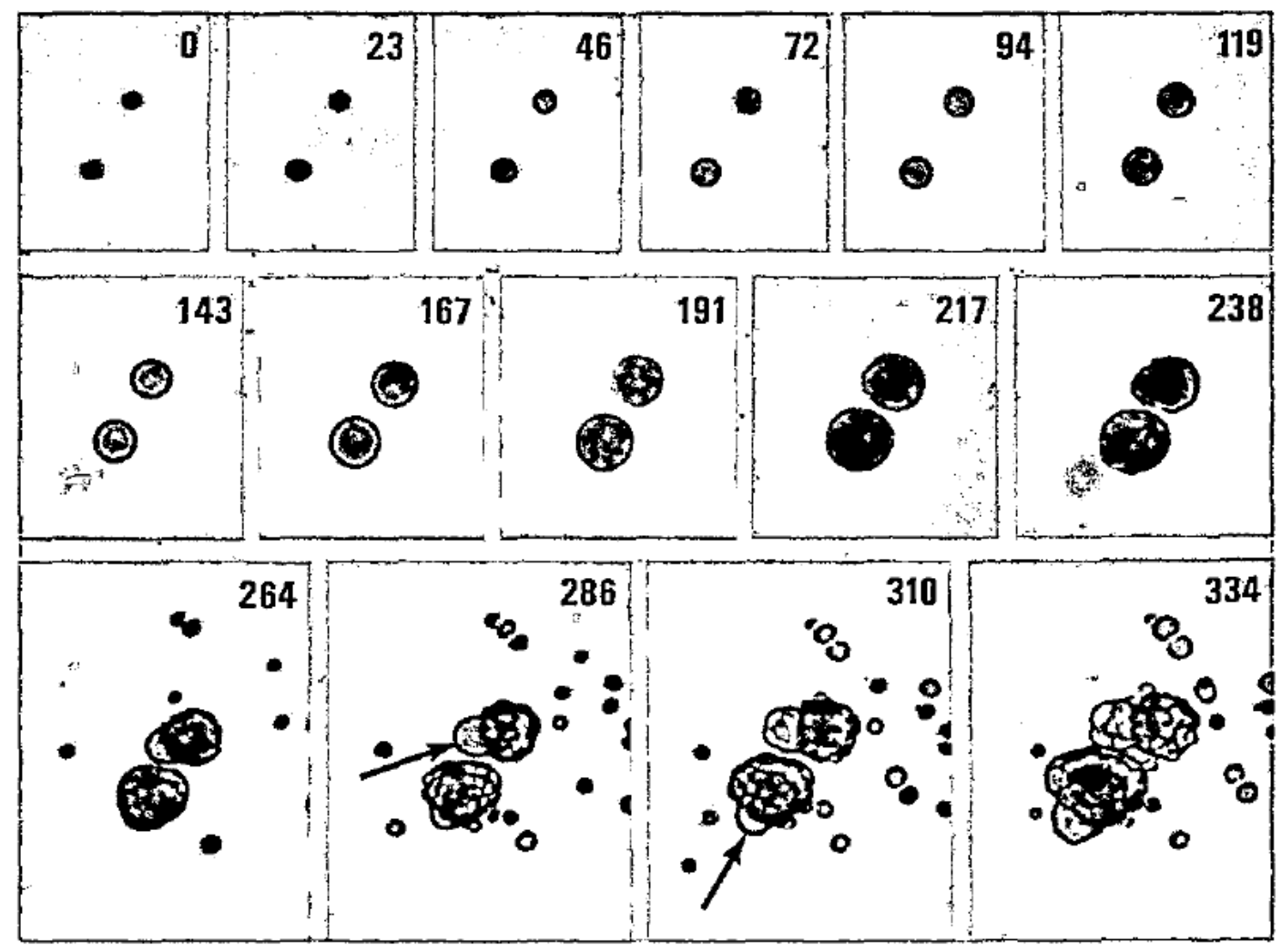


Figure 19

Electron micrographs of thin sections of Xenococcus strain 7307 grown in an agar overlay on medium MN. a. A cell prior to the onset of multiple fission. The PG, LP and F wall layers are closely appressed to one another. The cell contains two internal membrane configurations: the photosynthetic thylakoids and a stack of closely appressed unit membranes (arrow). X 12,000. b. The two cell stage of multiple fission. Note that the daughter cells have retracted from the F layer. of the parental cell wall. X 15,000. 


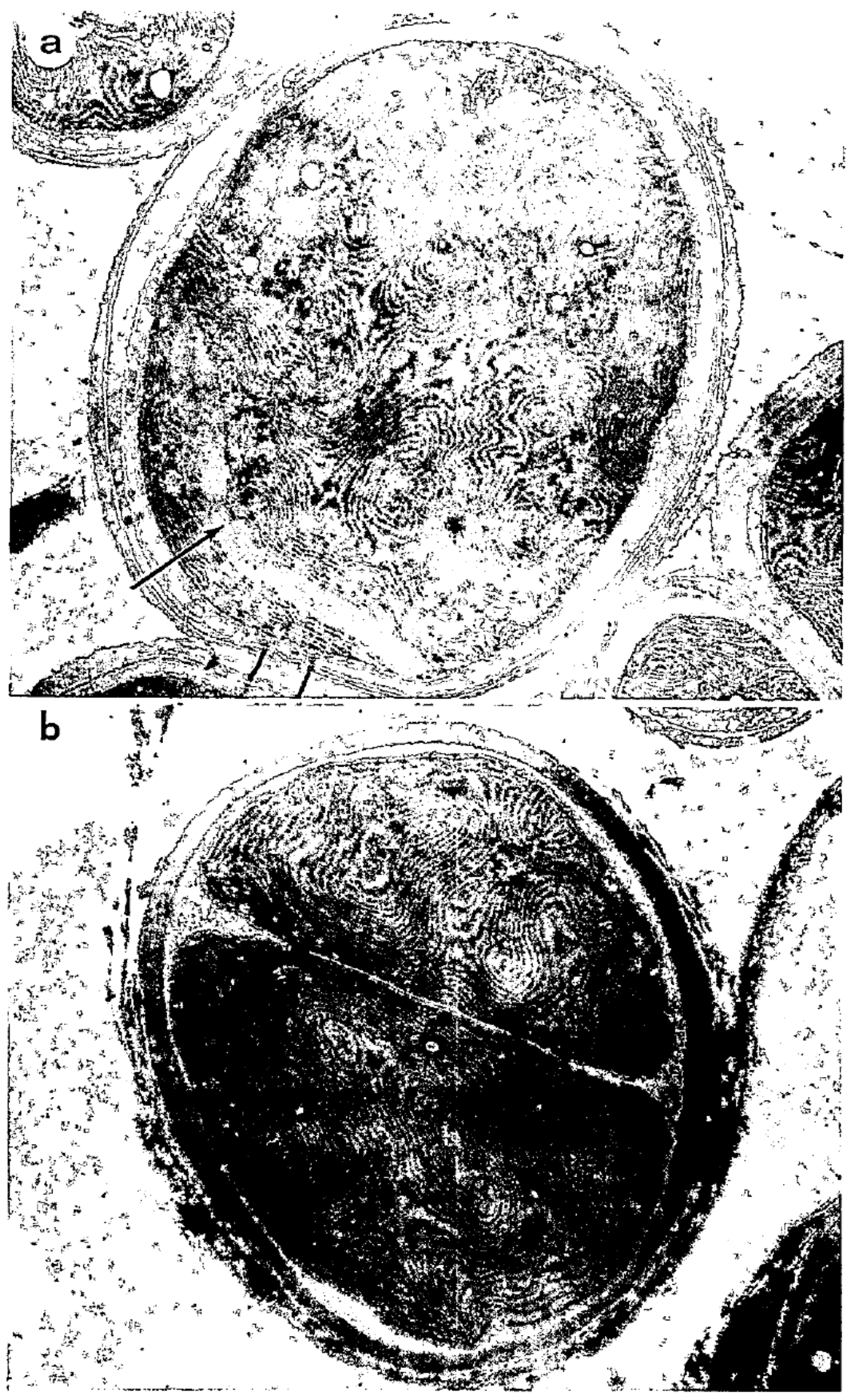




\section{Figure 20}

Electron micrographs of thin sections of Xenococcus strain 7307 from the same preparation as the cells illustrated in Figure 19. a. The four cell stage of multiple fission. X14,500. b. A cell which has cleaved into numerous spores, each surrounded by a distinct $F$ layer. X 11,250. 


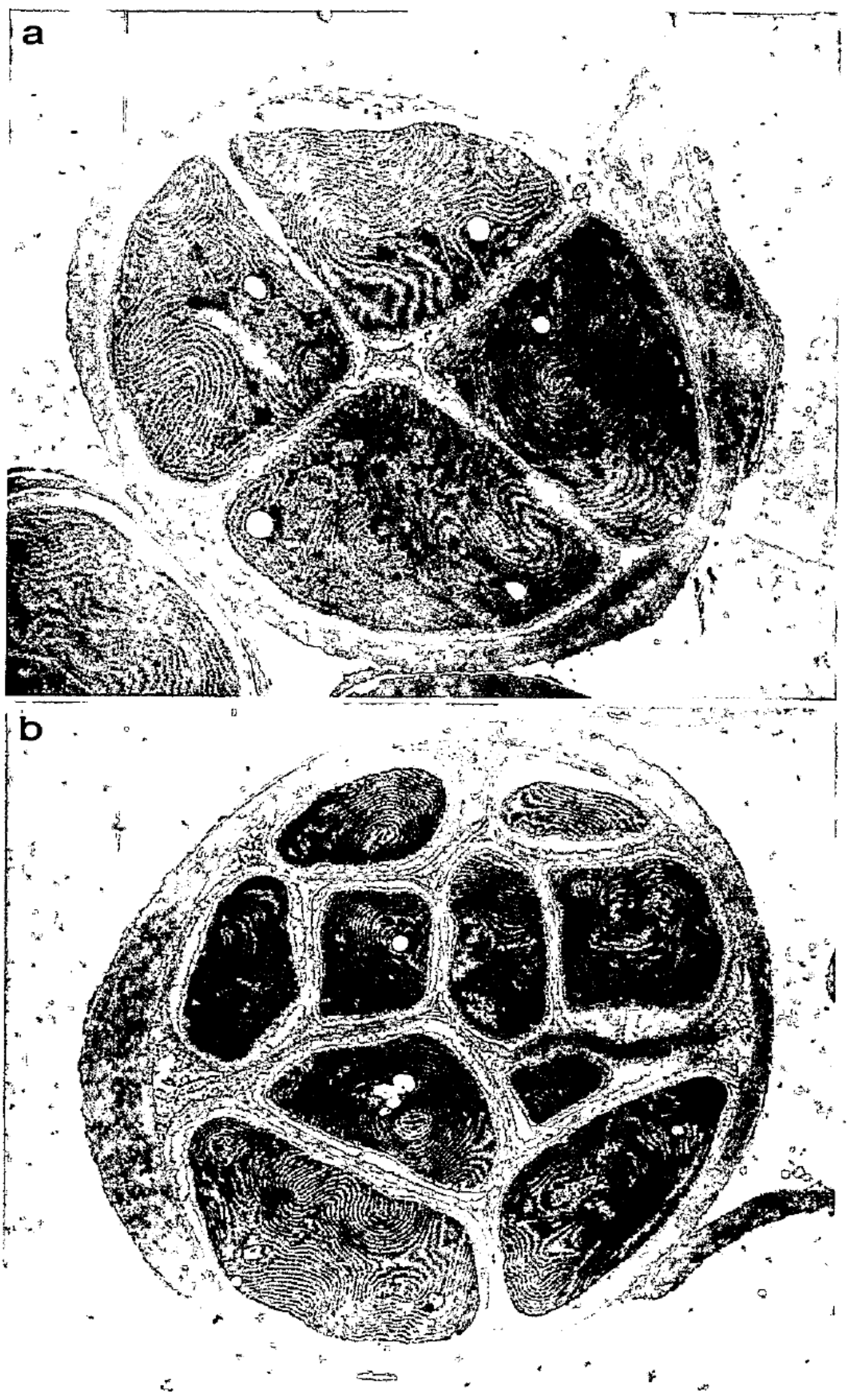


Figure 21

An electron micrograph of a thin section of Xenococcus strain 7307 grown on a plate of medium MN. The cells in the aggregate have begun to develop while remaining enclosed in the F layer of the previous generation. X 13,000. 


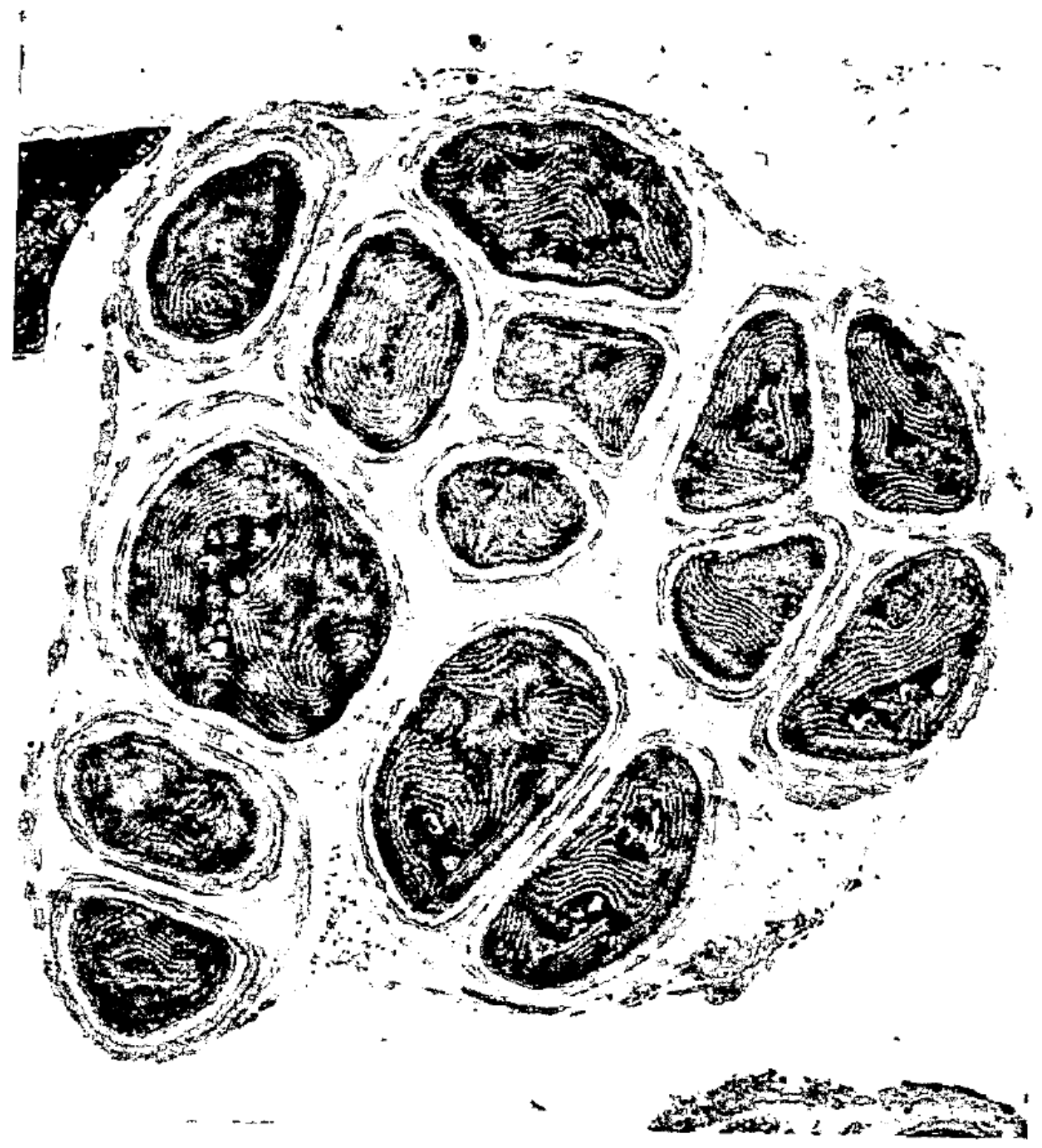


94

\section{Figure 22}

a. and b. Photomicrographs of Xenococcus strain 7306, grown on a plate of medium $M \mathbb{N}$, showing cells that have cleaved repeatedly in one plane (arrows). X1000, c. An electron micrograph of a thin section of a "cell of strain 7306, which has cleaved several times in one plane during the early stages of multiple fission. $\times 8000$. 


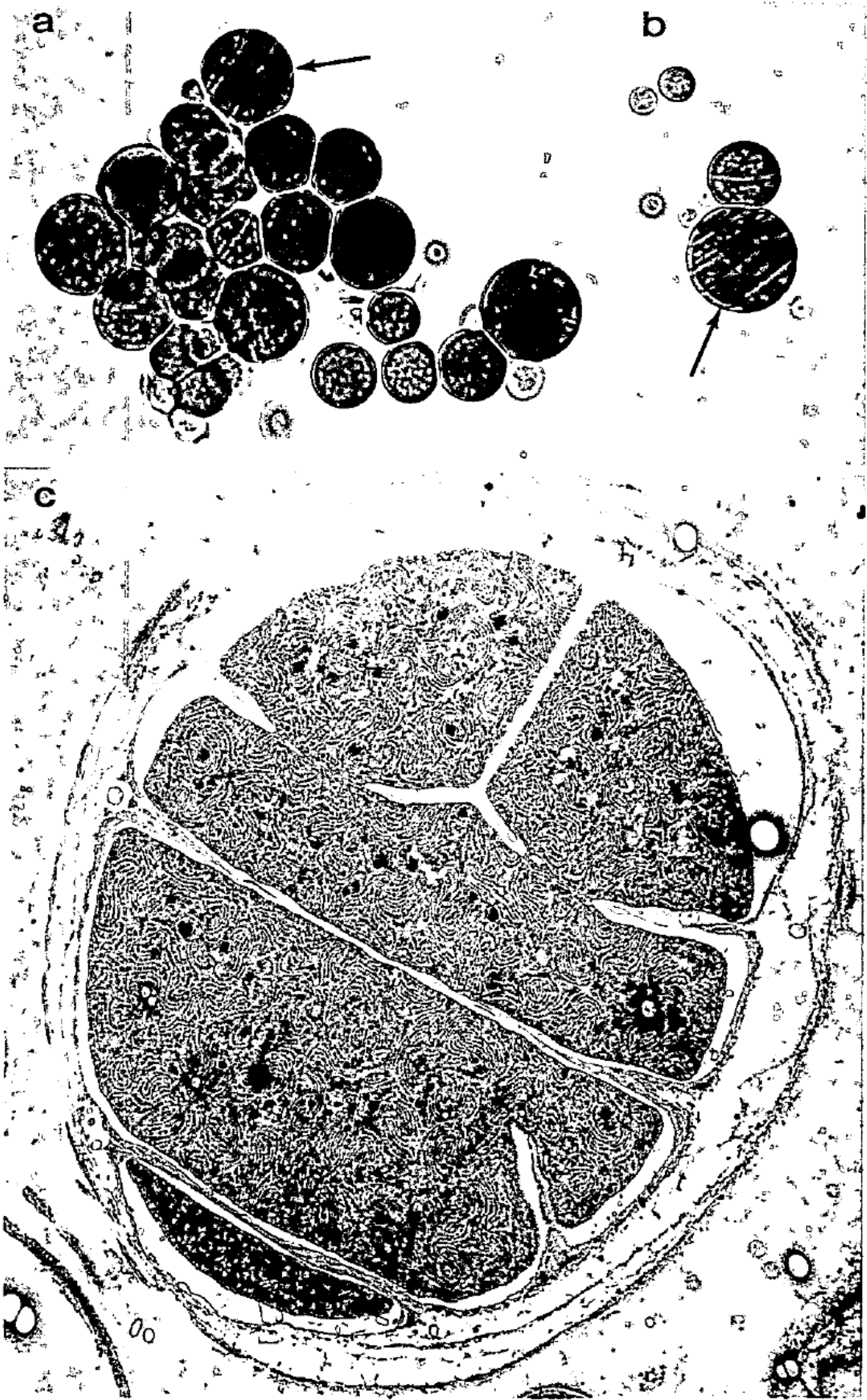




\section{Figure 23}

a. An electron micrograph of a thin section of strain 7305 grown in Iiquid medium ASN-III. It shows an unreleased spore surrounded by a thin F layer. Note the phycobilisomes (arrows) which are evenly spaced on the thylakoids, the burnt-out. polyphosphate inclusions (P) and the very electron-dense cylindrical bodies. X 34,000. b. and c. Electron micrographs of negatively stained preparations of the culture medium from very old (two months) flask cultures of strain 7305 . These micrographs revea1 the presence of a cyanophage which probably corresponds to the electron-dense cylindrical bodies seen in thin sections. This preparation was stained with $0.5 \%$ sodium molybdate. $\times 215,500$. 


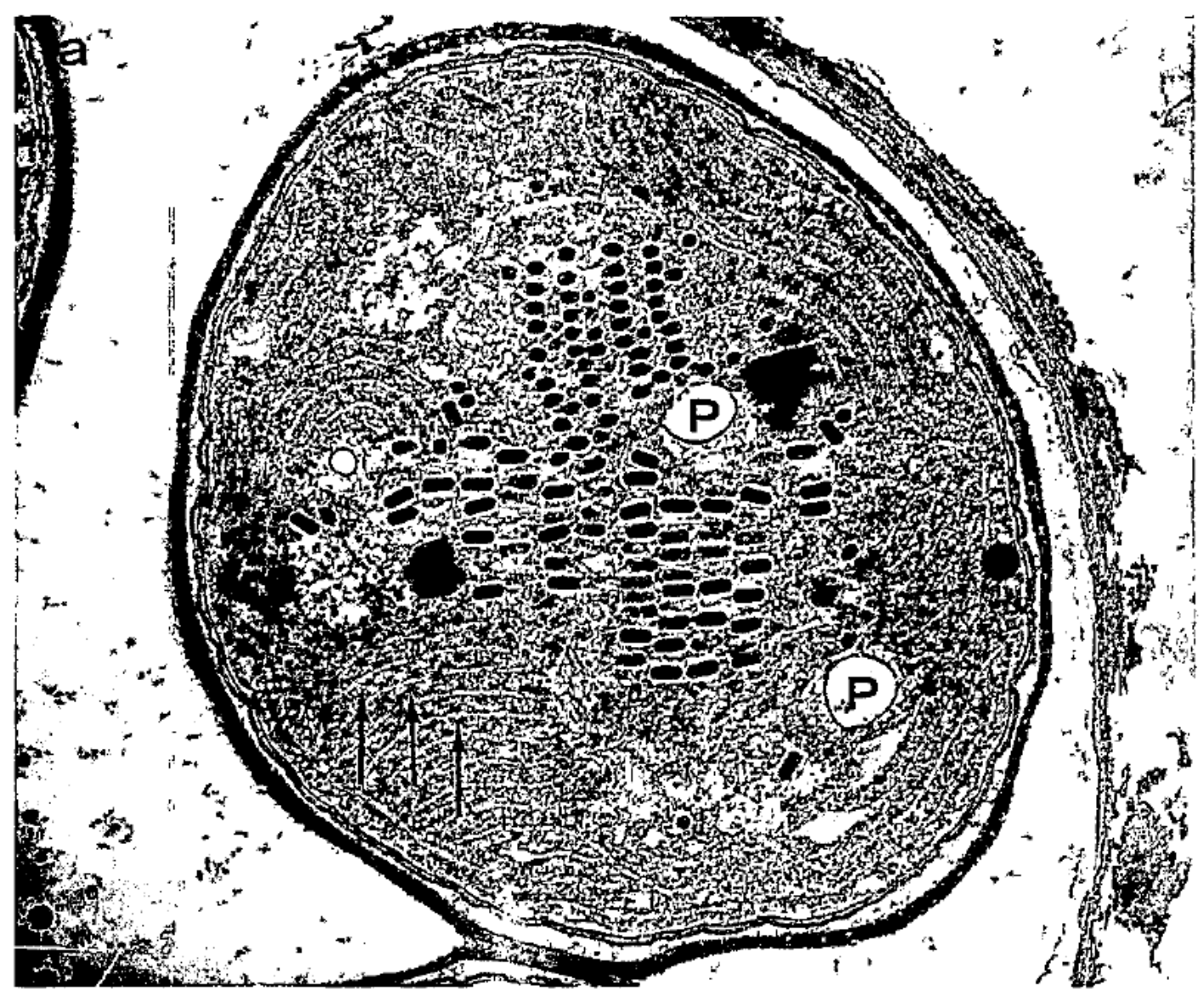

(b)


Figure 24

Schematic Develcjumental Cycle of Xenococcus
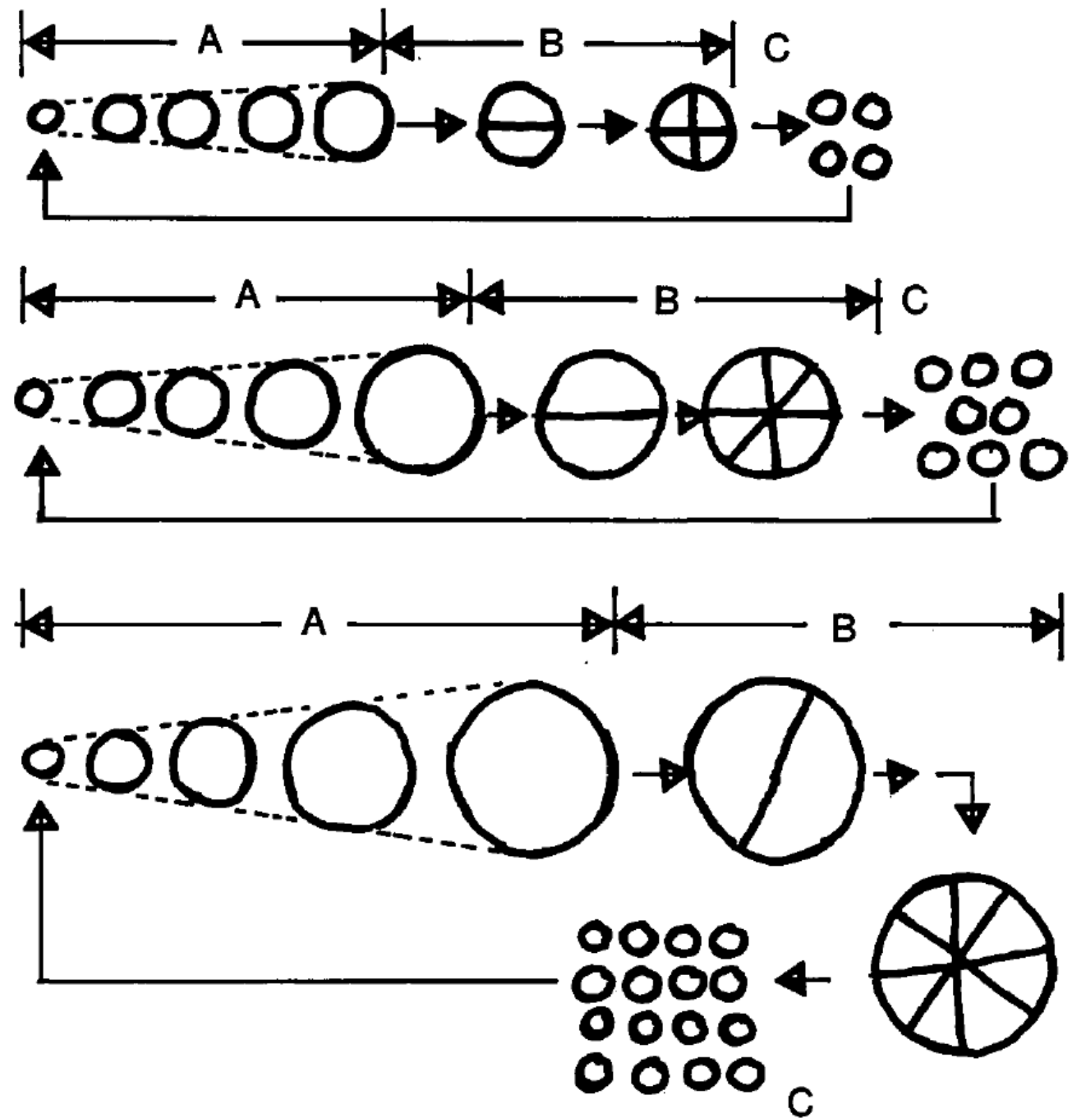
A Symmetric spore enlargement
B Multiple cleavage leading to spore formation
C Release of immotile spores 


\section{c. Dermocarpelza}

The developmental cycle of Dermocarpelza, represented by only one strain (7326), Is similar to that of Dermocarpa except that multiple fission is always preceded by at least one binary fission, and occurs In only one of the daughter cells produced through binary.fission. In fact, the special mode of development which is characteristic of Dermocarpelza reveals with particular clarity the distinctions between binary and multiple fission as these processes occur in the Pleurocapsales.

In Cooper dish cultures (Figure 25) the freshly released spores, each approximately $2 \ddot{\mu m}$ in diameter, undergo a brief period of motility (not illustrated). They then begin to enlarge asymmetrically to produce an ovoid cell which measures approximately $1.0 \times 1.3 \mu \mathrm{m}$ at the time of division. A transverse binary fission yields a small cell (the basal cel1) and a large cell (the apical cel1). The basal cell may undergo one further division in a plane at right angles to the first, to produce a pair of basal cells of equal size. The apical cell, on the other hand, invariably undergoes multiple fission, followed by spore release (photomicrograph taken at 193 hours in Figure 25). The detalls of cell division cannot be resolved in Cooper dish cultures; but the various division stages which precede spore release are clearly distinguishable in mass cultures examined under more favorable optical conditions (Figures 26a and 26b).

Electron micrographs of thin sections of dividing cells (Figures $27 \mathrm{a}, 27 \mathrm{~b}, 28 \mathrm{a}$ and $28 \mathrm{~b})$ reveal further details of the division process. The cell in Figure 27a has just completed the first binary fission which separates the large apical cell from the small basal cell. The three 
wall layers of the basal cell remain closely appressed, whereas the PG and IP wall layers of the apical cell have begun to retract from the F layer. Figure 27b shows an individual in which multiple fisston of the apical cell has begun, while the basal cell has undergone a second binary fission. The two basal cells have already started to synthesize a new $F$ layer, and remain closely appressed to the $F$ wall layer of the parental cell. Figure 28a shows a later stage of multiple cleavage, and Figure $28 \mathrm{~b}$ an individual in which multiple cleavage is complete. The F layer enclosing the basal cells has now become relatively thick; no synthesis of a new $F$ layer has occurred around the spores delimited in the apical cell.

After spore release has taken place through rupture of the $F$ wall layer of the apical cell, the basal cell (or cells) can undergo enlargement and repeat the division cycle. Each such repetition causes a thickening of the $\mathrm{F}$ layer which underlies the basal cells, and which consists of an F layer that has just been synthesized, together with one or more $\mathrm{F}$ layers synthesized during earlier generations. However, the $\mathrm{F}$ layer which surrounds the newly developing apical cell consists largely of newly synthesized material, together with adherent remnants of the F layer from the immediately previous generation. The F layer in the region of the apical cell is therefore frequently thinner and more irregular than that underlying the basal cell. This feature of wall structure, distinctive of Dermocarpelza, is particularly evident in Figures $27 \mathrm{a}$ and $28 \mathrm{a}$.

As in all members of the Pleurocapsales, the freshly released spores of Dermocarpella can attach to solid substrates. The possible influence of attachnent on the polarity of ensuing development was studied by 
preparing thin sections of individuals which had been grown on the surface of pieces of dialysis membrane. As shown in Figures 29a and $29 \mathrm{~b}$, the polarity of asymetric spore growth and subsequent division are completely unrelated to the site of attachment. The enlarging ovoid cell shown in Figure 29a (compare with Figure 27a) is attached to the substrate laterally, by a reglon which will subsequently become part of the apical cell. The mature individual in Figure $29 \mathrm{~b}$ is attached to the substrate by the pole of the apical cell. Hence, it is evident that the polarity of the growing spore is intrinsic, and is not determined by the point at which It happens to adhere to a substrate:

The number of spores released by single individuals of Dermocarpezla (Table XIII) is much less variable than in Dermocarpa and Xenococcus. This is probably attributable to the fact that the onset of binary fission occurs after the cell has attained a'fixed size, so that the volume of the apical cell (and hence the number of spores that it produces) is relatively constant.

The developmental cycle of Dermocarpelza is shown schematically in Figure 30. 
TABLE XIII

The Number of Spores Released by Single Parental

Cells of Dermocarpella Strain 7326

Strain

Total Number of

Determinations
Numbers of Spores Released

Range Individual values

7326

7

$60-120$

$60,76,80,94,101,107,120$ 
Figure 25

Successive photomicrographs of the development of a single spore of Dexmocarpella strain 7326 on medium MN in a Cooper dish culture over a period of 216 hours. Asymetric enlargement of the initially spherical spore leads, after 169 hours, to the formation of a large ovoid cell, which has probably already undergone binary fission, although the transverse wall is not resolved in this figure. After 193 hours spore release from the apical cell has occurred. The remaining basal cell is visible in the photograph at hour 216. X 500 . 


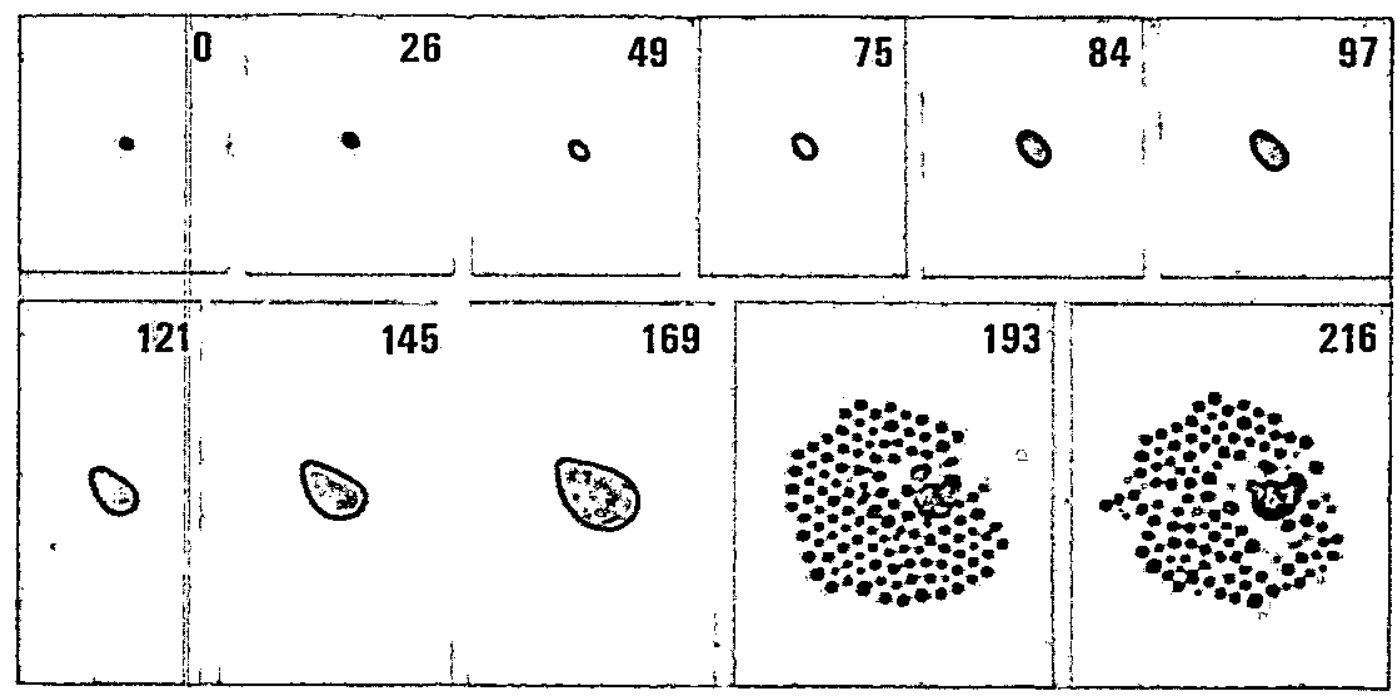




\section{Figure 26}

a. and b. Photomicrographs of a Ilquid culture in medium MN of Dermocarpelza strain 7326. These figures show division stages which cannot be resolved in Cooper dish cultures. They include: 1, an individual which has just undergone the first division, a binary transverse fission yielding a smal1 basal and a large apical cell; 2, an individual containing a single basal cell, and an apical cell.which has completed multiple fission; 3, individuals containing a pair of basal cells, and an apical cell which has completed multiple fission; 4, individuals in which spore release from the apical cell has occurred, revealing the outline of the parental $F$ wall layer, which also encloses the basal cell or cells. $X 1000$. c. An electron micrograph of a thin section of a Dermocarpe Zla cell, at an early stage of growth, on a piece of dialysis membrane placed on the surface of a plate of medium MN. Arrows indicate the surface of the dialysis membrane. The F layer of the cell wall flares out to produce a broad basal attachment of the cell to the membrane. $\mathrm{x} 57,000$. 


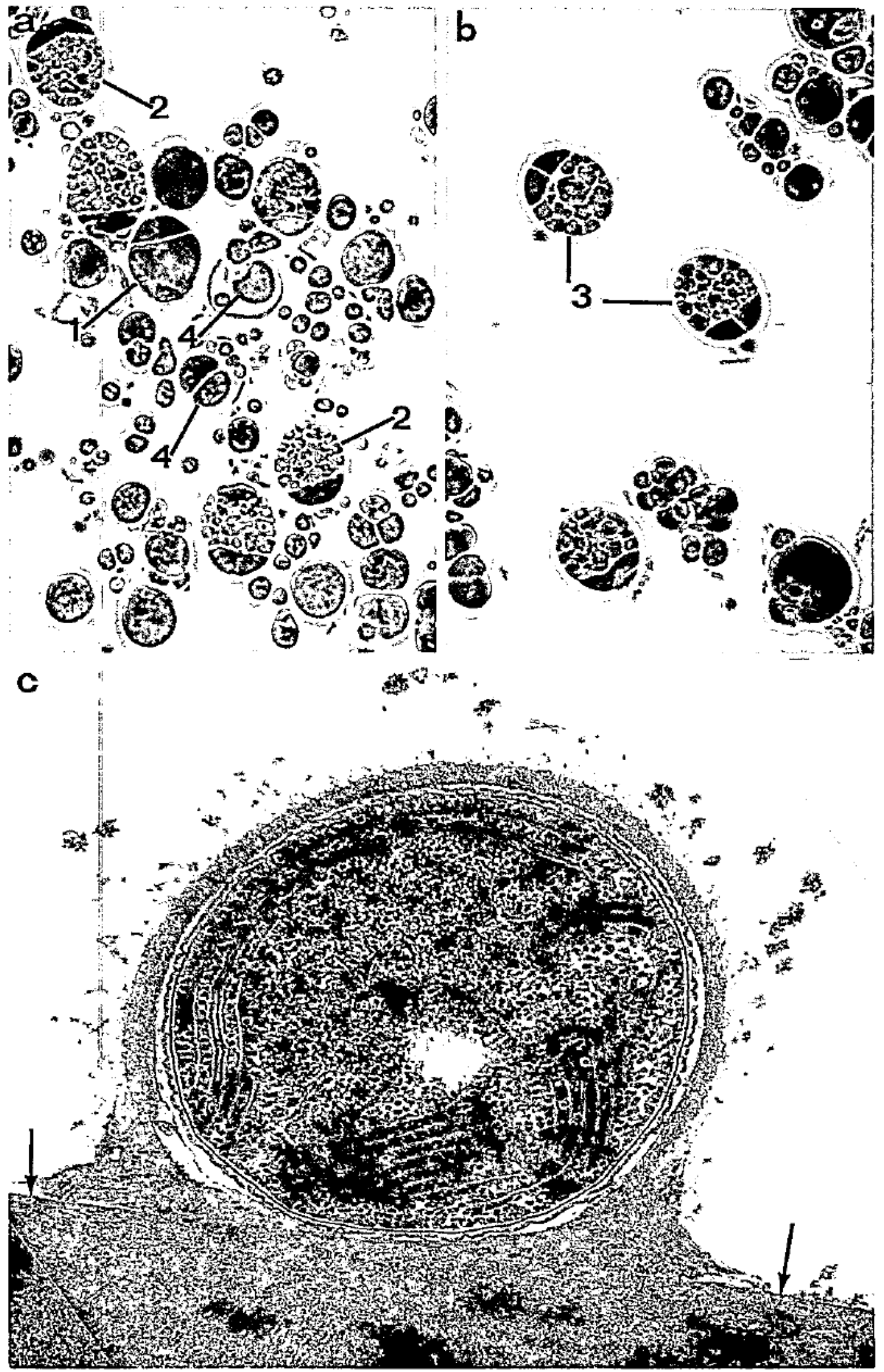




\section{Figure 27}

Electron micrographs of thin sections of Dermocarpelza strain 7326 grown on plates of medium MN. a. An individual which has just completed the binary fission which separates the apical cell from the basal cell. The $P G$, LP and $F$ wall layers of the basal cell remain closely appressed to one another, whereas the PG and LP layers of the apical cell have pulled away from the F 1ayer. Note the variation in thickness of the F layer (arrows). $\times 14,500$. b. An individual which has undergone a second binary fission to form two basal cells. The apical cell has begun to lundergo the successive divisions of multiple fission producing cleavage products which are initially not of equal size. The basal cells have begun to synthesize new F layer material over their entire surfaces, but no new synthesis of $F$ layer material has occurred around the dividing cells of the apical portion. $\mathrm{X} 15,000$. 

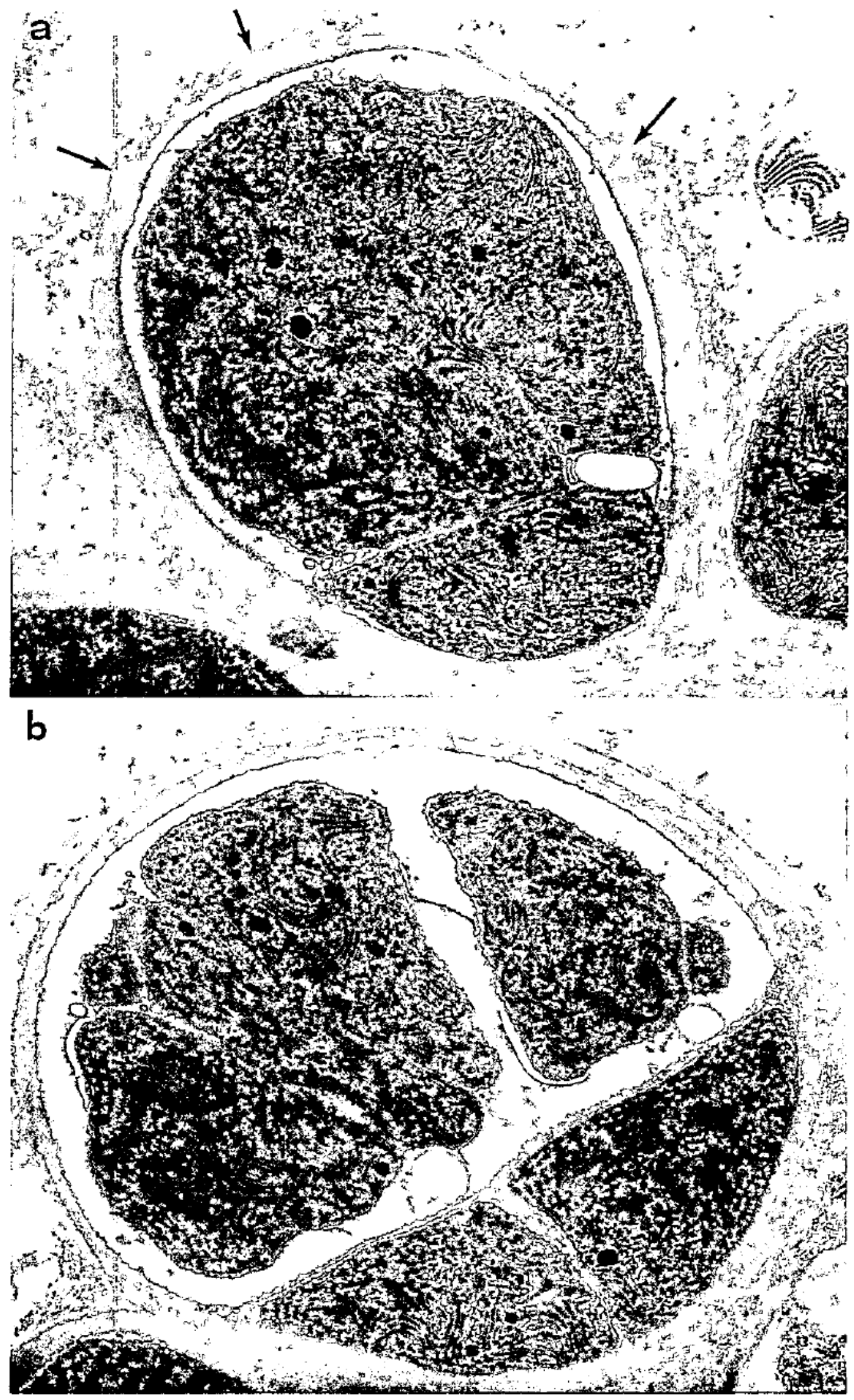
Figure 28

Electron micrographs of thin sections of Dermocarpella strain 7326. a. An individual nearing the completion of multiple fission. The $F$ layer surrounding the basal cells is markedly thicker than in the earlier developmental stage shown in Figure 27b. No $\mathrm{F}$ layer material surrounds the cleavage products in the apical cell. Note the variation in thickness of the enclosing F layer (arrows). . X13,500. b. An individual which has completed multiple fission and is filled with spores each surrounded only by the PG and LP wa11 layers. $X 10,500$. 

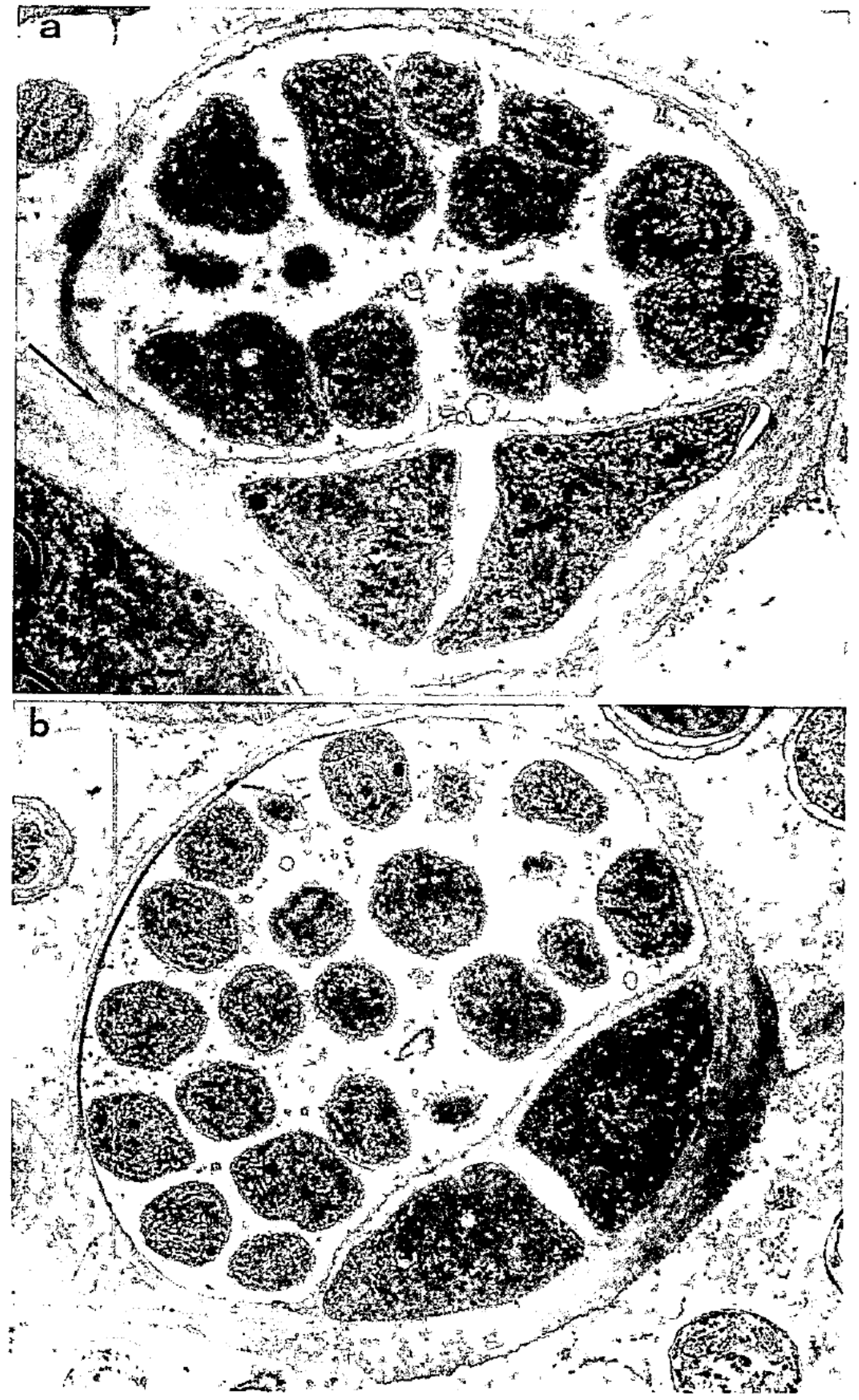
Electron micrographs of thin sections of Dermocarpella strain 7326 grown on pieces of idialysis membrane placed on plates of medium MN. a. A developing ovoid cell. which is Jaterally attached to the dlalysis membrane. $\mathrm{x} 41,000$. b. An individual attached to the dialysis membrane by its apical ce11. X14,600. 

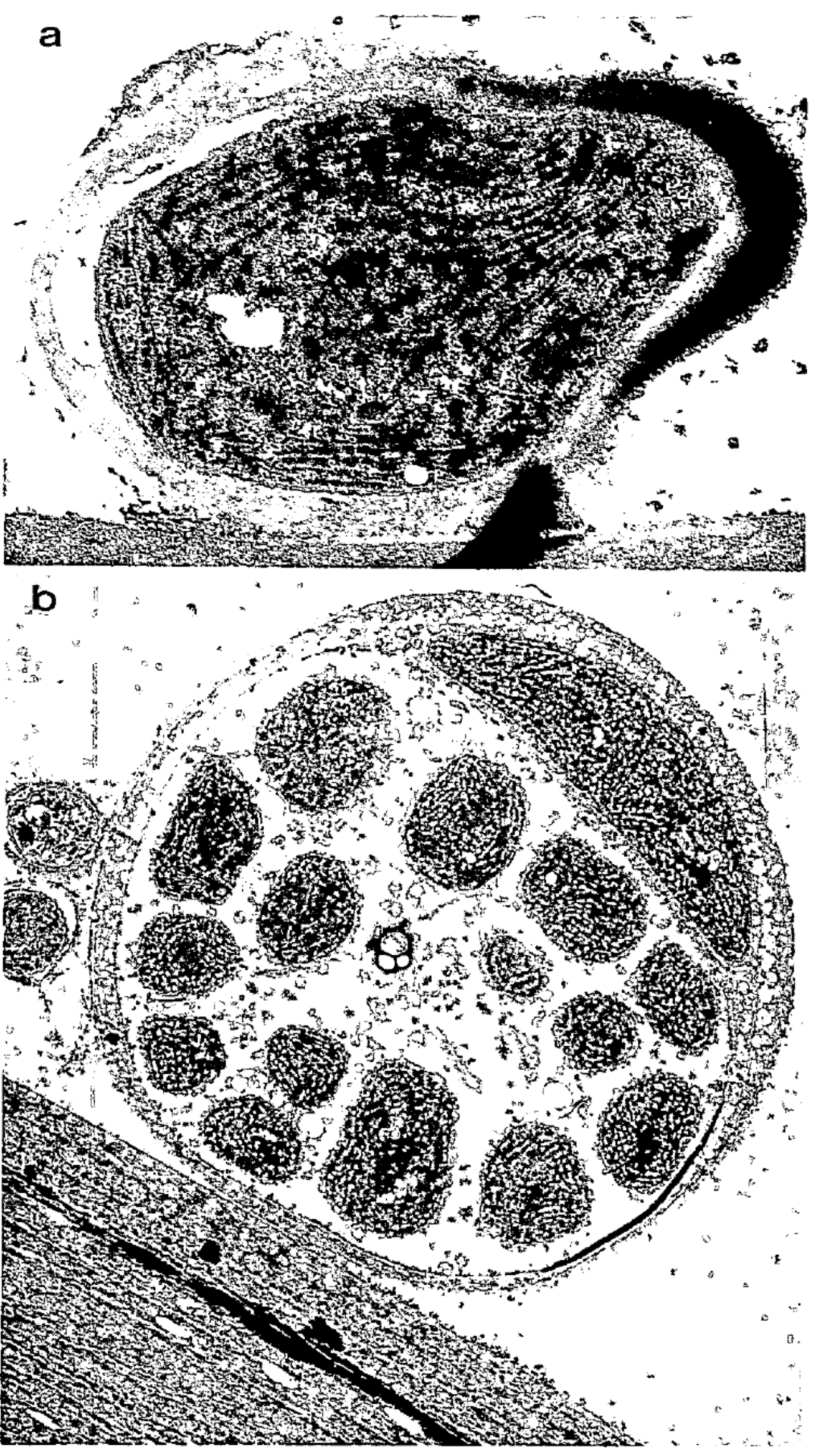
Figure 30

Schematic Developmental Cycle of Dermocarpella

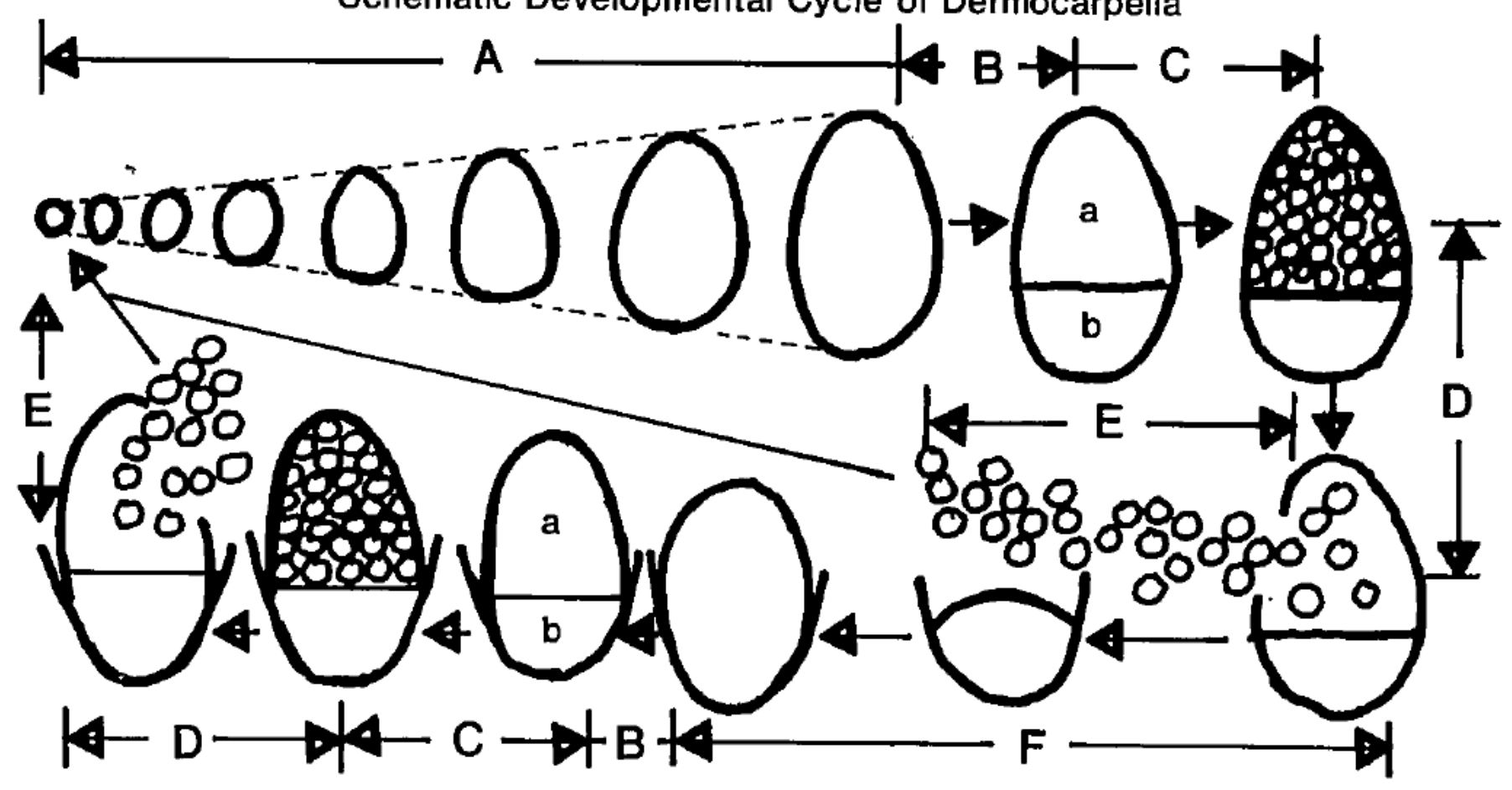
A Asymmetric spore enlargement
B Binary fission giving rise to a small basal cell (b) and a larger apical cell (a)
C Multiple cleavage of the apical cell leading to spore formation
D Spore release
E Period of spore motility
F Enlargement of basal cell 


\section{d. Myxosarcina}

In Myxosarcina spore enlargement is followed by repeated binary fissions in three regular planes, to produce cubical packets of cells which then undergo multiple fission and release motile spores. This mode of development is shown by two strains, 7312 and 7325 . Both the spores and the vegetative cells of strain 7325 are somewhat larger than those of strain 7312 (Table XIV). In large cell aggregates of strain 7325, the arrangement of the cells tends to become somewhat irregular (Figure 31d), whereas the cells in large aggregates of strain 7312 remain in a regular cubical array (Figure $31 b$ ).

The developmental cycles of the two strains in Cooper dish cultures are closely similar, and are illustrated by a series of photomicrographs of strain 7312 (Figure 32). The spore enlarges symmetrically until it reaches a predetermined size, characteristic of the strain (Table XIV). Following enlargement the spore begins to divide by repeated binary fissions in three regular planes leading to the formation of a cubical packet of cells. Almost all the cells in the aggregate undergo multiple fission simultaneously, which is followed by rupture of the surrounding F layers and release of spores. Following a brief period of motility (not illustrated) the spores begin to enlarge, and the cycle is repeated.

Both strains of Myxosarcina produce a relatively small (and probably constant) number of spores per parental cell (Table XIV), regardless of the culture.conditions. However, culture conditions do affect the number of binary fissions that precede the onset of multiple fission: the more favorable the conditions of growth, the earlier is the onset of multiple fission. 
T A B E X I V

STRUCTURAL PROPERTIES OF MYYOBarcina STRAINS

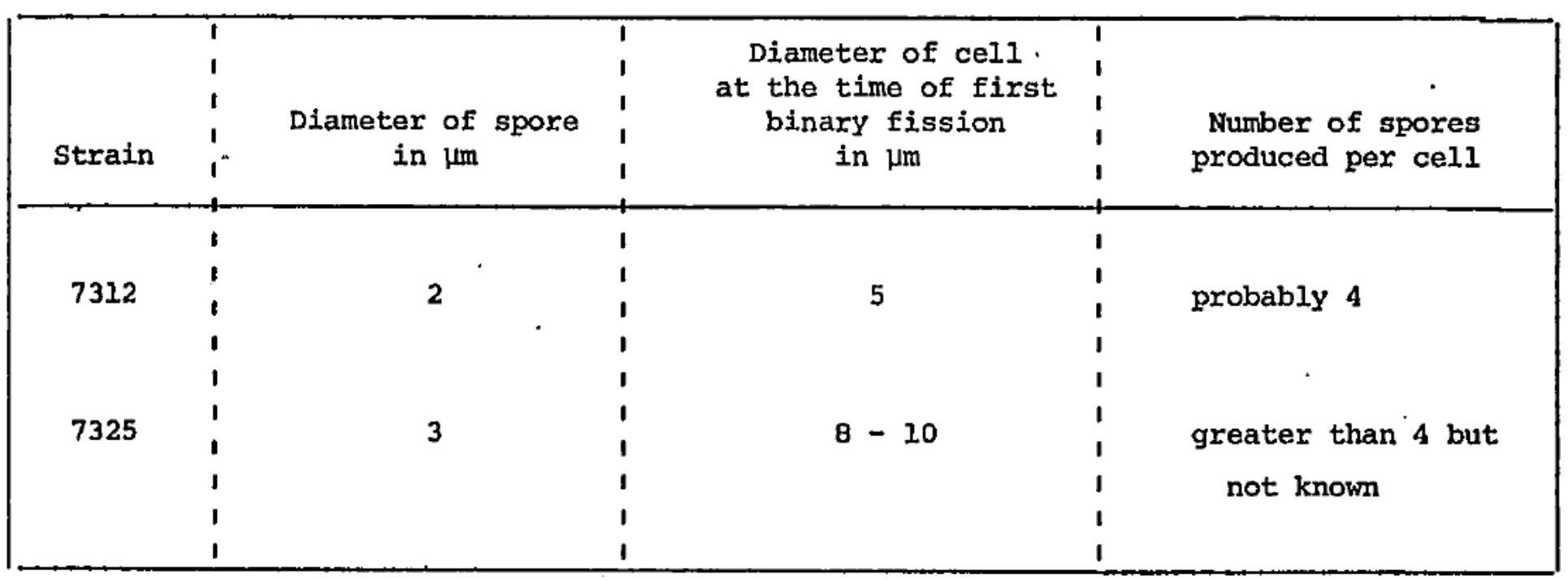


The developmental cycle of Myxosarcina is represented schematically In Figure 33. 
Figure 31

Photomicrographs of Myxosarcina strains 7312 and 7325 growing on plates of medium MN. a.- e., XI000, f., X 500. a. Young aggregates of strain 7312, showing the uniformity of cell size and the regularity of the planes of successive divisions. b. OIder aggregates of strain 7312, showing the maintenance of fairly regular cubical packets of cells. c. Young aggregates of strain 7325 , showing the uniformity of cell size and the Initial regularity of the successive divisions. d. older aggregates, in which the regularity of cell arrangement has been Iargely Iost. e. Cell aggregates of strain 7325 in which many packets of cells have completed multiple fission, and are filled with spores. f. Cell aggregates from an old liquid culture of strain 7325, in which the common enclosing $F$ layer of the cell wall is clearly visible (arrows). 

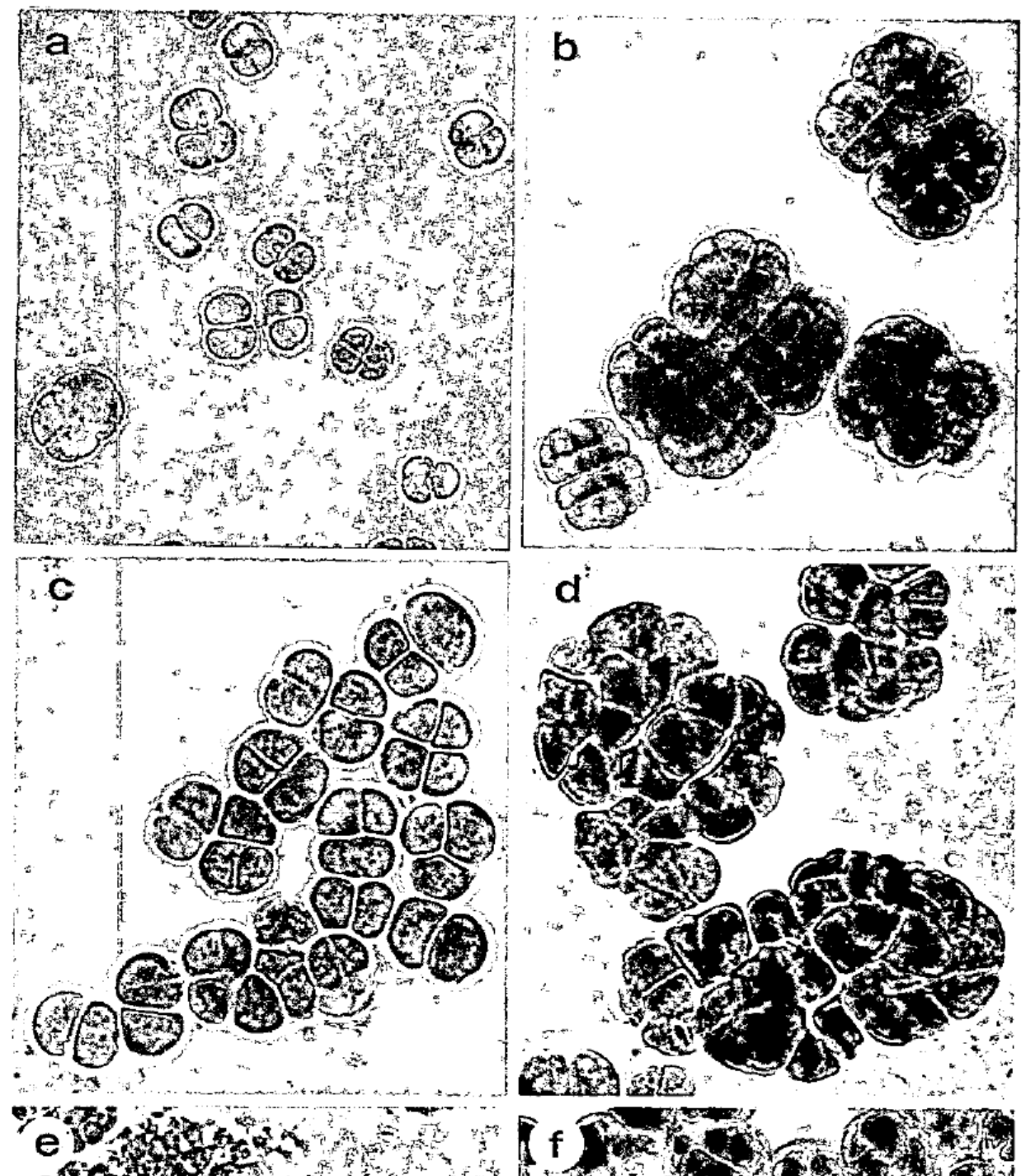

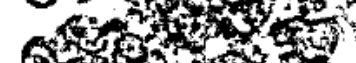

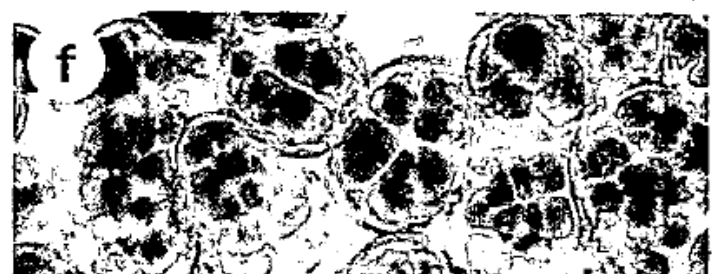

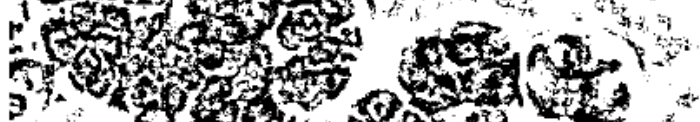

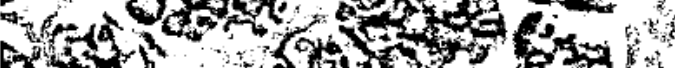

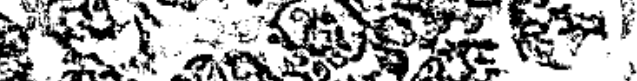

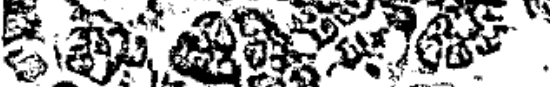

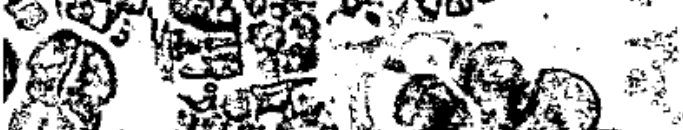

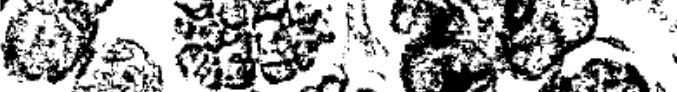
m

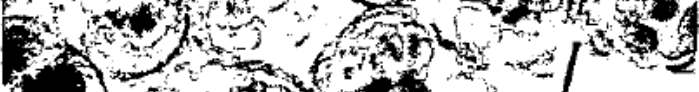
(1)

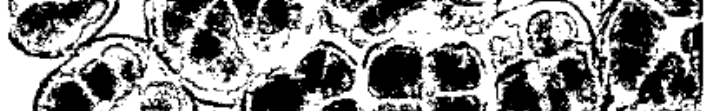
$(x+2)(x+1)$ (a) 


\section{Figure 32}

Successive photomicrographs of the development of a single spore of Myxosarcina strain 7312 on medium $\mathbb{N N}$ in a Cooper dish culture over a total perlod of 554 hours. The spore enlarges symmetrically until it reaches a size specific for each strain. It then begins to divide by binary fissions in three regular planes, to produce a cubical packet of cells. Almost all the cells in the packet undergo multiple fission simultaneously. X 500 . 


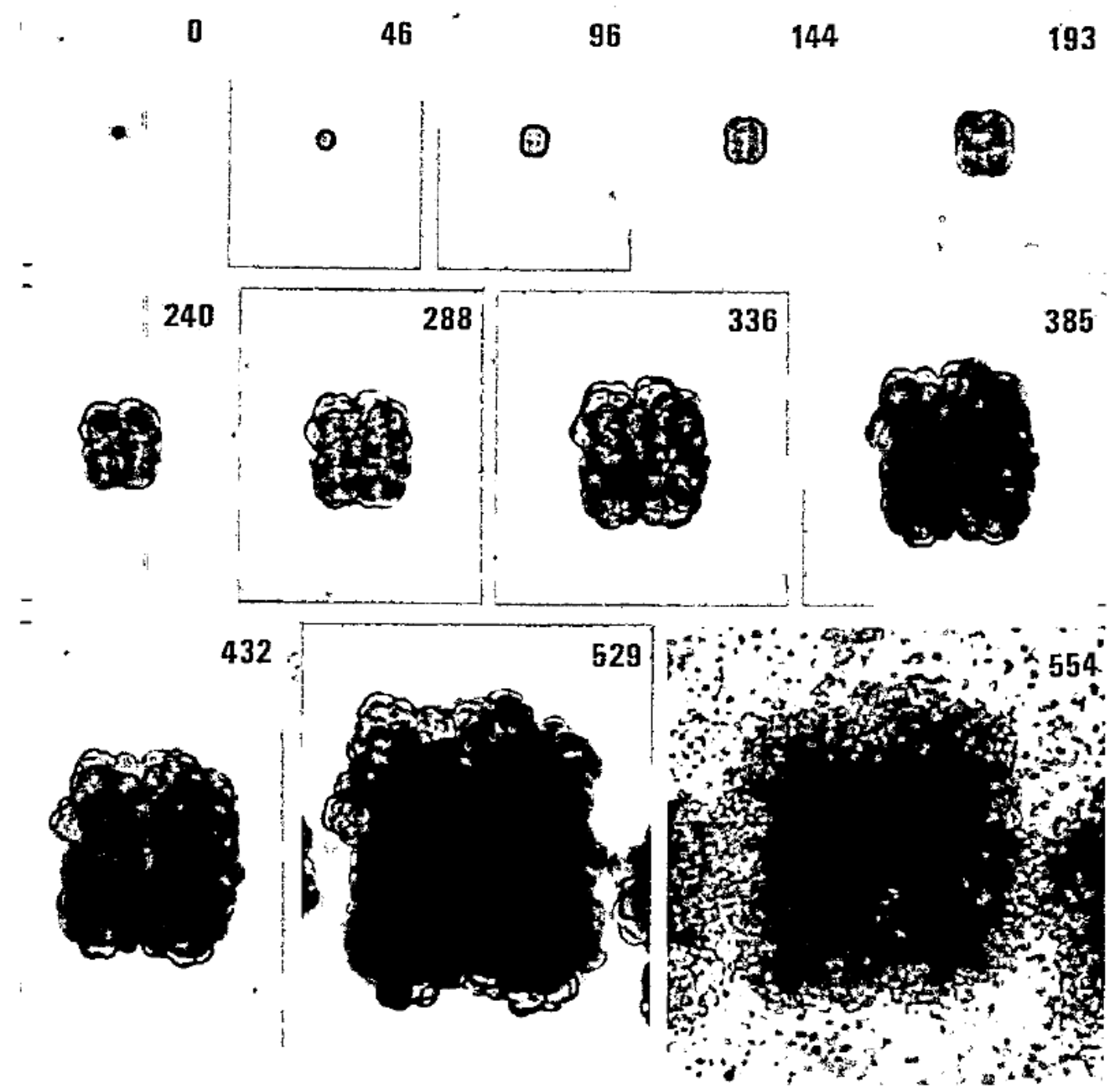


Figure 33

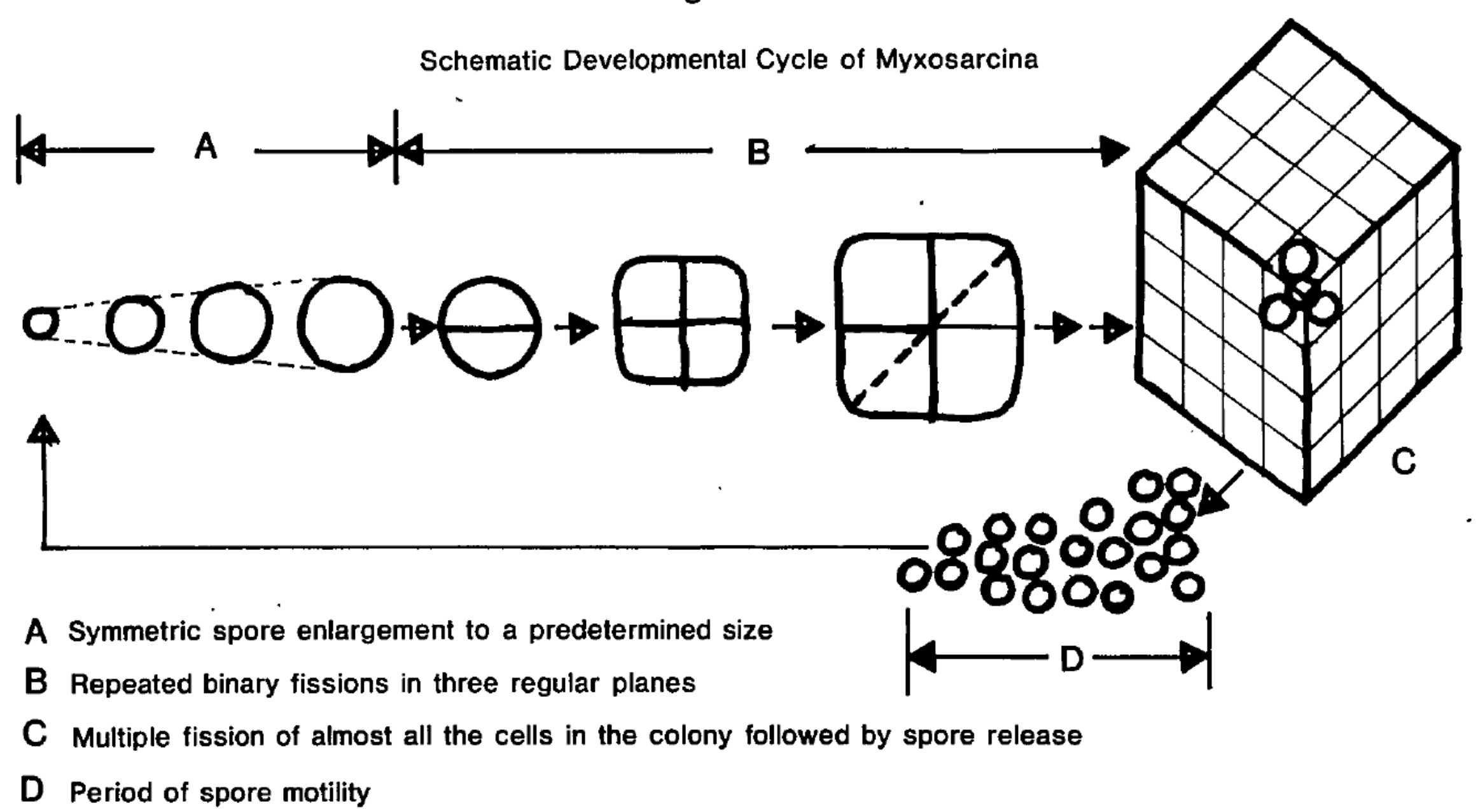




\section{e. Chroococcidiopsis}

The genus Chroococcidiopsis is not distinguishable from Myxoscarcina in mass cultures. In such cultures, it develops as cublcal or somewhat irregular cell masses (Figure 34) which, when crushed, break up into smaller cell clusters, typically containing from 2 to 8 cells, most of which are of similar size (Figure 35). As will be explained below, these cell clusters consist mostly of vegetative cells in the course of binary fission. The slightly smaller endospores are rarely observed in mass cultures, although a few groups of endospores (arrows) are present in Figure 35a.

Among the eight strains of Chroococcidiopsis in our collection, seven $(7203,7431,7432,7433,7434,7436$ and 7439$)$ are structurally Indistinguishable and, as will be described in a later section, also indistinguishable in physiological and chemical respects. Strain 6712 differs from the remaining strains in the size of the vegetative cells and spores (Table XV) and also in physiological and chemical respects.

The developmental cycle characteristic of Chroococcidiopsis is difficult, if not impossible, to determine by the examination of mass cultures, but is revealed by semi-continuous observations of growth in Cooper dish cultures. Figure 36 shows the development over a period of 302 hours of a single spore of strain 6712 . The spore underwent an initial enlargement, and started to divide after 72 hours. The first two divisions occurred at right angles to one another, producing after 120 hours a tetrad of vegetative cells, each considerably larger than the initial spore. Thereafter, the cell aggregate continued to grow until 229 hours, although the arrangement and size of its constituent cells could no longer be resolved. The release of small spores started at 
T A B L E $X$ V

STRUCTURAL PROPERTIES OF ChroOCOCCidiopsis STRAINS

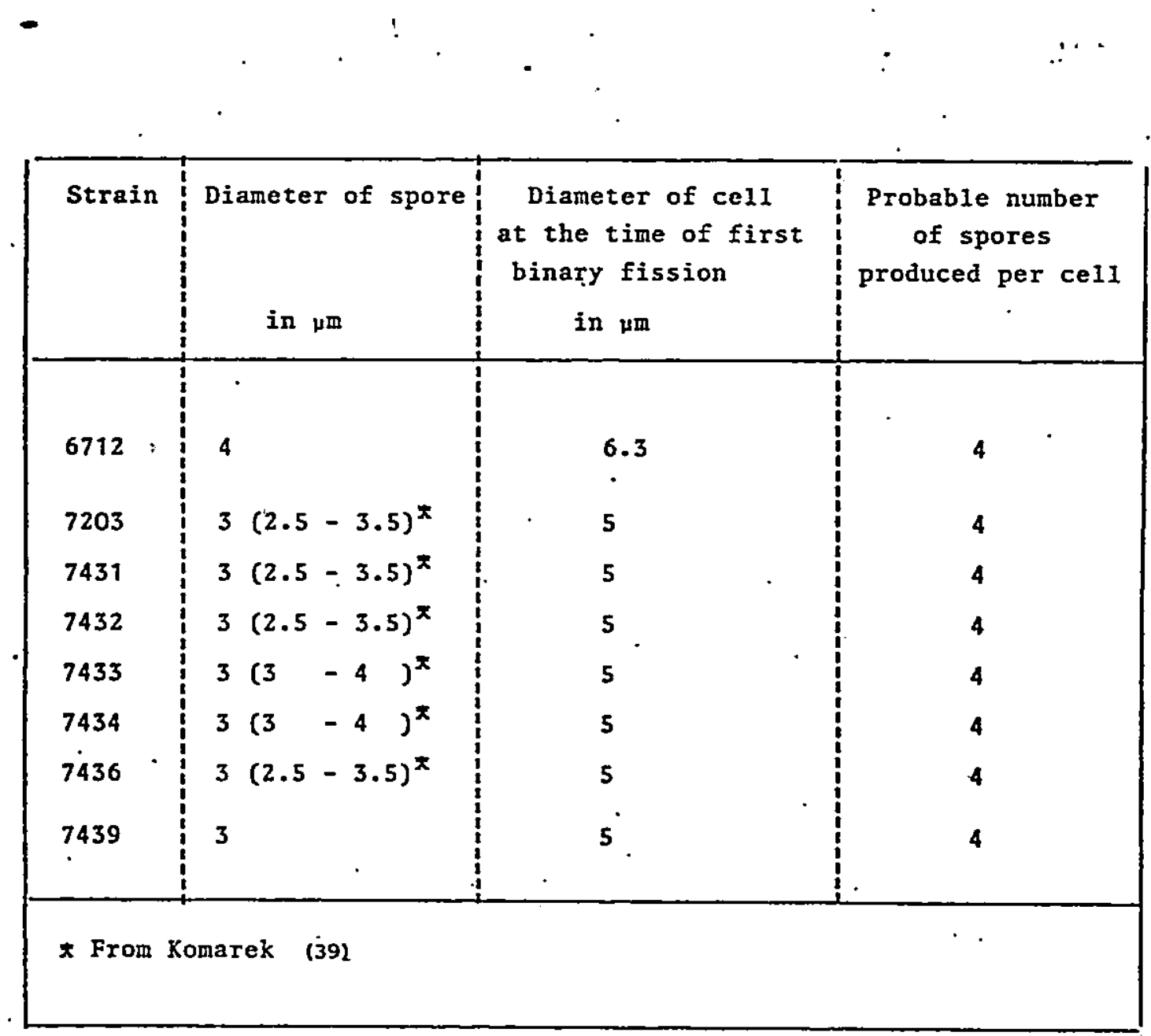


241 hours, and additional spores were liberated from the aggregate for many hours thereafter. After 302 hours, many of the spores had already enlarged and undergone one binary fission (arrows).

- Figure 37 shows the development over a period of 229 hours of a. group of three spores of strain 7432, typical of the remaining seven Chroococcidiopsis strains. The developmental sequence closely resembles that described above for strain 6712. The three spores included in the fleld of observation all enlarged at a similar rate, and underwent the first binary fission after attaining the same size. Small spores were released from the aggregate after 157 hours. 'After 208 hours, many spores had enlarged and undergone one binary fission (arrows). After 229 hours, an additional division of some of these spores had taken place, to produce tetrads (arrows).

Spore motility has never been observed in Chroococcidiopsis strains: when spore release occurs in a Cooper dish culture exposed to unidirectional illumination, the spores remain clustered evenly around the remains of the parental cells (Figure 15c). The absence of spore mo- : tility is, accordingly, the property which distinguishes Chroococcidiopsis from Myxosarcina.

The immotility of the spores of Chroococcidiopsis implies that synthesis of an $F$ layer occurs in the course of multiple fission leading to spore formation. The spores of these organisms do not differ greatly In size from the vegetative cells (Table XV), which indicates that a rather small (and probably constant) number of spores is produced from each vegetative cell. Hence the distinction between spores and vegetative cells, either by light microscopy or by electron microscopy, is particularly difficult in the case of this group, and rests entirely on 
the relatively small differences in cell size, evident in the light micrograph of a mass culture of strain 6712 (Figure 35a), and particular1y in Cooper dish cultures (Figures 36 and 37 ).

Several. representative electron micrographs of thin sections of Chroococcidiopsis aggregates are shown in Figures 38 and 39 . Figure $38 \mathrm{a}$ is a section of an aggregate which we interpret as having just undergone a binary fission, producing a two-celled individual. The Individual cells are of approximately the same dimensions as ce.lis in a Cooper dish culture which have just undergone the first division (Figure 37; 61 hours). The cel1 aggregate shown in Figure 38b is of approximately the same size as that shown in Figure $38 a$, but contains many more cells. It can be interpreted as a two-celled aggregate, both the cells of which are in the course of multiple fission. It should be noted that the cleavage products are individually surrounded by an F wall layer, which is in accord with the observation that free spores are never motile. Figure 39 shows an electron micrograph of a thin section of a larger Chroococcidiopsis aggregate. The distinction between spores and vegetative cells in such preparations cannot be made with certainty:

All Chroococcidiopsis strains except 6712 sometimes produce an unusual type of aggregate in liquid cultures (Figures $40 \mathrm{a}$ and $40 \mathrm{~b}$ ). They consist of spheres of widely varying size, which always contain many cells, and are intermixed in the population with aggregates of normal form (Figure 40a). We have not been able to follow the development of these spherical aggregates, and the-following interpretation of their nature is, therefore, hypothetical. They could arise from a single cell (or a palr of cells) which have undergone multiple fission, without 
subsequent spore release. The growth and vegetative division of the spores entrapped within the F layer of the parental cell (or pair of ce11s) might then lead to the formation of a spherical aggregate. A i configuration sometimes observed in electron micrographs of thin sections (Figure 40c) consists of a roughly spherical aggregate which could be an early stage in the formation of the larger spherical aggregates observed in light micrographs.

A diagrammatic representation of the developmental cycle of Chroociccidiopsis, based primarily on our observations of the growth of these organisms in Cooper dish cultures is shown In Figure 41 . It should be explicitly noted that the interpretation portrayed in Figure 41 differs considerably from that offered by previous workers $(28,24$, 39,41 ), even though one of these workers (41) based his conclusions on the study of non-axenic cultures of seven of the eight strains which we have examined (i.e., all except 6712). Earlier workers have assumed that Chroococcidiopsis is a unicellular organism which divides only by multiple fission. This basic assumption necessitated the development of relatively complex explanations to account for the various types of cel1s and aggregates observable in mass cultures $(24,39,41)$. The previous failure to recognize that Chroococcidiopsis can undergo both blnary and multiple fission accounts for the errors which have long been made in the interpretation of the development of these organisms. 
Figure 34

Photomicrographs of mass cultures of Chroococcidiopsis grown on agar plates of medium BG-11 showing the characteristic cell aggregates made by these strains. a. Strain 7203; b. Strain 7431; c. Strain 7432; d. Strain 7433; e. Strain 7434; f. Strain 7439. X1000. 


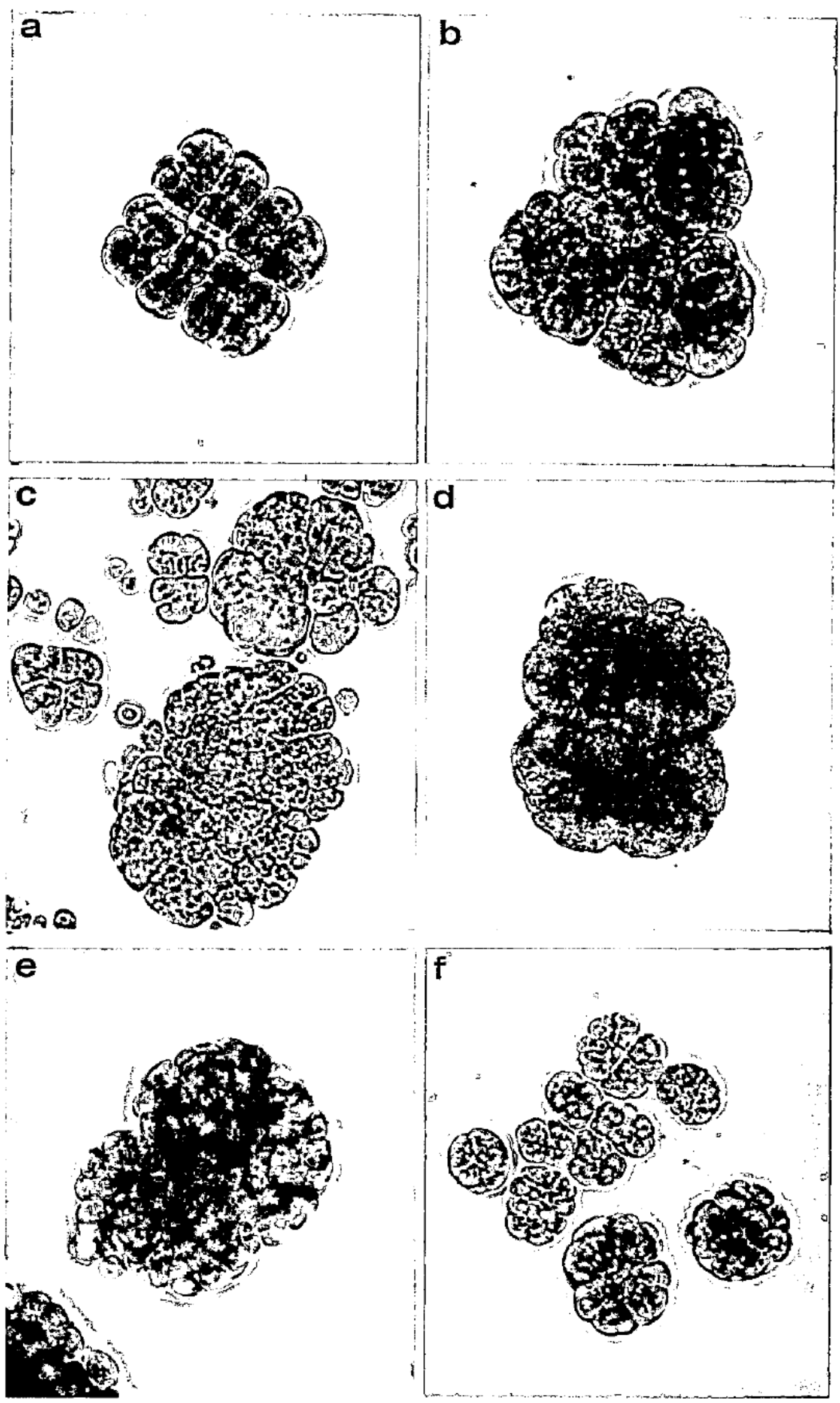


Figure 35

Photomicrographs of mass cultures of Chroococcidiopsis grown on agar plates of medium BG-11. The aggregates visible in Figure 34, when crushed, break up into smaller cell clusters, typically containing from 2 to 8 cells, most of which are similar in size. a. Strain 6712 , note the cells that have undergone multiple fission, resulting in the production of four spores per parental cell (arrows). b. Strain 7433; c. Strain 7434; d. Strain 7436; e. Strain 7439. $\times 1000$. 

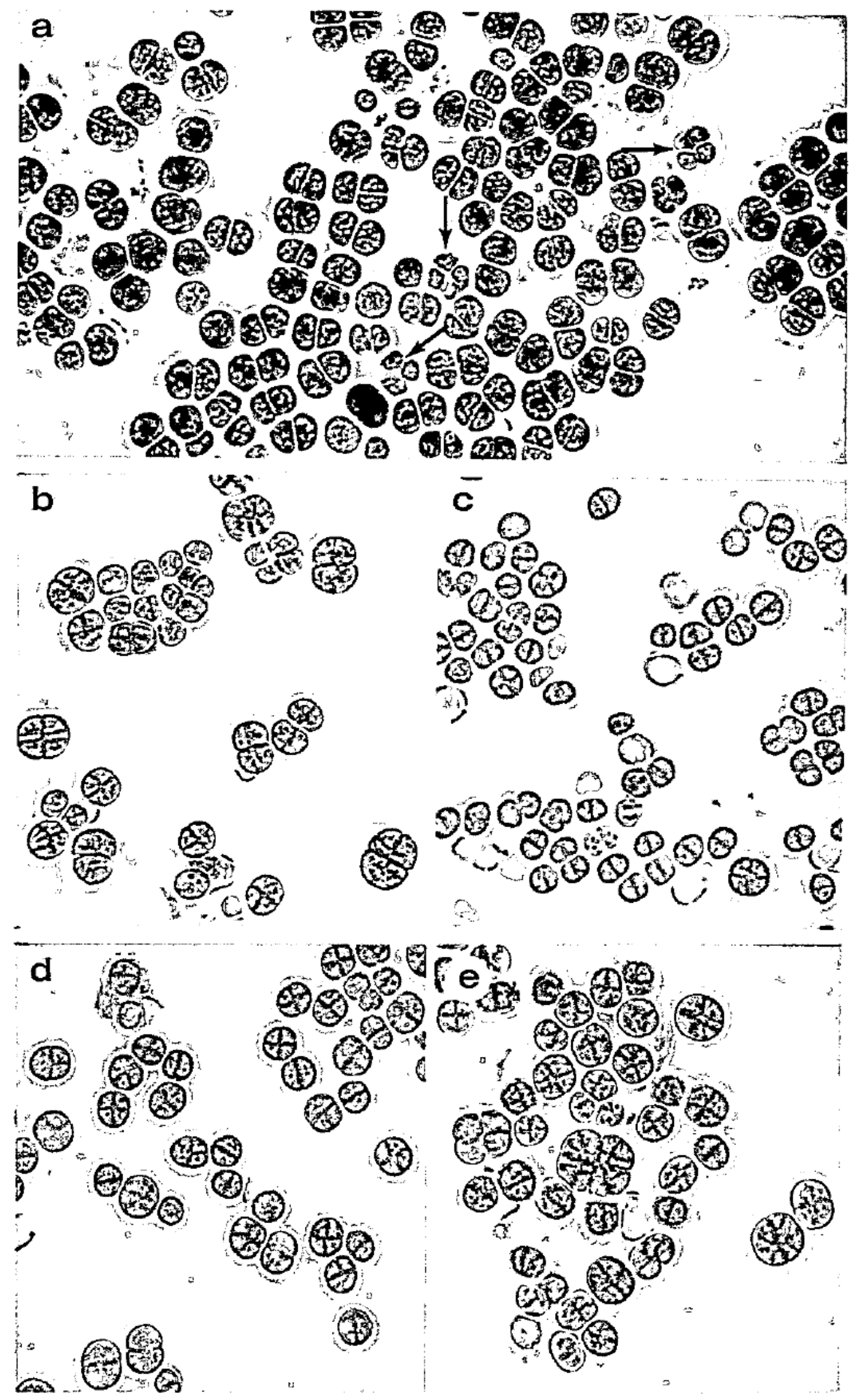


\section{Figure 36}

Development of Chroococcidiopsis strain 6712 on medium BG-11 supplemented with $0.3 \%$ sucrose in a Cooper dish culture. Successive photomicrographs of a single spore showing its development over a total period of 302 hours. The developmental pattern is identical to that of Myxosarcina (Figure 32) except that the spores released following multiple fission are immotile. X 500 . 


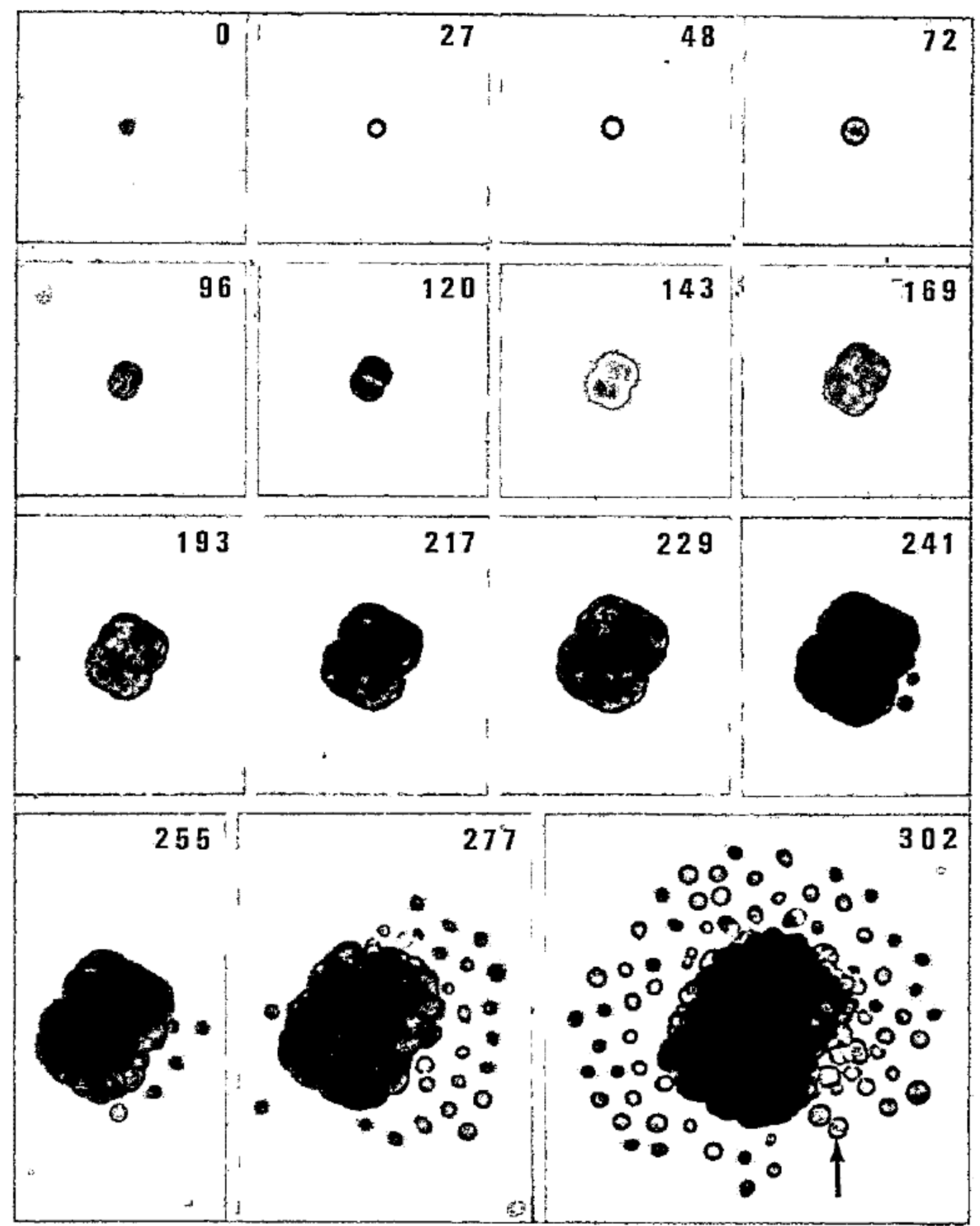


Figure 37

Successive photomicrographs of the development of three spores of Chroococcidiopsis strain 7432 . on medium BG-11 supplemented with $0.3 \%$ sucrose in a Cooper dish culture over a total period of 229 hours. The developmental pattern is the same as that shown for strain 6712 in Figure 36. X 500 . 


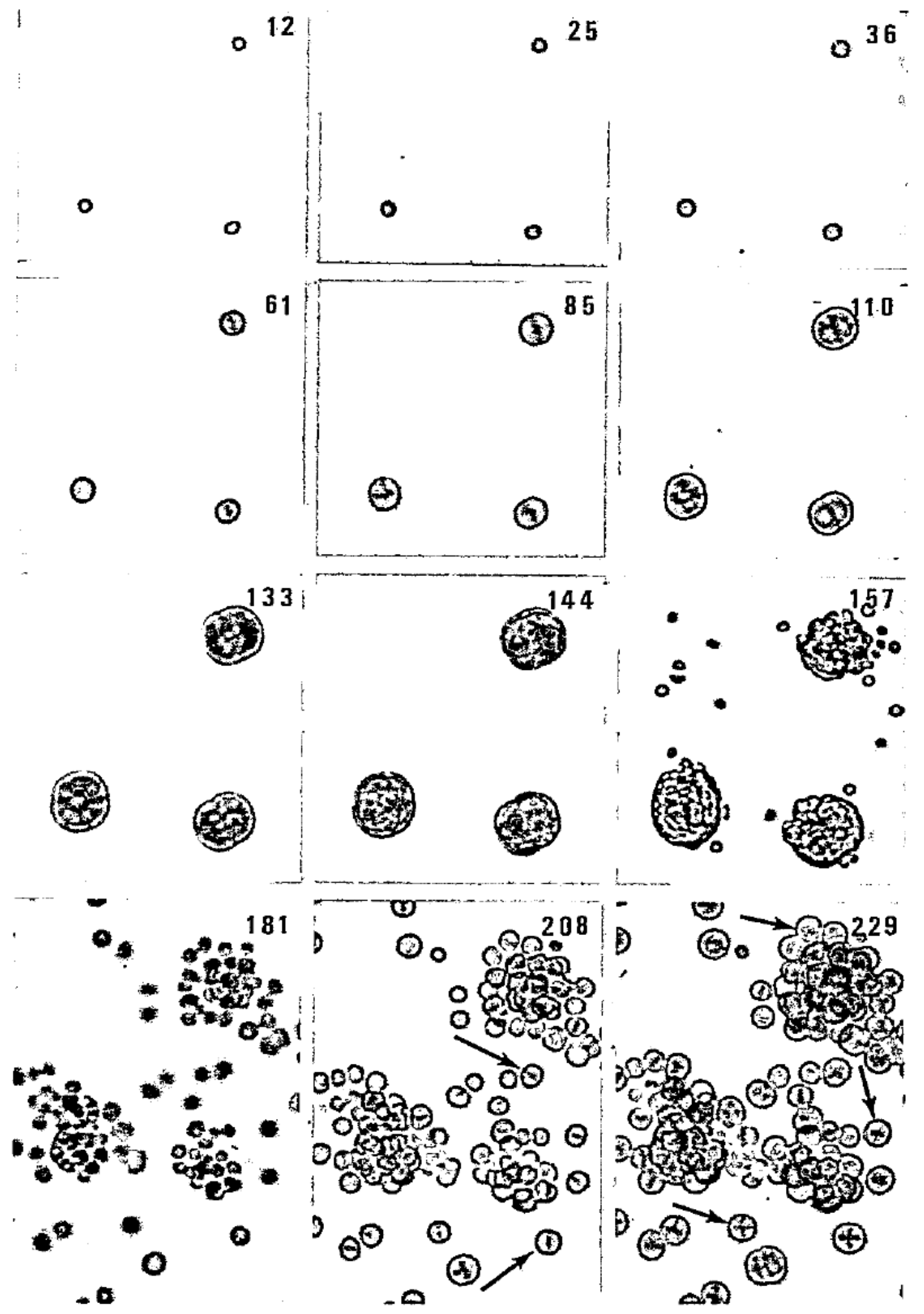


Figure 38

Electron micrographs of thin sections of Chroococcidiopsis strain 7436 grown on a plate of medium BG-11. a. Two vegetative cells which have divided by binary fission. X19,500. b. Two cells which have undergone multiple fission after the completion of one binary fission. Both the size of the cells and the thickness of their individual surrounding $\mathrm{F}$ layers indicate that multiple fission has taken place. X 25,000. 


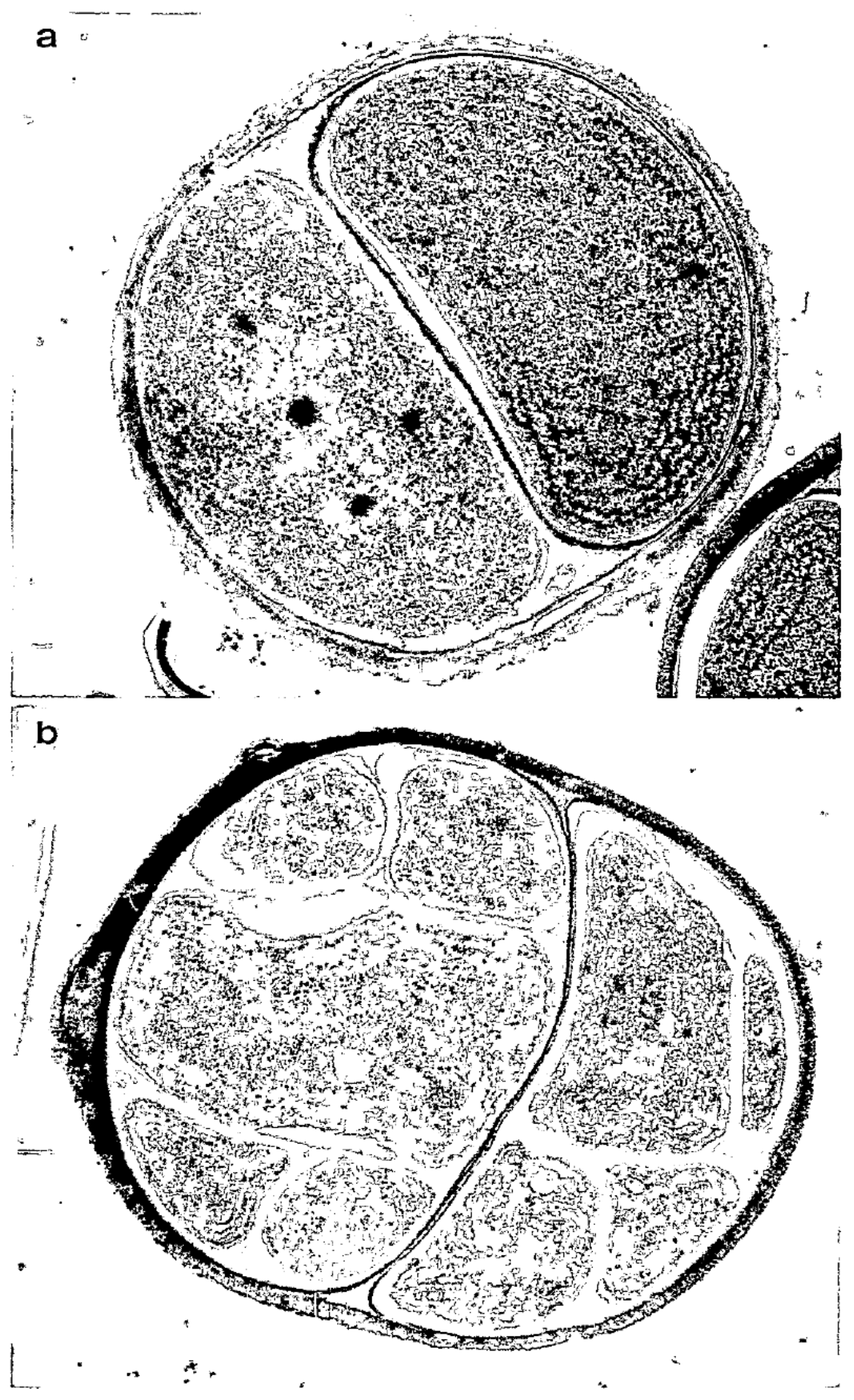


Figure 39

An electron micrograph of a thin section of Chroococcidiopsis strain 7432 grown in an agar overlay of medium BG-11. It reveals that small aggregates within a large colony are held together by their common surrounding $F$ layers. The F layer material also appears to hold the aggregates together even after the common surrounding $F$ layer has ruptured. Note the cell which has inltiated binary fission by the centripetal ingrowth of the PG and LP wall layers, and characteristic nucleoplasm (N) with associated carboxysomes (arrows). $\times 17,500$. 


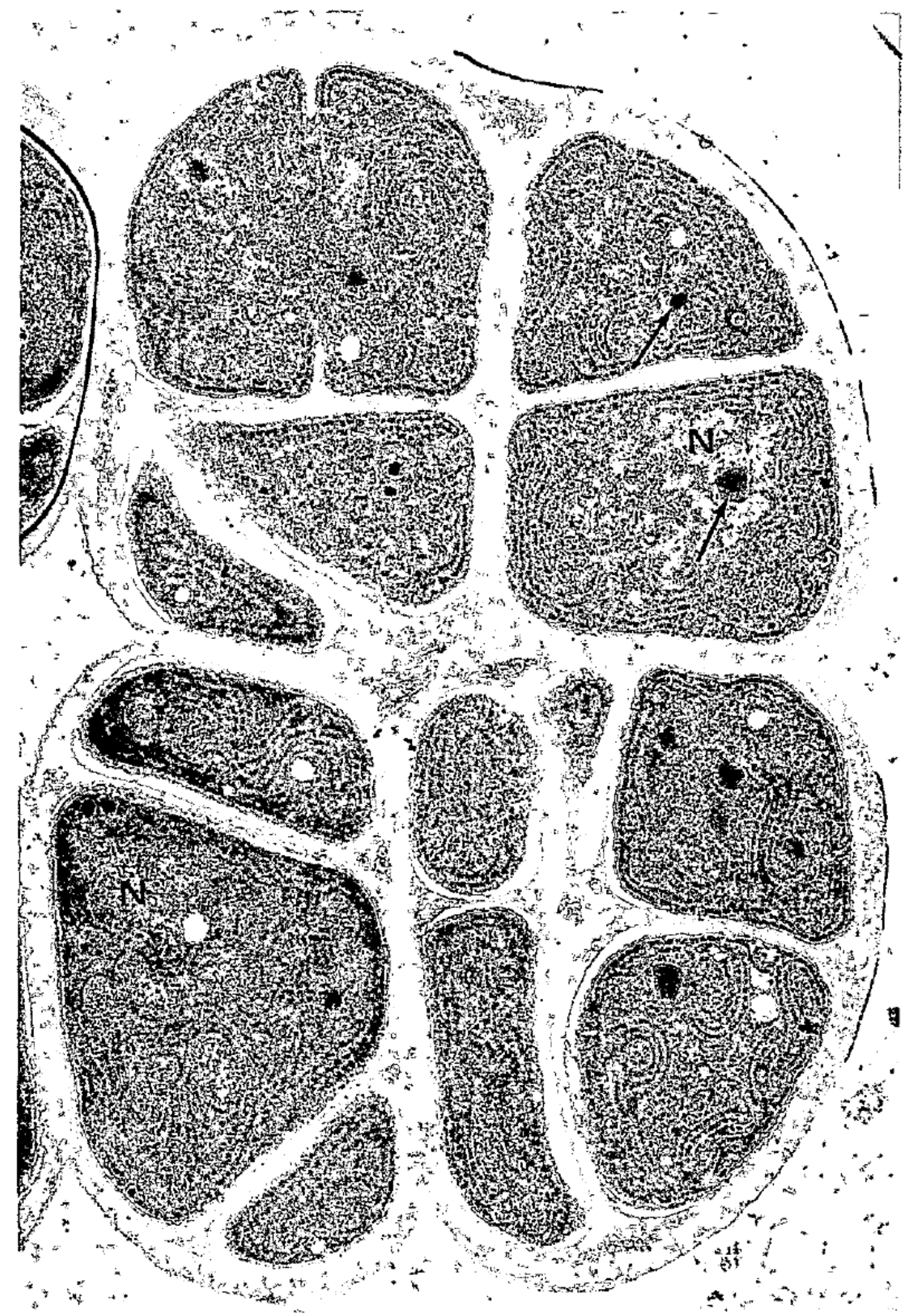




\section{Figure 40}

a. and b. Photomicrographs of Chroococcidiopsis strain 7431. a. A fleld showing the two types of cell aggregates. X500. b. A more detalled photograph of the spherical colonies produced by this strain. X 1000 . c. An electron micrograph of a thin section of strain 7432 revealing an individual which may be interpreted as having undergone multiple fission following the first binary fission. The many division planes that would be introduced if these spores developed within their common surrounding $F$ layer might explain the production of the spherical colonies seen in Figures $40 \mathrm{a}$ and $40 \mathrm{~b}$. Note the carboxysomes (arrows) and the characteristic nucleoplasm (N). X 21,500. 


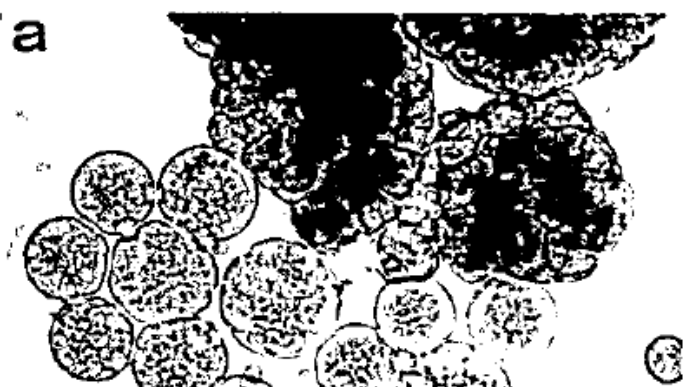

b if $x$ (3) 20.0.

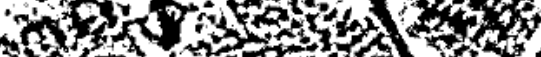

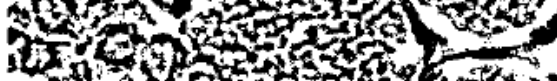
(90)

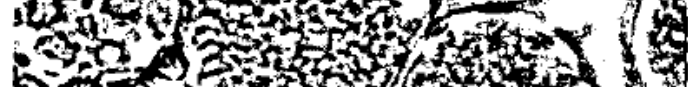

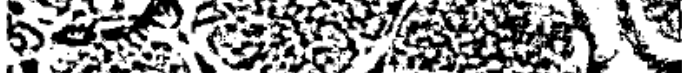

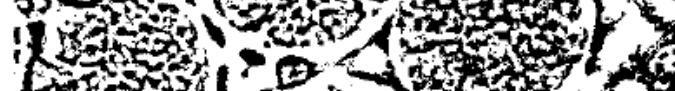

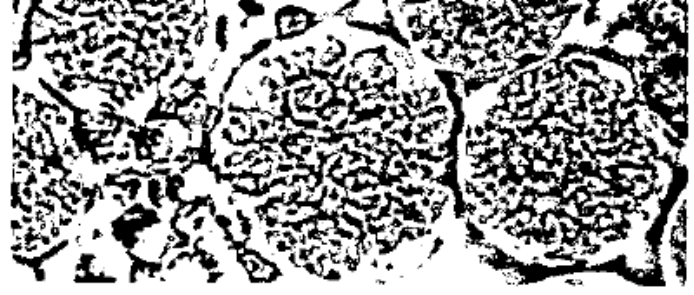

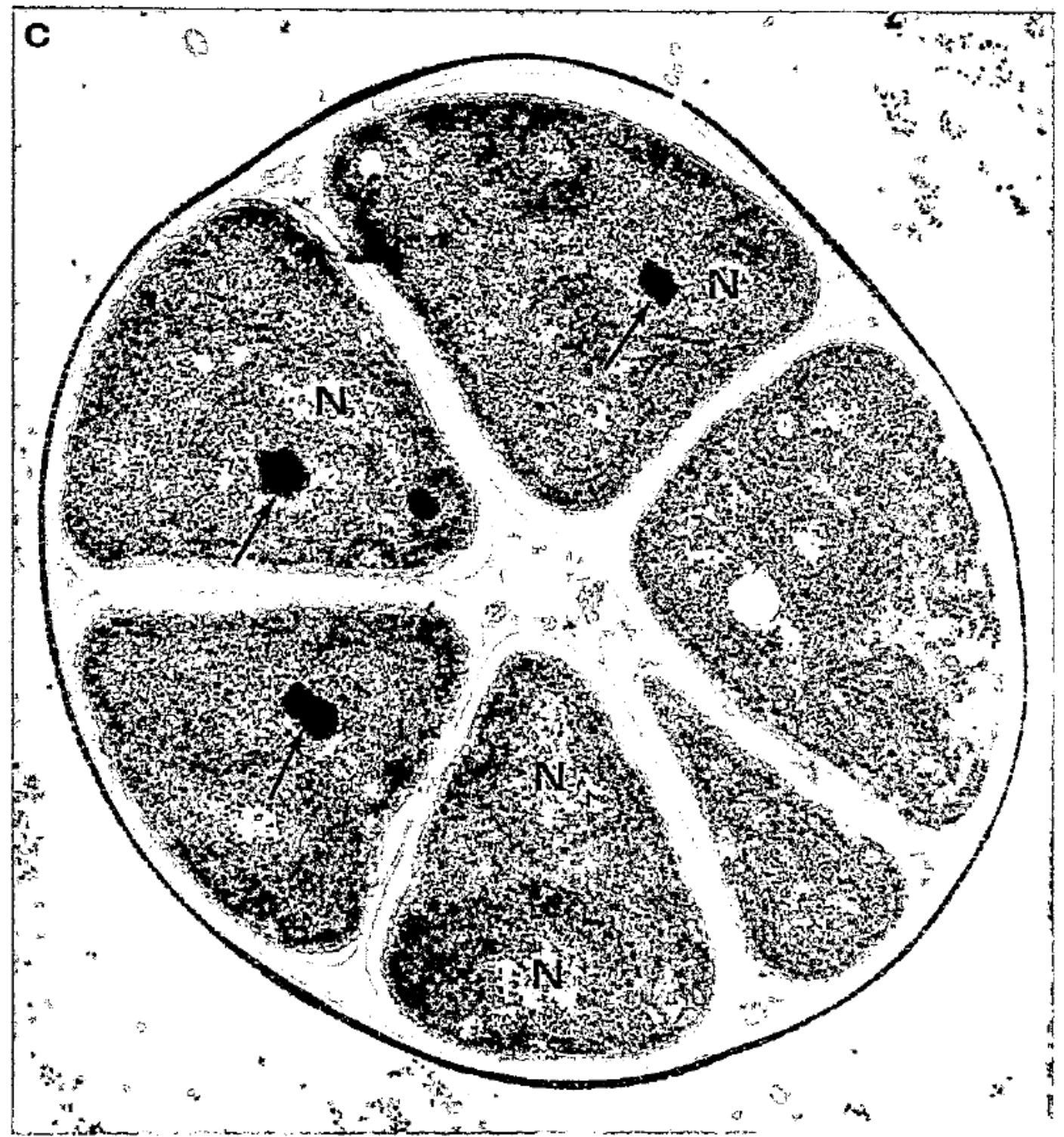


Figure 41

Schematic Developmental Cycle of Chroococcidiopsis

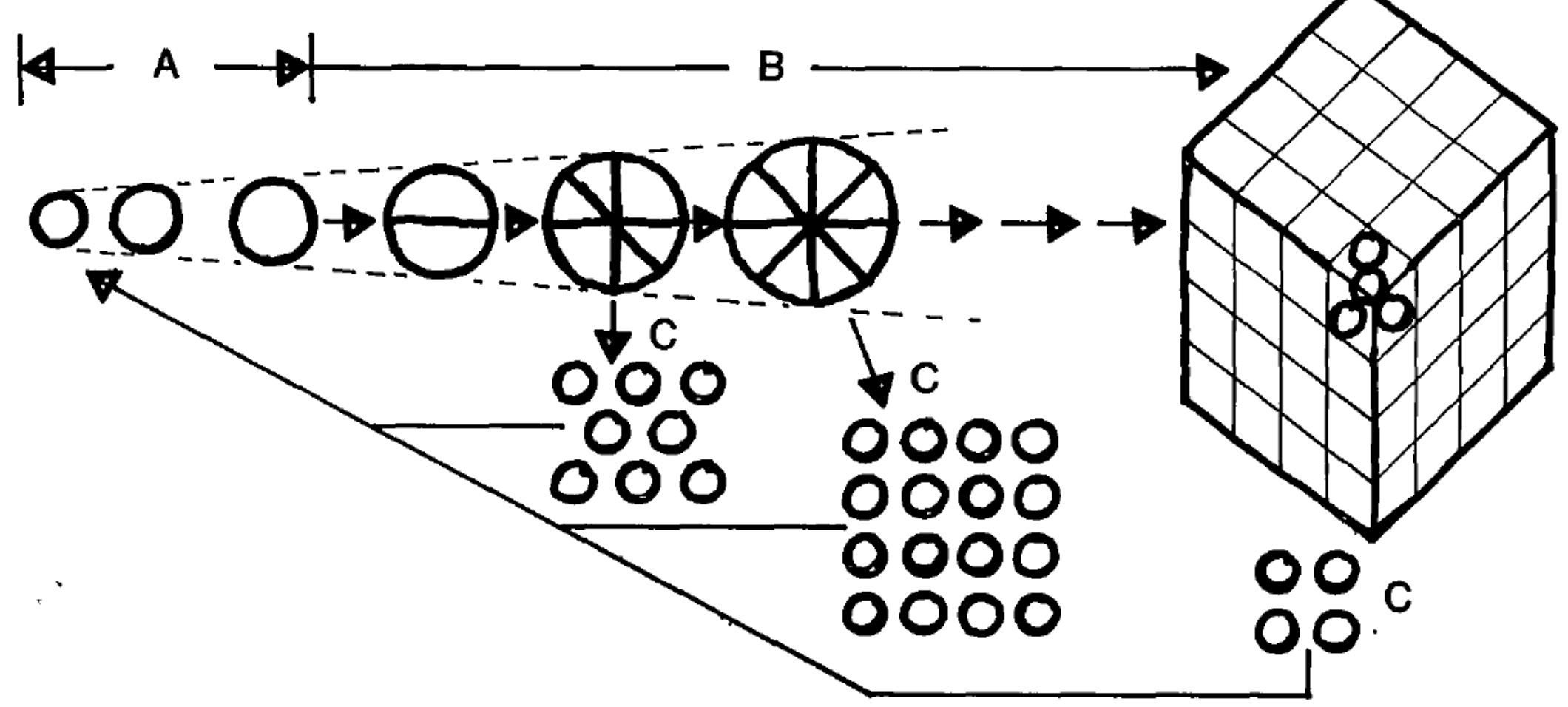

A Symmetric spore enlargement to a predetermined size

B Repeated binary fissions in three regular planes

C Multiple fission of almost all the cells in the colony followed by the release of immotile spores 


\section{Pleurocapsa}

\section{Developmental patterns}

The genus Pleurocapsa is represented in our collection by twelve strains $(7310,7314,7317,7319,7320,7321,7322,7324,7327,7440$, 7506, and 7516). Characteristically their developmental cycles involve spore enlargement, followed by binary fissions in many irregular planes, producing cell aggregates which may vary widely in size and range from Irregularly shaped clusters of cells to rather extensive filamentous assemblages. Eventually some of the cells in the aggregate undergo multiple fission, producing motile spores. The primary character common to all these strains that distinguishes them from Myxosarcina is the irregularity of the successive planes of binary fission, even early in vegetative growth. However, as will be described below, some strains can produce Myxosarcina-like aggregates under special conditions (growth at the expense of sugars).

When grown on solid mineral media, these strains display not only'a wide variety of cell sizes and shapes but also a remarkable diversity with respect to the size and form of the cell aggregates. The examination of such mass cultures' shows the presence of cells which have obviously undergone multiple fission, but reveals very little about the developmental cycles of the individual strains. Semicontinuous observation:s on Cooper dish culture:s show that the strains of Pleurocaps $a$ can be divided into two subgroups which differ in their mode of spore enlargement prior to the onset of binary fission.

In group I spore enlargement is symmetric; in group II it is asymetric. The developmental features characteristic of the strains belonging to each subgroup will be separately described below. Special 
T A B L E X V I

STRUCTURAL PROPERTIES OF PZEUrOCGDBa STRATNS

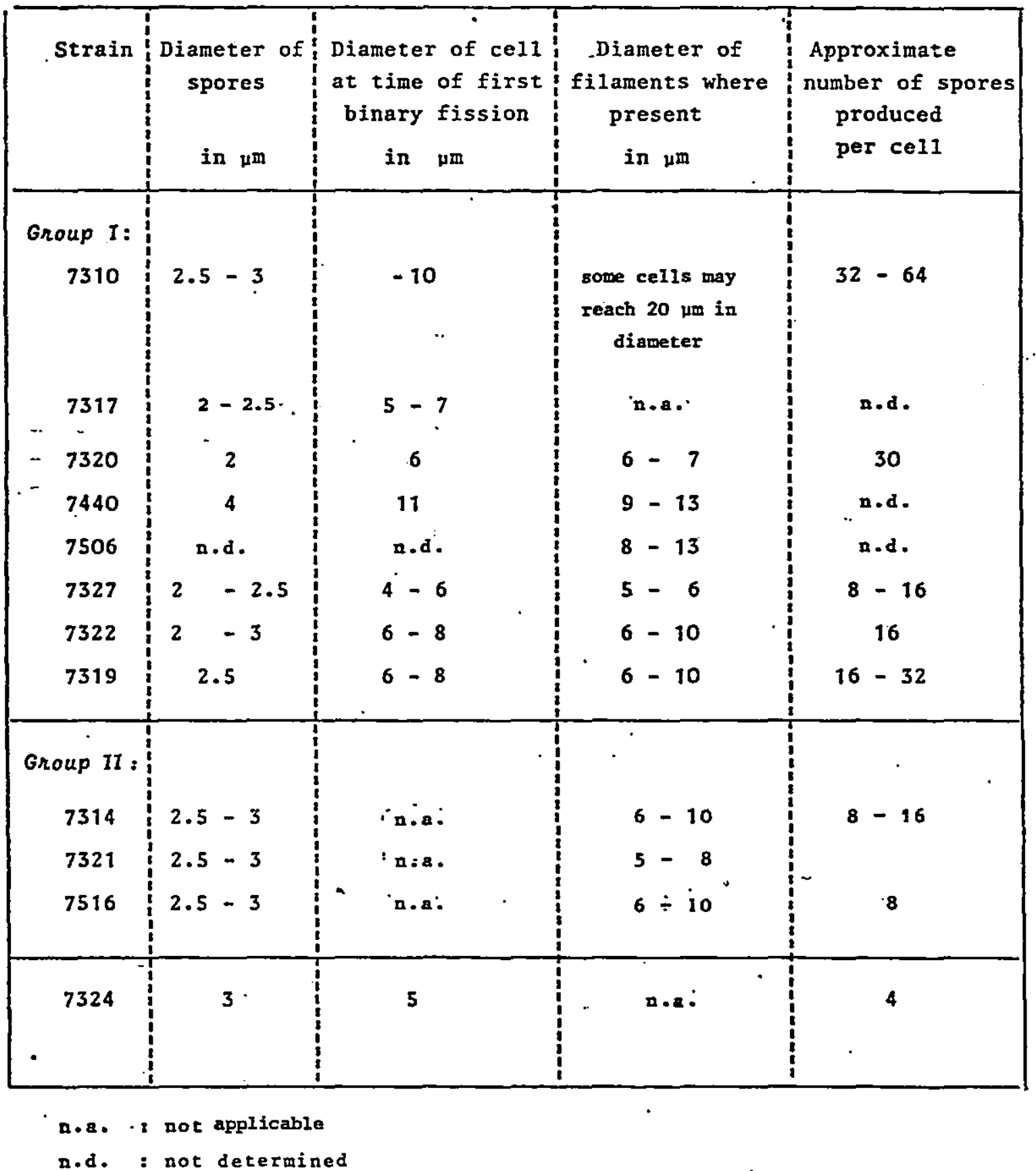


characteristics of the Individual strains are presented in Table XVI.

Strains of Group I $(7310,7317,7320,7440,7506,7327,7322,7319)$

Strains 7310 and 7317 typically produce small, undifferentiated cell aggregates (Figure 42). Their developmental cycles are initiated by symmetric spore enlargement, followed by binary fïssions. in many planes, producing compact, irregularly shaped clusters of cells which never produce extensive filamentous outgrowths (Figures 43 and 44). The two strains differ in cell size (Table XVI).

Strain 7320 also produces small cell aggregates (Figure 42 and 45) but unlike strains 7310 and 7317 the successive binary fissions follow a well-defined pattern resulting in the production of an aggregate of characteristic form. Following its symetric enlargement, the spore elongates and divides transversely (Figure 45). One of the resulting daughter cells then divides at right angles to the first plane of division, while the other cell simply increases in width but does not divide. This asynchronous division is responsible for the production of the dichotomously branched cell aggregates seen in mass cultures (Figure 42f) which are typical of this strain.

Strains 7440 and 7506 both form irregularly branched cell aggregates (Figures $46 \mathrm{a}$ and $46 \mathrm{~b}$ ). Strain 7440 readily produces spores in pure culture which develop by symmetric enlargement (Figure 47). Strain 7506 , on the other hand, has failed to reproduce by multiple fission since its isolation in pure culture, although spore formation was observed in unialgal cultures of this strain. Although its mode of spore enlargement has not been determined, its close general resemblance to strain 7440 suggests that it also belongs to Group $I$. 
Strains 7327,7322 and 7319 typically produce rather extensive, irregularly branched, filamentous cell aggregates (Figures 46c, 46d and 48-51). In these strains symmetrical spore enlargement is followed by binary fissions in many planes. Initially this results in the formation of a small, branched, filamentous aggregate which, following extensive growth, eventually forms a Iarge irregularly shaped central cluster of cells with peripheral radiating branches. As the aggregate enlarges, it is able to maintain its filamentous habit because the cells at the distal ends of the branches divide transversely in one plane. As the branches elongate, the subapical cells divide either in two planes to produce dichotomous branches or in many planes to produce the large, irregularly shaped clusters of cells from which the branches radiate.

Despite their broadly similar patterns of development, strains 7327 , 7322 and 7319 differ from one another with respect to the size of the vegetative cells, as shown in Table XVI. This difference is evident from the comparison of Figures $46 c, 46 \mathrm{~d}$ and 49). AlI these strains are facultative photoheterotrophs, as shown by their ability to grow in the light at the expense of sucrose in the presence of a concentration of DCMU which totally inhibits growth in a mineral medium. In strain 7327 , the addition of sucrose to a mineral medium does not modify development. However, the development of both strains 7319 and 7322 is significantly altered in a sucrose-containing medium. Under such conditions, strain 7322 develops as cubical packets of cells which are devoid of filamentous outgrowths and indistinguishable from a Myxosarcina (Figures $49 \mathrm{f}$ and 52). The addition of sucrose to the medium does not change the gross structure of the aggregates of strain 7319. However, the filamentous 
outgrowths, normally uniseriate at the tips, become multiseriate throughout their lengths (Figures $49 \mathrm{c}$ and $49 \mathrm{~d}$ ).

Strains of Group II $(7314,7321,7516)$

The spores of these strains are spherical and motile at the time of release, and cannot at this stage be distinguished from the spores of strains that belong to Group $I$. The difference is first apparent after the spores become immotile and start to enlarge. In the strains of Group II, enlargement occurs at first by elongation, producing a rodshaped cell. Very rapidly, however, the enlarging cell broadens at one pole to become club-shaped or pyriform (Figures 53-57). At this stage, the first division occurs, typically in a transverse plane. The planes of subsequent divisions vary; the resulting aggregate is of irregular shape, with a number of filamentous outgrowths. Some cells of the aggregate subsequently undergo multiple fission to produce motile spores. Typical developmental sequences for the strains of group II are shown in Figures 55-57.

In both groups of Pleurocapsa, as in Myxosarcina and Chroococcidiopsis, the number of binary fissions which precede the onset of multiple fission is not fixed: the more favorable the growth conditions, the earlier is the onset of multiple fission. Indeed, some strains which normally produce filamentous aggregates may under favorable growth conditions undergo multiple fission after only one or two binary fissions (Figure 42e). This behavior is shown by strain 7320 (Group I) and by strain 7314 (Group II).

Schematic developmental cycles for Groups I and II of Pleurocapsa are shown in Figures 59 and 60 respectively. 


\section{Strain 7324}

This strain, like the strains of Group I, is characterized by symmetrical spore enlargement (Figure 62). However, it is unusual in several respects. Binary fissions occur predominantly in two planes, forming relatively flat cell aggregates which may reach considerable size before undergoing multiple fission (Figure 61d). Nearly all the cells in the aggregate undergo multiple fission simultaneously, a property not possessed by any other strain which we have assigned to PZeurocapsa. In liquid cultures of strain 7324 that are several months old, some cells of the population become embedded in a mass of extracellular material which has the form of dichotomously branched threads with a diameter slightly less than that of the contained cells. The cells associated with this material are widely dispersed and are typically located at the apices of the threads (Figure 61e). Such structures, present only in old and presumably senescent cultures of this strain, resemble strikingly the classical illustrations of Hormathonema, a marine organism assigned to the Entophysalidaceae (order Chroococcales).

When growing under favorable conditions, the cells of strain 7324 are occasionally covered by an amorphous precipitate (Figure 61c) givIng them an appearance characteristic of, natural populations of Entophysalis (s. Golubic, personal communication).

\section{i1. The endolithic habitat}

Organisms which present the developmental features here described as representative of Pleurocapsa are traditionally assigned to two principal genera, Pleurocapsa and Hyella, distinguished solely by their growth habits in natural environments. The members of Pleurocapsa are 
epiphytes of epiliths, whereas the members of Hyelza are endoliths, which penetrate calcareous substrates. The eleven marine strains included in this study were all isolated from mollusk shells or rock chips, and could in principle have been either epiliths or endoliths. Except for strain 7516, observed to be endolithic in its natural habitat, the relations of these strains to their natural substrates were not determined at the time of their isolation. After pure cultures had been obtained, several strains $(7314,7319,7321,7322,7324)$ were inoculated into petri dishes containing chips of oyster shell partially immersed in medium $\mathbb{N}$ and incubated in the light for a total period of two years with periodic replacement of the culture medium. All grew profusely on the oyster shells; but none showed any penetration below the surface of this substrate. This experiment accordingly suggested that all the strains in question were epiliths and therefore assignable to the genus Pleurocapsa.

In the course of the more recent isolation of a member of this group (strain 7506) an attenpt was made to determine its endolithic or epiIithic nature by performing a similar experiment with a culture that was still unialgal and contained bacteria. Under these conditions, strain 7506 showed definite penetration of oyster shell chips after four months. Unfortunately, the behavior of this strain after purification could not be ascertained because in pure culture it has consistentIy failed to produce spores, and is thus unable to attach to solid substrates.

The fact that our first clear demonstration of endolithic growth in culture occurred with a strain that was not bacteria-free, suggested the possibllity that penetration of calcareous substrates by members of 
this group might be dejendent on the activity of associated acidproducing bacteria. In order to test this hypothesis, the bacterial population associated with the unialgal culture of strain 7506 was screened by plating on a variety of glucose-containing media both defined and complex, all furnished with a pH indicator (phenol red). The strongest acid production was observed on plates of nutrient broth supplemented with $0.5 \%$ glucose, and a varlety of acid-producing bacterial colonies which developed on plates of this medium were purified. One of these strains, selected on the basis of its marked acid-producing ability when grown in glucose-nutrient broth, was used in the following experiment.

Pleurocapsa strains 7319,7440 and 7516 (the latter known to be endolithic under natural growth conditions), were grown in the light in two series of flasks of medium MN containing oyster shell chips. One series was inoculated with pure cultures of the cyanobacteria, the other series was inoculated in addition with the acid-producing bacterium. At the time of writing, this experiment has been underway for two months. Strains 7440 and 7516 have both penetrated the calcareous substrate in the culture which contain the acid-producing bacterium, but show no sign of penetration in the control cultures lacking the bacterium (Figure 63). However, strain 7319 has penetrated the substrate both in the mixed and in the pure culture. The latter result is in contradiction with the observations previously made on this strain. Thus, while this experiment appears to indicate that associated chemoheterotrophic bacteria can play a role in facilitating the penetration of calcareous substrates by members of the Pleurocapsa group, penetration by at least one strain in pure culture is apparently also possible. Further work on 
this problem is required before any solld conclusions about the biological basis of the endolithic habit can be drawn. 


\section{Figure 42}

Photomicrographs of mass cultures of Pleurocapsa grown on agar plates of medium MN. a. and b. Individual cells and compact cell aggregates of strain 7310 . X1000. c. and d. Small cell aggregates of strain 7317. X 1000. e. Strain 7320: the field includes cells (arrows) which have undergone multiple fission at the one or two celled stage. X1000. f. Typical small dichotomously branched cell aggregates of strain 7320. $\times 1000$. 


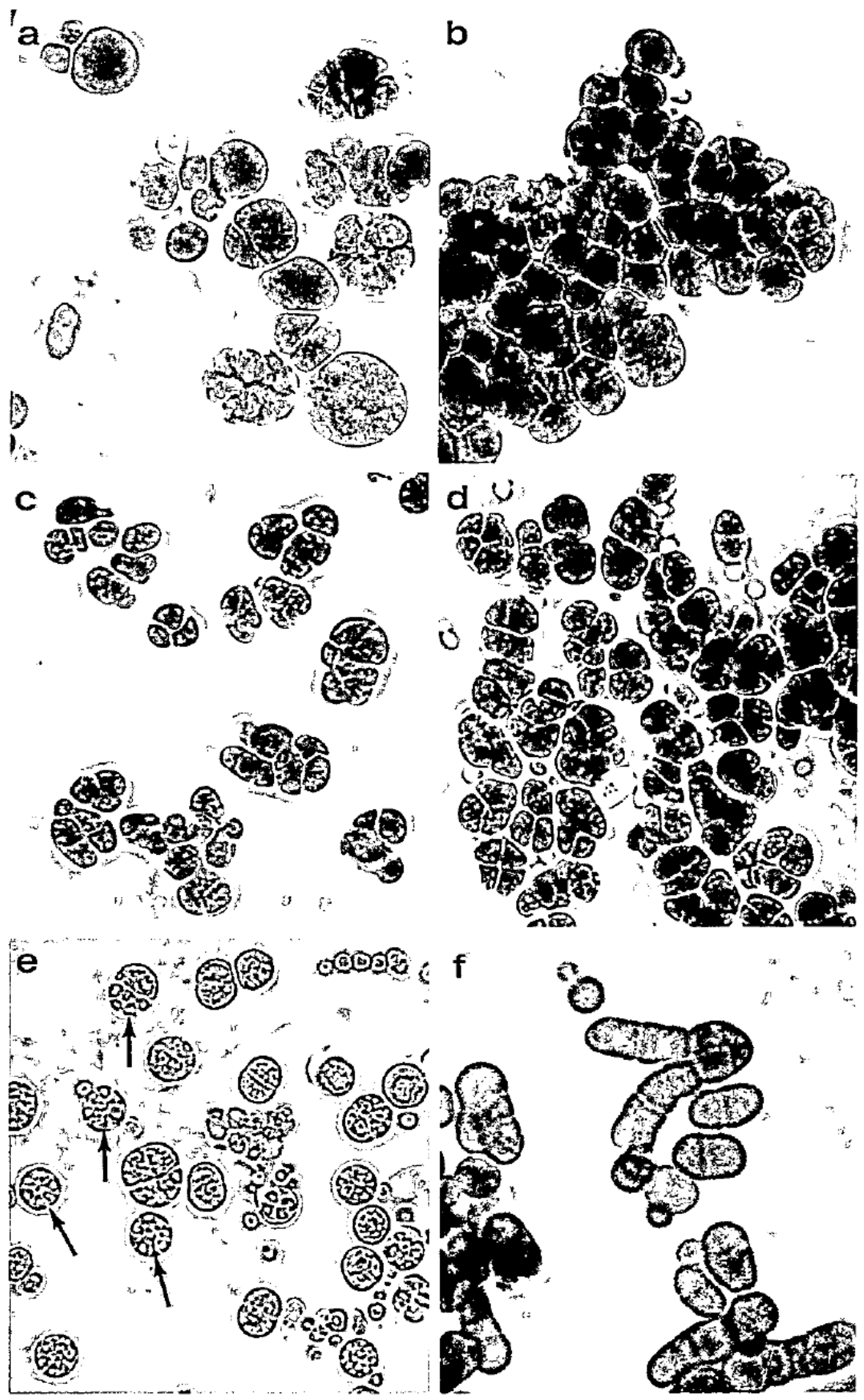




\section{Figure 43}

Successive photomicrographs of the development of a single spore of Pleurocapsa strain 7310 on medium MN in a Cooper dish culture over a total period of 350 hours. The spherical spore enlarges symmetrically and then begins to divide by binary fission in irregular planes to form a compact mass of cells. Eventually some of the cells in the aggregate undergo multiple fission and release spores. X 500 . 


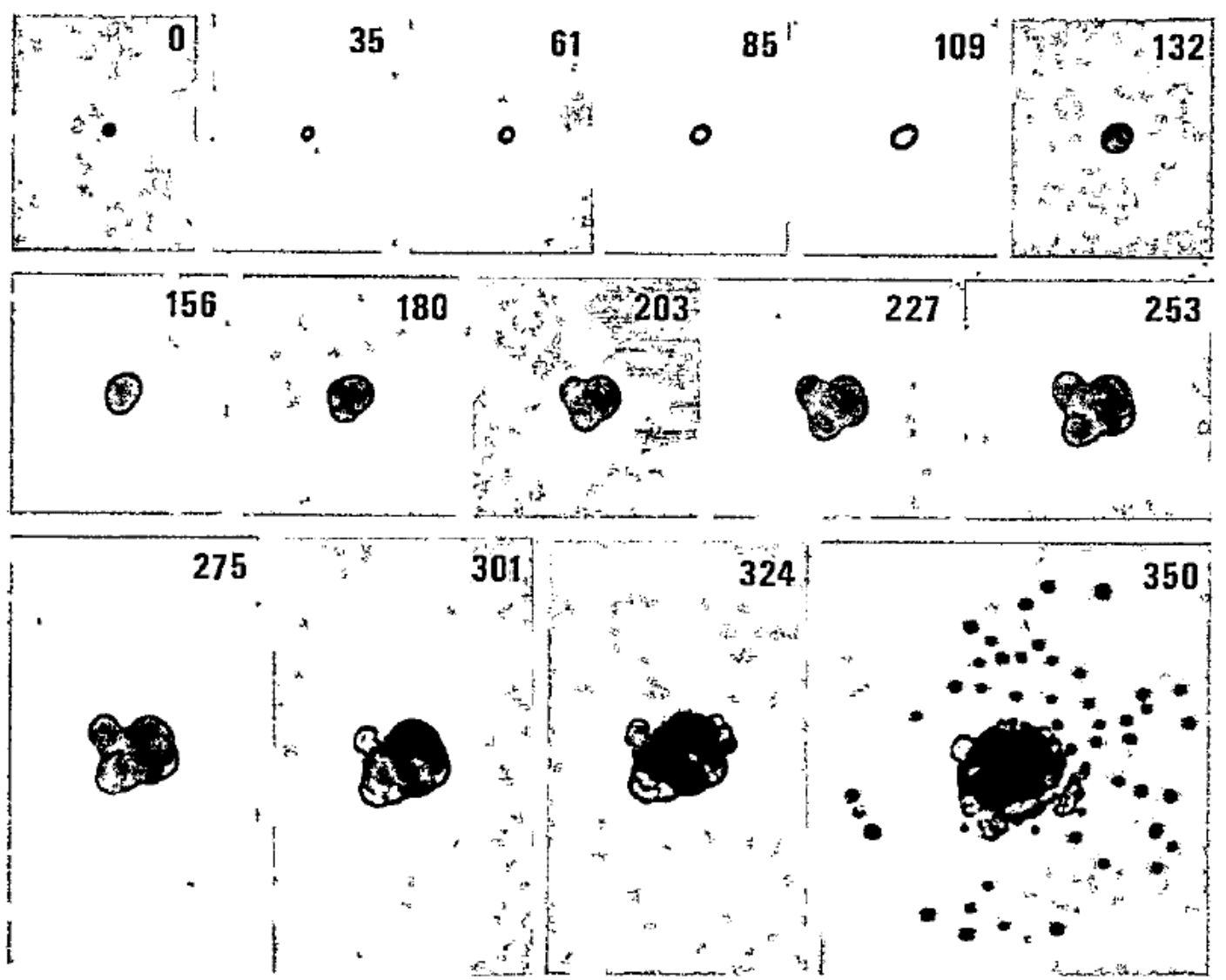




\title{
Figure 44
}

\begin{abstract}
Successive photomicrographs of the development of a single spore of Pleurocapsa strain 7317 on medium MN in a Cooper dish culture over a total period of 1104 hours. The developmental pattern of this strainis similar to that of strain 7310 (see Figure 43). X 500.
\end{abstract}




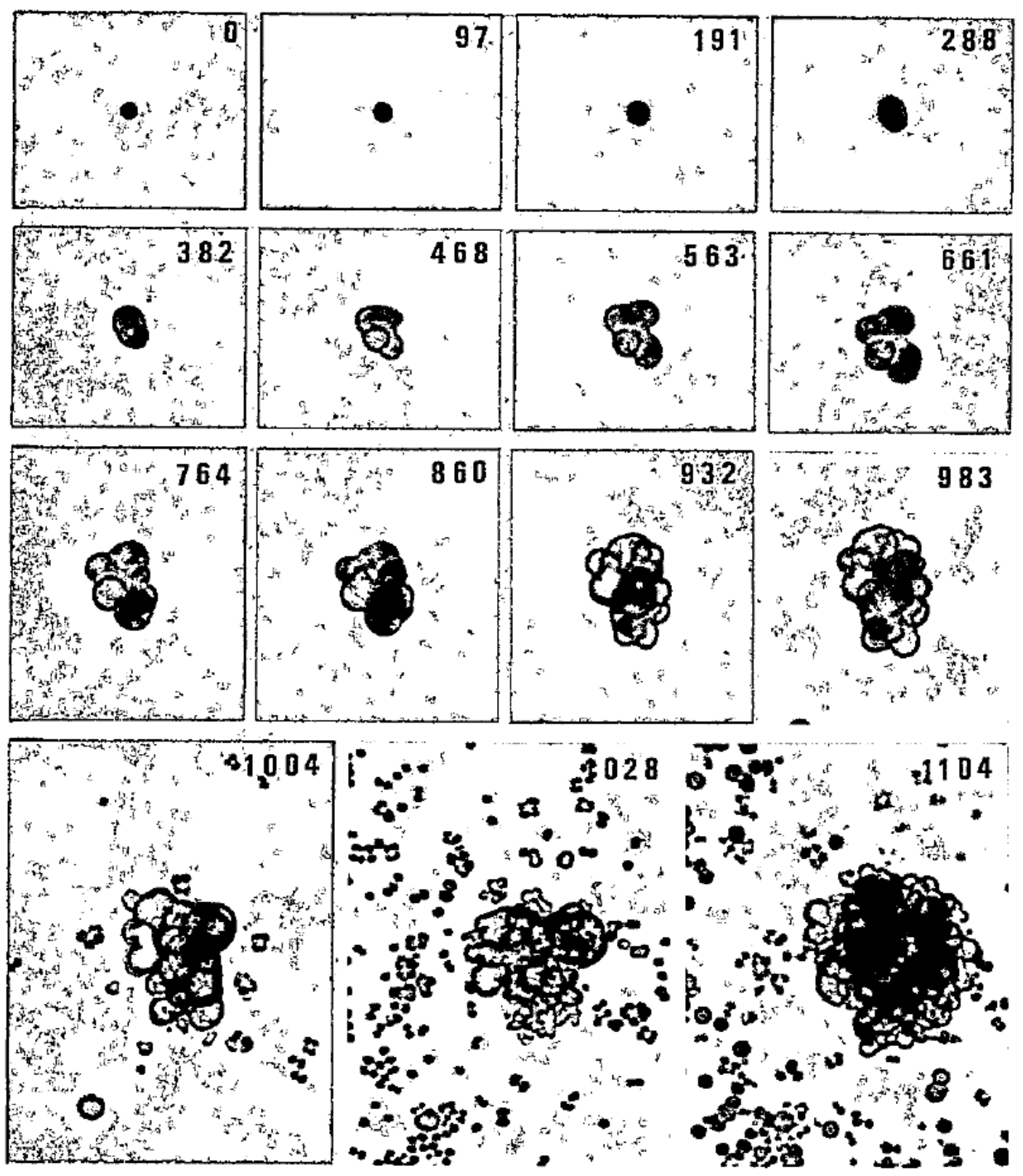




\section{Figure 45}

Development of PZeurocapsa strain 7320 on medium MN in Cooper dish culture over a total period of 290 hours. The spherical spore enlarges symmetrically and then divides transversely (hour 73). One of the two daughter cells produced then characteristically divides at a right angle to the plane of the first division. This second division is responsible for the dichotomously branched filaments formed by this strain (see Figure 42f). X 500 . 


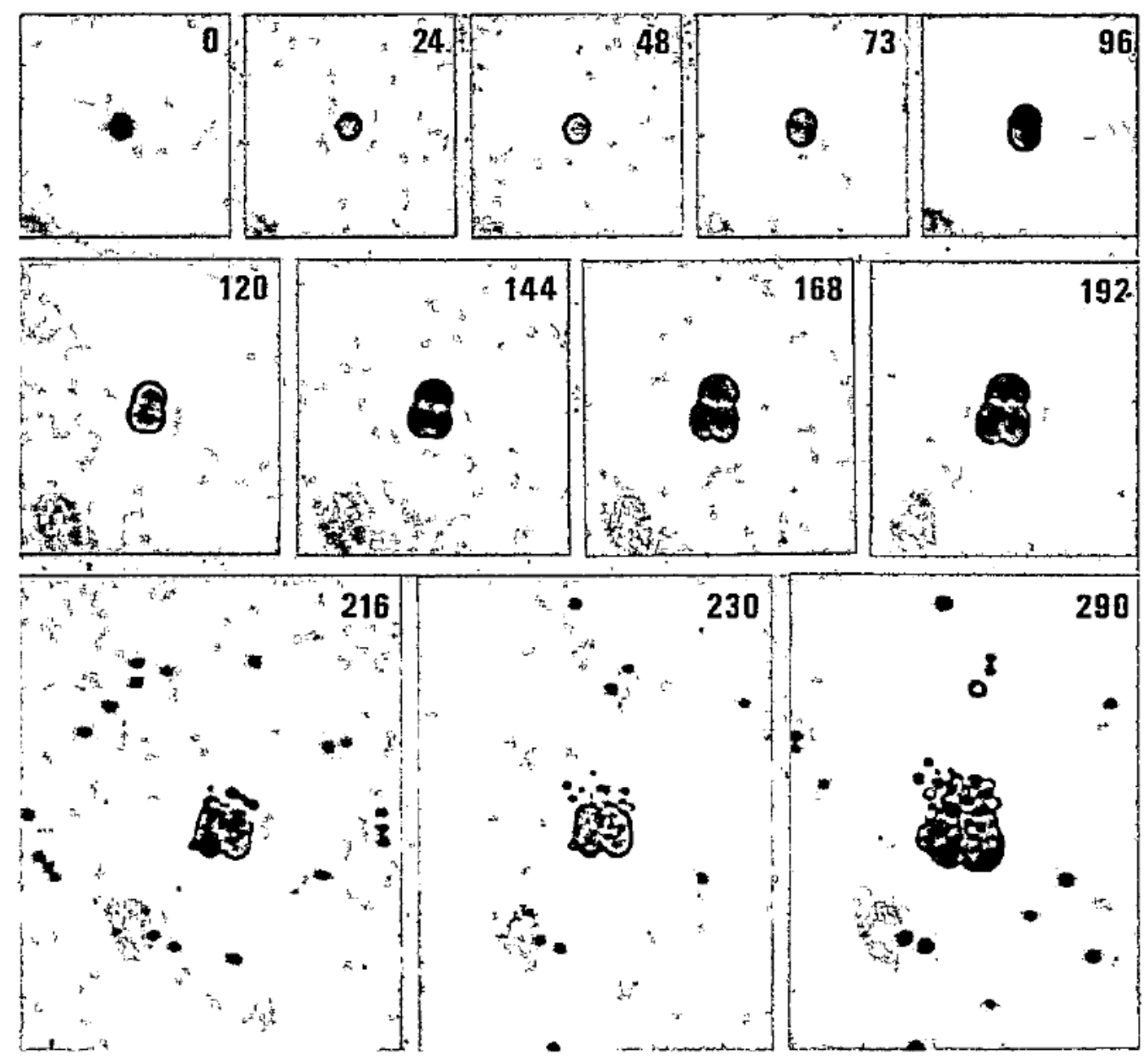


Figure 46

a. and b. Photomicrographs of mass cultures of two Pleurocapsa strains grown on plates of medium MN. a. Filamentous cell aggregates of strain 7440 , some of the cells of which have undergone multiple fission. X 1000 . b. Typical filamentous cell aggregates of strain 7506 . $\mathrm{X} 1000$. The boundary of the $\mathrm{F}$ layer is evident in both Figures $46 a$ and $46 b$ (arrows). .c. and d. Characteristic cell aggregates of the thermophilic strain 7327 grown on medium $B G-11$ at $37^{\circ} \mathrm{C}$. Some of the cells in the aggregate have undergone multiple fission (arrows). $\mathrm{x} 1000$. 


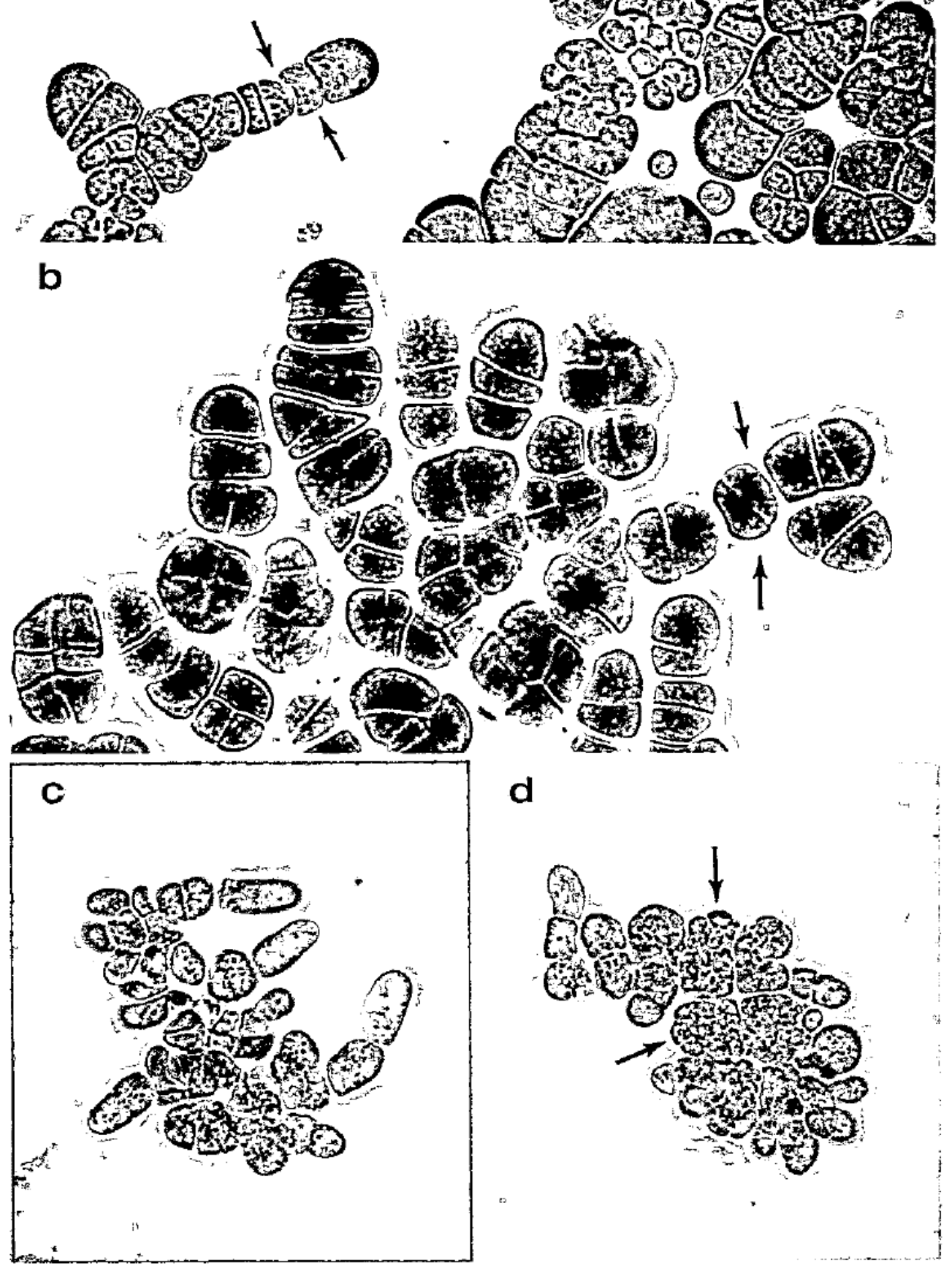

a

$00 \mathrm{x}$

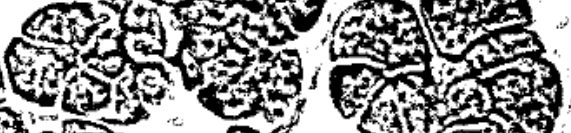

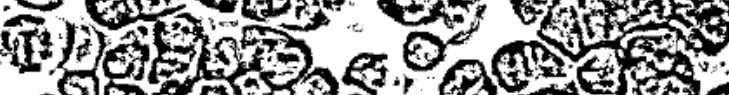
64 a 30 , .

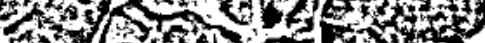

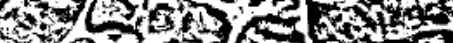

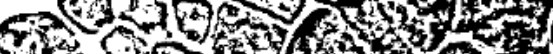

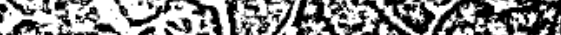

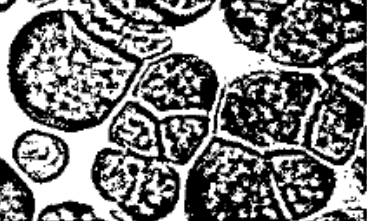


Figure 47

Successive photomicrographs of a single spore of Pleurocapsa strain 7440 grown on medium MN in a Cooper dish preparation. Following symmetric spore enlargement the cell began to divide by repeated binary fissions, however, the cells of the aggregate failed to undergo multiple fisston during the course of observation which. lasted for a total of 423 hours. $\times 500$. 


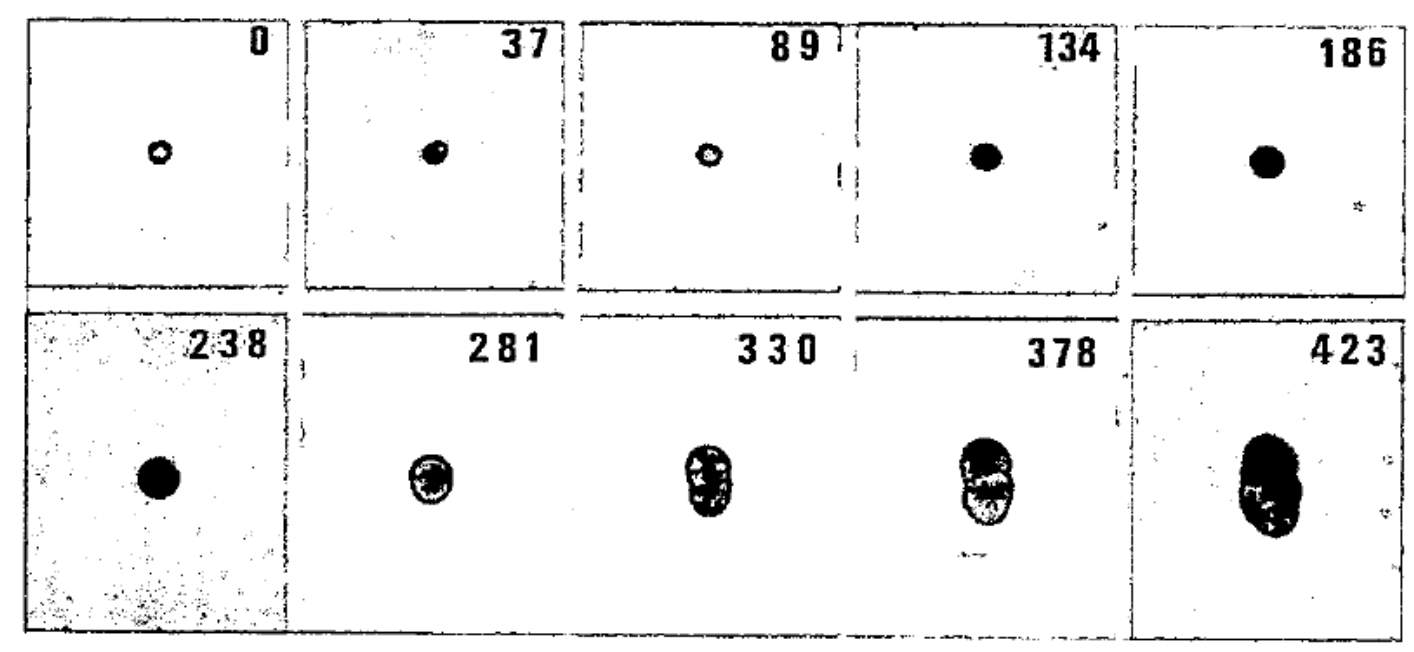


Successive photomicrographs of the development of PZeurocapsa strain 7327 on medium BG-11 incubated at $37^{\circ} \mathrm{C}$ in a Cooper dish culture over a total period of 252 hours. The spherical spore enlarges symmetrically and then begins to divide in many planes to produce a filamentous cell aggregate. Some of the cells in the aggregate subsequently undergo multiple fission and release spores. X 500 . 


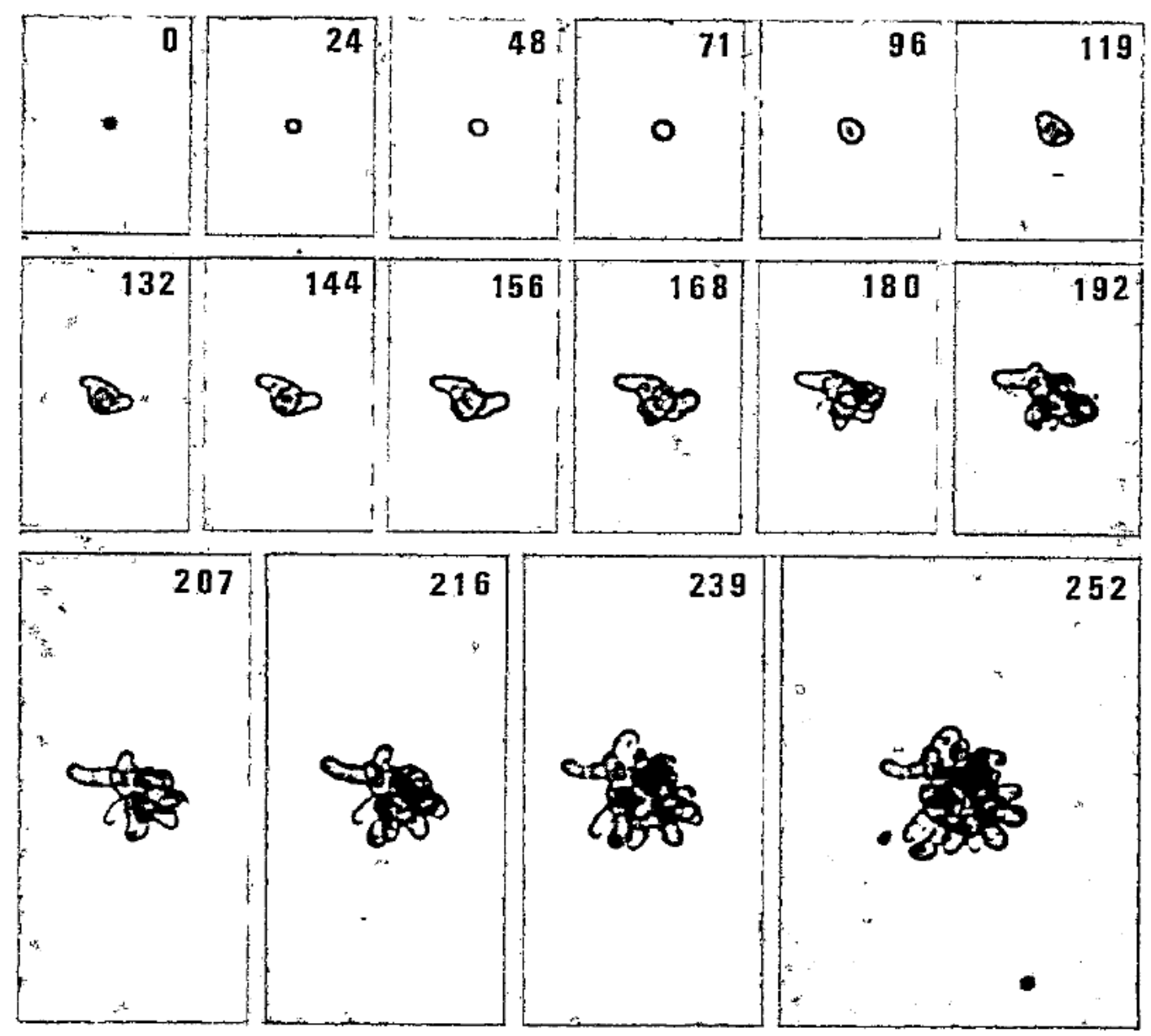


Figure 49

The influence of the medium on the development of two strains of Pleurocapsa. a. and b. Uniseriate branched filamentous aggregates of strain 7319 grown on mineral medium MN in the 1ight. a. X500; b. X1000. c. and d. Multiseriate filamentous aggregates of strain 7319 grown on medium $M N$ supplemented with $0.3 \%$ sucrose in the light. c. X 500; d. X1000. e. Filamentous aggregates of strain 7322. grown on mineral medium $M N$ in the 1ight. The field includes many spores. X1000. f. Cubical cell aggregates characteristic of strain 7322 grown on medium MN supplemented with $0.3 \%$ sucrose in the 1ight. $\times 1000$. 

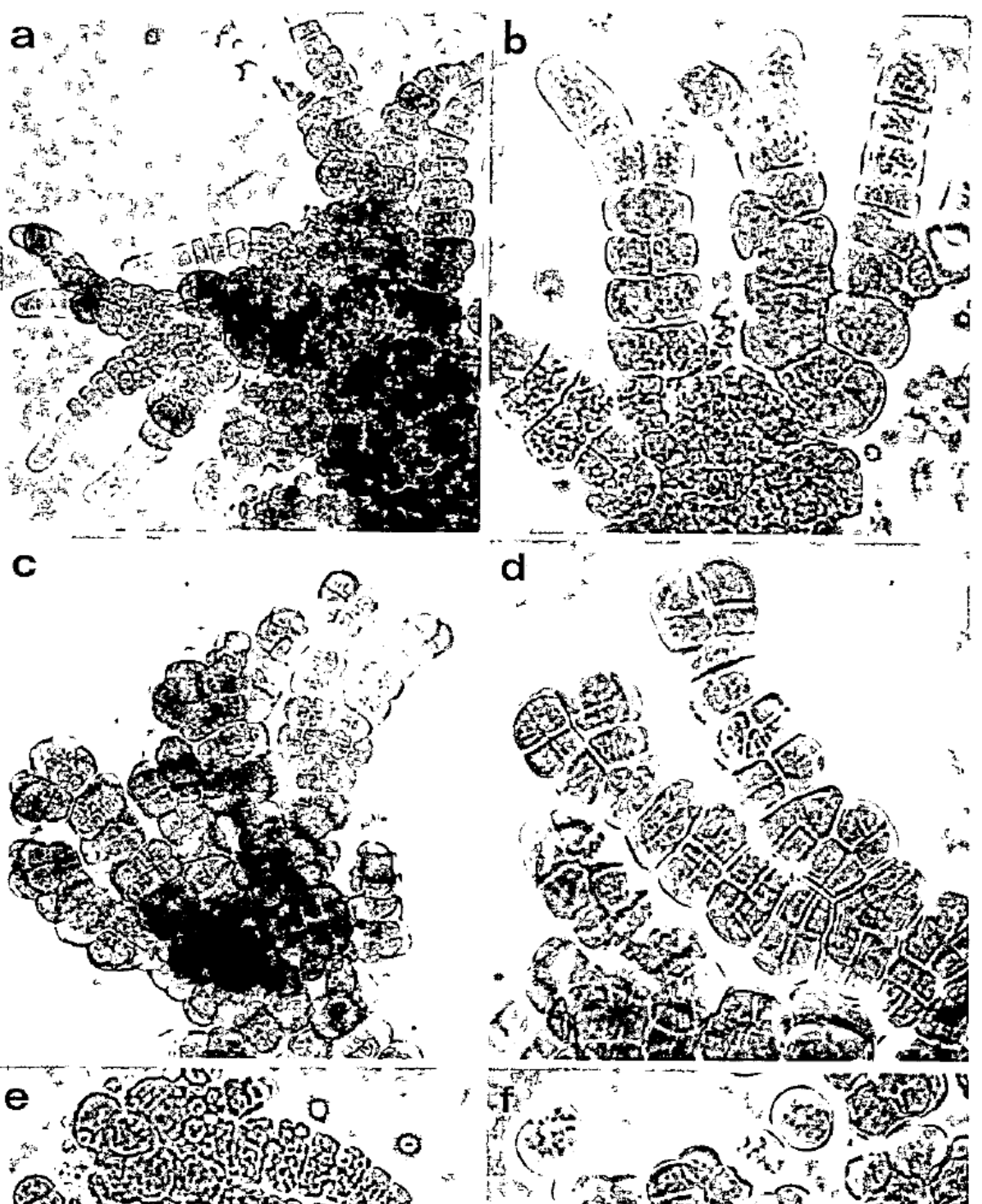

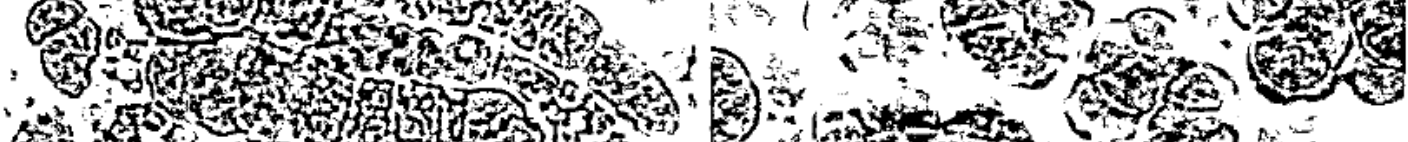
(4)

(3)

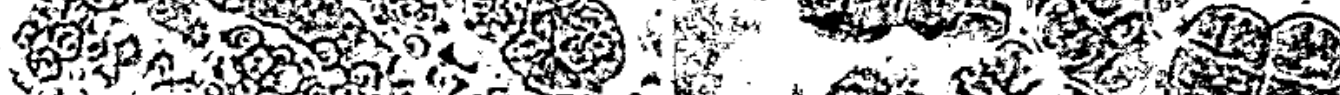

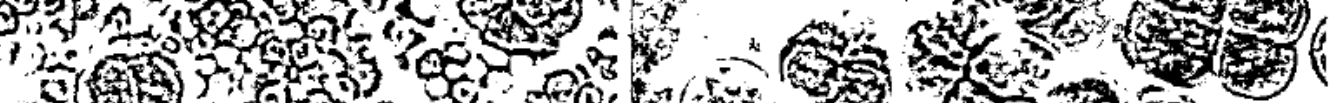
(1) 350 .

$\therefore 150$ 次壁 र 
Figure 50

Successive photomicrographs of the development of Pleurocapsa strain 7319 grown on medium MN in a Cooper dish culture over a total period of 620 hours. The spherical spore enlarges symmetrically and then begins to divide in many planes to produce a filamentous cell aggregate. Eventually some of the cells in the aggregate undergo multiple fission and release spores. X 500 . 
168

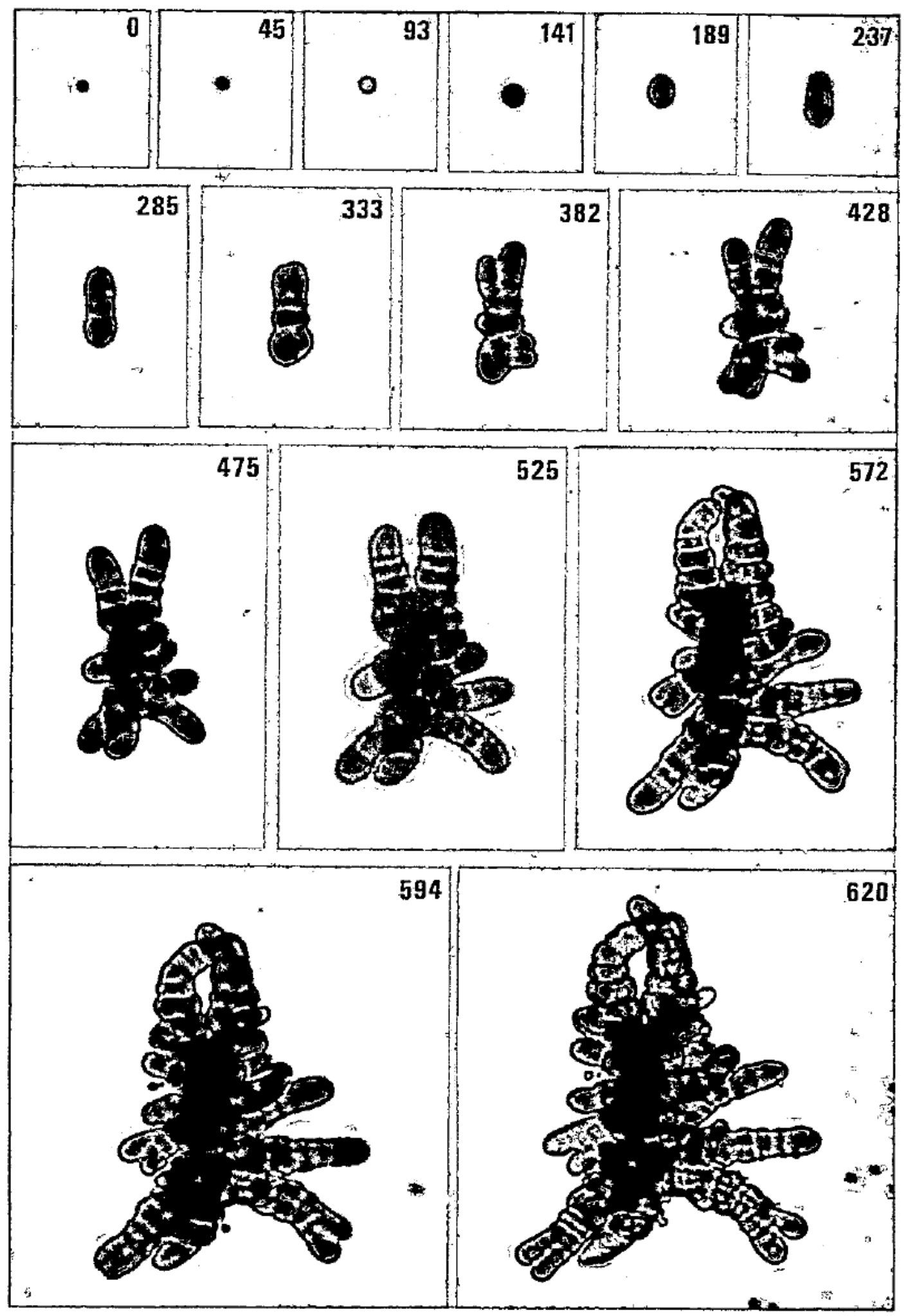


Figure 51

Successive photomicrographs of the development of Pieurocapsa strain 7322 grown on medium MN In a Cooper dish culture over a total period of 527 hours. The developmental pattern is similar to that described for strain 7319 in Figure 50. X 500 . 


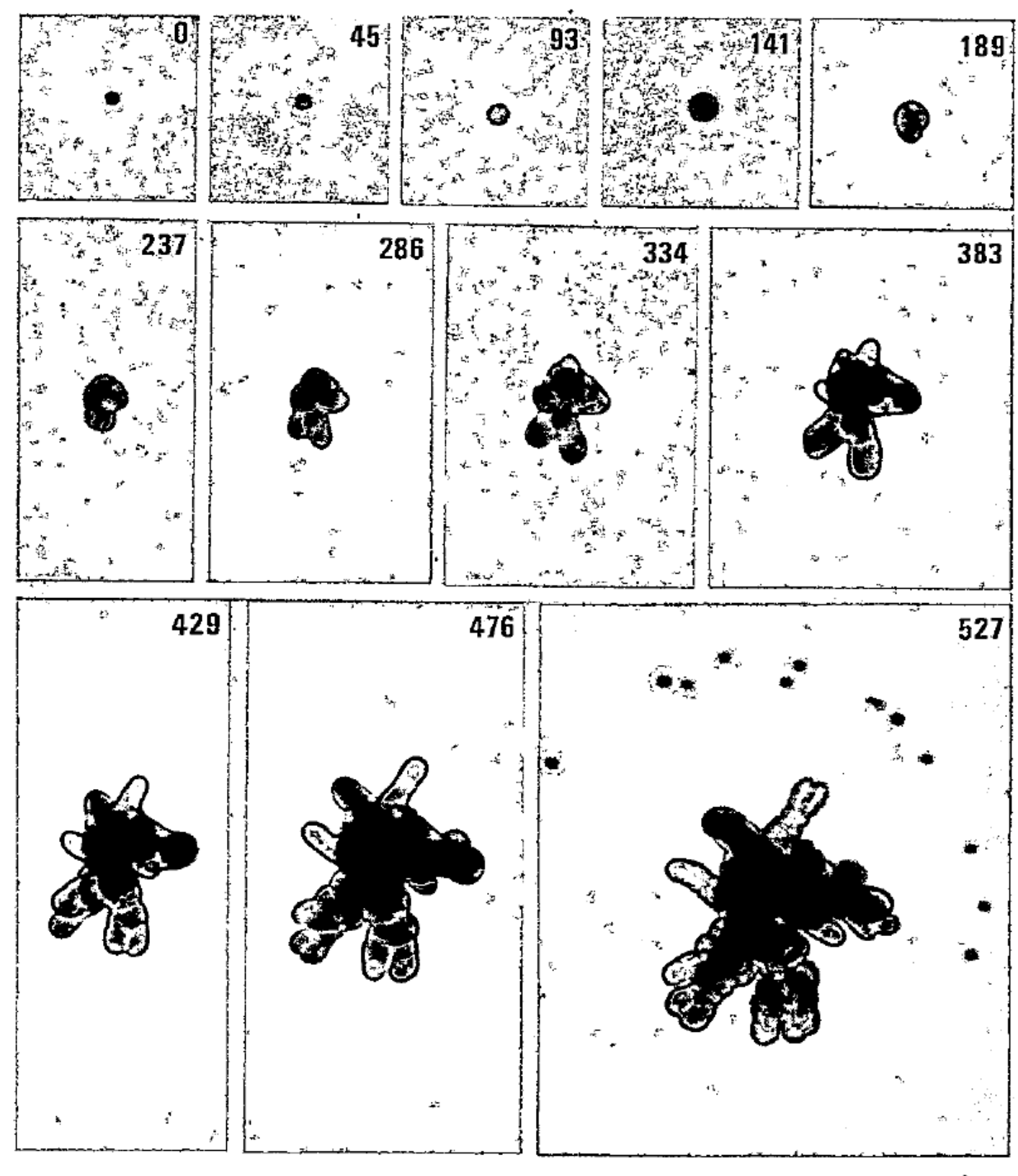




\section{Figure 52}

Successive photomicrographs of the development of strain 7322 grown in the light on medium MN supplemented with

- $0.3 \%$ sucrose in a Cooper dish culture over a total period of 278 hours. Under these conditions of growth, this strain forms.cubical cell aggregates which are indistinguishable from those produced by strains of Myxosarcina (see Figure 32). X 500 . 


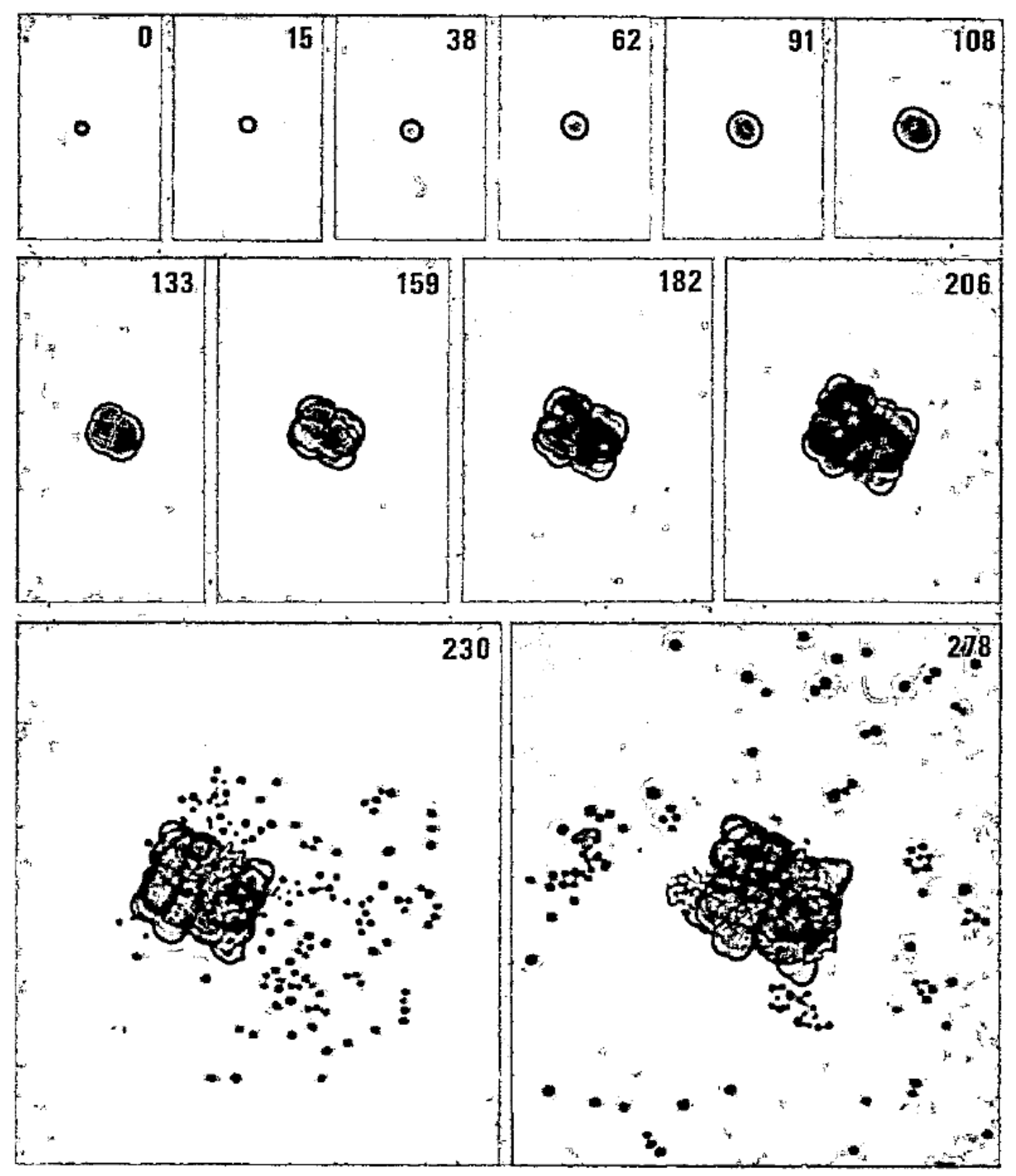




\section{Figure 53}

The outgrowth of spores of Pleurocapsa strains 7314 and 7321. An inoculation rich in spores was spread on a plate of medium MN, from which wet mounts were prepared after incubation for various periods in the light. a., b. and c. Successive stages in the development of spores of strain 7314. d., e. and f. Successive stages in the development of spores of strain $7321 . \times 1000$. 


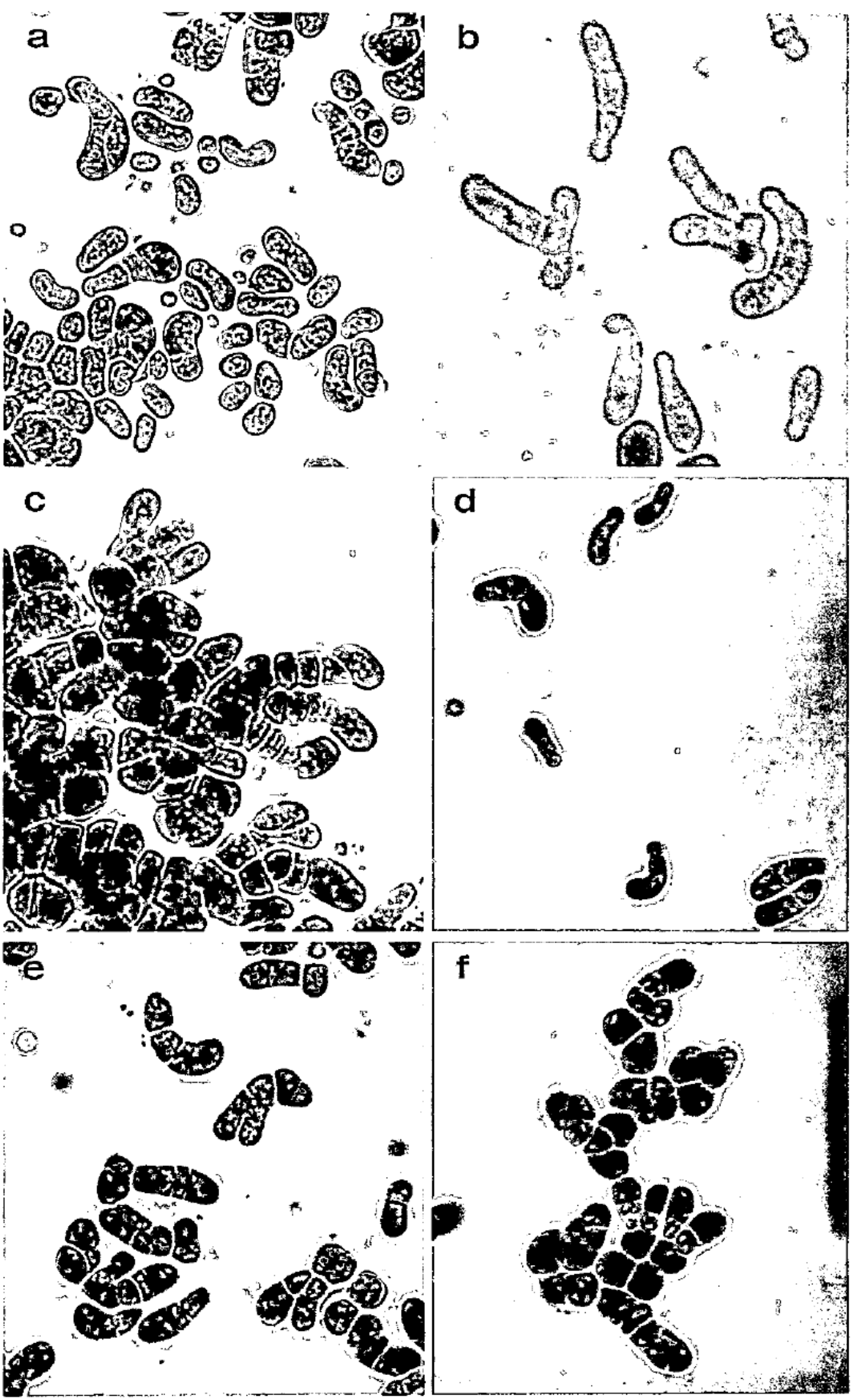




\section{Figure 54}

The outgrowth of spores of Pleurocapsa strain 7516, from a plate culture prepared as described in the legend of Figure 53. Some cells of the aggregates in Figure 54d have undergone multiple fission and produced spores (arrows). X1000. 


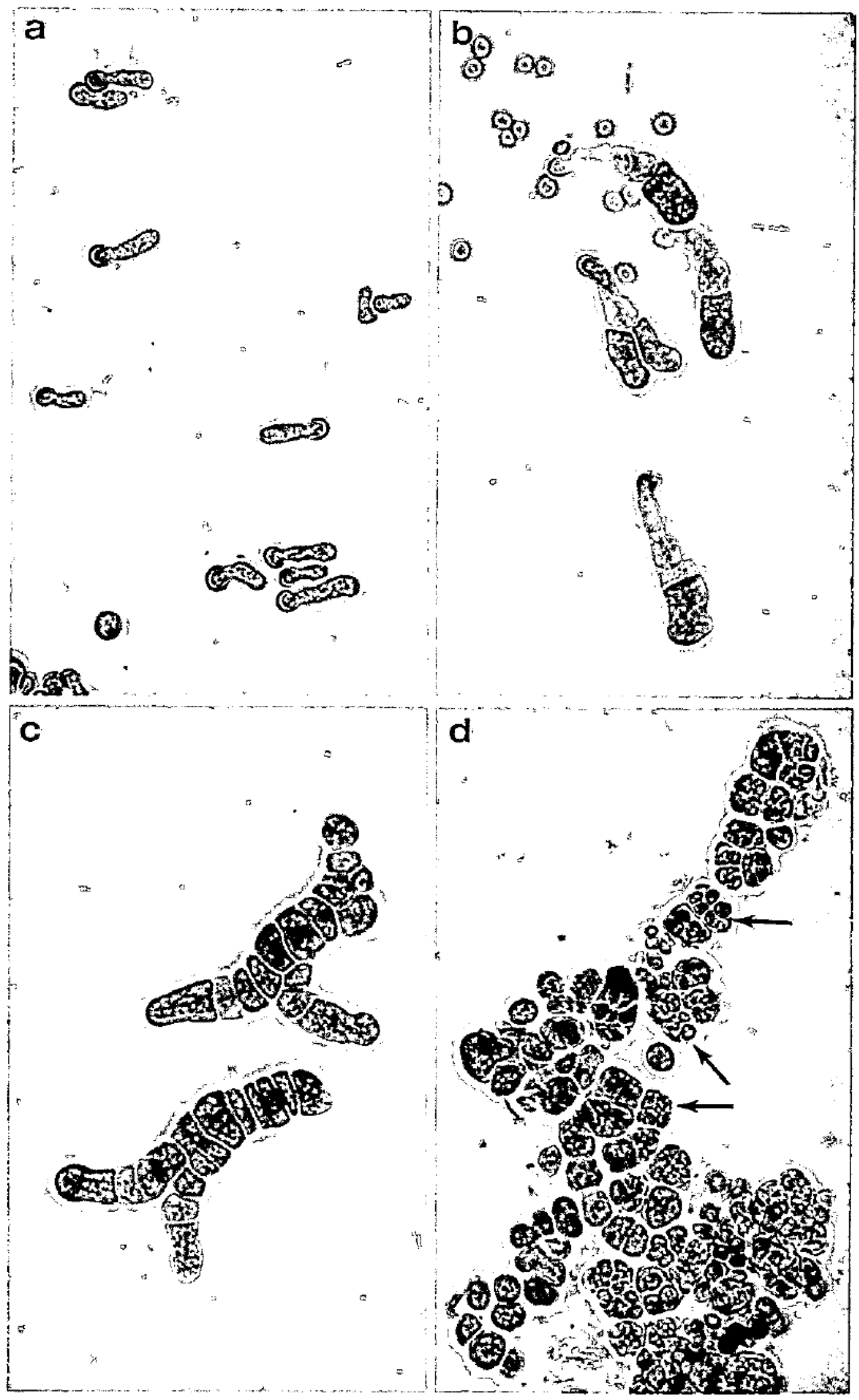


Figure 55

Successive photomicrographs of the development of Pleurocapsa strain 7314 grown on medium MN in a Cooper dish culture over a total period of 289 hours. The Initially spherical spore enlarges asymnetrically and then begins to divide in many planes producing a filamentous cell aggregate. Some of the cells in the aggregate have undergone multiple fission and released spores (starting at hour 198). In the photomicrographs taken at 246,270 and 289 hours, early stages in the development of two spores (arrows) are shown. X 500 . 


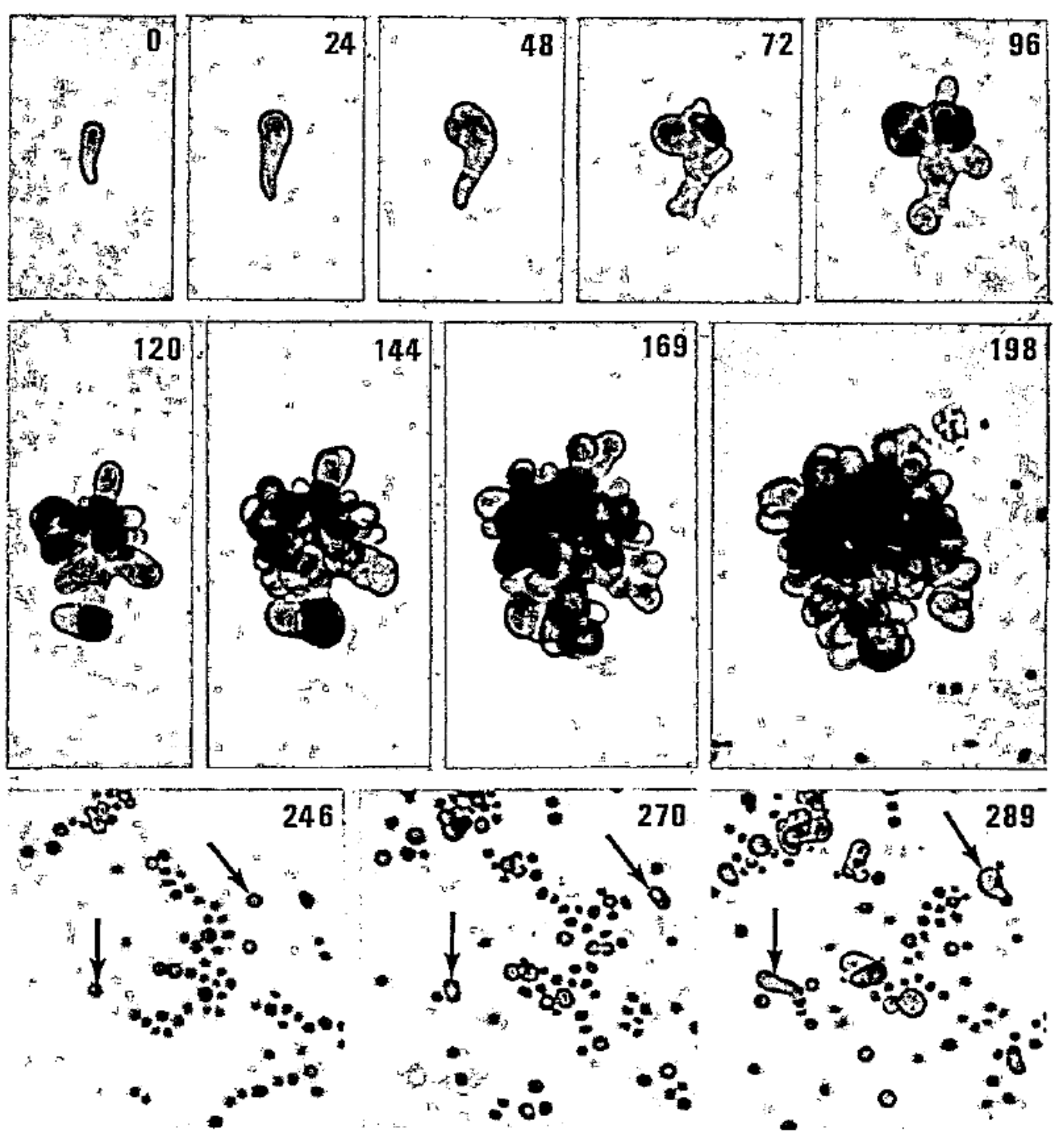


Figure 56

Successive photomicrographs of the development of Pleurocapsa strain 7321 grown on medium MN supplemented with $0.3 \%$ sucrose in a Cooper dish culture over a total period of 206 hours. The developmental pattern of this strain is similar . to that described for strain 7314 in Figure 55. X 500 . 


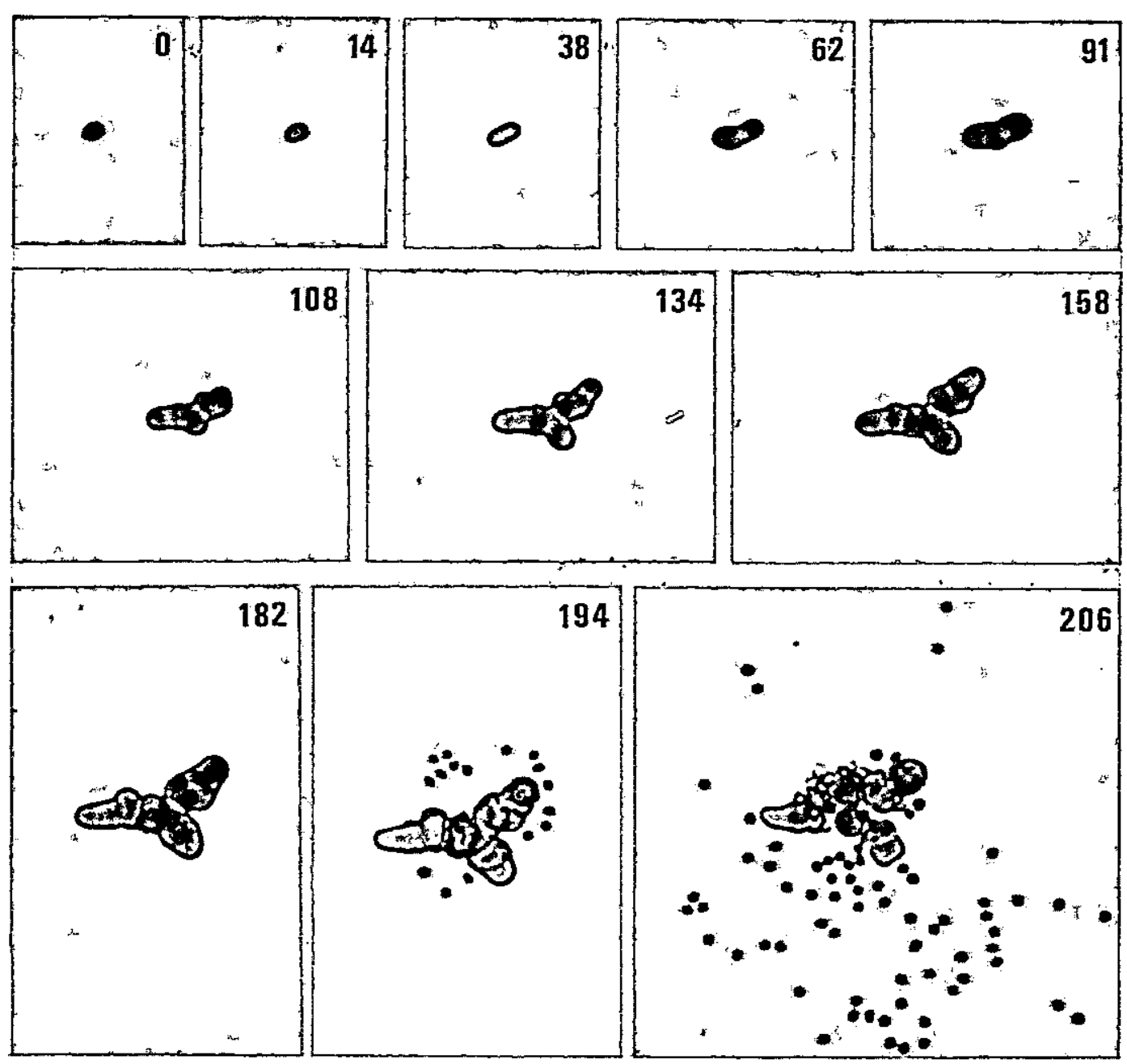




\section{Figure 57}

Successive photomicrographs of the development of Pleurocapsa strain 7516 grown on medium MN in a Cooper dish culture over a total period of 689 hours. The developmental pattern of this strain is similar to that described for strains 7314 (Figure 55) and 7321 (Figure 56). X 500. 


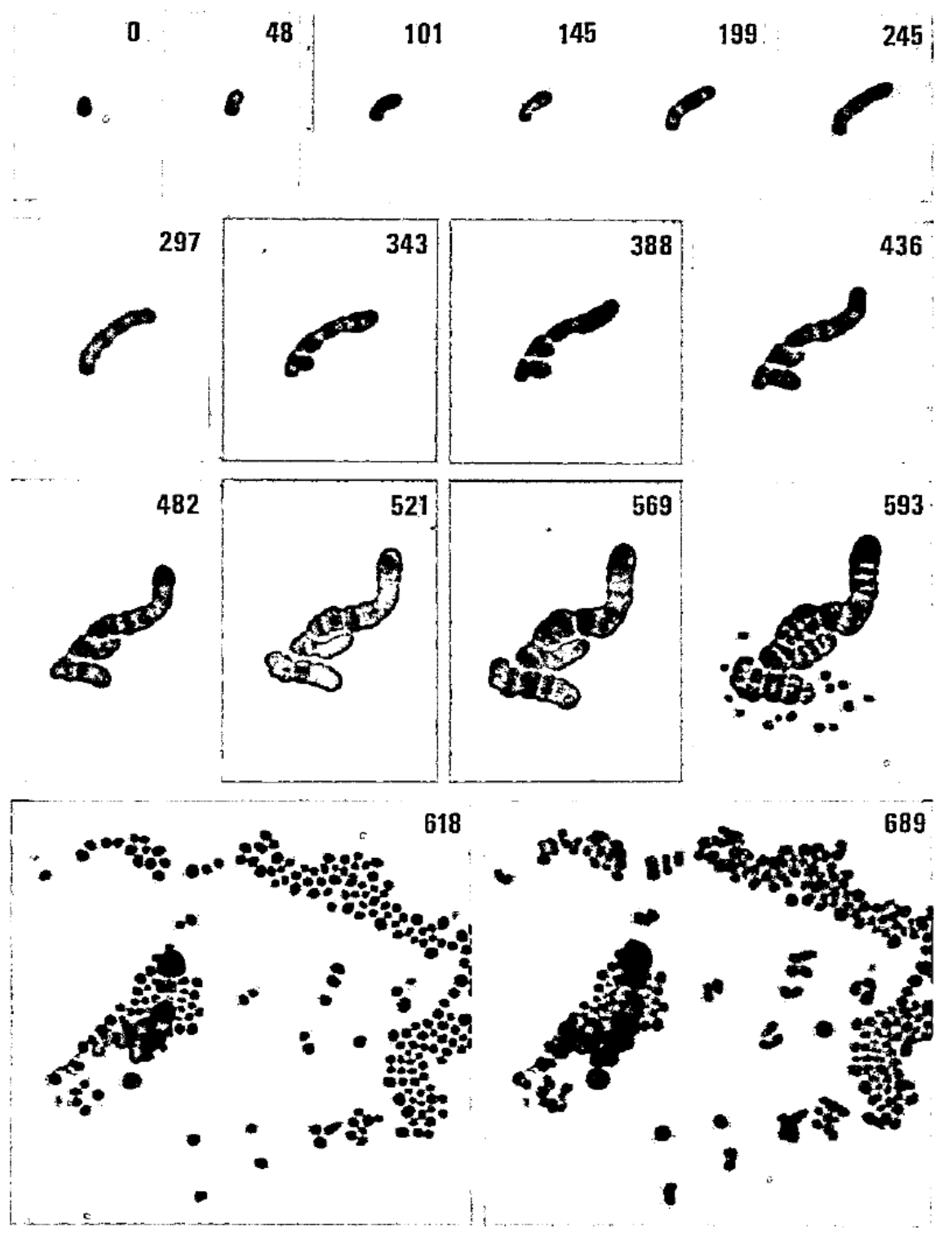




\section{Figure 58}

An electron micrograph of a thin section of Pleurocapsa strain 7314 grown in an agar overlay on medium MN. Each cell is enclosed by individual PG, LP and F wall layers. The group of cells is also enclosed by additional $F$ layers synthesized during previous generations. As cell mass increases the outermost layers of $\mathrm{F}$ wall material become either stretched (as indicated by their loss of electron density) (arrows) or torn (arrows) to accommodate the increased volume. $\times 14,000$. 


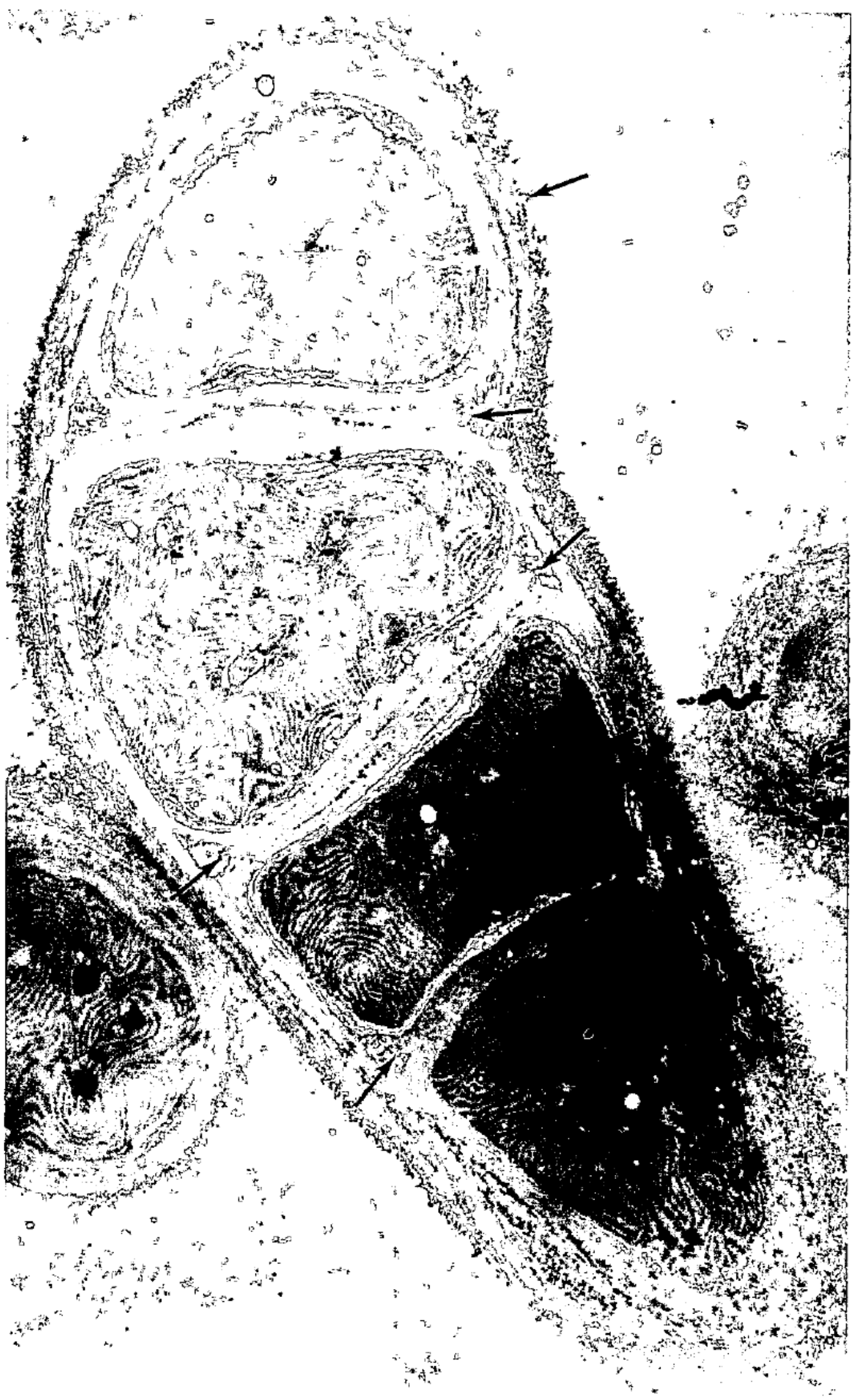


Figure 59

Schematic Developmental Cycle of Pleurocapsa Group-I

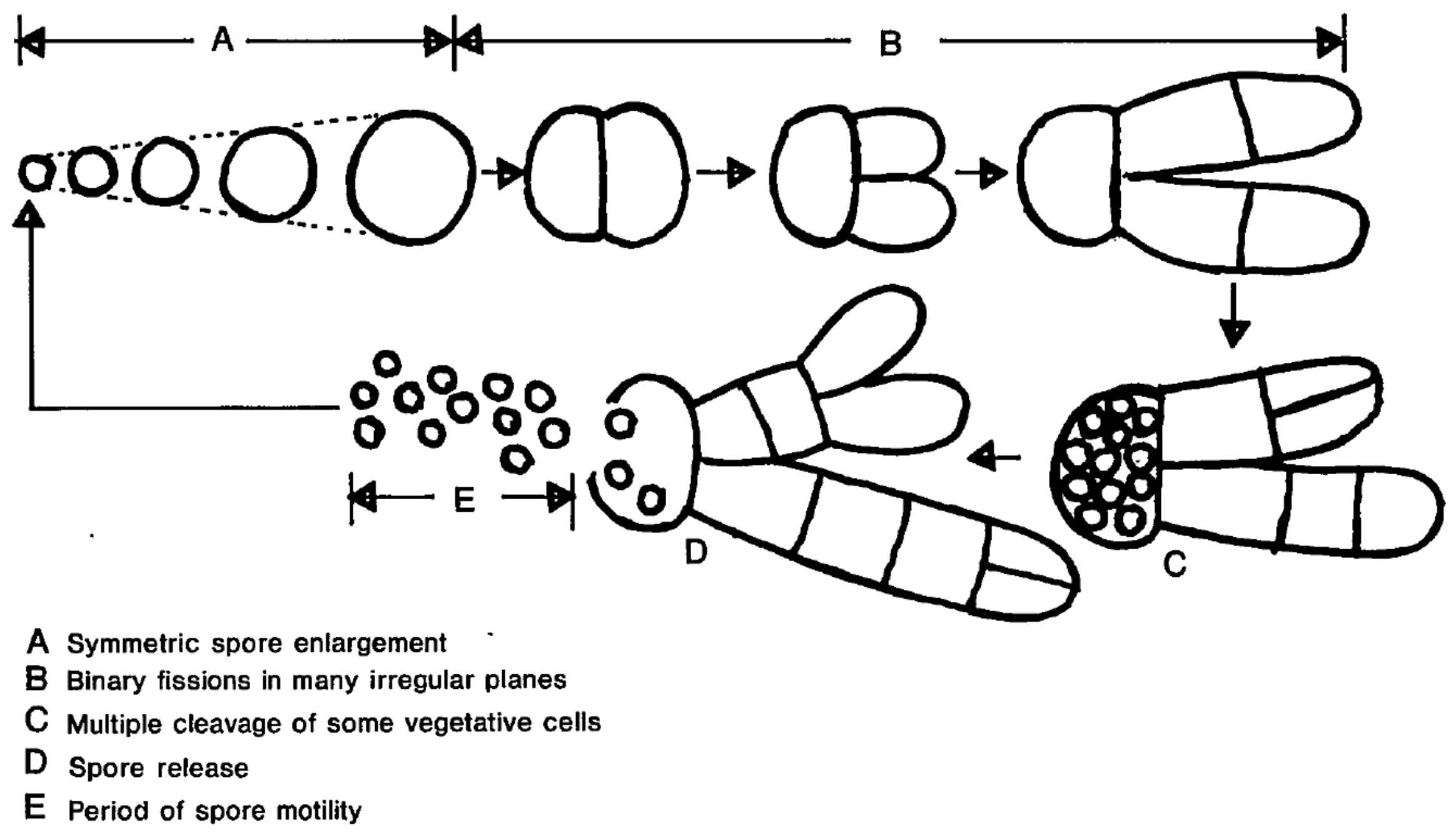


Figure 60

Schematic Developmental Cycle of Pleurocapsa Group-II

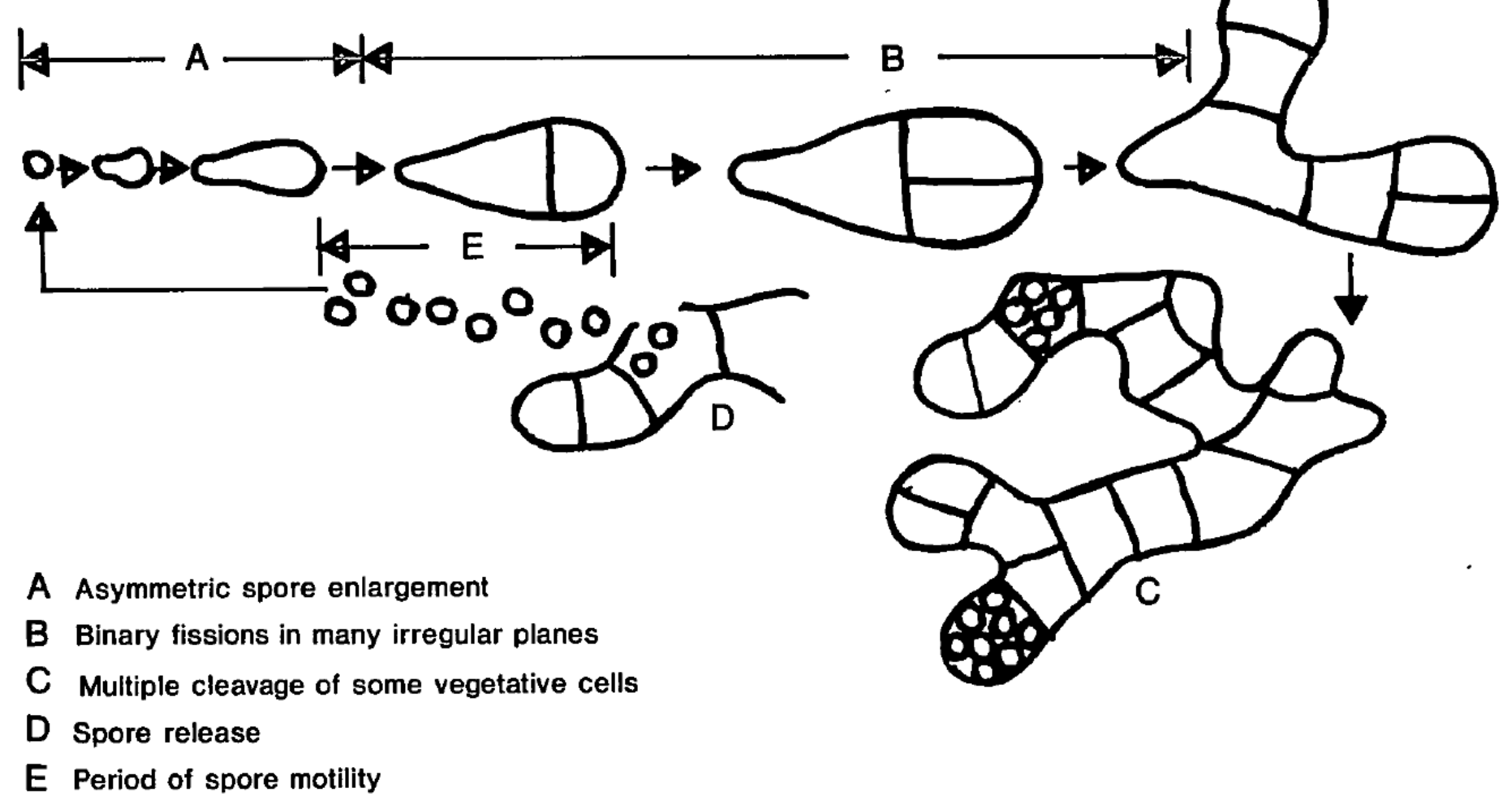




\section{Figure 61}

Photomicrographs of mass cultures of Pleurocapsa

strain 7324 grown in medium MN. a. An early stage of vegetative growth on an agar plate. X1000. b. A later stage of development on an agar plate: some cell aggregates are undergoing multiple fission "(arrows). $\mathrm{X} 1000$. c. Cell aggregates from a liquid culture; the groups of cells are covered with an amorphous precipitate. X1000. d. A large aggregate on an agar plate. X 500 . e. A preparation from an old (2 months) liquid culture, showing threads of extracellular material in which isolated clumps of cells are embedded. Phase contrast $\mathrm{X} 500$. 


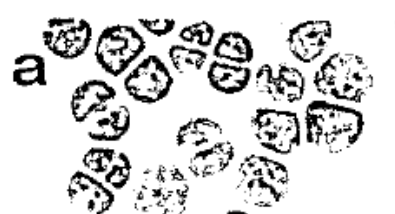
田数

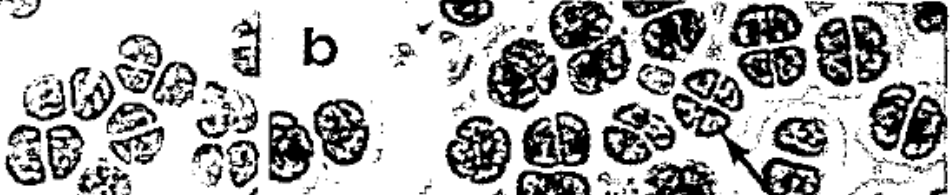
4

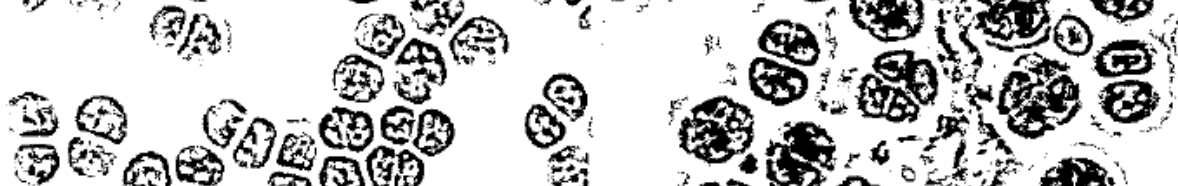
9.9.

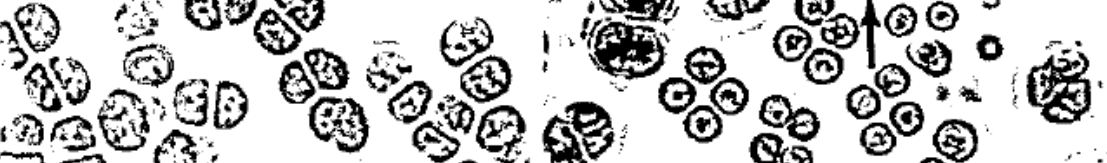
गुํㅐ

$c$ 3 . A 9 : 约然 63 o $d$ 10. (1) (1) 2)

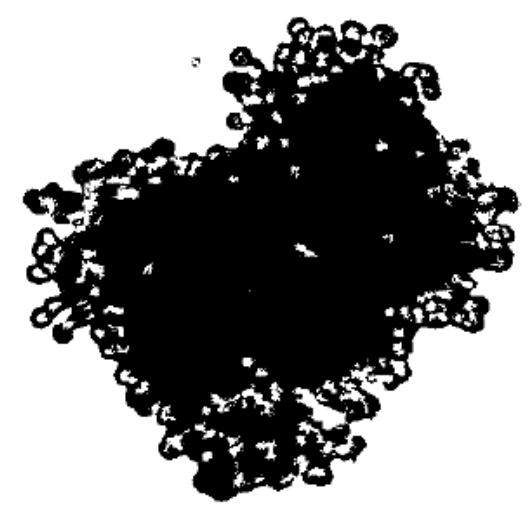
or d

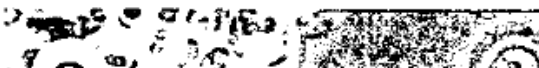

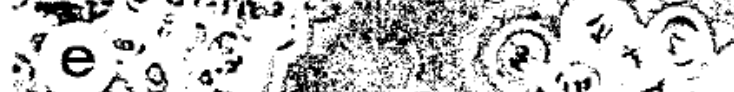

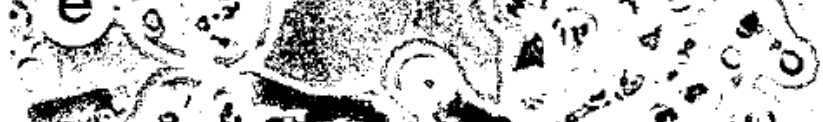

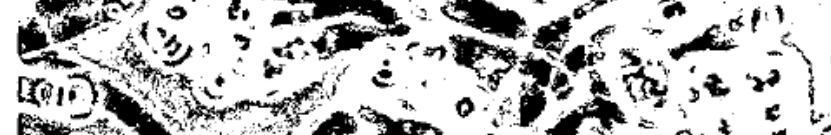

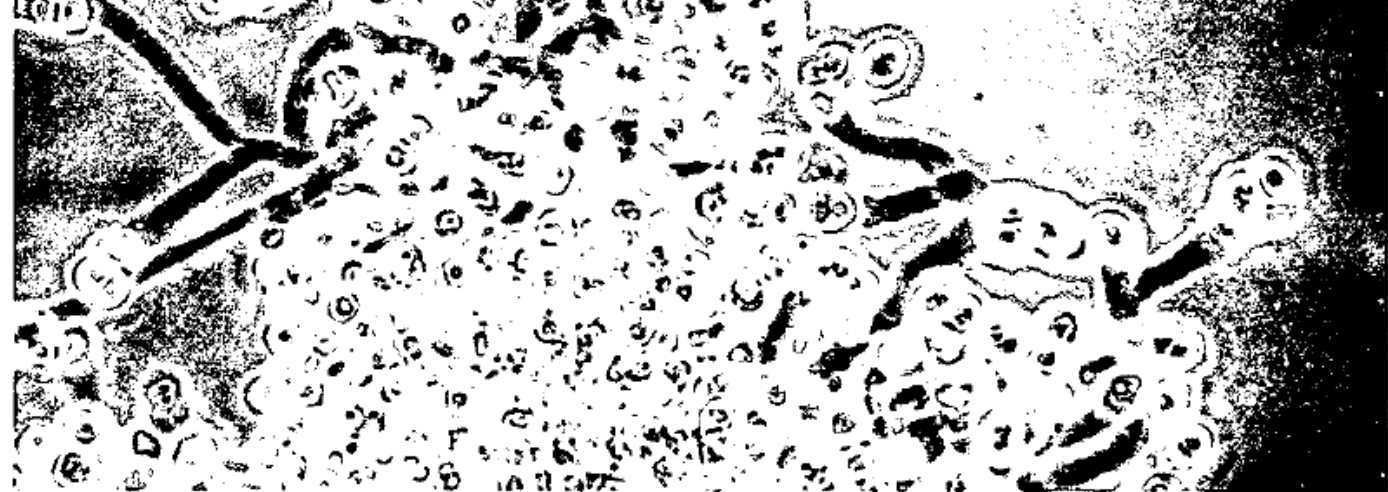




\section{Figure 62}

Successive photomicrographs of the development of Pleurocapsa strain 7324 grown on medium $\mathbb{M N}$ in a Cooper dish culture over a total period of 160 hours. The spore enlarges symmetrically and then divides by binary fissions predominantly in two planes to form a flat irregular cell aggregate. AlI the cells in the aggregate underwent multiple fission simultaneously. X 500 . 


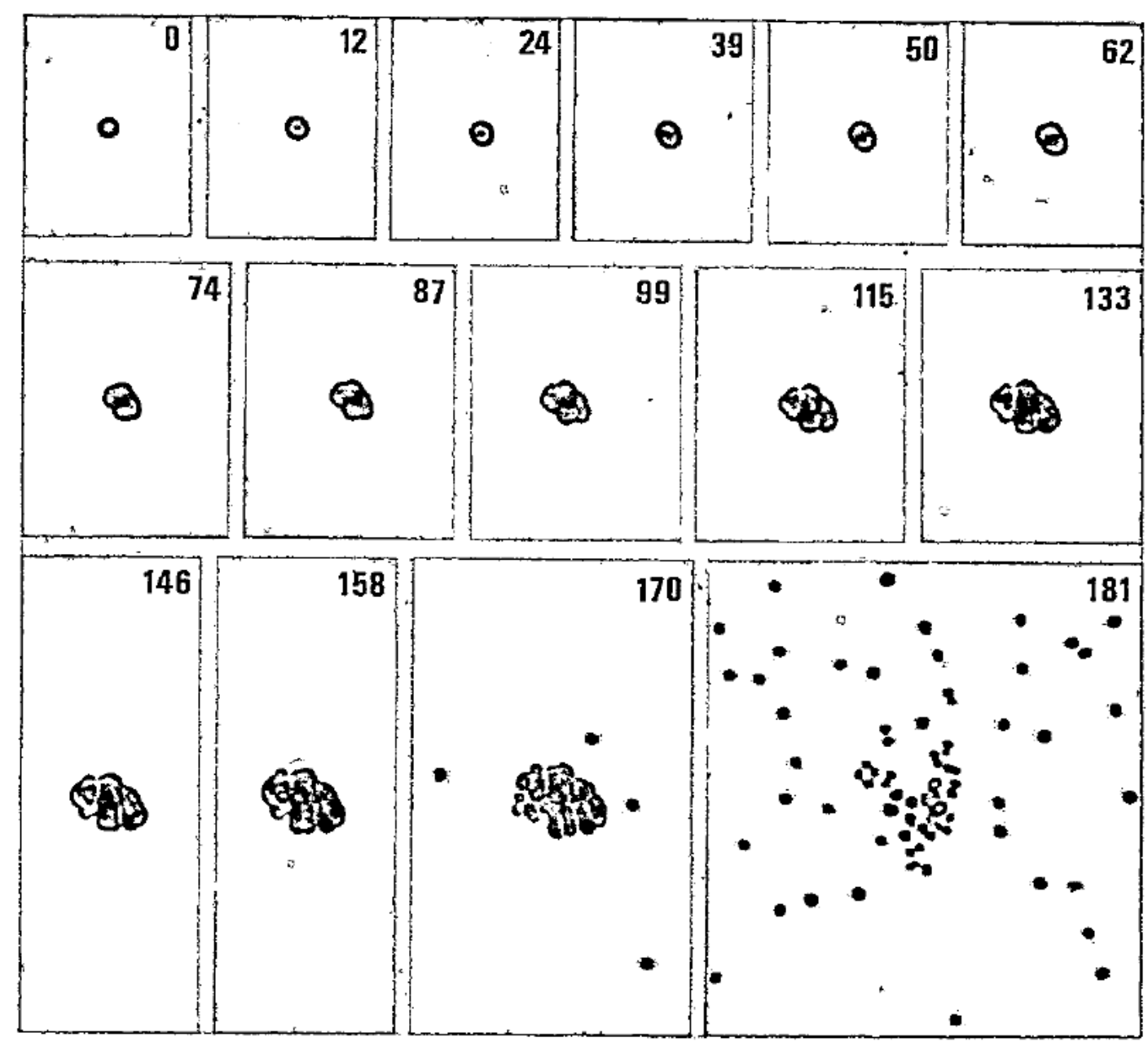




\section{Figure 63}

Photomicrographs of three Pleurocapsa strains growing on fragments of oyster shell immersed in medium MN, and incubated in the light. Prior to photography, the oyster shells were scraped in order to remove the surface growth. The photomicrographs on the left side of the plate (a., c. and e.) show the appearance of oyster shells from pure cultures of the three Pleurocapsa strains. The photomicrographs on the right side of the plate (b., d. and $f_{.}$) show the appearance of oyster shells from cultures which were simultaneously inoculated with a chemoheterotrophic acid producing bacterium. a. and b., Strain 7440; c. and d., Strain 7516; e. and f., Strain 7319. All X200. In axenic culture, strain 7440 shows no penetration of the calcareous substrate (Figure 63a), but penetrates extensive1y (Figure 63b) in two-membered culture. The same behavior is shown by strain 7516; the cell aggregates in Figure 63c are growing on the surface whereas several aggregates in Figure 63d (arrows) have begun to penetrate. Strain 7319 has penetrated the calcareous substrate both in the axenic culture (Figure 63e) and in the two-membered culture (Figure 63f). 

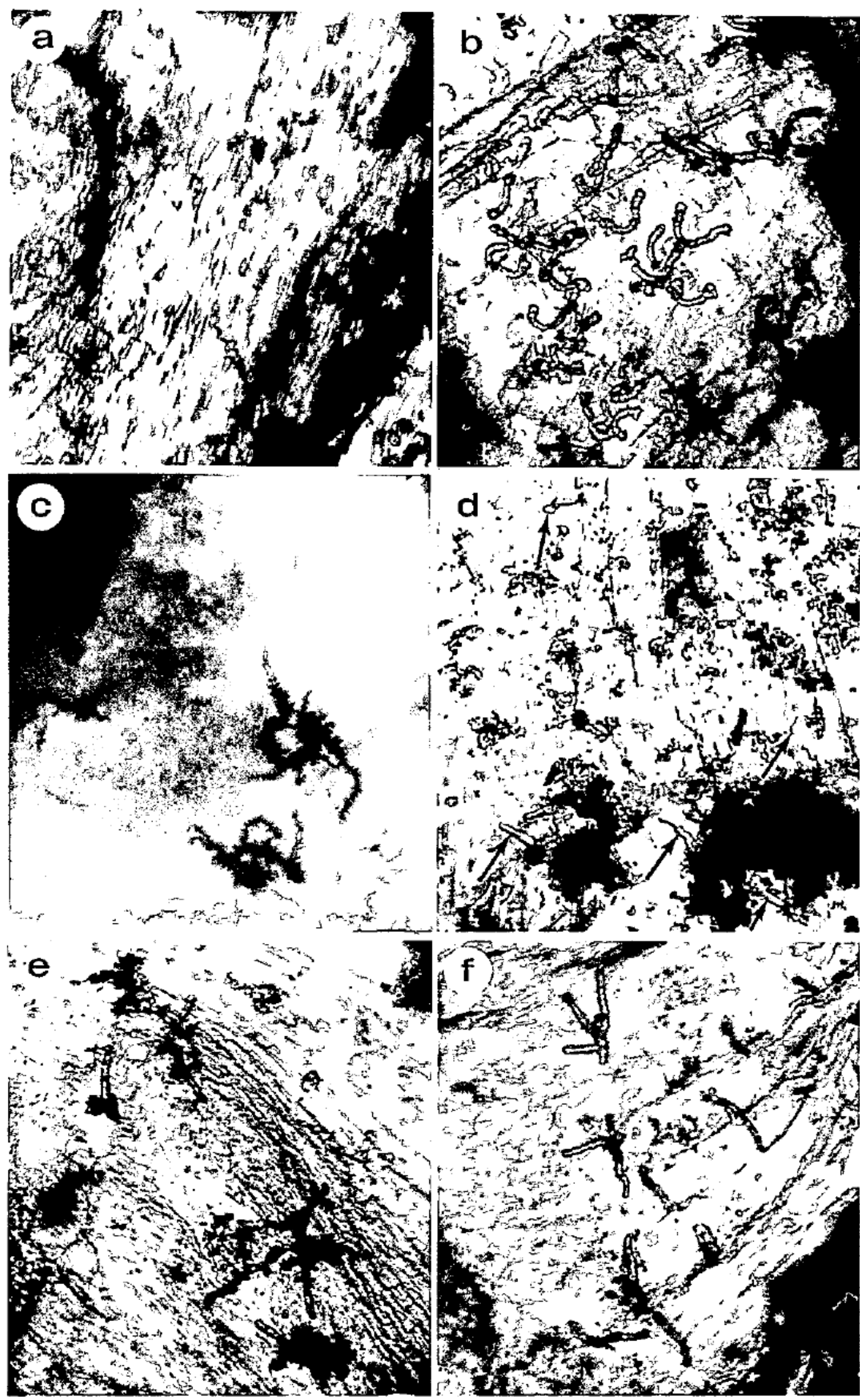

d o d o d d $\therefore$ ard 4 of on and on (n)

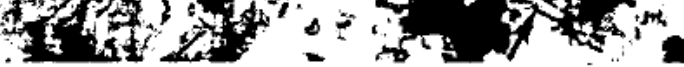

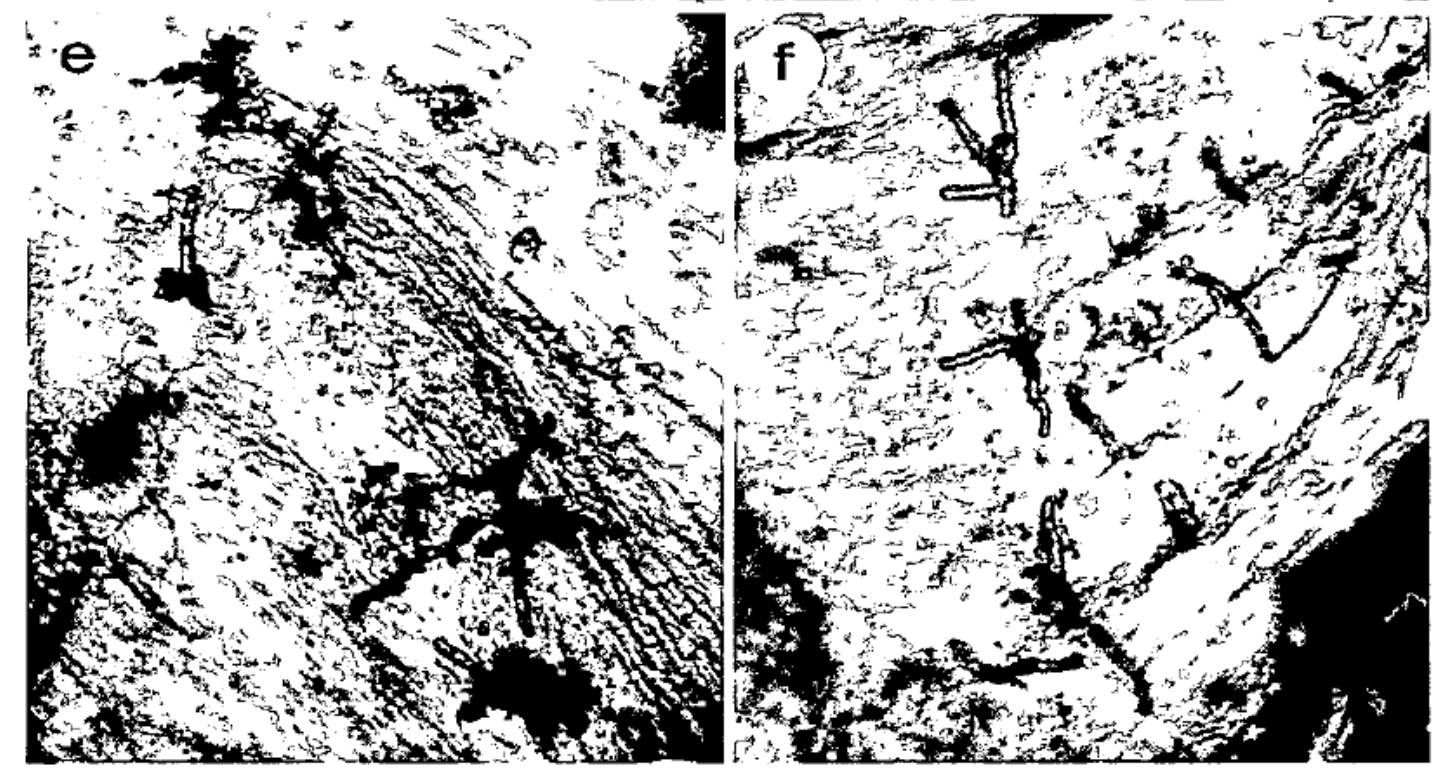




\section{The Structure and Development of Chamaesiphon}

Two strains in our collection, both of fresh water origin, are unicellular cyanobacteria which reproduce exclusively by budding. They appear to be representatives of the genus Chamaesiphon, although the cells are not invested by a distinct sheath open at one end "pseudovagina"), reported1y characteristic of most Chamaesiphon spp. when growing on natural substrates (35).

On agar plates of medium BG-11, both strains form small compact colonies, consisting of cells embedded in an amorphous layer of slime, which are very difficult to disperse. In liquid cultures, the cells do not attach to the glass walls of the culture vessel.

The cells are spherical to ovoid, and rather variable in size (Figure $64 a-d)$. The cells of strain 7430 are considerably larger than those of strain 6605 (Table XVII). For this reason, the unusual mode of division of strain 7430 is more obvious in light microscopic preparation than that of strain 6605. As shown in Figure $64 \mathrm{c}$ and 64d, mass cultures of strain 7430 contain many division stages in which the daughter cells are of markedly different size (arrows), a character less evident in strain 6605 (Figure $64 \mathrm{a}$ and 64b).

The fact that both these strains reproduce by bud formation was established by semi-continuous observations on slide cultures. Figure 65 shows the development in a slide culture of strain 6605 . During the period of observation ( 151 hours) the cells labelled 1 and 2 each underwent approximately two doublings. The parent cell, initially spherical, elongated and produced a spherical bud from one pole. After detachment of the bud, a second bud developed at the same position on the mother cell. Hence bud formation appears always to occur at the same pole of 
T A B L E X V I I

STRUCTURAI, PROPERTIES OF ChamaEsiphon STRAINS

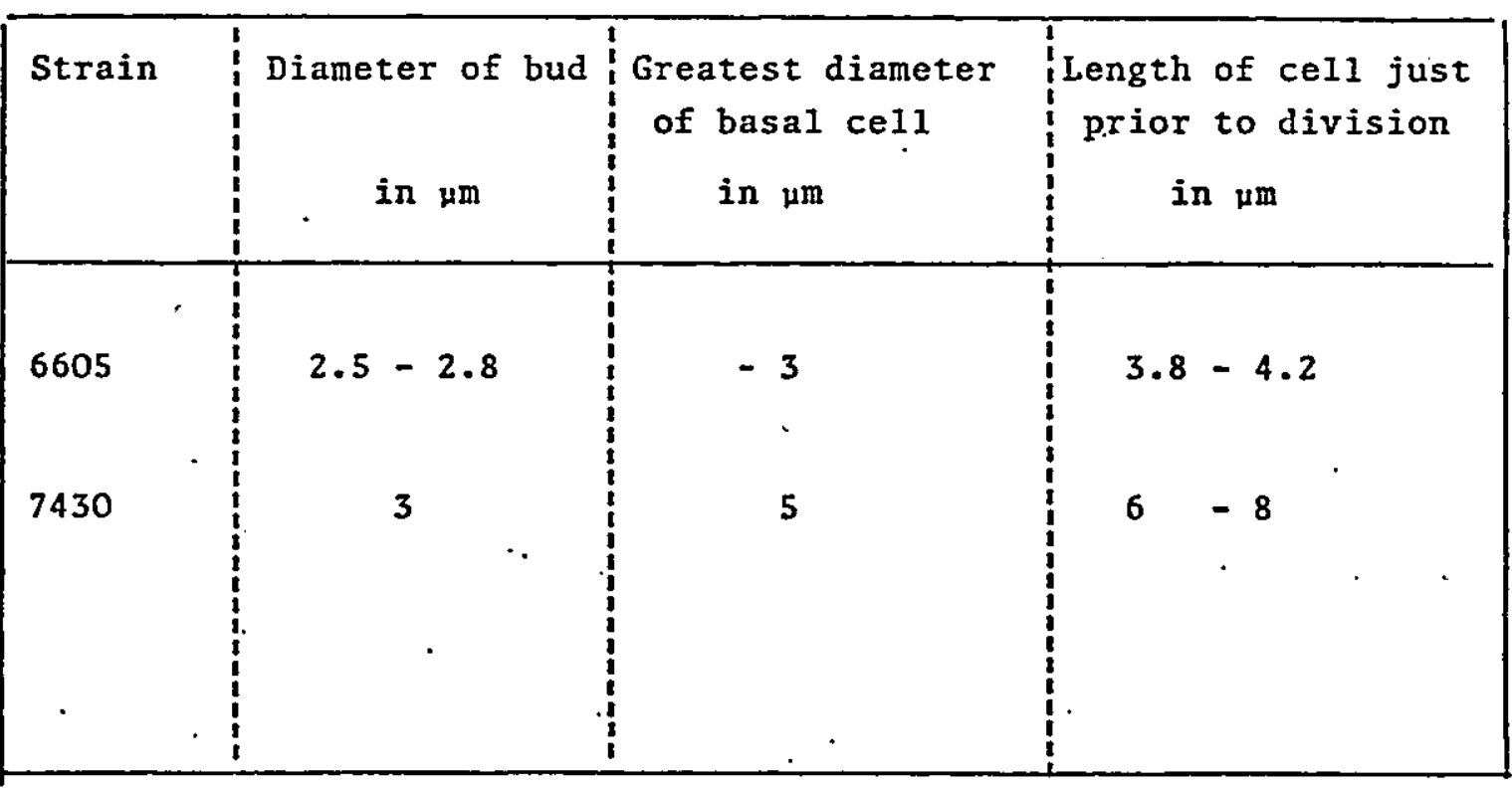


a mother cell, which we shall term the reproductive pole. Relative to the mother cell from which it arises, each bud has an "old" pole (i.e., that which originally existed on the mother cell) and a "new" pole (i.e., that which is formed at the site of cross wall formation). One of these poles must become the reproductive pole of the developing bud. The buds initially formed from the cells labelled 1 and 2 in Figure 65 had elongated and divided by the end of the period of observation. In both cases, buds arose from the "new" poles of these daughter cells. In other words, the newly formed poles of both the mother and the daughter cell are the reproductive poles.

Figure 66 shows the development in a slide culture of strain 7430 . The arrows point to a cell which formed two buds over the period of observation (236 hours). Both developed successively from the same pole of the mother cell. Polarized bud formation is therefore likewise characteristic of this strain. The daughter cells did not develop sufficiently to permit a determination of the relationship between the reproductive poles of the mother and daughter cells.

The examination of thin sections of strain 7430 in the electron microscope reveals that its cell wall is composed only of the PG and LP layers. The absence of an $\mathrm{F}$ layer distinguishes this organism sharply from all members of the Pleurocapsales (Figure 64e and f). As revealed by thin sections, cross-wall formation during budding closely resembles the same process during binary fission in members of the Chroococcales. At the onset of division, the thylakoids are dispersed throughout the cytoplasm (Figure 67), and become divided between the mother cell and the bud by the centripetal invagination of the cell wall, as is typical of other unicellular cyanobacterla. This 
separation of pre-existing thylakoids between the mother cell and the bud differs from the internal membrane formation in other budding bacterla. In Nitrobacter sp. (77, p. 469) and Rhodopseudomonas sp. (59, p. 62) the internal membrane system of the mother cell does not enter the bud. In such bacteria, the internal membrane system of the bud arises de novo from invaginations of the cytoplasmic membrane.

The developmental cycle of Chamaesiphon, as inferred from the study of these two strains, is represented schematically in Figure 68. 


\section{Figure 64}

a., b., c. and d. Photomicrographs of Chamaesiphon grown in 1iquid medium BG-11. a. and b. Strain 6605. Phase contrast, X 2000. c. and d. Strain 7430. X 2000. e. and f. Electron micrographs of thin sections of Chamaesiphon strain 7430 to show cell wall structure. Arrows point to the PG and LP wall layers. $X 207,700$. 


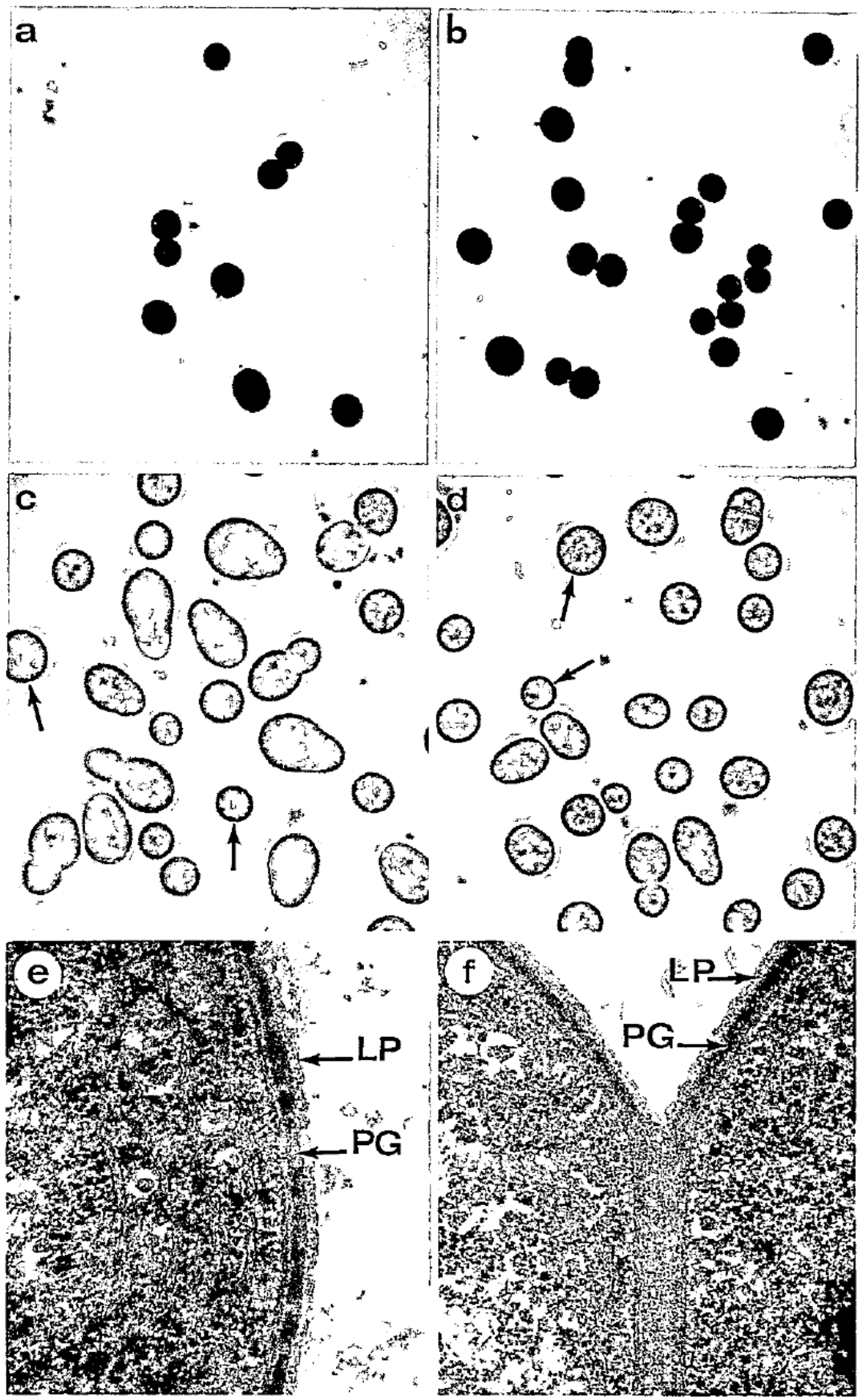




\section{Figure 65}

Successive photomicrographs of the development of Chamaesiphon strain 6605 grown on medium BG-1I in a slide culture over a total period of 151 hours. This series of micrographs reveal that this strain divides by budding. Note that successive daughter cells are always cut off from the same pole of the basal cell. X 1000 . 


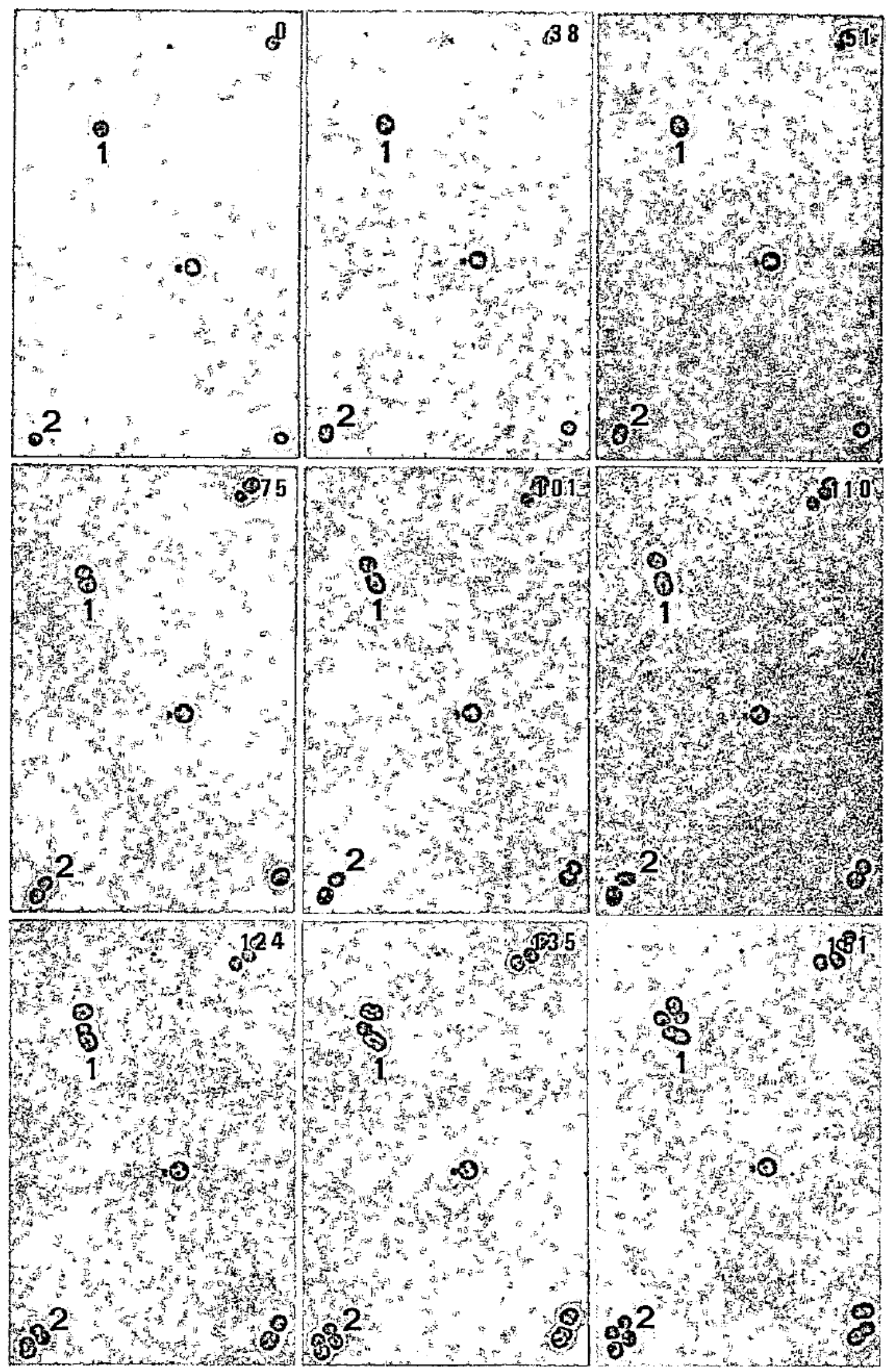


Successive photomicrographs of the development of Chamaesiphon strain 7430 grown on medium BG-11 in a slide culture over a total period of 236 hours. The developmental pattern of this strain is similar to that of strain 6605 (Figure 65). $\mathrm{X} 1000$. 


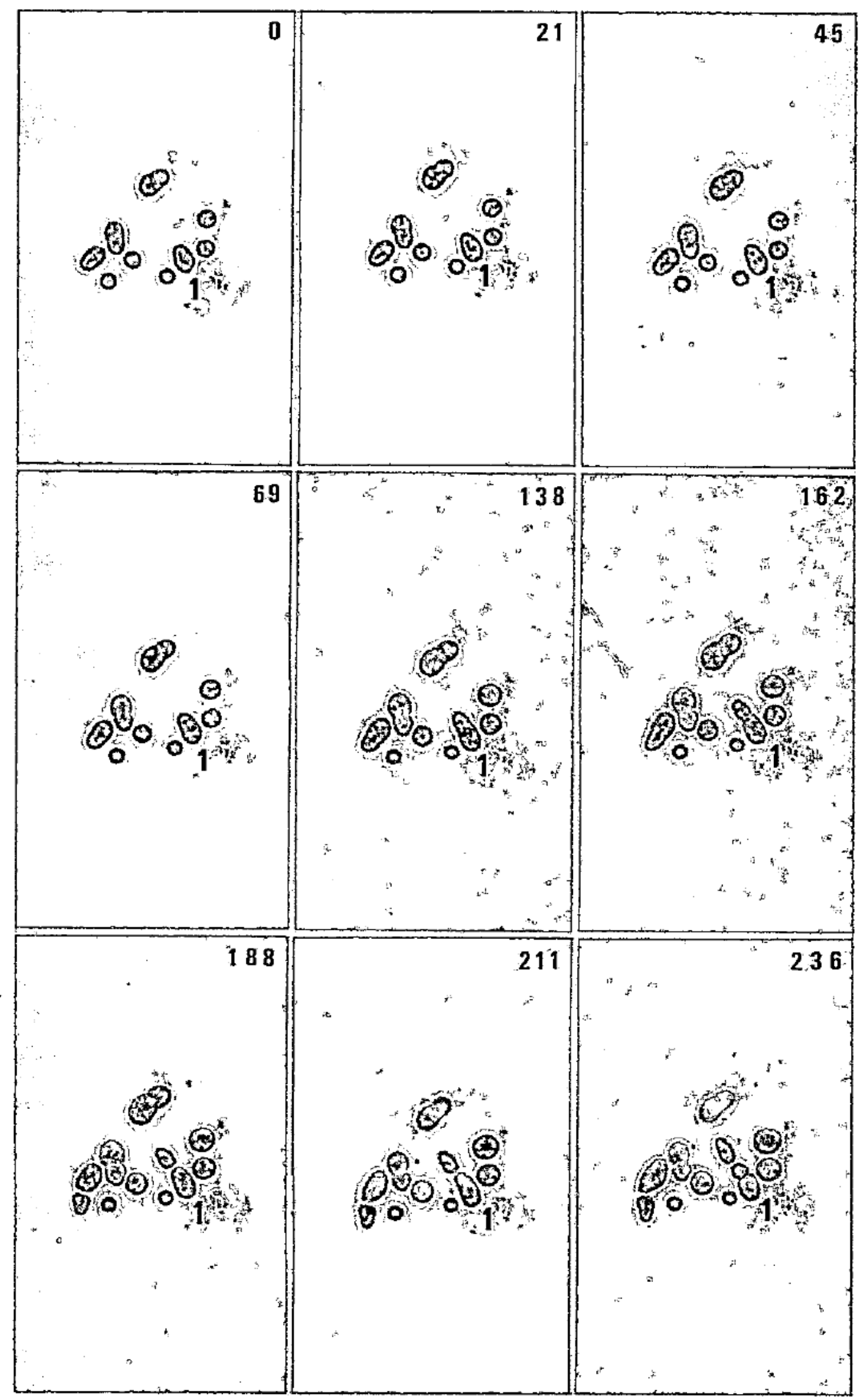




\section{Figure 67}

Electron micrographs of thin sections of strain 7430 grown in an agar overlay of medium BG-11. This series of electron micrographs shows several stages of bud development. a. $\times 18,000$, b. $\times 16,500$, c; $\times 16,500$. 

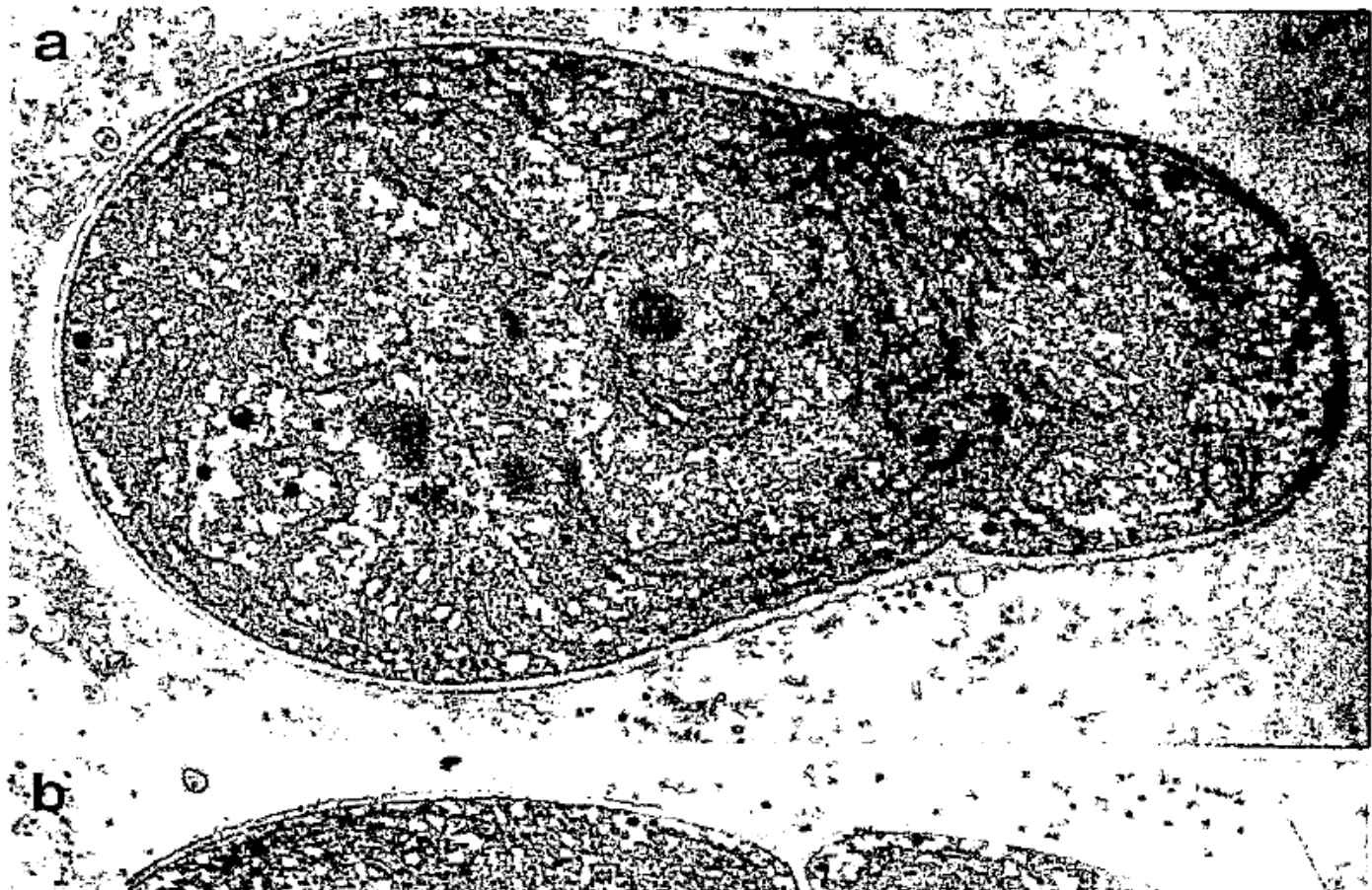

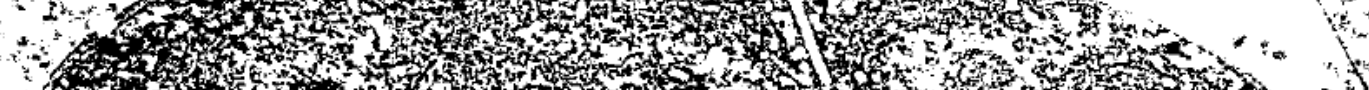
(At)

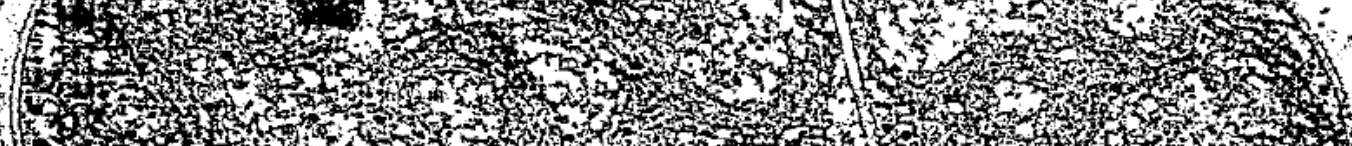

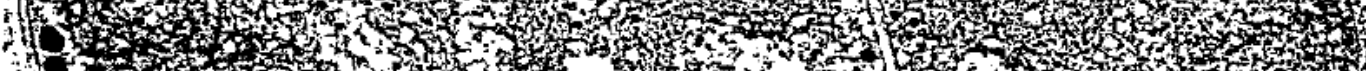

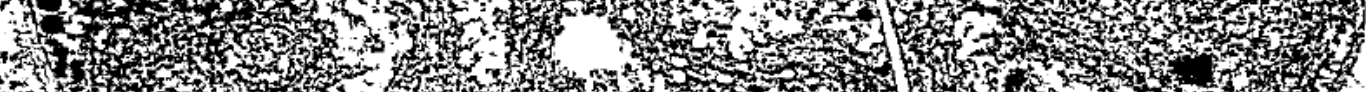
1. (3)

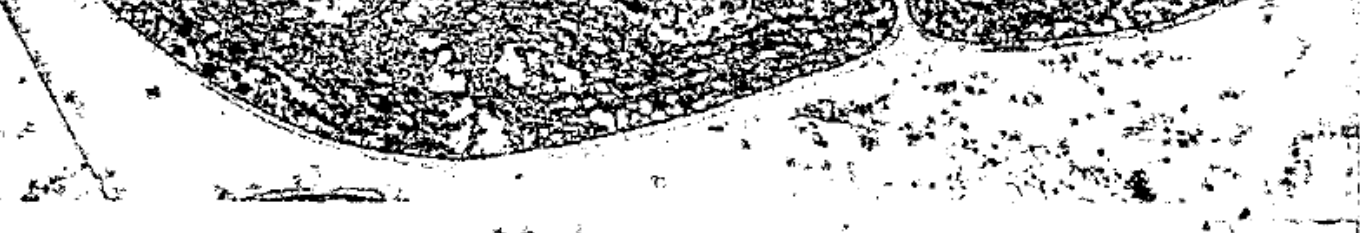

C.

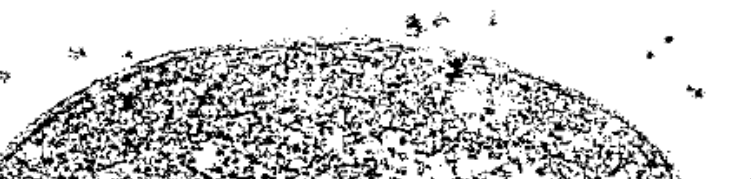

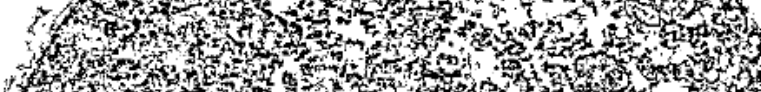

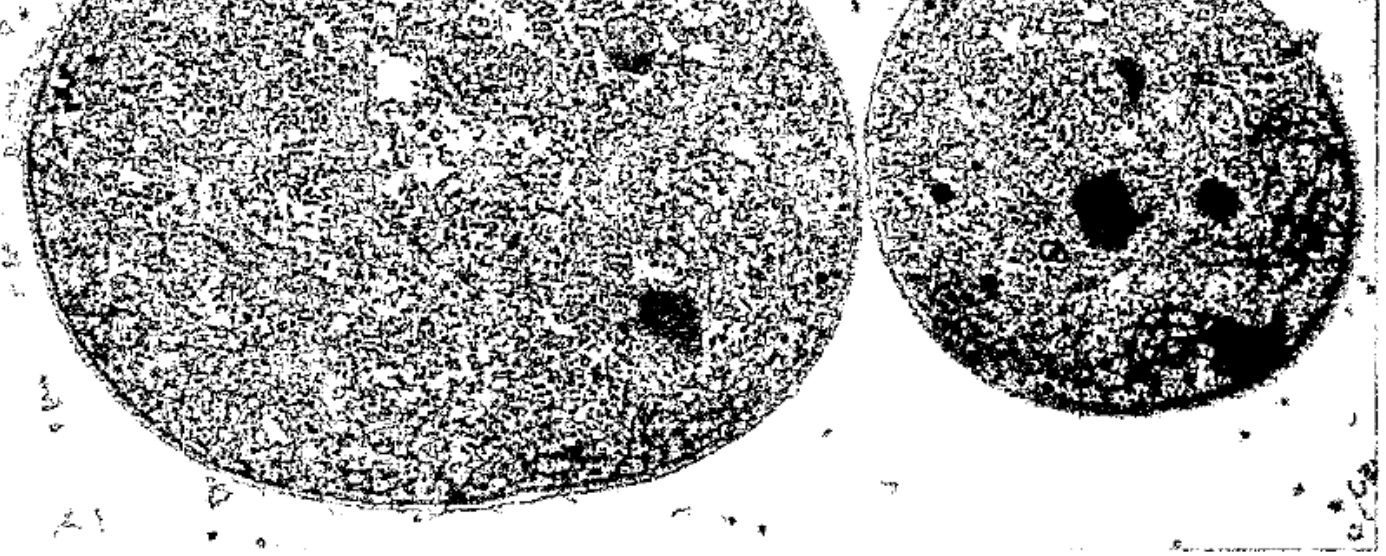

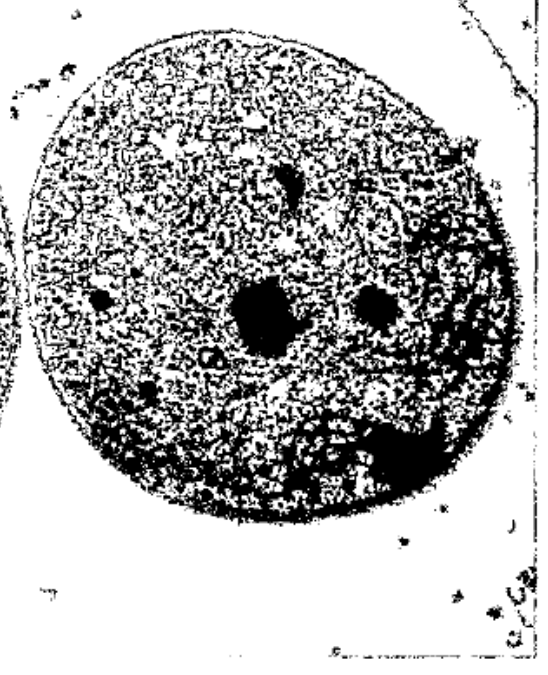


Figure 68

Schematic Developmental Cycle of Chamaesiphon

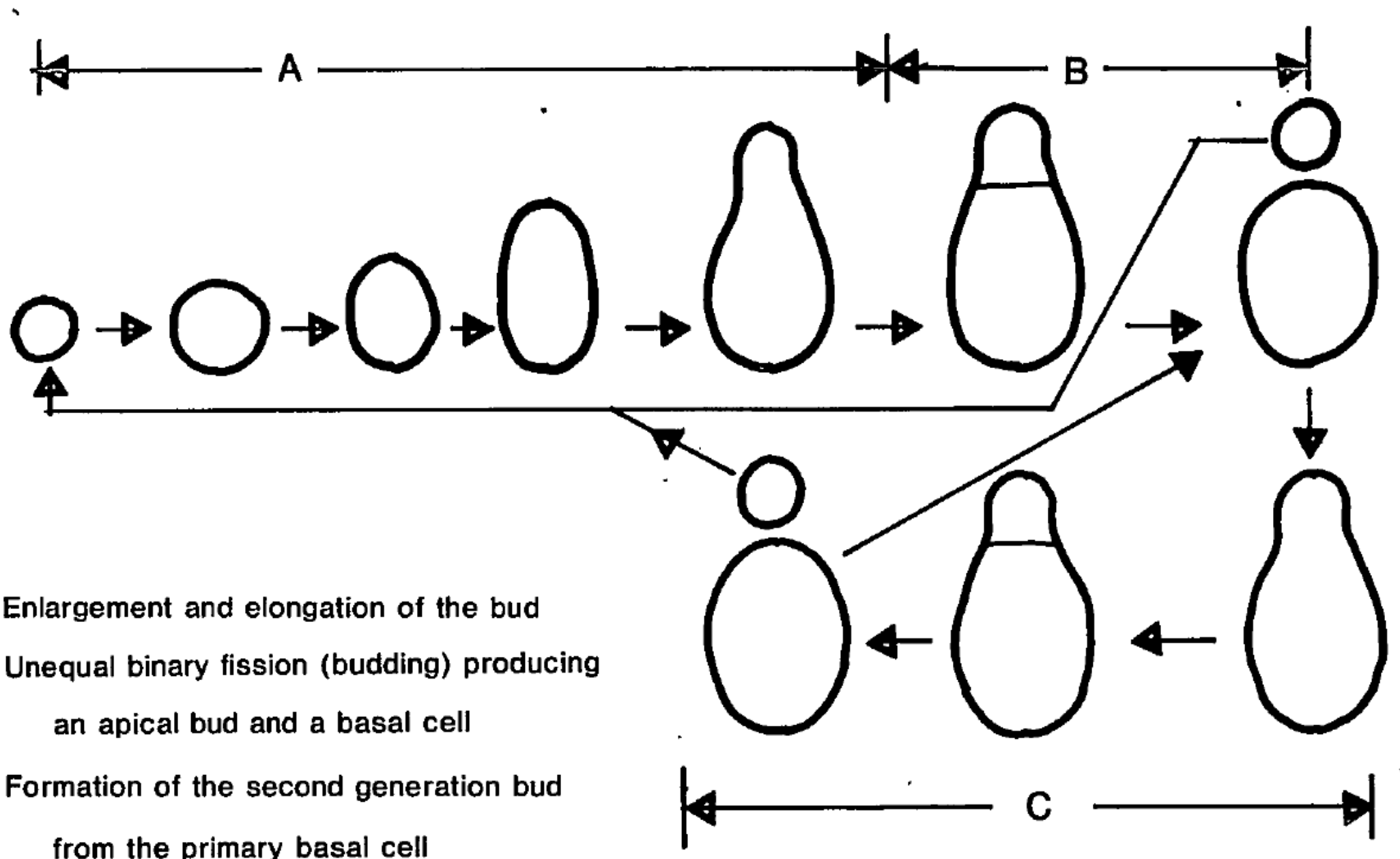




\section{Nutritional Properties of the Pleurocapsales and Chamaesiphonales}

\section{Ionic Requirements}

A number of analyses of the Ionic requirements of marine bacteria belonging to several different taxa $(50,51,52,53,61)$ show that these organisms can be distinguished from members of the same taxonomic groups of non-marine origin by their relatively elevated requirements for sodium, magnesium, calcium and halides. Since the Pleurocapsales. Include members both of marine and of non-marine origin, it therefore appeared of interest to analyze their specific requirements for these tons. For comparative purposes, six marine representatives of the Chroococcales were also included in this study.

Table XVIII shows the minimum concentrations of sodiun and chloride necessary to support continued growth of the strains examined. Some strains, which were all of terrestrial origin (Dermocarpa 7437 and 7438; Chroococcidiopsis strains) show no detectable growth requirement for either ion. The maximal levels of sodium and chloride in the medium employed (calculated from the analytical data furnished by the manufactorers for the salts which make up this medium) are $1.5 \times 10^{-5} \mathrm{M}$ and $3.4 \times 10^{-6}$ M respectively. Consequently, if these strains do require efther ion, their requirements are met by concentrations equal to or less than these values. All the remaining strains examined have readily detectable requirements for sodium, and in most cases also for chloride, although the minimal concentrations necessary for growth vary widely. With the exception of Pleurocapsa 7327 (isolated from a hot spring), these strains are all of marine origin. As a rule, any given strain requires concentrations of sodium and chloride that are similar. The requirements of these strains for a monovalent cation could in no case 
TA B L E X VII

MININUM SODTUM AND CHLORIDE REQUIREMENTS FOR GROWTH OF MARINE AND TERRESTRIAL CYANOBACTERTA

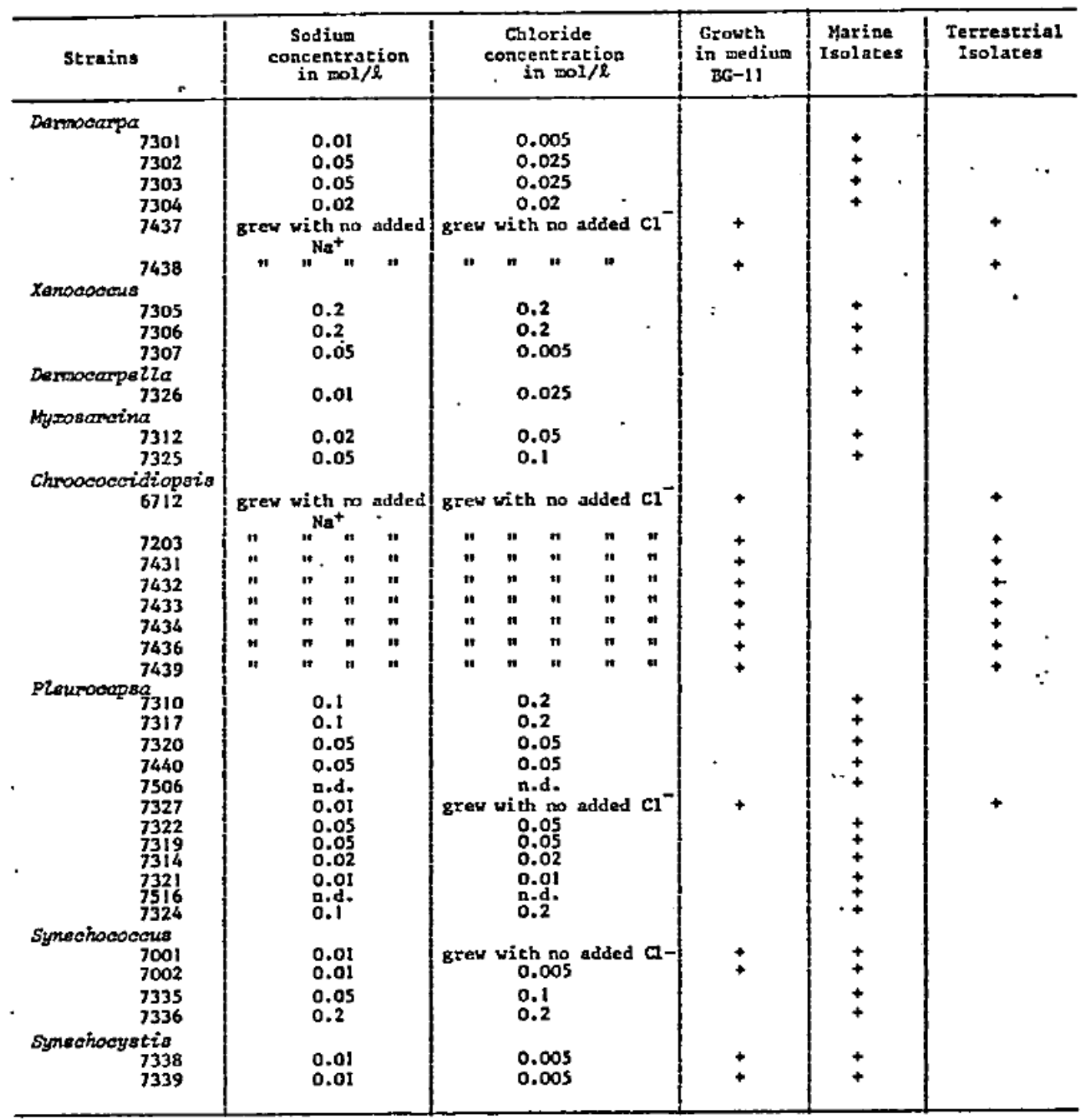

n.d. : not determined 
be met by substitution of potassium for sodium. Furthermore, the level of sodium necessary to support growth could not be decreased by an increase in the potassium concentration. These observations show that sodium is not required to maintain a minimum osmolarity, and suggest that it is a specific ionic requirement.

As also shown in Table XVIII, strains of terrestrial origin, whether or not they show a sodium requirement, can grow well in medium $\mathrm{GB}-11$, which has a sodium concentration of $0.015 \mathrm{M}$. Strains of marine origin, on the other hand, fall into two categories with respect to growth in medium BG-11. Synechococcus strains 7001 and 7002, and Synechocystis strains 7338 and 7339 can grow well in this medium. All four strains have very low sodium and chloride requirements which are met by this medium. All remaining marine strains are unable to grow in BG-11. They also fail to grow when this medium is supplemented with $0.5 \mathrm{M}$ sodium chloride, a concentration which exceeds the minimal requirements of the strains in question for both ions. Hence, for these marine strains medium BG-11 must be deficient in other ions than sodium and chloride. The nature of these additional ionic requirements is suggested by the fact that these strains grow well in medium ASN-III, which has far higher levels of magnesium and calcium than does medium BG-11. It is accordingly probable that these marine strains have elevated requirements for four ions: sodium, magnesium, calcium and chloride. Experiments designed to determine the minimum levels of magnesium and calcium required for growth revealed that the effects of these divalent cations are interrelated. The minimal level of either ion which supports growth is influenced by the level of the other one. It should be further noted that some of the marine strains (e.g., Dermocarpezla 7326, 
Pleurocapsa 7321) which have elevated requirements for magnesium and calclum have relatively low sodium and chloride requirements. They are Indistinguishable in this respect from some strains able to grow in medium $B G-11$.

Selected marine representatives of the Pleurocapsales (7301, 7302, $7303,7304,7310,7312,7314,7317,7319,7320,7321,7322,7324,7325)$ were examined to determine their halotolerance. All these strains could grow in medium ASN-III when the sodium chloride concentration was raised to $5 \%(w / v)$, but falled to grow when transferred to the same medium containing $10 \%(\mathrm{w} / \mathrm{v})$ sodium chlorlde.

2. Vitamin Requirements

Although in most cases primary isolations from natural material were conducted by plating on media not furnished with vitamins, subsequent purification of rearly all strains both marine and fresh water was carried out on plating media supplemented with vitamin $B_{12}$. Consequently, it appeared desirable to screen our pure strains for a possible vitamin $\mathrm{B}_{12}$ requirement. Such experiments showed that Dermocarpa 7301 and Pleurocapsa 7317 (both of marine origin) have an obligate requirement for this vitamin. Several other strains both marine (Dermocarpa strains 7302, 7303; Pleurocapsa 7310) and fresh water (Chamaesiphon 6605) are definitely stimulated by vitamin $B_{12}$ although they can grow in its absence.

\section{Nitrogen Sources}

With the exception of strains 7440,7506 and 7516 , which have not been tested, all members of the Pleurocapsales and Chamaesiphonales can use either ammonia or urea in place of nitrate as a source of combined nitrogen. Other possible combined nitrogen sources have not been 


\section{T A B L $\quad$ E $\quad$ X I X}

THE ABILITY OF STRAINS BELONGING TO THE PLEUROCAPSALES AND CHAMAESIPHONALES TO SYNTHESIZE NITROGENASE WHEN INCUBATED ANAEROBICALLY

IN THE LIGHT IN THE PRESENCE OF DCNU

\begin{tabular}{|l|c|c|}
\hline Genera & Positive & Negative \\
\hline Dexmocarpa & 7301,7303 & $7302,7304,7437,7438$ \\
\hline Xenococcus & 7305 & 7306,7307 \\
\hline Dermocarpella & & 7326 \\
\hline Mysosarcina & 7312 & .7325 \\
\hline Chroococcidiopsis & $\begin{array}{l}\text { 6712,7203,7431,7432 } \\
7433,7434,7436,7439\end{array}$ & \\
\hline & $7320,7327,7322$ & $7310,7317,7440,7506$ \\
\hline Pleurocapsa & $7314,7321,7516,7324$ & 7319 \\
\hline Chamaesiphon & & 6605,7430 \\
\hline
\end{tabular}


examined. None of the strains belonging to the Pleurocapsales or Chamaesiphonales can grow aerobically in the light in a medium devold of combined nitrogen. The capacity for aerobic nitrogen fixation is consequently absent from these groups. However, when incubated anaerobically in the 1ight in the presence of DCMU (see Methods) many strains develop nitrogenase activity as determined by the test of acetylene reduction $(17,65$ ) (see Table XIX).

\section{Heterotrophy}

All strains were examined for their ability to utilize the three carbohydrates: glucose, fructose and sucrose, both as photosynthetic carbon sources (growth in the presence of DCMU in the 1ight) and as sole carbon and energy sources for dark growth. As shown in Table XX, many strains (27 of 34) can develop photoheterotrophically at the expense of one or more of these sugars, sucrose being most comnonly utilized. Certain sucrose-utilizing strains (11 of 23) fail to grow at the expense of one or both of the constituent monosaccharides, presumably because they lack specific permeases for the monosaccharides. In general, the sugars which can be utilized as photosynthetic carbon sources by a given strain are also capable of supporting its chemoheterotrophic growth in the dark. Although all strains of Chroococcidiopsis grow well at the expense of utilizable sugars in the dark, dark growth of organisms belonging to other genera is frequently either slow or not reproducible; such behavior is indicated by the symbol $\mathrm{V}$ (variable growth) in Table $x x$. The difficulty of obtaining reproducible growth on sugars in the dark may account for cases in which strains that grow with a given sugar in the light in the presence of DCMU are apparently unable to utilize the same sugar for dark growth (see data for strains 7310 and 7506). 
T A B L E X X

THE ABILITY OF MEMBERS OF THE PLEUROCAPSALES AND CHAMAESIPHONALES TO UTILIZE SUGARS FOR PHOTOHETEROTROPHIC AND CHEMOHETEROTROPHIC GROWTH

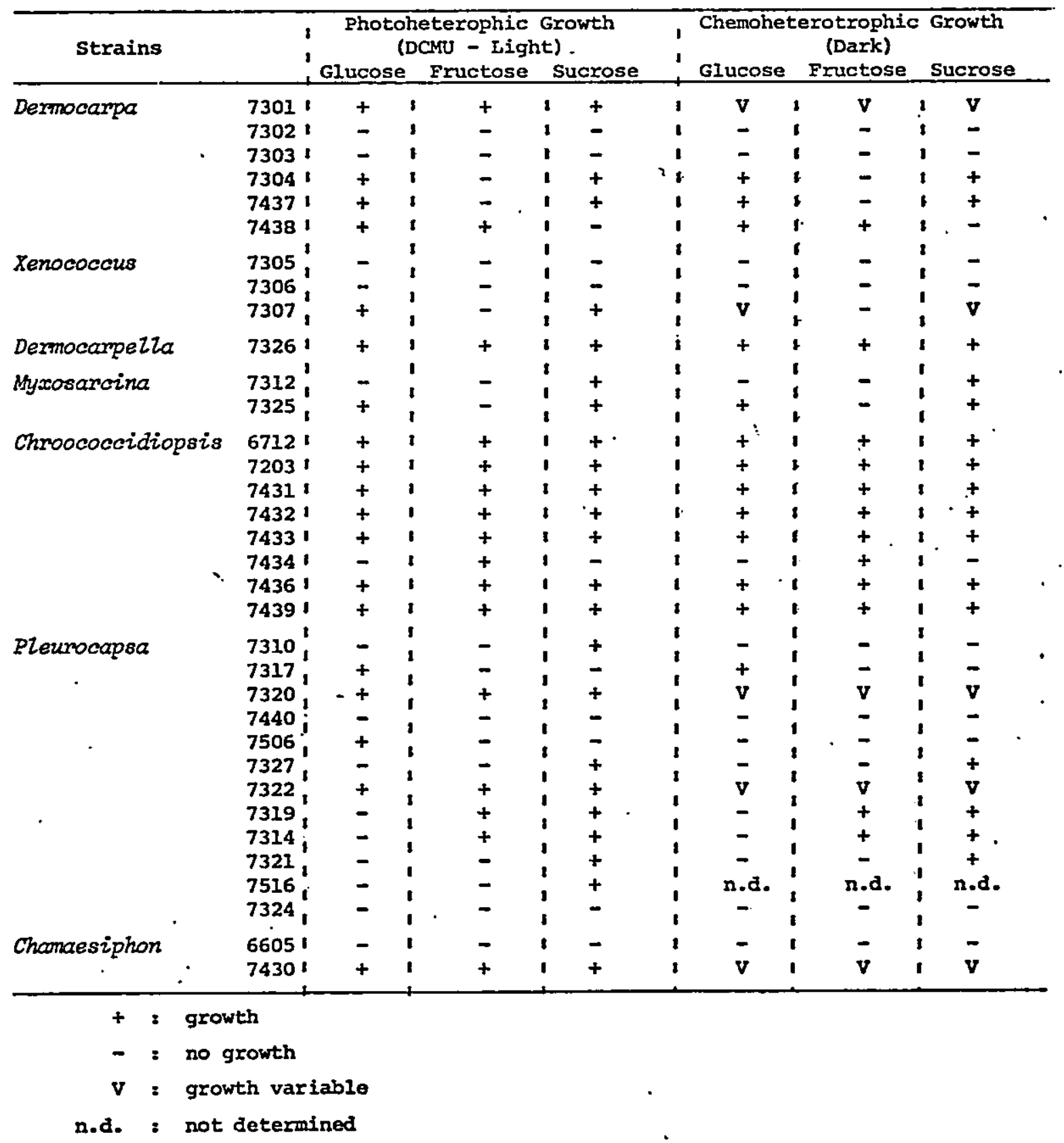


As shown in Table XX, heterotrophy has a highly sporadic distributIon. Several genera (Dermocarpa, Xenococcus, Pleurocapsa and Chamaeoiphon) contain some strains which are obligate photoautotrophs and others which are facultative heterotrophs.

5. Temperature Relationships

The study of temperature relationships has been Iimited to the determination of the maximum temperature at which photosynthetic growth can occur (Table XXI). Pleurocapsa 7327 was isolated from a thermal spring and consequently has a higher maximum temperature of growth $\left(55^{\circ} \mathrm{C}\right)$ than any of the other strains examined. The temperature maxima of the remaining members of the Pleurocapsales range from 30 to $44^{\circ} \mathrm{C}$, and most of them can grow at temperatures greater than $35^{\circ} \mathrm{C}$. This may appear surprising in view of the marine origin of many of these strains. It should be noted, however, that they were isolated at temperatures of 20 to $25^{\circ} \mathrm{C}$, which would have counter-selected any markedly psychrophilic members of the group. Both strains of Chamaesiphon have relatively low temperature maxima, possibly attributable to the fact that these organisms typically develop in cold streams and lakes.

With the exception of PZeurocapsa 7327, which cannot grow at temperatures below $37^{\circ} \mathrm{C}$, all strains grow well at 20 to $22^{\circ} \mathrm{C}$. The difficulty of measuring growth rates in the Pleurocapsales makes it impractical to determine temperature optima.

E. Chemical Characterization of the Pleurocapsales and Chamaesiphonales 1. Pigment Composition

The major photosynthetic pigments characteristic of these strains have been surveyed in a preliminary fashion by measurements, of the 
T A B L E X X I

APPROXIMATE MAXIMUM TEMPERATURE PERMITTING GROWCH OF MEMBERS OP THE

PLEUROCAPSALES AND CHAMAESIPHONALES

\begin{tabular}{|c|c|c|c|c|c|c|c|}
\hline Temperature & Dermocarpa & Xenococcus & Dermocarpeila & Myxosarcina & Chroococcidiopsis & Pleurocapor & Chamaesiphon \\
\hline 27 & & & $\dot{.}$ & & & & 7430 \\
\hline 30 & 7304 & 7306 & & & & 7317 & 6605 \\
\hline 35 & 7302 & $\begin{array}{l}7305 \\
7307\end{array}$ & 7326 & 7325 & & $\begin{array}{l}7310 \\
7440\end{array}$ & \\
\hline $\begin{array}{r}37 \\
-\quad\end{array}$ & $\begin{array}{l}7301 \\
7303\end{array}$ & & . & & & $\begin{array}{ll}7322 & 7321 \\
7314 & \end{array}$ & \\
\hline 39 & . & & & 7312 & 6712 & $\begin{array}{l}7320 \\
7319\end{array}$ & \\
\hline 40 & - & & . & & $\begin{array}{ll}7433 & 7436 \\
7434 & 7439\end{array}$ & $\cdot$ & . \\
\hline 44 & $\begin{array}{l}7437 \\
7438\end{array}$ & & & & $\begin{array}{l}7431 \\
7432\end{array}$ & . & . \\
\hline 55 & & - & & & & 7327 & - \\
\hline
\end{tabular}


absorption spectra of crude cell-free extracts. This was followed by a methanol extraction of chlorophyll and a closer spectral characterization of the phycobiliproteins in the supernatant after removal of the particulate fraction by high speed centrifugation.

Ifke other cyanobacteria (70) all these organisms show absorption maxima attributable to chlorophyll at 675 and $440 \mathrm{~nm}$ in crude cell-free. extracts. After methanol extraction the position of the red peak shifts to $663 \mathrm{~nm}$, typical of chlorophy 11 a

The phycobiliproteins show maxima both in crude cell-free extracts and in the supernatants after high speed centrifugation at approximate1y $618 \mathrm{~nm}$ and in some strains at 565 and $550 \mathrm{~nm}$. The peak at $618 \mathrm{~nm}$ corresponds to the absorption maximum of phycocyanin and the peaks at 565 and $550 \mathrm{~nm}$ to the absorption maxima of one (or more) phycoerythrins.

It is known that certain phycoerythrin-producing cyanobacteria can undergo marked alterations of their phycobiliprotein complement in response to growth with light of different qualities, a phenomenon known as chromatic adaptation. Representative strains were screened for their ability to adapt chromatically during growth in red and in green light. In addition, some facultatively chemoheterotrophic strains were grown in the dark at the expense of sugars. The pigment compositions of cells grown under these different conditions are shown in Table XXII, where pigment concentrations are expressed as $\mathrm{mg}$ of pigment per $100 \mathrm{mg}$ of cell protein. Chlorophy11 was determined after methanol extraction, whereas phycocyanin and phycoerythrin were calculated from the absorbancies at two wavelengths of the supernatant fraction from cell-free extracts. These calculations were made from the simultaneous equations established by Bennett and Bogorad (5) on the basis of the absorption spectra of 
purified phycocyanin and phycoerythrin from the filamentous cyanobacterium Fremyelza diplosiphon. The numerical values obtained using these equations are correct only if the phycocyanin and phycoerythrin of the strains examined have absorption spectra Identical with those of the corresponding pigments of Fremyella diplosiphon, an assumption which is not necessarily valid for all cyanobacteria, since it is known that cyanobacterial phycoerythrins do vary in spectral properties $(12,64)$. However, since the purpose of these experiments was to detect possible changes in the ratio between phycocyanin and phycoerythrin under different growth conditions, possible errors in the absolute numerical values for each pigment would not affect the conclusions which can be derived from them.

Table XXII shows that as a general rule the cellular chlorophy,11 content varies little in response to light quality. The chlorophyll contents of dark grown cells are slightly lower than those of cells grown in red and green 1ight. For any given strain, the total- phycobiliprotein content of the cells (sum of phycocyanin and phycoerythrin) also remains remarkably constant in red and green light, which suggests that the overall differential rate of synthesis of phycobiliproteins is not affected by light quality in members of these groups. Furthermore, the total phycobiliprotein concentration of dark grown cells is in most cases comparable to that of cells grown in red and green light. Notable exceptions are Myxosarcina 7312 and 7325 and Pleurocapsa 7327 where the dark-grown cells have roughly 50 percent of the phycobiliprotein content of light grown cells. An even more extreme reduction of cellular phycobiliprotein content as a consequence of dark growth occurs in Pleurocapsa 7314, wherethe value is only 12 to $15 \%$ of that for 1ight grown cells. 
T A B L E XXII

CONCENTRATIONS OP THE MAJOR PHOTOSYNTHETIC PIGMENTS OP STRAINS OP THE PLEUROCAPSAIES AND CHAMARSIPHONAZEg GROWN UNDER DIFFERENT CONDITIONS OF LLEUMINATIONS

All values are expreseed as $\mathrm{mg}$ pigment per $100 \mathrm{mg}$ of total cell protein

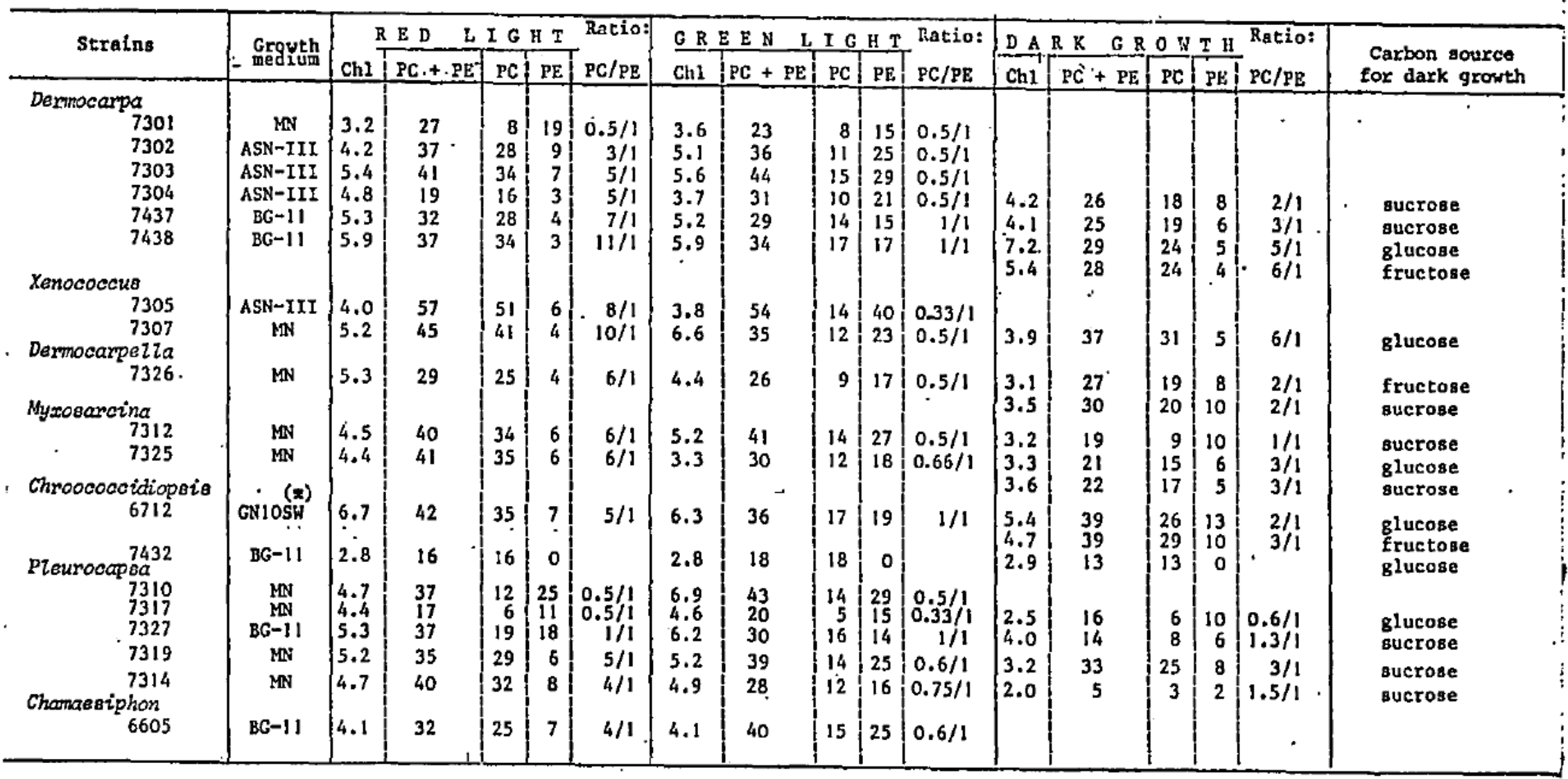

(w) Medium GN1OSW is medium BG-11 made with $10 \%(\mathrm{v} / \mathrm{v})$ sea water. 
Another interesting feature of the data is the very wide differences between strains grown under the same conditions with respect to phycobiliprotein content. Depending on the strain, these proteins may represent anywhere from 15 to over $50 \%$ of total cell protein in Iight grown cultures of different strains.

Although total phycobiliprotein content is little affected by light quality, many strains show a marked capacity for chromatic adaptation, evidenced by major changes in the phycocyanin/phycoerythrin ratio after growth in red and in green light. Some examples of this behavior are shown graphically in Figures 69 and 70 . In every case where a response occurs, synthesis of phycoerythrin is favored by growth in green light. When such strains are grown in the dark, the cellular phycocyanin/phycoerythrin ratio resembles that characteristic of cells grown in red light (i.e., synthesis of phycocyanin is favored). of the 18 phycoerythrin producing strains examined, only four failed to show a chromatic response (Table XXII). Figure 71 shows graphically the behavior under different growth conditions of one of these non-respondIng strains. It can be seen that the phycocyanin/phycoerythrin ratios are essentially unchanged by growth in green light, in red light and in the dark.

Failure to synthesize phycoerythrin appears to be rare among the Pleurocapsales. The only strains which lack this pigment are a group of Chroococcidiopsis strains which closely resemble one another in their phenotype and are exemplified (Table XXIII) by strain 7432. Of the two Chamaesiphon strains examined, one (6605) synthesizes phycoerythrin, whereas the other (7430) does not. 
T A B E X XIII

MAJOR PATTERNS OF PHYCOBILIPROTEIN SYNTHESIS BY STRAINS OF THE PLEUROCAPSALES AND CHAMAESIPBONALES

\begin{tabular}{|c|c|c|c|}
\hline Genera & $\begin{array}{l}\quad \text { A } \\
\text { Phycoerythrin absent, } \\
\text { Phycocyanin synthesis } \\
\text { constitutive }\end{array}$ & $\begin{array}{l}\text { B } \\
\text { Phycocyanin and Phycoerythrin } \\
\text { present and synthesized } \\
\text { constitutively }\end{array}$ & $\begin{array}{l}\text { C } \\
\text { Phycocyanin and Phycoerythrin present, } \\
\text { Phycocyanin to Phycoerythrin ratio } \\
\text { variable depending on the light quality }\end{array}$ \\
\hline Dermocarpa & & 7301 & $\begin{array}{l}7302,7303,7304 \\
7437,7438\end{array}$ \\
\hline Xenococcus & · & & $7305,7306,7307$ \\
\hline Dermocarpella & • & & 7326 \\
\hline Myxosarcina & · & & $\begin{array}{l}\because: 7312 \\
\therefore: 7325\end{array}$ \\
\hline Chroococcidiopsis & $\begin{array}{l}7203,7431,7432,7433,7434 \\
7436,7439\end{array}$ & & 6712 \\
\hline Pleurocapoa & - & $\begin{array}{l}7310,7317,7321,7324 \quad \therefore \\
7327\end{array}$ & $\because \quad 7320,7440,7322,7319,7314$ \\
\hline Chomaesiphon & 7430 & & 6605 \\
\hline
\end{tabular}




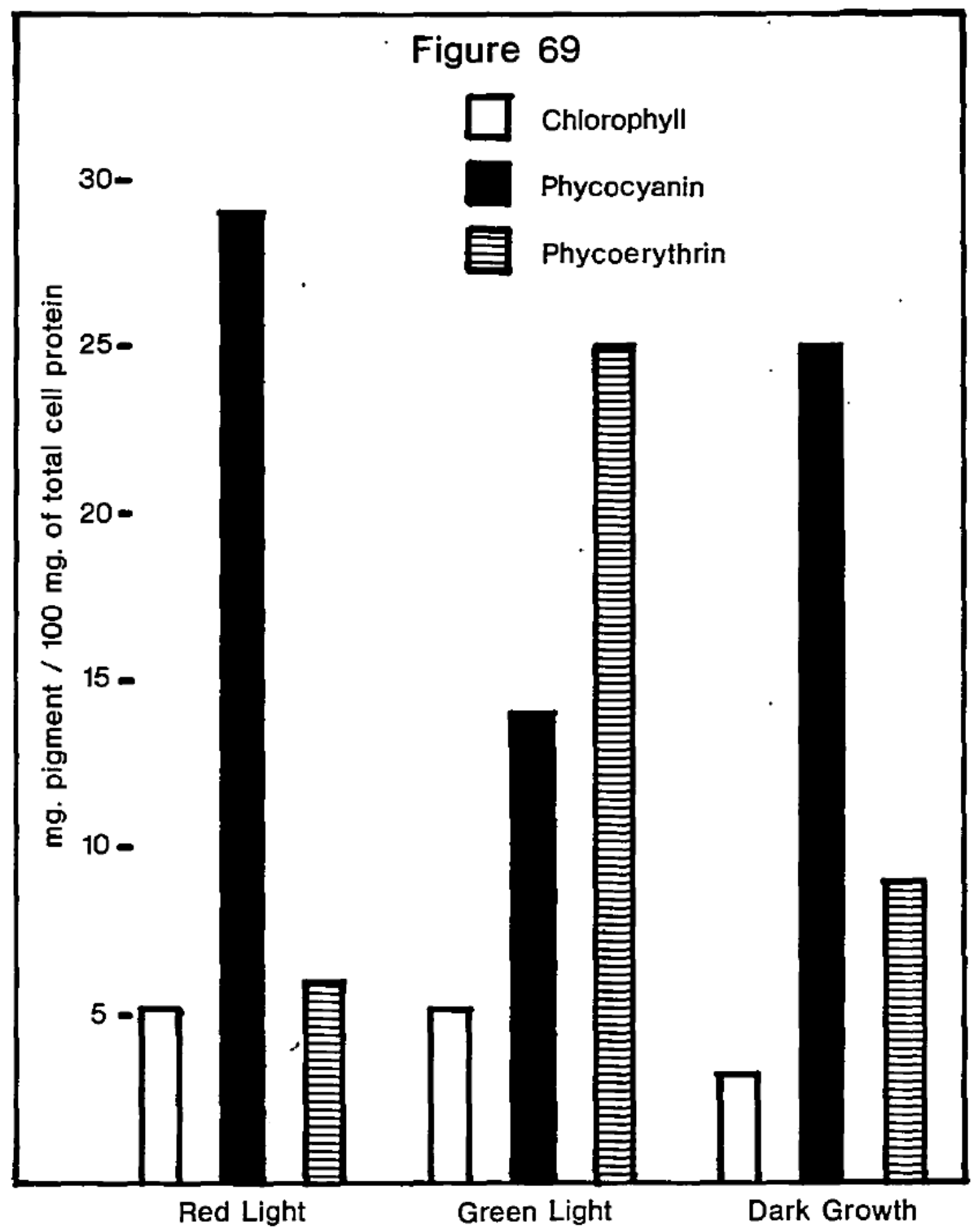

A graphic illustration of chromatic adaptation in Pleurocapsa strain 7319, evidenced by major changes in the phycocyanin and phycoerythrin levels following the growth of cells photoautotrophically in red and green light and chemoheterotrophically in the dark. ChlorophyIl is not markedly altered under these conditions. 


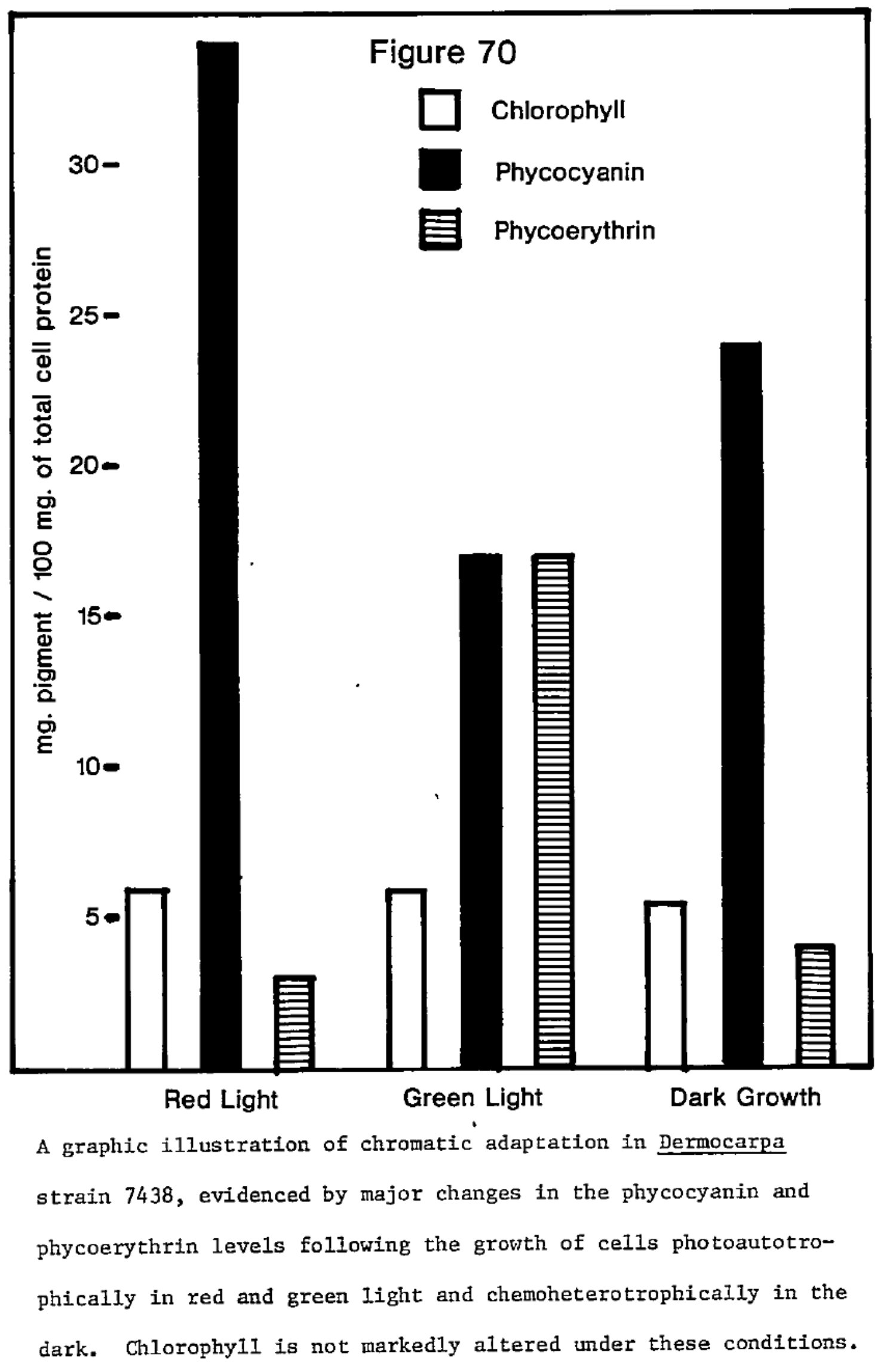




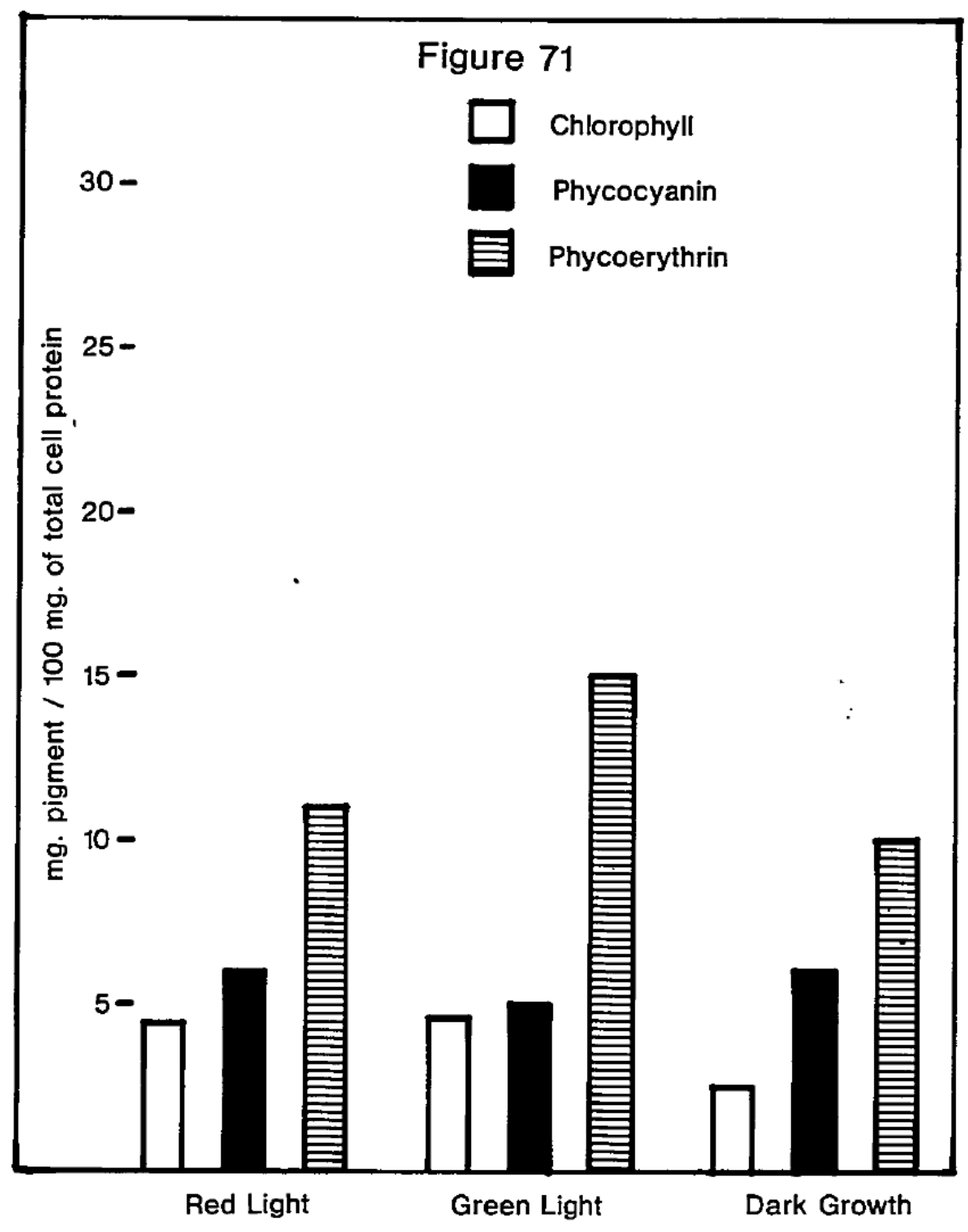

A graphic illustration of a phycoerythrin producing strain of Pleurocapsa (7317) which does not show a chromatic response, as evidenced by the fact that the phycocyanin and phycoerythrin levels are essentially unaltered following the growth of cells photoautotrophically in red and green light and chemoheterotrophically in the dark. Chlorophyll is not markedly altered under these conditions. 


\section{Cellular Fatty Acid Composition}

Previous studies have shown that the fatty acid composition of cyanobacteria varies widely among the representatives of the Chroococcales and Hormogonales $(37,38)$. Fatty acid analyses performed by Dr. C. N. Kenyon on cells of most of our strains shows a similar intragroup variability among the members of the Pleurocapsales (Table XXIV). In fact, the only common feature is the invariable presence of poly- unsaturated fatty acids, which range from 5 to $50 \%$ of the total cellular fatty acids. One unusual feature of many members of the Pleurocapsales is the exceptionally high content of $\mathrm{C}_{16}$ fatty acids, which almost entirely replace $C_{18}$ fatty acids and include polyunsaturated derivatives. This chemical feature is characteristic of Dermocampa, Xenococous, Dermocarpelza, Myxosarcina and Pleurocapsa with the exception of the thermophilic strain 7327 . It is not invariably correlated with a marine origin, being shared by two fresh water strains of Dermocarpa (7437 and 7438) and also encountered in one strain of the fresh water genus Chroococcidiopsis (6712). With this exception, Chroococcidiopsis strains have a very high content of the $\mathrm{C}_{18}$ polyunsaturated fatty acids $18: 2$, and $18: 3 \alpha$, which account for approximately 50\%. of their total cellular fatty acids.

Since the order Chamaesiphonales is represented by only two strains, the data are insufficient to permit any generalizations about the fatty acid compositions in this group. Nevertheless, it is worthy of note that these two strains, which clearly belong to different species, share a closely similar fatty acid composition characterized by a high total content of polyunsaturated fatty acids, which include both $\mathrm{C}_{16}$ and $\mathrm{C}_{18}$ components. 
T A B L E $X X I$ V

CELLULAR FATTY ACID COMPOSITION OF STRATNS IN THE PLEUROCAPSALES AND CHAMAESIPHONALES (1)

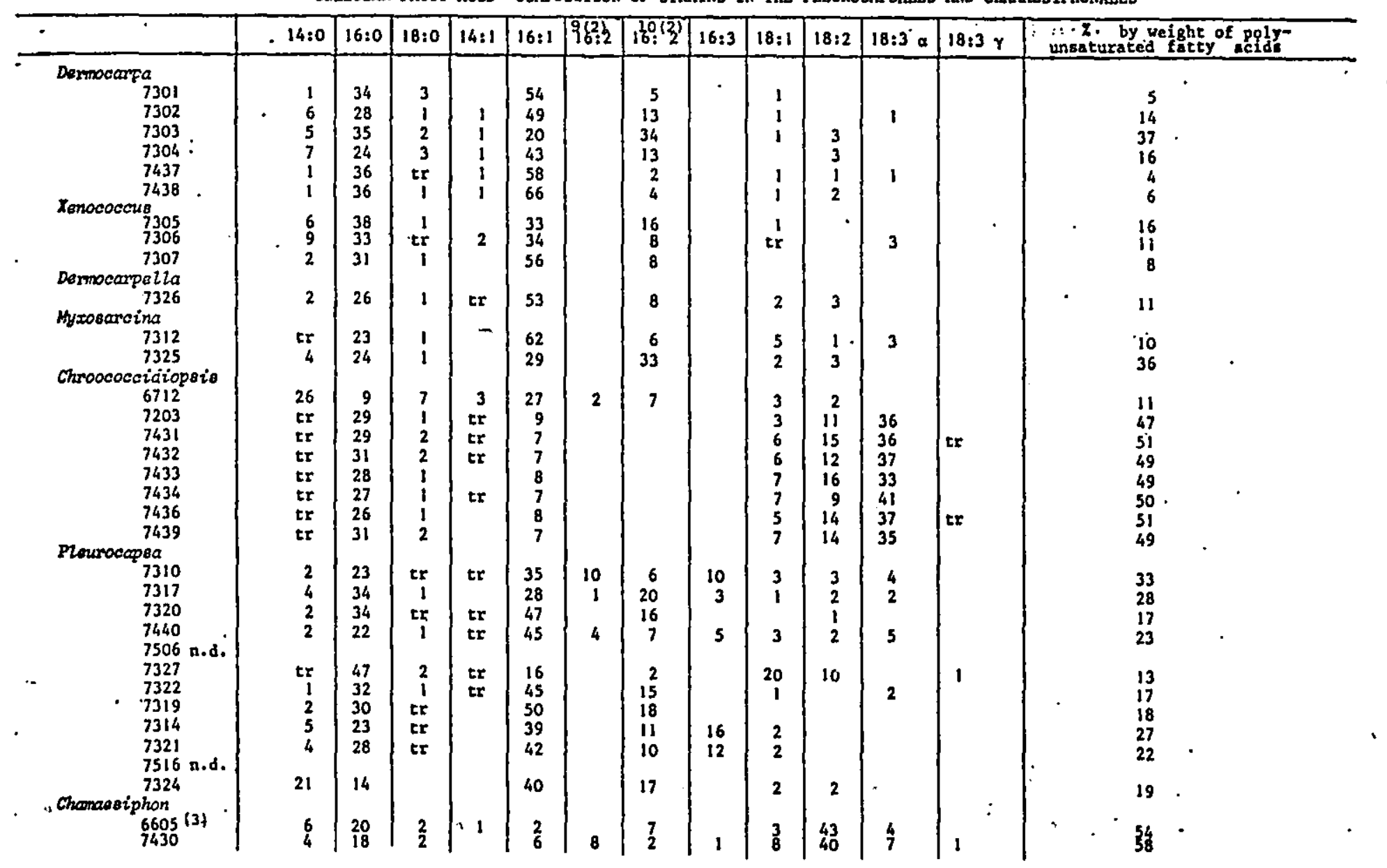

(1) Values given as percentage of total fatty aclde as determined by gag-11quid chromotography,

(2) Elution peaks 9 and 20 are both $26: 2$ LatEy acids that have not yet been Identifiod.

(3) Prom Xonyon at al. (38).

n.d.s not determined 


\section{Mean DNA Base Composition}

Prior to the present work, mean DNA base compositions had been determined for only two members of the Pleurocapsales, in both cases by buoyant density measurements. These values are shown in Table XXV, together with the present more extensive determinations based on $\mathrm{T}_{\mathrm{m}}$ values.

The total span of DNA base composition within the order, is rather narrow: 40.7-46.5 moles percent guanine plue cytosine $(G+C)$. Furthermore, the intrageneric ranges are in some cases almost as wide: 40.744.0 for Dermocarpa; 40.8-46.3 for Chroococaidiopsis; 42.8-46.5 for Pleurocapsa. This character is evidently of no value for making generic separations, although it may eventually prove useful to distinguish species.

Table XXV also shows the mean DNA base compositions of two strains of Chamaesiphon. The values are almost identical, and slightly higher than the highest values found in the Pleurocapsales.

\section{DISCUSSION}

\section{A. Physiological and Chemical Properties of the Pleurocapsales}

The analysis of the physiological properties of the pure cultures of spore-forming cyanobacteria in our collection was undertaken primarily to ascertain the possible taxonomic utility of such properties, which can be determined only on axenic strains and have therefore not had any place in the traditional taxonomy of cyanobacteria. The results obtained show that such characters as: specific ionic requirements for growth, the ability to synthesize nitrogenase anaerobically, the ability to adapt chromatically, fatty acid composition and DNA. base composition are 
TABLE XXV

Mean DNA Composition of Members of the Pleurocapsales and Chanaesiphonales

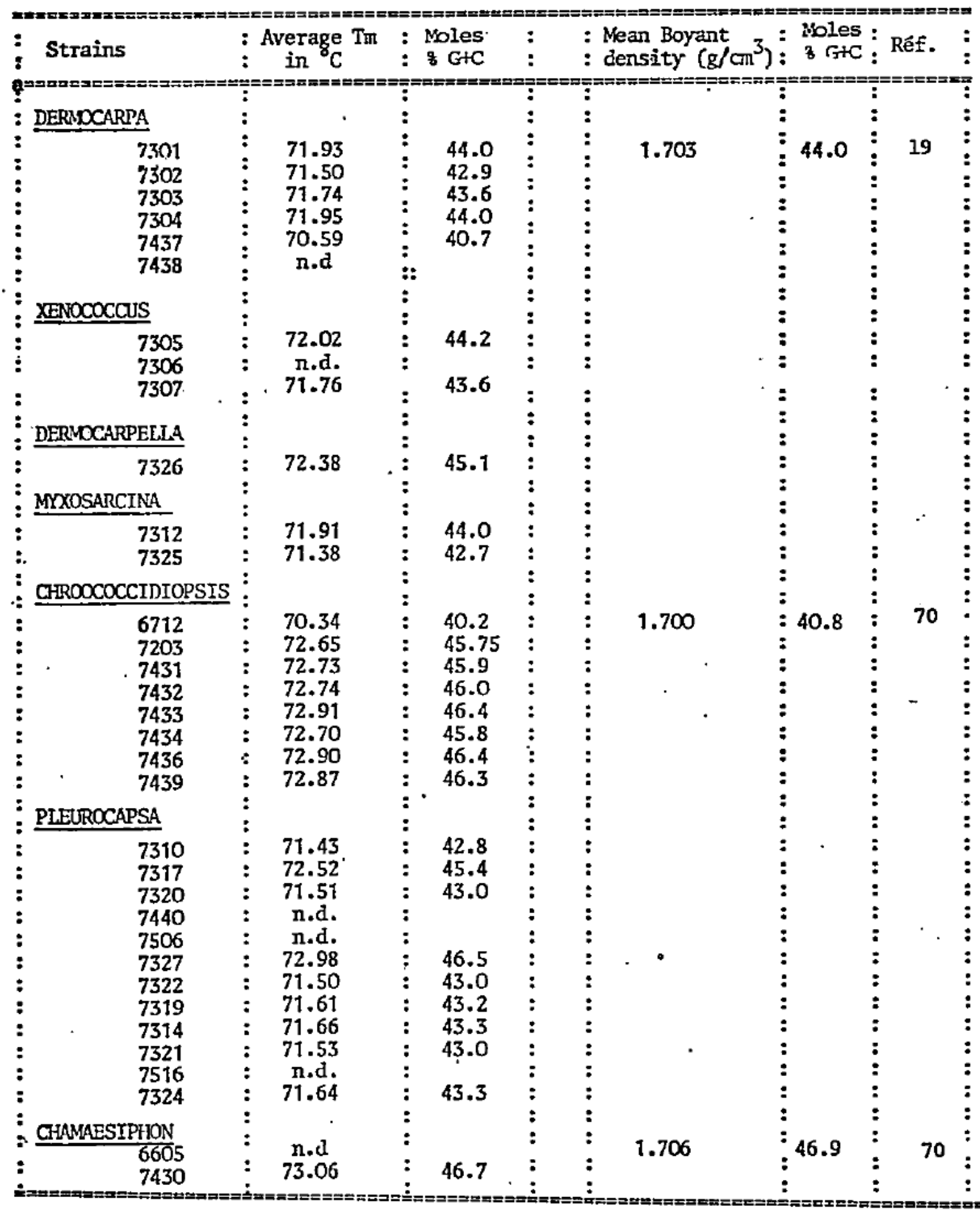

n.d. - not determined' - 
for Dermocarpa 7437 and 7438 , as well as for seven strains of Chroococcidiopsis $(7203,7431,7432,7433,7434,7436$ and 7439).

5. Mean DNA Composition

In the cyanobacteria as a whole the span of mean DNA composition is wide, extending from 35 to 70 moles \% guanine plus cytosine, a range almost as extensive as that for prokaryotes as a whole (29-74 moles\% $G+C)$. Since the mean base composition of the DNA can be significantly altered only by a very large number of base substitutions affecting most if not all segments of the genome, the wide dispersion of the values in cyanobacteria implies that this taxonomic group is an old one, withIn which a considerable amount of evolutionary divergence has occurred. In this context it is of interest to compare the ranges of DNA base composition characteristic of the major taxonomic subgroups among the cyanobacteria. Figure 72 is based on our data for the Pleurocapsales and Chamaesiphonales and on the data of other workers (19, 70, M. Herdman, personal communication) for the remaining taxa. Excluding, the Chamaesiphonales, for which only two determinations are available, the values show an interesting general trend. For the Chroococcales and for the non-heterocyst-forming members of the Nostocales, DNA base , composition spans an extremely wide range. On the other hand, the values for all heterocyst-forming cyanobacteria, whether true branchers (order Stigonematales) or not (order Nostocales) are much narrower, all falling between 39 and 48 moles \% G + C. The values for the Pleurocapsales likewise fall into a narrow range (40 to 46 moles \% $G+C)$. In view of the relatively large number of strains which have now been analyzed among nostocalean and pleurocapsalean cyanobacteria, 


\section{Figure 72}

Moles Percent $\mathrm{G}+\mathrm{C}$ in DNA

\section{Chroococcales}

Chamaesiphonales

Nostocales

Heterocyst - formers

Nonheterocyst -formers

(Including Pseudanabaena)

\section{Stigonematales}

Pleurocapsales

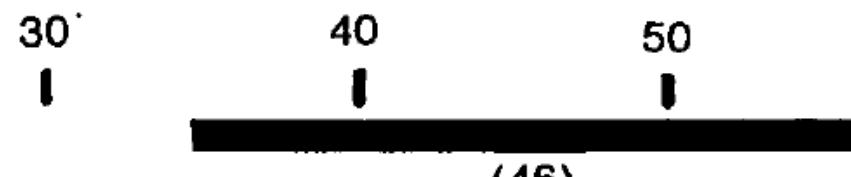

(46)

(2)

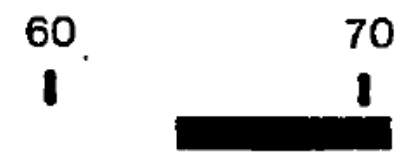

(12)

70 
it is probable that the narrow ranges for these two groups do not reflect inadequate sampling but are true expressions of the degree of diversity in DNA base composition. The narrow ranges of DNA base composition of these two groups do not necessartly imply of course that they are of recent evolutionary origin, since evolutionary divergence may or may not be reflected by an overall change in DNA base composition. It is interesting to note that the three major groups which have comparatively narrow ranges of DNA base composition (Pleurocapsales, Stigonematales and heterocyst-forming members of the Nostocales) are preclsely those characterized by the greatest degree of structural and developmental complexity.

\section{B. The Taxonomy of the Pleurocapsales and Chamaesiphonales}

\section{Circumscription and Redefinition of the Orders Pleurocapsales} and Chamaesiphonales and of Their Major Constituent Genera

The two orders Chamaesiphonales (synonym Dermocarpales) and Pleurocapsales, which are accepted in recent taxonomic treatments of the cyanobacterfa (e.g., 7, 16) were originally proposed by Geitler in 1942 (29). It is therefore necessary to examine and evaluate the criterla upon which Geitler proposed these two orders, and the nature of the properties which distinguish their members.

Geltler's lengthy characterizations of the two orders (in effect, descriptions rather than definitions) contain extensive comments about the assumed course of structural evolution among cyanobacteria, and it is evident that the taxonomic proposals which he advanced were considerably influenced by these speculative considerations. The 
following passage, taken from his description of the order Pleurocapsales $(29$, p. 79) is typical:

"Es sind dies Formen, welche die Weiterentwicklung von Entophysalidaceenartigen Chroococcalen-Typen zu ausgesprochenen Fadenalgen, allerdings Fadenalgen von nicht hormogonaler, sondern pleurocapsaler Organisation, darstellen; zuden terten typischerweise Endosporangien auf, die den Chroococcalen noch fehlen. Gegenüber den Dermocarpales. s. str. dieser Bearbeitung, die ebenfalls Sporangien ausbilden, besteht der Unterschied darin, dass vegetative Teilungen ablaufen; während die Dermocarpales den typischen Protococcalen unter den Grunalgen entsprechen, sind die Pleurocapsales mit den Ulotrichalen vergleichbar.

Nach dem Gesagten sind Pleurocapsalen und Dermocapsalen gleichwertige Entwicklungsreihen. Sie stehen nicht in dem Sinn in einem ntheren Zusammenhang, dass sich die eine Reihe von der anderen ableiten wirde; vielmehr gehen beide auf die Chroococcalen zurück, nehmen aber von da aus verschiedene Entwicklung: die Pleurocapsalen gehen zur Fadenbildung uber (wobei aber die durch den engen Zusammenhalt der Zellen gegebene Organisation der Hormogonalen noch nicht erreicht wird), während die Dermocarpalen unter Unterdruckung der vegetativen Zweiteilung, oder anders ausgedruckt, unter Betonung des einzelligen Zustands extrem protococcoide Organisation erreichen. Die Dermocarpalen stellen also eine Sackgasse der Entwicklung dar, die in den exosporinen Formen (Chamaesiphon) ihr Ende findet. Die Hormogonalen sind dagegen von den pleurocapsalen abzuleiten."

A translation of this passage follows:

'These are the forms which represent the further development of Chroococcalean organization of the Entophysalis type into filamentous algae having, not a hormogonalean, but a pleurocapsalean organization. Furthermore, typical endosporangia occur, which are still lacking in the Chroococcales. In contrast to the Dermocarpales, as described here which also form sporangia, vegetative divisions occur in the Pleurocapsales. Whereas the Dermocarpales correspond to typical protococcalean forms in the green algae, the pleurocapsales are comparable to the Ulothricales.

From what has been stated above, the Pleurocapsales and Dermocarpales are developmental sequences of equal importance. This does not mean that one series can be derived from the other. Rather, both are derived in divergent directions from the Chroococcales. The Pleurocapsales are transitional to filamentous forms (although they have not attained the close cellular association of the Hormogonales) while the Dermocarpales have undergone a suppression of binary fission, or in other words, have achieved an extreme protococcoid organization within the framework of unicellularity. The Dermocarpales therefore represent a blind alley of development, which terminates with the exosporeproducers (Chomaesiphon). The Hormogonales on the other hand must be derived from the Pleurocapsales.' 
T A I E X X V I

CRITERIA EMPLOYED BY GEITLER TO SEPARATE THE ORDERS

DERMOCARPALES AND PLEUROCAPSALES (29)

Differential Character $\quad$ DERMOCARPAIES $\stackrel{\text { Order }}{\text { PLEUROCAPSALES }}$

Structure:

1. Unicellular

1. Multicellular

Reproduction by Means of:

2. Exospores or Endospores

2. Endospores

Polarity of organism:

3. Present

3. Absent

Major constituent genera:

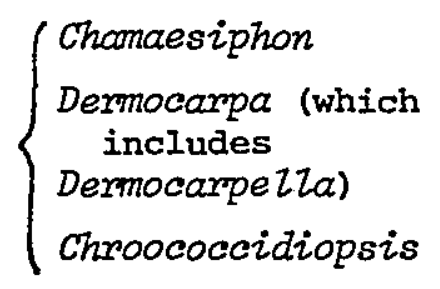

$\left\{\begin{array}{l}\text { Xenococous } \\ \text { Myxosarcina } \\ \text { Pleurocapsa } \\ \text { Byella }\end{array}\right.$ 